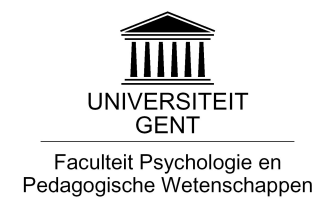

\title{
IMPLEMENTATION AND EVALUATION OF CASE MANAGEMENT FOR SUBSTANCE ABUSERS WITH COMPLEX AND MULTIPLE PROBLEMS
}

Wouter Vanderplasschen

Promotor: Prof. Dr. E. Broekaert

Proefschrift ingediend tot het behalen van de academische graad van Doctor in de Pedagogische Wetenschappen, in het openbaar verdedigd op dinsdag 22 juni 2004 om 15u. 



\section{Begeleidingscommissie:}

Prof. Dr. E. Broekaert (promotor), Vakgroep Orthopedagogiek, Universiteit Gent

Prof. Dr. I. De Bourdeaudhuij, Vakgroep Bewegings- en Sportwetenschappen, Universiteit Gent

Prof. Dr. T. Decorte, Vakgroep Strafrecht en Criminologie, Universiteit Gent

Prof. Dr. P. Van Oost, Vakgroep Experimenteel-klinische en Gezondheidspsychologie, Universiteit Gent

\section{Examencommissie:}

Prof. Dr. G. De Soete (voorzitter), Decaan Faculteit Psychologie en Pedagogische Wetenschappen, Universiteit Gent

Prof. Dr. E. Broekaert (promotor), Vakgroep Orthopedagogiek, Universiteit Gent

Prof. Dr. I. De Bourdeaudhuij, Vakgroep Bewegings- en Sportwetenschappen, Universiteit Gent

Prof. Dr. T. Decorte, Vakgroep Strafrecht en Criminologie, Universiteit Gent

Prof. Dr. H. Siegal, Center for Interventions, Treatment and Addictions Research, School of Medicine, Wright State University, Dayton (Ohio)

Prof. Dr. H. Van Hoorde, Vakgroep Psychoanalyse en Raadplegingspsychologie, Universiteit Gent

Orthopedagogische Reeks Gent, Nummer 17, 2004

ISSN: 0779-1046

$\mathrm{D} / 2003 / 6585 / 17$

v.z.w. Consultatie- en Begeleidingsdiensten en Orthopedagogisch Observatie- en Behandelingscentrum, J. Guislainstraat 47, 9000 Gent

Universiteit Gent, Vakgroep Orthopedagogiek, H. Dunantlaan 2, 9000 Gent

Lay-out: Kathy Colpaert

\footnotetext{
Alle rechten voorbehouden. Behoudens de uitdrukkelijk bij wet bepaalde uitzonderingen mag niets uit deze uitgave worden vermenigvuldigd, opgeslagen in een geautomatiseerd gegevensbestand of openbaar gemaakt, op welke wijze ook, zonder de uitdrukkelijke, voorafgaande en schriftelijke toestemming van de auteur en uitgever.

No part of this book may be reproduced in any other form by print, photoprint, microfilm or any other means without written permission from the publisher
} 

ACKNOWLEDGEMENTS

\section{ACKNOWLEDGEMENTS}

This story goes back to the day I received my Master degree at the Ghent University and I was certainly convinced to exchange research for practice after 5 years of hard study. Less than 24 hours later, I decided to start working on a research project that was intended to improve the practice of substance abuse treatment. At that time and not until some years ago, I did not know that this issue would become the subject of a PhD-dissertation. However, during more than 7 years I was able to learn a lot about the practice of substance abuse treatment in diverse settings through numerous visits to treatment centers, interviews and informal talks with caregivers and service providers, practical trainings, international exchanges, and study visits. I became really interested in the organization of substance abuse treatment and an intervention called "case management". At the beginning of my dissertation, I would like to thank all the people who "managed my case" and who assisted me on this wonderful and very interesting journey. Without your help and input this thesis would never have been possible.

First, I am greatly indebted to all substance abusers that have participated in one way or another in this study. I hope your efforts and contribution will finally lead to what we all want: a treatment system that is optimally addressing clients' needs and helps people to reduce and, if possible, solve their problems.

I also want to thank the directors and practitioners from all participating substance abuse treatment organizations in the province of East-Flanders: CGG De Drie Stromen, CGG Eclips, CGG Zuid-Oost-Vlaanderen, De Kiem, De Pelgrim, De Sleutel, GGZ Waas en Dender, MSOC Gent, PC Sleidinge, PC St-Jan-Baptist, PZ St-Camillus, and Traject. I appreciate your constructive collaboration and openness, although I know some of the objectives and innovative concepts of this study may have been threatening to you.

Special thanks go out to the case managers from the implementation phase of the study: Ann, Bart, Cassandra, Eddy, Fernand, Gert, Janna, Jo, Kristel, Lionel, Luc, Piet, Vanessa, and Wim. Without your time, energy and efforts we would never have been able to bring this theoretical concept into practice in this region. Further, I am especially grateful to Alphonse, Katrien and Sven who helped to realize an adapted model of case management that should better meet clients' and the network of services' needs. I admire your enthusiasm and dedication and hope this study will be as supportive for you as were our discussions and deliberation for me.

I would like to thank the Province of East-Flanders (Provincie Oost-Vlaanderen) and the Regional Board on Mental Health Care (PopovGGZ) for their financial and logistic support of this project. In particular, I owe many thanks to Bert Mostien and Patrick Claeys, who worked as care coordinators in the fields of substance abuse treatment and mental health care, respectively. From the beginning, you supported this project as regards its content and provided feedback when necessary. Your contribution has been of great 
value to me and was indispensable for many of the recent innovations in substance abuse treatment in the province of East-Flanders.

Special gratitude goes to Prof. Dr. E. Broekaert, my supervisor, who stimulated my interest for substance abuse problems and who was the ideal captain on this long and winding journey. Eric, thank you for your support and trust, the inspiring Socratic dialogues and all the opportunities you gave me throughout the last 6 years. With my "magnum opus" the "annus horriblis" nearly comes to an end and I hope it brings the crops you expected from it.

Sincere thanks also go to Prof. Dr. P. Van Oost, who offered me the opportunity to start this study and who gave encouraging and constructive reflections on my work. Many thanks also to Prof. Dr. I. De Bourdeaudhuij and Prof. Dr. T. Decorte for critically reading parts of my dissertation and contributing valuable suggestions. In addition, I would like to thank Prof. Dr. G. De Soete, Prof. Dr. H. Siegal and Prof. Dr. H. Van Hoorde for being part of the examination committee.

Special thanks are due to Prof. R. Rapp and Prof. Dr. J. Wolf. Richard, I was really honored that you wanted to collaborate with us and I learnt a lot from our meetings in Dayton and Ghent. Judith, the work you have been doing concerning case management in the Netherlands has been very inspiring to me and opened up many new ways for this dissertation. The continuous support and reflections of both of you have provided me with many new insights.

I want to thank all my colleagues for their interest and support, especially those whom I was collaborating with closely concerning distinct projects related to this dissertation (Dieter, Geert, Griet, Ilse, Joke, Kim, Stijn, and Veerle). I wish you all good luck and courage for the tasks you plan to achieve in the near future.

Kurt and Kathy, I owe you many thanks, as you have been a great help to me for finishing this huge work. Kurt, you left the project more than a year ago, but we kept on collaborating and I hope we will continue to do so. I wish you all the best with your new, challenging job and think this is a new step in bringing into practice what we have already conceptualized theoretically. Kathy, you took over from Kurt and soon got settled in your new job. I really appreciate your endless efforts and now it is time for you to go your own way. You can count on me for that.

Also thanks to all the students who worked with me on parts of this dissertation, especially Jessica and Katrijn whose help was more than welcome during the last part of this study.

Finally, I am happy to thank my family and friends, since you were a big source of support, courage, pleasure and recreation.

I particularly want to thank my parents for offering me so many opportunities, showing genuine interest in the things I was doing and supporting me endlessly. Especially during 
these last hard months, your practical help and encouragement, as well as the one I received from my sister and family-in-law has been of invaluable worth to me.

Ellen, you showed me the right example and, better than anyone else, you know where I have been going through. You took care of me so much on this long trip. I promise you to do the same on all our future trips.

Thiemen, I guess you don't know what "papa" has been busy with so much the last couple of months. Your enthusiasm, joy of living and activity level has been inspiring to me and was the ideal change for my intellectual work. Next week we will go bicycling, and as a good case manager, I promise to take you all the way on your journey of life.

Wouter, April 20, 2004 



\section{PREFACE}

Substance abuse is a multi-faceted and complex problem that necessitates a holistic approach to treatment, since not only clients' drug use should be addressed but also the broader issues they are confronted with in their lives, such as (mental) health, housing, employment, relational and judicial problems (Brindis \& Theidon, 1997; McLellan, Arndt, Metzger, Woody, \& O’Brien, 1995). However, few treatment programs are equipped to provide the expanded array of services necessary to meet clients' broader needs.

Although not all cases of substance abuse are chronic and recovery is possible, substance abuse is increasingly regarded as a chronic and relapsing disorder (McLellan, 2002). Ongoing support services and continuing care are considered a crucial part of preventing relapse and assisting clients in stabilizing and overcoming their problems (Brindis \& Theidon, 1997). In order to realize continuing care, treatment should be made more attractive to clients and monitoring of clients is necessary, besides the coordination and integration of substance abuse interventions (McLellan, 2002).

Several interventions and strategies have been developed to give a comprehensive, individualized and continuing response to clients' needs, including integrated treatment, centralized intake facilities, treatment matching and case management (Brindis \& Theidon, 1997; Drake, Mercer-McFadden, Mueser, McHugo, \& Bond, 1998; Hser, Polinsky, Maglione, \& Anglin, 1999; Scott \& Foss, 2002). However, little information is available about the implementation and evaluation of these practices.

The major purpose of this dissertation was to examine whether existing treatment programs in a clear-cut region in Belgium (Ghent, East-Flanders) provide coordination and continuity of care, and if available services can be optimized by the implementation of case management and an integrated treatment system for substance abusers.

In chapter 1, we look at the nature and extent of substance abuse problems and the organization of substance abuse treatment. We finish this chapter by formulating the research questions and aims of this thesis.

Chapter 2 describes a study that examined coordination and continuity of care in agencies that are involved in the treatment of substance abusers. Different aspects of coordination and continuity of care are explored and two alternative approaches that may contribute to the quality of substance abuse treatment are proposed.

A structural approach to improve coordination and continuity of care is outlined in chapter 3. The first part describes the history and evolution of distinct treatment models and the impetus and prerequisites for the integration of treatment systems. The second part focuses on how such an integrated treatment system can be realized in Belgian 
substance abuse treatment. We do so by providing an overview of the different steps that are necessary to establish such an integrated treatment system for substance abusers.

In chapters 4 to 7 , we address a specific intervention that is aimed at promoting coordinated and continuous care at individual level: case management.

Chapter 4 reviews the development and implementation of case management for substance abusers from a comparative perspective. Six key questions concerning the implementation of this intervention are dealt with, based on empirical findings from the United States, the Netherlands and Belgium.

The results of an exploratory study concerning the implementation of case management for substance abusers in Belgium are described in chapter 5. During 12 months, we examined the role and outcomes of a model of case management that was implemented as an additional treatment modality in specialized substance abuse treatment agencies among a small sample of substance abusers with multiple and complex problems.

Chapter 6 provides a review of the effectiveness of different models of case management for substance abusers: the brokerage and generalist model, assertive community treatment and intensive case management, the strengths-based model, and clinical case management. We analyzed all peer-reviewed articles that have studied the effects of these models among various substance abusing populations, e.g. dually diagnosed persons, homeless substance abusers, drug-involved offenders, and substance abusing women.

In chapter 7 , we looked at the effectiveness of intensive case management for assisting multiple and frequent service users in the region of Ghent. Since this study was part of an ongoing project, we opted for a qualitative study and explored whether the initial 6-month outcomes met the postulated goals among a small subgroup, in order to attune the goals, target population, conceptualization and activities, if necessary.

The final chapter 8 contains an overview and general discussion of our main findings. Implications for the practice of substance abuse treatment, limitations of the study and recommendations for further research are provided.

This dissertation comprises several papers, which have been submitted for publication, are under editorial review or have already been published. To make each of these papers selfcontaining and to meet the editors' requirements, the content of some of the chapters may overlap. Moreover, as these papers have been submitted to journals with a different scope, word use may sometimes vary especially for naming substance abuse problems: addiction, substance use disorders, problem drug use, substance abuse. 


\section{REFERENCES}

Brindis, C.D., \& Theidon, K.S. (1997). The role of case management in substance abuse treatment services for women and their children. Journal of Psychoactive Drugs, 29(1), 79-88.

Drake, R.E., Mercer-McFadden, C., Mueser, K.T., McHugo, G.J., \& Bond, G.R. (1998). Review of integrated mental health and substance abuse treatment for patients with dual disorders. Schizophrenia Bulletin, 24(4), 589-608.

Hser, Y.I., Polinsky, M.L., Maglione, M., \& Anglin, M.D. (1999). Matching clients' needs with drug treatment services. Journal of Substance Abuse Treatment, 16(4), 299-305.

McLellan, A.T. (2002). Have we evaluated addiction treatment corretcly? Implications from a chronic care perspective. Addiction, 97(3), 249-252.

McLellan, A.T., Arndt, I., Metzger, D.S., Woody, G.E., \& O’Brien, C.P. (1993). The effects of psychosocial services in substance abuse treatment. Journal of the American Medical Association, 269, 1953-1959.

Scott, C.K. \& Foss, M.A. (2002). Impact of centralized intake on drug and alcohol treatment placement decisions. Journal of Psychoactive Drugs, 34(1), 7-15. 



\section{CONTENTS}

\section{Chapter 1: General introduction}

1.1. Prevalence of and reactions to substance abuse

1.1.1. Prevalence of substance abuse problems $\quad \ldots \ldots \ldots \ldots \ldots \ldots . . \ldots 15$

1.1.2. Societal reactions to substance abuse $\ldots \ldots \ldots \ldots \ldots \ldots \ldots . \ldots 17$

1.1.3. Substance abuse problems and treatment demand ......... 20

1.2. Substance abuse treatment in the region of Ghent, East-Flanders (Belgium)

1.2.1. The organization of substance abuse treatment $\ldots . \ldots \ldots \ldots .23$

1.2.2. Treatment demand due to substance abuse problems ....... 25

1.3. Evaluation of substance abuse treatment

1.3.1. Challenges to the field of substance abuse treatment ....... 28

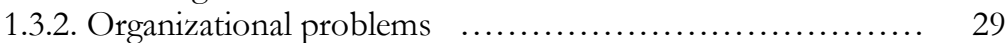

1.3.3. Alternative approaches to the delivery of services $\ldots . \ldots \ldots . \quad 30$

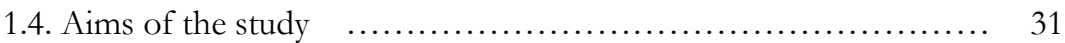

\section{Chapter 2: Coordination and continuity of care in substance abuse treatment: an evaluation study in Belgium}

2.1. Introduction

2.1.1. Substance abuse and treatment in Belgium $\quad \ldots \ldots \ldots \ldots \ldots . . . . .43$

2.1.2. Specific characteristics of drug abusers $\ldots \ldots \ldots \ldots \ldots \ldots \ldots . . \ldots 4$

2.1.3. Quality of substance abuse treatment $\ldots \ldots \ldots \ldots \ldots \ldots \ldots . . \ldots . \ldots . \ldots \ldots$

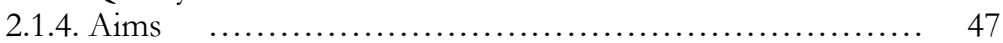

2.2. Methods

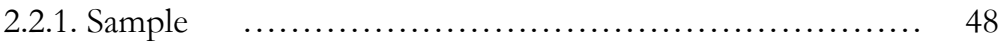

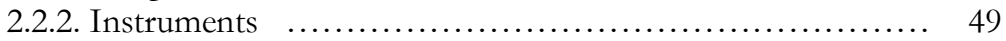

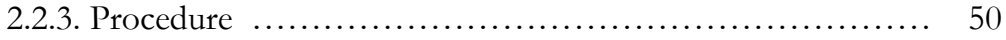

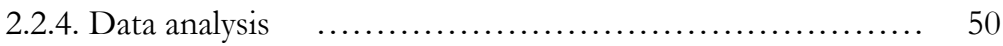

2.3. Results

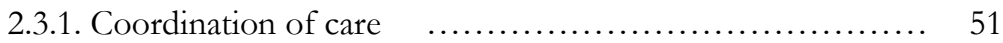

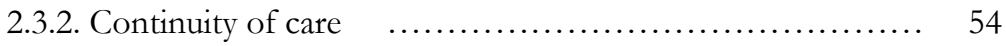

2.4. Discussion

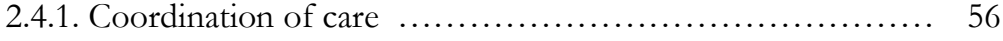

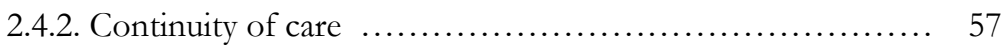

2.4.3. Implications of the study $\ldots \ldots \ldots \ldots \ldots \ldots \ldots \ldots \ldots \ldots . \ldots \ldots 7$ 
Chapter 3: The integration of treatment systems for substance abusers

3.1. Towards the integration of treatment systems for substance abusers

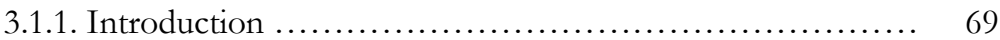

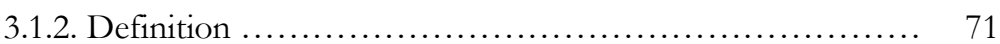

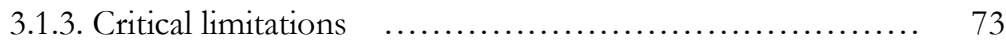

3.1.4. Prerequisites for the integration of treatment systems ..... 77

3.1.5. Similarities between the American and the

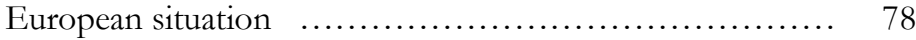

3.1.6. Conclusions .................................... 79

3.2. Coordination of care in substance abuse treatment: the gradual establishment of an integrated treatment system for substance abusers

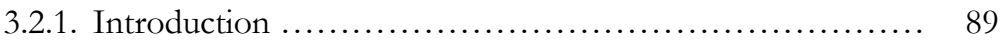

3.2.2. The development of integrated treatment systems for substance abusers $\ldots \ldots \ldots \ldots \ldots \ldots \ldots \ldots \ldots . . \ldots$

3.2.3. A step-by-step plan for the establishment of an integrated treatment system $\ldots \ldots \ldots \ldots \ldots \ldots \ldots \ldots . . \ldots 1$

3.2.4. Discussion and conclusion .......................... 101

Chapter 4: Comparative review of the development and implementation of case management for substance use disorders in North America and Europe

4.1. Introduction

4.2. Key questions concerning the implementation of case management

4.3. Conclusion

Chapter 5: Implementation of case management for substance abusers: an exploratory study in Belgium

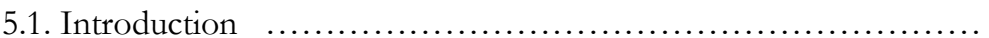

5.2. Material and methods

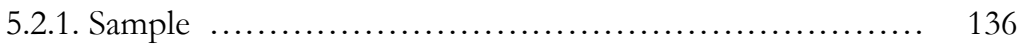

5.2.2. Procedure and instruments $\ldots \ldots \ldots \ldots \ldots \ldots \ldots \ldots \ldots \ldots . \ldots \ldots \ldots$

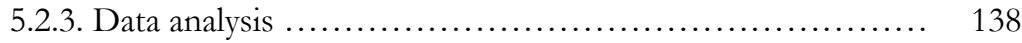


5.3. Results

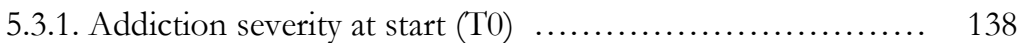

5.3.2. Addiction severity 12 months later (T1) $\ldots \ldots \ldots \ldots \ldots \ldots . . . . .139$

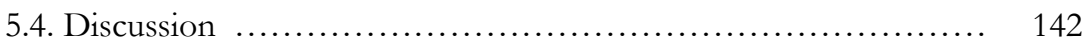

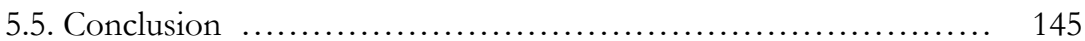

Chapter 6: Review of the effectiveness of different models of case management for substance abusers

6.1. Introduction

6.1.1. Effectiveness of substance abuse treatment $\ldots \ldots \ldots \ldots \ldots \ldots .151$

6.1.2. Implementation of case management $\quad \ldots \ldots \ldots \ldots \ldots \ldots \ldots . . \ldots 151$

6.1.3. Effectiveness of case management $\quad \ldots \ldots \ldots \ldots \ldots \ldots \ldots \ldots . \ldots 153$

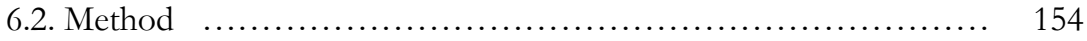

6.3. Results

6.3.1. Assertive community treatment and intensive case

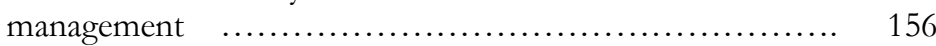

6.3.2. Strengths-based case management $\quad$..................... 159

6.3.3. Generalist or standard case management $\quad$............... 160

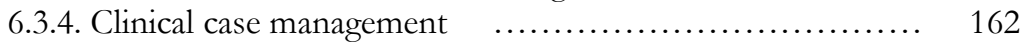

6.3.5. Brokerage case management $\quad \ldots \ldots \ldots \ldots \ldots \ldots \ldots \ldots . \ldots . \ldots . \ldots 2$

6.4. Discussion

6.4.1. Effectiveness of different models of case management $\ldots \quad 163$

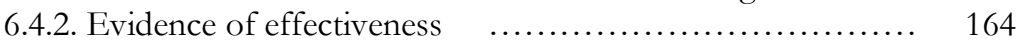

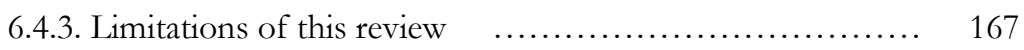

6.4.4. Limitations of the presented studies and guidelines for further research $\ldots \ldots \ldots \ldots \ldots \ldots \ldots \ldots \ldots \ldots \ldots \ldots, 168$

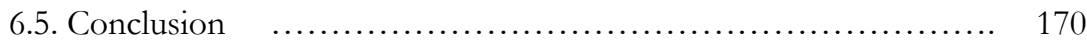

Chapter 7: Qualitative study on the effectiveness of case management for multiple service users in Belgian substance abuse treatment

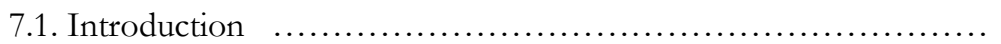

7.2. Program description

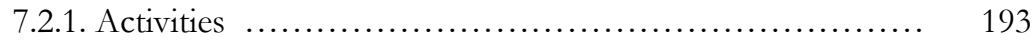

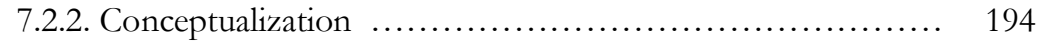


7.3. Methods

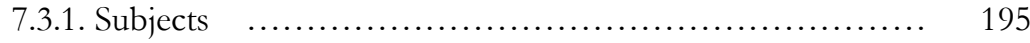

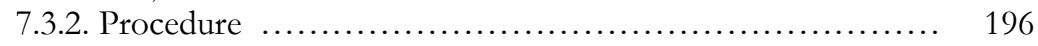

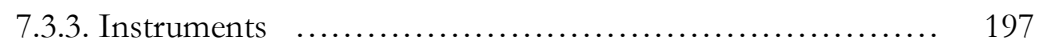

7.3.4. Data analysis ....................................... 198

7.4. Results

7.4.1. Baseline characteristics ................................ 198

7.4.2. The case management intervention $\quad \ldots \ldots \ldots \ldots \ldots \ldots \ldots . . . \ldots 200$

7.4.3. Six-month outcomes ............................. 201

7.5. Discussion

7.5.1. The case management intervention $\ldots \ldots \ldots \ldots \ldots \ldots \ldots \ldots . . . . . . . .206$

7.5.2. Effectiveness of the intervention ........................ 206

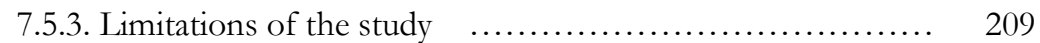

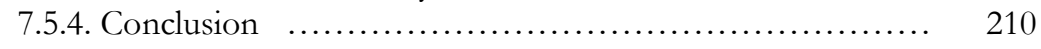

\section{Chapter 8: General discussion}

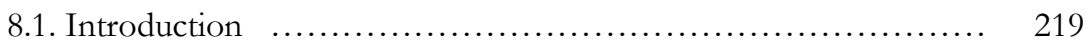

8.2. Main findings ............................................ 220

8.3. Implications for the practice of substance abuse treatment ....... 228

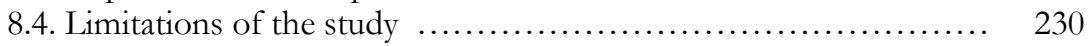

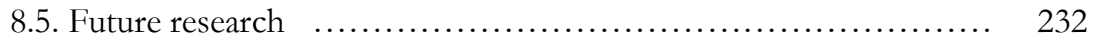




\section{Chapter 1}

\section{General introduction ${ }^{1}$}

ABSTRACT. Starting from the extent of substance use and substance abuse problems in the European Union and Belgium, we look at distinct societal reactions to substance use, including repression, prevention, treatment and harm reduction. We particularly focus on treatment demand data, since these provide us with information about substance abusers entering treatment and about the organization of treatment services. Such information is examined for the region around Ghent (East-Flanders, Belgium). It appears that substance abusers' multiple and chronic problems necessitate a comprehensive and ongoing approach, but few programs are equipped to provide such services. Moreover, additional problems are observed concerning the organization of substance abuse treatment. Case management is suggested as an alternative approach to improve coordination and continuity of care, but the application of this intervention among substance abusers is still in its infancy. The aims of the study particularly relate to the implementation and evaluation of case management, and its integration in the system of services.

\footnotetext{
1 This chapter is based on:

Vanderplasschen, W., Lievens, K., \& Broekaert, E. (2001a). De instroom in de Oost-Vlaamse drughulpverlening: registratie van intakes en aanmeldingen tussen oktober 1999 en mei 2000 (Orthopedagogische Reeks Gent Nummer 13). Gent: Universiteit Gent, Vakgroep Orthopedagogiek;

Vanderplasschen, W., Lievens, K., \& Broekaert, E. (2001b). Implementatie van een methodiek van case management in de drughulpverlening: een proefproject in de provincie Oost-Vlaanderen (Orthopedagogische Reeks Gent Nummer 14). Gent: Universiteit Gent, Vakgroep Orthopedagogiek;

Vanderplasschen, W., Colpaert, K., Lievens, K., \& Broekaert, E. (2003). De Oost-Vlaamse drughulpverlening in cijfers: kenmerken, zorggebruik en uitstroom van personen in behandeling (Orthopedagogische Reeks Gent Nummer 15). Gent: Universiteit Gent, Vakgroep Orthopedagogiek.
} 



\subsection{PReVAlenCe of AND REACtions to substance ABUSE}

\subsubsection{PREVALENCE of SUbSTANCE ABUSE PROBLEMS}

Anthropological research has shown that substance use is of all times and places: opium use was already reported among the Egyptians around 1500 BC, Greeks and Romans drank beer and wine, and the chewing of coca leaves is an age-old custom in South America (Van Epen, 1995). While drug preferences and availability have changed over time (Tucker, 1999), the demand for psychoactive substances has been a constant in most societies and only some primitive African pygmy tribes have not been affected by substance use. Most substances were initially used for their recreational and/or therapeutic effects (e.g., opium, cocaine, amphetamines, and alcohol) and related problems were only reported much later. The first reports about large-scale alcohol abuse and dependence go back to the industrial revolution, while Western societies were not confronted with other substance abuse problems as early as the 1950s (Kooyman, 1993; Tucker, 1999).

Nowadays, alcohol use is a socially accepted habit in most countries, but at the same time abuse of this substance is identified as one of the major causes of health problems. The global prevalence of alcohol-related disorders (harmful use and dependence) has been estimated to be around 1.7\%, including significantly higher rates in North America and Europe (WHO, 2001). In the beginning of the 1990s, the prevalence of alcohol abuse and dependence in the United States was estimated to be around 7.4\% (4.1\% among females, $11 \%$ among males) (Grant et al., 1994). The prevalence of alcohol abuse in Belgium has recently been taken to be around $6 \%$ of the total population, which means that at least 500,000 Belgians are directly affected by this problem (Cattaert \& Pacolet, 2002). According to the $\mathrm{WHO}$ criteria, up to $10 \%$ of all Belgians have a harmful drinking pattern since they use more than 6 standard glasses of alcohol daily (for women the norm for harmful use is 4 standard glasses/day).

From the 1950s and 1960s on, several Western countries were confronted with young people who started to use heroin, amphetamines, LSD, and cannabis as a new kind of hedonism (Kooyman, 1993). Soon, it appeared that these individuals indulged themselves beyond normative limits, which was countered by severe social control and penalization of possession and trade of these drugs and the insistence to abstain from any use of illicit drugs (Tucker, 1999). Later, also other substances were introduced on the drug market, such as cocaine, XTC, and several other synthetic drugs (Van Epen, 1995).

The worldwide prevalence of heroin and cocaine use disorders was recently estimated to be around $0.25 \%$ (WHO, 2001). According to the United Nations, about 180 million people around the world, or $4.2 \%$ of all persons aged 15 years and above, used drugs in the late 1990s (UNDCCP, 2000). This number included 144 million persons consuming 
cannabis; 29 million people using amphetamine-types of stimulants; 14 million individuals taking cocaine and 13 million opiate users, of whom 9 million were dependent on heroin.

Cannabis is the most frequently used illegal drug in the European Union, and the lifetime prevalence of cannabis use (the number of persons that have ever used this substance) is estimated to be around $20 \%$ of the total population (EMCDDA, 2003). The lifetime prevalence of other substance use is much lower: amphetamines and XTC (0.5 to 5\%), cocaine $(0.5$ to $3 \%)$, and heroin (<1\%) (EMCDDA, 2000, 2001, 2002, 2003). In most EUcountries, recent use (last year) of cannabis is estimated to occur among 5 to $10 \%$ of all adults, while the prevalence rates of recent use of other illegal drugs are below 1\%.

Substance use is more prevalent among men and especially occurs among persons aged 15 to 34 years (EMCDDA, 2000). During the 1990s, cannabis use has been constantly growing throughout the whole European Union, while similar trends have been observed for the use of XTC, cocaine and amphetamines in some EU-countries (EMCDDA, 2003).

The number of problem drug users, i.e. persons who use opiates, cocaine or amphetamines intravenously/regularly over a longer period of time (EMCDDA definition), is estimated to be between 1 and 1.5 million EU-residents (EMCDDA, 2003). Large variations in the number of problem drug users are observed between the member states and the prevalence varies between 2 to 4 (e.g., the Netherlands, Germany, and Austria) and 6 to 10 cases (Italy, Portugal, United Kingdom, and Luxembourg) per thousand inhabitants between 15 and 64 years old. Most countries report opiates as primary drug among problem drug users, while cocaine and amphetamines are mostly registered as main substance of abuse among problem users in Spain, and Sweden and Finland, respectively.

Little information is available about the lifetime prevalence of substance use in Belgium, except for some specific populations or regions (De Donder, 2000). Since 2001, lifetime and last month prevalence of cannabis and amphetamine/XTC use is questioned in the National Health Interview Survey. Lifetime prevalence of cannabis and amphetamine/XTC use were reported by $10.8 \%$ and $2.3 \%$ of the population between 15 and 64 years old (Sleiman, 2003). Recent cannabis use was reported by $2.8 \%$ of the sample and recent amphetamine/XTC use by less than $1 \%$.

In addition, few figures are available about the extent of problem drug use in Belgium. The recent prevalence of intravenous drug use has been estimated to be around 4.2 per 1000 Belgians between 15 and 64 years (EMCDDA, 2003). 


\subsubsection{SOCIETAL REACTIONS TO SUBSTANCE ABUSE}

\section{a REPRESSION}

The temperance movement was the first societal reaction against growing alcohol problems and led to Prohibition in the United States from 1920 to 1933 (Tucker, 1999). This interdiction only caused modest reductions in per capita alcohol consumption, but induced an exponential growth of illegal alcohol production and trade, and other illicit activities. The repeal of Prohibition did not result in rapid and sustained increases in alcohol consumption, as some had feared it would. Nowadays, most countries apply a liberal alcohol policy, while only some countries have strict regulations concerning the sale and use of alcohol (e.g., Sweden, Finland, and the United States). Research has shown that increased alcohol-related harm is associated with more widespread availability of alcohol and lack of governmental regulations such as taxations (Leppänen, Sullström, \& Suoniemi, 2001). According to Tucker (1999), the extent of substance-related social problems in a given culture typically varies inversely with the extent to which substance use is incorporated into normative social rules and rituals.

Repressive measures have also been a popular way to deal with other forms of substance use, which is illustrated by the American War on Drugs and the penalization of drug use and possession in most European countries (EMCDDA, 2000; Tucker, 1999). It appears that repression has had little positive impact on the reduction of drug use and related problems, but instead caused adverse outcomes such as increased incarceration and individuals' loss of rights and liberties (Tucker, 1999). Moreover, prevalence rates of problem drug use do not show a direct relation with a country's drug policy, since countries with a restrictive policy (e.g., Sweden) do not report substantially more problems than countries with a liberal policy (e.g., the Netherlands) (EMCDDA, 2000).

Belgium has chosen a third way in the discussion between a repressive and tolerant policy. Since a few years, the Belgian drug policy can be characterized as a "normalization" approach and intends to control and reduce drug-related risks (De Ruyver \& Casselman, 2000; Federale Regering, 2001). Repression is considered to be the last resource ("ultimum remedium") to deal with drug problems.

\section{a PREVENTION}

Given the increased prevalence of morbidity (e.g., infection with HIV, HCV, $\mathrm{HBV}$, and tuberculosis, and psychological distress) and mortality (e.g., overdoses, AIDS, fatal accidents, and suicide) among (intravenous) drug users (EMCDDA, 2001; Tucker, 1999), other approaches to substance abuse problems than repression are clearly needed. From the 1970s on, drug prevention strategies have been developed in several countries to keep young adults from using substances or to stop substance use among those already 
experimenting or using regularly. Prevention is often addressed at school populations, since this setting offers long-term and continuous contacts with large groups of young people (EMCDDA, 2003). Preventive interventions that are integrated in the school's curriculum are deemed most effective (Tobler, 2001), while purely informative and unstructured prevention activities do not seem effective (Hansen, 1992). Other prevention initiatives have been directed at community or recreational settings, the workplace, and families, or make use of the mass media. Little information is available about the effectiveness of such interventions, except that mass media campaigns have shown little influence on the reduction of drug use if not combined with other means of communication (Paglia \& Room, 1999). Overall, primary and secondary prevention activities are mainly based on local experiences and contextual needs rather than on evidence-based practice (EMCDDA, 2003).

In Belgium, prevention strategies have mostly addressed secondary school populations (Vanderplasschen, De Donder, Lenoir, \& Roets, 2001). However, the focus of prevention activities recently shifted also to other settings (Sleiman, 2003), since the new Belgian drug policy starts from the idea that prevention is better than cure and that considerable efforts are necessary to prevent drug use (Federale Regering, 2001). Still, the budget for prevention activities remains relatively low when compared to that for treatment (De Ruyver et al., 2004).

\section{口 TREATMENT AND HARM REDUCTION}

The establishment of specialized treatment services for substance abusers goes back to the observation that this population had specific needs and was often not adequately helped in existing (mental) health care agencies (Tucker, 1999). Already in the 1930s, Dr. Bob and Bill W. founded the "Alcoholics Anonymous", a self-help movement for supporting alcohol addicts towards sobriety (Broekaert \& van der Straeten, 1997). Based on self-help principles and the experiences of Chuck Dederich and his disciples in Synanon, Daytop Village was established in 1964 as the first drug-free therapeutic community for drug addicts in the United States (Broekaert, Vanderplasschen, Temmerman, Ottenberg, \& Kaplan, 2000). This method quickly spread all over the United States and was later also implemented elsewhere. Besides therapeutic communities, numerous programs have developed other psychosocial interventions that aim at total abstinence from drugs, promotion of health and employment status, reduction in criminal involvement, and reintegration into society.

Evaluation of distinct psychosocial interventions for substance abusers shows varying results (Gossop, Marsden, \& Stewart, 2001), but it is estimated that generally 30 to $50 \%$ of all persons entering this type of treatment complete the program successfully (EMCDDA, 2002). Several authors (Gossop, Marsden, Stewart, \& Rolfe, 1999; Hubbard, Craddock, \& Anderson, 2003; Simpson, 1981) have associated longer length of stay in treatment (retention) with more successful outcomes. 
Psychosocial interventions are usually preceded by detoxification treatment in specialized centers or hospitals. Physical detoxification is intended to break the drug using habit, and to motivate clients for and, if possible, refer them to an advanced level of treatment. Naltrexone, clonidine, lofexidine, and buprenorphine have been proven to be effective drugs for reducing withdrawal symptoms (EMCDDA, 2002). Although methadone is frequently used for detoxification treatment, its main effects are related to substitution therapy. In addition, positive effects have been reported about rapid opiate detoxification under general anesthesia (Rabinowitz, Cohen, \& Atias, 2002), but these promising results need to be confirmed in further research. After all, due to a lack of studies that have focused on the differential effectiveness of various drugs for detoxification treatment, it remains unclear which kind of therapy is best suited for what type of client (EMCDDA, 2002).

As it soon appeared that the goal of recovery and reintegration into society was not feasible for all drug addicts, the search for new interventions and strategies that yield good results has characterized the field of substance abuse treatment from the beginning (Rapp, Siegal, Li, \& Saha, 1998; Saleh et al., 2002). Methadone substitution treatment was identified as an effective and cheap tool to reduce heroin use and criminal involvement among opiate addicts (Drucker, 1995). Also other substitution drugs were introduced such as buprenorphine and LAAM, but these have been prescribed to a far less extent (EMCDDA, 2002). Evaluation of methadone maintenance treatment has shown that this intervention is effective for reducing drug use, and risk and criminal behavior. Similar results have been found for substitution treatment with buprenorphine, but the latter substance seems especially indicated for reducing the risk of overdose and continued side use of other drugs (EMCDDA, 2002).

In addition, several other interventions were established to reduce the harmful consequences of substance abuse, for both the individual user and the society (Marlatt, Blume \& Parks, 2001). These interventions are often referred to as harm reduction, and include a wide range of services, such as needle exchange programs, outreach activities, low threshold facilities, primary medical care, vaccination programs, information about safe use, first aid trainings, pill testing, peer support, consumption rooms, and controlled heroin prescription (EMCDDA, 2003). The harm reduction approach encourages and accepts any change that reduces harm or the risk of harm, even if it falls short of abstinence (HRC, 2001). Harm reduction initiatives can be considered to be a form of tertiary prevention, since they address persons in an advanced stage of substance use. The effectiveness of several of these interventions has been proven for some specific purposes e.g., for reducing drug-related nuisance and promoting safer use (consumption rooms), and for reducing sharing of needles and syringes (needle exchange programs) (EMCDDA, 2002). A randomized and controlled trial that evaluated heroin prescription in the Netherlands has shown that the combined therapy with heroin and methadone (experimental group) was more effective than methadone treatment alone (control group) 
(Blanken, 2002; Van den Brink, Hendriks, Blanken, Huijsman, \& Van Ree, 2002). Moreover, more clients from the experimental group demonstrated overall improvement.

As substance abuse is often associated with drug-related and other offences, psychosocial and harm reduction initiatives were also established in prisons e.g., detoxification, drugfree wards, prison-based therapeutic communities, and methadone maintenance (EMCDDA, 2003). Moreover, the criminal justice system offers several treatment alternatives to prison sentences, especially in case of minor offences. Research has shown that such compulsory treatment alternatives can be effective for reducing drug use and criminality (Anglin \& Hser, 1991; Grichting, Uchtenhagen, \& Rehm, 2002).

While the abstinence-oriented approach has been the predominant treatment model over the last 25 years, harm reduction initiatives have recently become increasingly popular in several EU-member states e.g., Germany, the Netherlands, Spain, and the United Kingdom. Moreover, the initial incompatibly of both treatment philosophies has been replaced by efforts to breach the gap between both approaches e.g., by the combination of methadone maintenance and therapeutic community treatment (De Leon, 1997).

Substance abuse treatment in Belgium has been mainly abstinence-oriented, but the recent reform of the drug policy led to a more prominent role of harm reduction initiatives (Federale Regering, 2001). As opposed to other countries (e.g., the Netherlands, Germany, and the United States), treatment for alcohol and drug abusers is strictly separated (Kinnunen \& Nilson, 1999). Consequently, treatment initiatives for drug abusers consist of a limited, but clearly structured number of services.

Drug-free treatment is provided in in- and outpatient centers (e.g., psychiatric hospitals, mental health care centers, therapeutic communities), while substitution treatment is mainly delivered by outpatient medical-social care centers. Harm reduction initiatives include HIV and HCV prevention campaigns, needle exchange programs, peer support, pill testing, and low threshold facilities. In addition, feasibility studies are currently conducted concerning the implementation of drug consumption rooms (Antwerp) and controlled heroin prescription (Liège). Treatment facilities in prisons are limited to a few drug-free wards, detoxification, and substitution treatment, and several treatment alternatives have been developed instead of prison sentences.

\subsubsection{SubSTANCE ABUSE PROBLEMS AND TREATMENT DEMAND}

A public health approach to substance abuse problems - rather than a repressive approach - prevails in most Western countries, but little information is available about the percentage of substance abusers contacting treatment services. Some American authors have stated that only a minority of all problem drug users contacts self-help groups and treatment services, especially those with most severe problems (Tucker, 1999). In the Netherlands, it is estimated that harm reduction and treatment initiatives reach about $80 \%$ of the total substance abusing population (Van den Brink, 2002). This relates to the 
availability and accessibility of low threshold initiatives and the wide range of treatment alternatives for drug abusing offenders.

No such information is available for the situation in Belgium (De Donder, 2002), but based on data from 1996 it was estimated that about one third of all intravenous drug users followed substitution treatment (EMCDDA, 2001). In addition, figures of the National Institute of Health and Disability Insurance [Rijksinstitunt voor Ziekte- en Invaliditeitsverzekering (RIZIV)] show that more than 15,000 persons have contacted at least once a specialized center for substance abuse treatment between 1980 and 1999. However, these figures do not reveal any information about the relative coverage of these centers (INAMI, 2001).

Utilization studies in treatment centers provide direct information about these services and the treatment demand of persons with drug problems, and indirectly about the extent and characteristics of problem drug use, trends in drug use and means of administration (Stauffacher \& Kokkevi, 1999). On the other hand, such information is limited to those persons contacting treatment services. Moreover, most studies do not control for double counts, although some substance abusers contact various treatment services within a relatively short period of time (Kinnunen \& Nilson, 1999). Finally, treatment demand data concerning substance abuse problems in Europe relate almost exclusively to drug problems, while such information is not or only partially available concerning alcohol problems (EMCDDA, 2003).

Data from utilization studies show that the number of persons who were treated for drug problems in one of the EU-member states has constantly increased during the last decade (EMCDDA, 2003). Several reasons may account for this trend: improved registration methods, growing availability of treatment services, more differentiation of treatment programs, and increased coverage. Overall, most persons that enter drug treatment in one of the EU-countries are men in their twenties or thirties. The average age of persons entering treatment is 29.8 years, but the average age of people who are treated for the first time for such problems is 26.9 years (EMCDDA, 2003). Persons who use cannabis as primary drug are usually younger than heroin or cocaine users. The percentage of women in treatment varies between 2:1 (Sweden, Luxembourg, and Ireland) and 6:1 (the Netherlands, Spain, Greece, and Italy) (EMCDDA, 2002, 2003). Higher prevalence of service utilization among men can be attributed to differential patterns of substance use between men and women, and differential accessibility of treatment services. Although relatively fewer women enter treatment, a comparison of prevalence and utilization data has shown that the number of women asking for treatment is higher (EMCDDA, 2002).

Generally, the socio-economic status of persons entering treatment is significantly lower as compared by that of the general population: half of all drug abusers only have a degree of primary education, and about the same percentage is unemployed (EMCDDA, 2003). The percentage of foreigners in substance abuse treatment usually reflects the number of foreigners in the general population. However, ethnic origin is a better indicator than 
nationality to assess such differences, and studies that have applied this indicator have shown a higher prevalence of drug abuse problems among ethnic minority groups (Vandevelde, Vanderplasschen, \& Broekaert, 2003).

Most drug abusers contact treatment services spontaneously, or because family members urge them to do so (EMCDDA, 2003). The majority of the persons that are treated for drug problems report abuse of opiates (50 to $70 \%$ ), while cannabis has become the second most important substance of abuse (10 to $20 \%$ ), followed by cocaine (5 to $15 \%$ ) and amphetamines (3 to 10\%). Poly drug use has become increasingly popular, and over 50\% of all substance abusers report a secondary or tertiary drug (especially cannabis, cocaine, or alcohol) besides their primary drug. The most common way to administer heroin is injecting or smoking ("chasing the dragon"), but the prevalence of intravenous use among heroin addicts tends to decrease (EMCDDA, 2003). Cocaine is mostly sniffed or smoked, while amphetamines are usually taken orally. Among the population treated for drug problems, it appears that the use of heroin remained stable or even decreased over the years, while cannabis use has been registered more frequently. In some countries, although not all, a similar trend has been observed for cocaine use (EMCDDA, 2003). Finally, most registered persons started using cannabis and amphetamines when they were between 15 and 19 years old, while the first use of heroin and cocaine is usually situated between 20 and 29 years.

A lack of comparable data about drug treatment demand in Belgium has been observed by several authors (De Donder, 2000; Sleiman \& Sartor, 2002). This has resulted in incomplete or even missing data in recent comparisons of basic treatment demand data between all EU-member states (EMCDDA, 2003; Sleiman, 2003). Despite several registration systems that collect data about the characteristics of persons that follow treatment for substance abuse problems, most of these systems are limited to a specific setting (e.g., psychiatric hospitals, mental health care centers, specialized substance abuse treatment agencies), a particular region or community (e.g., Flanders, Brussels, the Frenchspeaking community), or a specific organization. Methodological differences do not allow the combination and analysis of these data on national level (Colpaert \& De Clercq, 2003), but if we keep these limitations in mind, some interesting information can be derived from these studies.

Different data sources show that the average age of persons in treatment for substance abuse problems in Belgium varies between 24.7 and 30.8 years (Molnar, Pecsteen, Hariga, Bastin, \& Dal, 2002; ODB-CTB, 2000; Raes \& Lombaert, 2003; Thienpont, 2003; Vandenbussche, 2001). The average age for the first treatment in specialized substance abuse treatment is 28 years (INAMI, 2001). The percentage of women in treatment is around 20\% in most centers and varies between 15.6\% and 26\% (Molnar et al., 2002; ODB-CTB, 2000; Raes \& Lombaert, 2003; Thienpont, 2003; Vandenbussche, 2001). Half of all substance abusers in treatment use opiates as primary drug (Molnar et al., 2002; ODB-CTB, 2000; Raes \& Lombaert, 2003; Thienpont, 2003), while fewer persons report 
cannabis (6.9 to $25.5 \%$ ), cocaine (5 to $14.2 \%$ ), and amphetamines (1 to $23 \%$ ) as their main source of problem drug use. About half of all registered clients in specialized substance abuse treatment had injected drugs (Thienpont, 2003). Data about facilities that treat alcohol and/or drug abusers show that $43.2 \%$ of all registered persons had alcohol problems, $15.7 \%$ reported cannabis as primary drug and $13.8 \%$ opiates (Vandenbussche, 2001).

Following this general introduction about the prevalence of substance abuse problems and different societal reactions to this problem, in particular treatment interventions, we focus on some characteristics of the region studied. We look at the organization of substance abuse treatment, and at data about treatment demand and the characteristics of the population treated in these centers.

\subsection{SUBSTANCE ABUSE TREATMENT IN THE REGION OF GHENT, EAST-FLANDERS (BELGIUM)}

\subsubsection{THE ORGANIZATION OF SUBSTANCE ABUSE TREATMENT}

As in most other Belgian cities, no data are available about the extent of drug problems in the region of Ghent (Sleiman, 2003). Given the frequent prevalence of such problems in urban areas, it can be expected that at least several hundreds of people are affected by substance abuse in a city of over 200,000 inhabitants, which is part of a province (East-Flanders) of in total more than 1,000,000 inhabitants. Historically, the region around Ghent was one of the first in Belgium to deal with substance abuse problems. Already in the 1960s, an organization was founded for the study, prevention and treatment of alcoholism and other substance use disorders [Instellingen voor de Studie, Preventie en Behandeling van Alcoholisme en andere Toxicomaniën (vzw IAT)]. This organization initially provided outpatient treatment to alcoholics [Centrum voor de Studie, Preventie en Behandeling van Alcoholisme en andere Toxicomaniën (CAT)], but when this region was confronted with heroin addiction at the beginning of the 1970s, the vzw IAT established a psychiatric hospital that exclusively addressed alcohol and drug addicts [De Pelgrim, 1973] (Broekaert, Raes, \& Soyez, 1997). In 1976, this organization was involved in the establishment of the first hierarchical therapeutic community for drug addicts in Belgium [De Kiem, 1970] (Broekaert, Soyez et al., 2001). First, De Kiem was organized as a specific ward inside De Pelgrim, but later became an independent organization that currently consists of a therapeutic community, a drug-free outpatient treatment center, prison-based treatment interventions, and various prevention initiatives. Around the same time (1974), De Sleutel was founded as a democratic therapeutic community for young adults with different kinds of problems (Broekaert, Raes \& Soyez, 1997). This initiative had its roots 
in alternative youth care, anti-psychiatry, the theory of Maxwell Jones, and psychodynamic therapy. From 1976 on, it gradually changed into a hierarchical drug-free therapeutic community.

As most mental health care centers and psychiatric hospitals were at that time rather reluctant to treat drug abusers, several specialized initiatives were established during the 1980s, including crisis intervention centers, day-care centers, and therapeutic communities (Maertens, 1997). De Sleutel developed a comprehensive network of prevention and treatment initiatives all over Flanders, with a strong concentration of these centers around Ghent (e.g., a crisis intervention center, day-care center, and therapeutic community). Meanwhile, psychiatric hospitals, mental health care centers, and psychiatric wards of general hospitals gradually opened their doors to substance abusers (Spooren, van Heeringen, \& Jannes, 1996). Currently, several psychiatric hospitals and mental health care centers offer specialized services for drug abusers (Vanderplasschen, Mostien, Claeys, Raes, \& Van Bouchaute, 2001). The latest additions to the treatment program of these centers have been a ward for dually diagnosed persons at the psychiatric hospital in Sleidinge, and a crisis unit at the psychiatric ward of the University Hospital in Ghent. Most of the above-mentioned services can be characterized as abstinence-oriented initiatives that offer detoxification and/or psychosocial treatment.

From the 1990s on, also other initiatives were established that were rather inspired by a harm reduction approach e.g., street corner work, and medical-social care centers [medischsociale opvancentra (MSOC)] (Broekaert \& Raes, 1998). Street corner work aimed at outreaching, case finding, information, health promotion, and, if necessary, referral to other agencies. The medical-social care centers are generally involved in substitution treatment, needle exchange, peer support, health promotion, and low threshold medical care. More recently, the increased demand for social reintegration and employment stimulated the establishment of social workplaces, which focus on the training and employment of, among others, substance abusers who have few qualifications and little work experience.

Besides these treatment services for drug abusers, nearly all psychiatric hospitals, mental health care centers, psychiatric wards of general hospitals, and some initiatives for sheltered living offer specialized services to alcoholics. Treatment for both target groups is usually strictly separated, and in several of the latter agencies drug abuse is an exclusion criterion. On the other hand, relatively few alcoholics address drug abuse treatment agencies given the specific population in these centers. Since we particularly focus on organizational problems that arose in the field of drug abuse treatment (cf. 1.3), this study will be mainly restricted to drug abusers. Still, some of the motives, objectives, results, conclusions and recommendations of this study are also valid for alcoholics and the organization of treatment for this target group. 


\subsubsection{TREATMENT DEMAND DUE TO SUBSTANCE ABUSE PROBLEMS}

The historical evolution and lack of directions on behalf of the government account for an extensive and differentiated number of treatment initiatives in the region around Ghent, including relatively many residential services e.g., therapeutic communities and departments in psychiatric hospitals. As few objective and comparable information was available about the number, characteristics, and service utilization of persons who contact one or more of these centers, we set up two similar utilization studies between 1999 and 2002 (Vanderplasschen, Colpaert, Lievens, \& Broekaert, 2003; Vanderplasschen, Lievens, \& Broekaert, 2001a). The first utilization study included 11 treatment centers and focused on treatment requests and demands during an 8-month period, based on all clients who asked for treatment in one of these agencies. Eighteen agencies participated in the second, analogous study that intended to register treatment demand and continued treatment participation after six months among all substance abusers addressing one of the specialized centers.

Analysis of the data of the first registration period (Vanderplasschen, Lievens, \& Broekaert, 2001a) showed that treatment demand in the region around Ghent is relatively high as compared to other, larger Belgian cities such as Antwerp, Brussels and Liège (Stauffacher, 1999; Van Dijck, Bruggeman, Demey, Todts, \& Van Hal, 2000). During an 8-month period, in total 1,647 treatment demands were registered in 11 participating agencies. It was estimated that 1,202 unique persons accounted for all treatment demands, which meant that more than one quarter of all treatment demands $(27 \%)$ concerned clients that asked for treatment twice or more during the registration period. Analysis of the data about unique clients revealed that almost $20 \%$ had been registered twice $(12 \%)$ or more $(7.5 \%)$, and that $15 \%$ of all clients had been registered in at least 2 different agencies. The number of "revolving door clients" or persons who asked for treatment in at least 3 different centers was estimated to be 48 substance abusers, or $4 \%$. Although this is a numerically small group, these persons accounted for $13.9 \%(\mathrm{n}=229)$ of all treatment demands.

Part of this study focused on "treatment requests", which also include more general questions for information or advice besides "treatment demands" that usually concern persons with a specific treatment need who show up for initial assessment (Vanderplasschen, Lievens, \& Broekaert, 2001a). Analysis of these data showed that 18\% of all treatment requests did not result in further actions by one of the services involved. Moreover, it was demonstrated that about $15 \%$ of all registered clients did not show up for the initial intake assessment after they had made an appointment for such a session. This type of dropout particularly occurred among young drug abusers $(<20$ years), while women and persons who had been treated before in the agency were more likely to be invited for and to attend initial assessment. On the other hand, women were more likely to drop out after initial assessment. 
Results of the second utilization study concerned all clients that had an initial intake assessment $(n=1,500)$ between December 2001 and May 2002, and a random sample of clients who were already in treatment in December 2001 ( $n=463)$ (Vanderplasschen, Colpaert et al., 2003). The largest group of clients was registered in residential detoxification treatment $(29.8 \% ; \mathrm{n}=585)$, while more than a quarter of all clients followed drug-free outpatient treatment $(27.7 \% ; n=543)$, or long-term residential treatment $(n=496$; $25.2 \%$ ). All other clients were registered in outpatient methadone maintenance treatment $(17.3 \% ; n=339)$. In total 1,500 unique clients were identified, of whom $19.1 \%$ had had at least two intake assessments during the registration period. The number of "revolving door clients" within this 6-month period was estimated to be $2.9 \%$, and accounted for $9.9 \%$ of all intake assessments.

Most registered persons were men $(79.8 \%)$, but the percentage of female clients was relatively higher in long-term residential treatment $(22.3 \%)$ and outpatient methadone maintenance treatment $(21.3 \%$ ) (Vanderplasschen, Colpaert et al., 2003). The average age was 26.5 years and most clients were between 20 and 29 years old (53.5\%). Over 15\% of all clients were younger than 20 years. We observed a significantly higher percentage of women in the latter age group $(27.8 \%)$, as opposed to older age groups $(<20 \%)$. Average age was significantly higher among clients in methadone maintenance treatment than among those in drug-free outpatient treatment. More than $25 \%$ of all registered clients had a place of residence outside the province of East-Flanders, which illustrates that the extensive offer of treatment services in this region is attractive to inhabitants of other regions.

Analysis of these clients' drug use showed that the vast majority were poly drug users $(83.2 \%)$ (Vanderplasschen, Colpaert et al., 2003). Half of them (49.1\%) were dependent on opiates (heroin). Cannabis (29.1\%), cocaine (24.5\%), sedatives $(21.2 \%)$, and methadone $(20.8 \%)$ were reported to be other frequent sources of problem drug use. According to the registering agencies, $27.2 \%$ had opiates as primary drug and about the same number $(27 \%)$ used several substances, while cannabis was the primary drug for almost one fifth of all clients $(17 \%)$. Less than half of all registered persons had injected drugs (41.4\%), and $29.8 \%$ had been using drugs intravenously the previous year.

The study of the service utilization of these clients showed that $27.3 \%$ contacted for the first time a substance abuse treatment agency during the registration period (Vanderplasschen, Colpaert et al., 2003). Half of all clients who had been treated before were registered in a center where they had been in treatment before, and $80 \%$ had been treated previously in one of the 18 participating services. Most clients contacted substance abuse treatment agencies spontaneously (29.8\%), while $12.2 \%$ was referred by their social network (family or friends). Police and the criminal justice system accounted for $19.5 \%$ of all referrals, while in- and outpatient substance abuse treatment referred $15.9 \%$ of all clients. Furthermore, general practitioners and psychiatric hospitals referred more than 5\% of all clients. 
More than $80 \%$ of all intake assessments resulted in the start of a treatment episode, while $7.7 \%$ of the clients were directly referred to another treatment center (Vanderplasschen, Colpaert et al., 2003). No further steps were undertaken in $11.1 \%$ of all initial assessments, mostly due to a decision of the client. When we looked at the state of this treatment episode six months later, we observed that $28.2 \%$ of all treatment episodes that were started could be considered as "ended after mutual deliberation". In $76.4 \%$ of these cases further treatment was planned afterwards. About one quarter of all treatment episodes $(24.8 \%)$ still continued at the end of the registration period. Less than half of all treatment episodes had been discontinued early and unilaterally: in $37.2 \%$ of the cases clients themselves stopped treatment early, and in $8.5 \%$ of all cases clients were discharged early due to various reasons, such as drug use, aggression, and violation of the rules. A significant association was found between younger age and early dropout. As opposed to clients in inpatient agencies, significantly less clients in outpatient treatment discontinued treatment early or were discharged early.

Finally, analysis of the duration of treatment shows that more than $35 \%$ of the total sample was in treatment for at least 6 months. For most clients (56.8\%), treatment lasted less than three months, and $19.8 \%$ of all clients stayed less than one week in treatment. A clear association was observed with the type of treatment followed. While $88.1 \%$ of all clients in detoxification treatment stopped this intervention within a one-month period, $70 \%$ of all clients in long-term residential treatment stayed longer than one month in treatment. In $85 \%$ of all cases, methadone maintenance treatment lasted longer than 6 months, and also $55.1 \%$ of all treatment episodes in outpatient drug-free treatment lasted at least for 6 months.

Based on a screening of all persons who followed in- or outpatient substance abuse treatment during the first week of October 1999 in one of the above-mentioned agencies $(n=396)$, we found that the vast majority of the clients (87.4\%) had been dependent on one or more illicit drugs for at least 2 years (Vanderplasschen, Lievens, \& Broekaert, 2001b). According to their caregivers, $88.4 \%$ of them had problems related to at least 3 life domains of the Addiction Severity Index: drugs (90.7\%); family and social relations (78.8\%); physical health (56.1\%); police, the courts (45.8\%); employment and income (45.1\%); psychological and emotional problems (40.3\%); and alcohol (21.5\%). In addition, $49.9 \%$ of these clients had been treated in at least 3 different agencies (including this treatment episode), and $45.7 \%$ had been in treatment before in the center where they were registered.

The presented data demonstrate that many drug abusers contact treatment services in the region around Ghent. While the characteristics of the treated population varies considerably from agency to agency, most clients have in common that they have multiple and long-term problems and most of them have been treated for such problems before. 
Half of all registered clients had been treated before in at least 2 other agencies and about one fifth of this sample asked at least twice for treatment within a 6 to 8 -month period. Only some clients $(<5 \%)$ were identified as "revolving door clients" or "drug treatment tourists". Consequently, the way treatment is organized for this target group should meet the needs and characteristics of this population.

\subsection{EVALUATION OF SUBSTANCE ABUSE TREATMENT}

\subsubsection{CHALLENGES TO THE FIELD OF SUBSTANCE ABUSE TREATMENT}

The previous paragraphs have shown that substance abuse treatment consists of various treatment modalities and interventions, including different objectives, target groups, and methods. Evaluation studies have demonstrated the effectiveness of some of these modalities (e.g., methadone maintenance, therapeutic communities, cognitivebehavioral therapy), while no or insufficient evidence is available about the effectiveness of other interventions (van Gageldonk, de Zwart, van der Stel, \& Donker, 1997). Despite positive evaluations, considerable dropout and relapse have been associated with almost every intervention (EMCDDA, 2002; Sindelar \& Fiellin, 2001). Therefore, most recent insights into the treatment of substance abuse problems start from a "stepped care"approach and stress the importance of tracking and monitoring clients over time (van Gageldonk et al., 1997).

Substance abuse is increasingly recognized as a chronic and relapsing disorder, characterized by multi-faceted and complex problems (Brindis \& Theidon, 1997; McLellan, 2002). During this process, motivation for change and problem severity may vary (McLellan, Arndt, Metzger, Woody, \& O'Brien, 1993; Prochaska, DiClemente, \& Norcross, 1992), requiring specific interventions at certain moments. For most substance abusers, treatment will not be limited to one single treatment episode (Willenbring, 1996), but will rather consist of a sequence of interventions directed at the momentary needs of the individual and characterized by coordination and continuity of care (Graham, Timney, Bois, \& Wedgerfield, 1995). Some evidence is available for a cumulative effect of different interventions over time (Hser, Anglin, Grella, Longshore, \& Prendergast, 1997), but few authors have studied such effects since it is extremely difficult to examine the combined or separate effect of different treatment episodes. A comprehensive approach, and ongoing support services and continuing care will be necessary to prevent relapse and to assist clients in stabilizing and overcoming their problems (Brindis \& Theidon, 1997). However, few programs are equipped to provide such wrap-around and continuous services. 


\subsubsection{ORGANIZATIONAL PROBLEMS}

In spite of the above-mentioned challenges, several authors have reported problems concerning the organization of health care, and substance abuse treatment in particular (Alemi, Stephens, \& Butts, 1992; Van Riet \& Wouters, 1996). First, the deinstitutionalization of treatment and the increased stress on outpatient treatment resulted in a myriad of fragmented programs with differing eligibility criteria (Brindis \& Theidon, 1997; McLellan et al., 1999). When clients are in need of several services, coordination and communication problems may arise, as caregivers are not always informed about the involvement of other agencies (Alemi et al., 1992; van Achterberg, Stevens, Hekkink, Crebolder, \& Philipsen, 1995). Second, the institution-based organization of treatment should make room for a functional organization consisting of specific modalities and a more client-centered approach characterized by participation, emancipation, treatment planning, and involvement of the clients' social network. Moreover, continuous services of varying intensity should be provided to respond to the changing needs of this population. Finally, several target groups are served inadequately or not at all by existing services, and especially persons with severe and complex problems are at risk of falling through the cracks of the system (van Riet \& Wouters, 1996). Such populations include dually diagnosed persons, substance abusing mothers, and immigrants (Broekaert, Vanderplasschen, \& Soyez, 1999; Vanderplasschen, Derluyn, \& Broekaert, 2002).

Some of these problems have also been identified in Belgian substance abuse treatment. A state of the art in this sector from 1995 revealed a lack of programming of treatment services by the authorities, lack of cooperation and communication after referral, few deliberation, no centralized intake facilities, lack of monitoring of clients and follow-up after treatment, no standardized and uniform registration system, and services that lack a clear profile (Raes, Lenders, \& Geirnaert, 1995). In addition, no information is available about the effectiveness of different interventions, except some for therapeutic communities (Broekaert, Raes, Kaplan, \& Coletti, 1999). The study concluded that case management was needed in order to guide clients through the complex network of services, among others (Raes et al., 1995). Other authors have stated that the lack of coordination includes the risk of a chaotic network of services that may lead to duplicated work and "treatment tourism" (Maertens, 1997). Moreover, the "fee for services" subsidizing system does not stimulate cooperation, but rather promotes competition. Finally, the lack of monitoring and evaluation does not allow the detection of misuse of available resources. Networking, case management and centralization of the intake process were suggested as alternatives for these structural and organizational problems (Maertens, 1997).

We have organized 15 focus groups with a small sample of substance abusers ( $\mathrm{n}=95)$ from in- and outpatient services and drug consumer organizations to evaluate the organization 
of substance abuse treatment (Vanderplasschen \& De Wilde, 2002). Results showed that these persons were generally satisfied with the availability of services, especially low threshold facilities and methadone maintenance treatment, and with the therapeutic relationship they had with individual caregivers (Sergeant \& Van Havere, 2002). On the other hand, these substance abusers criticized the lack of attention to housing, employment, and occupational problems, little information about the long-term effects of methadone, long waiting lists in some agencies (e.g., detoxification and crisis intervention centers), lack of participation and involvement in the treatment process, and lack of aftercare services (Vanderplasschen \& De Wilde, 2002). The needs clients expressed concerning the organization of treatment mostly related to more individualized and comprehensive care, adapted services in various stages of their addiction, involvement of stabilized or recovered drug users, increased accessibility of services, and more information about and participation in the treatment process.

\subsubsection{Alternative APPROACHES TO THE DELIVERY OF SERVICES}

Given the characteristics of substance abusers (e.g., multiple and chronic problems, various treatment episodes) and the organizational problems this field faces, several alternatives have been suggested to improve the quality of substance abuse treatment. Case management is such a promising approach that was developed to provide a comprehensive and ongoing response to clients' needs (Brindis \& Theidon, 1997). Building on the substantial history of this intervention with other at-risk populations (e.g., severely mentally ill persons, disabled persons, elderly, and multi-problem families), several programs for substance abusers in the United States began to integrate case management services as an effective and cost-efficient method of delivering coordinated care from the 1990s onwards.

The origins of case management go back to the 1920s, when Mary Richmond applied the term "social casework" to activities that affected the adjustment between individuals and their social environment (SAMHSA, 1998). Social casework was characterized by the coordination of human services, conservation of public funds, care for poor and sick people, belief in the worth and dignity of clients and the empowerment of vulnerable populations (Hall, Carswell, Walsh, Huber, \& Jampoler, 2002). This social work intervention focused on poor and disadvantaged people who were struggling with basic survival needs and its activities were similar to the key functions of what we now call case management. Other authors (Brindis \& Theidon, 1997; Hall et al., 2002) even situate the roots of case management in the nineteenth century (1863), since the early history of human services included settlement houses and charity organization societies, which were involved in case coordination and can thus be regarded as an early conceptualization of case management. 
The boom of case management was associated with the deinstitutionalization of psychiatric care, which led to the expansion of community-based services (Ashery, 1996; Siegal et al., 1995). The categorical nature of eligibility for services and the fragmentation of service delivery hampered the effective utilization of such services and necessitated the introduction of so-called "case managers". Since the 1970s, a wealth of literature has been published concerning the implementation, practice and evaluation of case management among mentally ill persons (Burns, Fioritti, Holloway, Malm, \& Rossler, 2001). Evaluation studies have generally demonstrated positive outcomes such as reduced hospitalization rates, increased use of outpatient and community services, improved quality of life, and high client satisfaction (Ziguras \& Stuart, 2000).

The application of this intervention among substance abusers is still in its infancy. It has been defined as "that part of substance abuse treatment that provides ongoing supportive care to clients and facilitates linking of clients with appropriate helping resources in the community" (Birchmore-Timney \& Graham, 1989), but no consensus exists about its definition (SAMHSA, 1998). While some agreement can be found about case managers' basic functions and the core principles of this intervention, many issues concerning the implementation and evaluation of case management remain unanswered: What are the motives and objectives of this intervention? Should it be directed at some specific target groups? How can case management be integrated in existing services or in the network of facilities? How long should this intervention be continued? Who should do this? What are the effects of this intervention on clients' functioning and the system of services?

This dissertation seeks for responses to these and other questions.

\subsection{AIMS OF THE STUDY}

In Belgium, provinces are responsible for the coordination of prevention initiatives for substance abusers [provinciale preventieplatforms middelenmisbruik], while the regional Boards on Mental Health Care [overlegplatforms geestelijke gezondheidszorg] are responsible for the coordination of treatment initiatives in the field of mental health care. In 1996, the Prevention Platform on Substance Abuse [Preventieplatform Middelenmisbruik Oost-Vlaanderen] and the Regional Board on Mental Health Care [Overlegplatform Geestelijke Gezondheidszorg Oost-Vlaanderen (PopovGGZ)] agreed to cooperate concerning the coordination of substance abuse prevention and treatment in the province of East-Flanders. The main

objective of this cooperation was to improve the quality of treatment and the delivery of services for substance abusers. This study examines the process of ameliorating the organization of substance abuse treatment in the province of East-Flanders between 1997 and 2003. 
The aims of the study were threefold. First, we wanted to explore the current organization of substance abuse treatment in this region, and particularly looked at indicators of coordination and continuity of care since the multiple, complex and chronic problems of substance abusers necessitate such an approach. Few studies have provided such information and contextual factors hamper the general nature of these data. Second, since case management was suggested as a potential response to the needs of particular clients, we wanted to examine how this intervention could best be implemented and also looked at available evidence about the effectiveness of this intervention. Although deliberate implementation has been identified as a decisive factor for the success of case management, little information is available about crucial aspects when implementing this intervention. Moreover, despite the fact that several authors have studied the effects of case management, controversy remains about the effectiveness of this intervention due to few randomized and controlled studies and a lack of systematic review studies. Third, besides a more coordinated and continuous approach for some clients, we wanted to look at ways to bridge the gap between various treatment modalities and to improve coordination and continuity of care at structural level. Little information is available about how different modalities and interventions can be combined and integrated into a comprehensive treatment system, and which steps precede the establishment of such a network of services.

We achieved our objectives by means of a sequence of separate studies.

In order to study the organization of substance abuse treatment, and aspects of coordination and continuity of care, we interviewed caregivers in all agencies that address substance abusers in this region and analyzed a random selection of client files in some of these centers (chapter 2). We assessed the quality of different aspects of the treatment process, including intake procedure, treatment planning, keeping of client files and registration of client characteristics, referral, cooperation and communication with other agencies, follow-up and monitoring of clients, and case management practices.

To explore the prerequisites for the integration of different treatment modalities, we examined similarities and dissimilarities between these modalities, and discussed incentives and preconditions for the integration of treatment systems with practitioners and directors from both harm reduction and abstinence-oriented settings during an international symposium (first part of chapter 3). Based on various discussion groups with practitioners, directors, policymakers, and researchers in the province of East-Flanders, we distinguished five steps that are necessary to implement an integrated treatment system for substance abusers (second part of chapter 3). We looked at advantages and disadvantages of such a system based on available literature and experiences from other regions.

In order to assess crucial elements of the implementation of case management we reviewed the literature concerning the implementation of this intervention for substance abusers from a comparative perspective (chapter 4). In collaboration with researchers from the United States and the Netherlands, we focused on six key questions that are deemed 
essential for successful implementation. It concerns the motives, objectives and target group of this intervention, its integration in the network of services, the choice of an adequate model of case management, skills and qualifications of the case manager, and the continuity and evaluation of this intervention.

In addition, the implementation of a model of case management was evaluated based on a small-scale study in several treatment agencies in the region around Ghent (chapter 5). We looked at client outcomes, mediating variables, and several aspects of implementation in order to further optimize the implemented model.

The effectiveness of different models of case management for substance abusers was reviewed based on the results of studies that were published between 1993 and 2003 in peer-reviewed journals (chapter 6). The (differential) effectiveness of intensive case management/assertive community treatment, the strengths-based model, generalist case management, and the brokerage and clinical model was analyzed, including an analysis of its effects among specific target groups such as homeless persons, drug-involved offenders, substance abusing women, and dually diagnosed persons.

Finally, we set up a randomized and controlled study in the region of Ghent to look at the effectiveness of intensive case management for substance abusers who are recognized as multiple and frequent service users. Preliminary results of this ongoing study are presented, based on a qualitative study of the initial effects of this intervention among the first 20 clients who were involved in this project (chapter 7). We examined whether intensive case management contributed to the realization of the postulated goals, which factors elicited these effects, and how clients themselves evaluated this intervention. 


\section{REFERENCES}

Alemi, F., Stephens, R., \& Butts, J. (1992). Case management: a telecommunication practice model. In R.S. Ashery (Ed.), Progress and Issues in case management (NID A Research Monograph 127) (pp. 261-273). Rockville: National Institute on Drug Abuse.

Anglin, M.D., \& Hser, Y. I. (1991). Criminal justice and the drug-abusing offender. Policy issues of coerced treatment. Behavioral Science and the Law, 9(3), 243-267

Ashery, R.S. (1996). Case management for substance abusers: more issues than answers. In H. Siegal \& R. Rapp (Eds.), Case management and substance abuse treatment: practice and experience (pp. 141-154). New York: Springer Publishing Company.

Birchmore-Timney, C., \& Graham, K. (1989). A survey of case management practices in addictions programs. Alcoholism Treatment Quarterly, 6(3/4), 103-127.

Blanken, P. (2002). The Dutch heroin trial: investigating the effectiveness of the medical coprescription of heroin. In International Harm Reduction Association (Ed.), Book of Abstracts of the 13th International Conference on Reduction of Drug Related Harm (pp. 200). Ljubljana, Slovenia: International Harm Reduction Association.

Brindis, C.D., \& Theidon, K.S. (1997). The role of case management in substance abuse treatment services for women and their children. Journal of Psychoactive Drugs, 29(1), 79-88.

Broekaert, E., \& Raes, V. (1998). Drug abuse treatment in Europe: country reports Belgium. In M. Coletti (Ed.), Evaluation of treatment: a European overview (pp. 10-35). Rome: Cedis Editrice.

Broekaert, E., Raes, V., Kaplan, C., \& Coletti, M. (1999). The design and effectiveness of Therapeutic Community research in Europe: an overview. European Addiction Research, 5, 21 35 .

Broekaert, E., Raes, V., \& Soyez, V. (1997). Research developments in Therapeutic Communities. Merelbeke: Training and Research in Therapeutic Communities (TRTC).

Broekaert, E., Soyez, V., Vanderplasschen, W., Vandevelde, D., Bradt, R., Morival, M., et al. (2001). The Video Addiction Challenge Test: A New Instrument for Qualitative Substance Abuse Assessment, Treatment Planning and Research in Therapeutic Communities. International Journal of Social Welfare, 10(2), 134-141.

Broekaert, E., Vanderplasschen, W., \& Soyez, V. (Eds.). (1999). Proceedings of the second international symposium on substance abuse treatment and special target groups. Community as a method. Ghent, Belgium: Ghent University, Department of Orthopedagogics \& the European Federation of Therapeutic Communities (EFTC).

Broekaert, E., Vanderplasschen, W., Temmerman, I., Ottenberg, D.J., \& Kaplan, C.D. (2000). Retrospective study of similarities and relations between American drug-free and European therapeutic communities for children and adults. Journal of Psychoactive Drugs, 32(4), 407-417.

Broekaert, E., \& van der Straeten, G. (1997). Histoire, philosophie et développement de la communauté thérapeutique en Europe. Psychotropes: Revue Internationale des Toxicomanies, 3(1), $7-23$.

Burns, T., Fioritti, A., Holloway, F., Malm, U., \& Rossler, W. (2001). Case management and assertive community treatment in Europe. Psychiatric Services, 52(5), 631-636. 
Cattaert, G., \& Pacolet, J. (2002). Schatting van het alcoholgebruik/misbruik in Vlaanderen en België. Brussel - Leuven: Vereniging voor Alcohol- en andere Drugproblemen - Katholieke Universiteit Leuven, Hoger Instituut voor de Arbeid.

Colpaert, K., \& De Clercq, T. (2003). Implementing the "Treatment Demand Indicator" in Belgium: registration of drug users in treatment. Brussels: Scientific Institute for Public Health.

De Donder, E. (2000). Alcohol, illegale drugs \& medicatie: recente ontwikkelingen in Vlaanderen. Leuven: Acco.

De Donder, E. (2002). Alcohol, illegale drugs \& medicatie: recente ontwikkelingen in Vlaanderen 2001. Leuven: Acco.

De Leon, G. (1997). Passages: A therapeutic community oriented day treatment model for methadone maintained clients. Journal of Drug Issues, 27(2), 341-342.

De Ruyver, B., \& Casselman, J. (2000). Het Belgisch drugbeleid anno 2000: een stand van zaken drie jaar na de anbevelingen van de parlementaire werkgroep drugs. Leuven - Ghent: Katholieke Universiteit Leuven, Onderzoeksgroep Gerechtelijke geestelijke gezondheidszorg - Universiteit Gent, Onderzoeksgroep Drugbeleid, strafrechtelijk beleid en internationale criminaliteit.

De Ruyver, B. Casselman, J., Pelc, I., Geenens, K., Nicaise, P., From, L., et al. (2004). Drugbeleid in cijfers: studie naar betrokken actoren, overheidsuitgaven en bereikete doelgroepen. Brussel: Federale Diensten voor Wetenschappelijke, Technische en Culturele Aangelegenheden.

Drucker, E. (1995). Harm reduction: A public health strategy. Current Issues in Public Health, 1, 64-70.

Gossop, M., Marsden, J., \& Stewart, D. (2001). NTORS after five years. Changes in substance use, health and criminal behaviour during the five years after intake. London: National Treatment Outcome Research Study, National Addiction Centre.

Gossop, M., Marsden, J., Stewart, D., \& Rolfe, A. (1999). Treatment retention and 1 year outcomes for residential programmes in England. Drug and Alcohol Dependence, 57(2), 89-98.

European Monitoring Centre for Drugs and Drug Addiction (EMCDDA). (2000). Annual report on the state of the drugs problem in the European Union 2000. Luxembourg: Office for Official Publications of the European Communities.

European Monitoring Centre for Drugs and Drug Addiction (EMCDDA). (2001). Annual report on the state of the drugs problem in the European Union 2001. Luxembourg: Office for Official Publications of the European Communities.

European Monitoring Centre for Drugs and Drug Addiction (EMCDDA). (2002). Annual report on the state of the drugs problem in the European Union and Norway 2002. Luxembourg: Office for Official Publications of the European Communities.

European Monitoring Centre for Drugs and Drug Addiction (EMCDDA). (2003). Annual report on the state of the drugs problem in the European Union and Norway 2003. Luxembourg: Office for Official Publications of the European Communities.

Federale Regering. (2001). Beleidsnota van de federale regering in verband met de drugproblematiek. Brussel: Federale regering. 
Graham, K., Timney, C., Bois, C., \& Wedgerfield, K. (1995). Continuity of care in addictions treatment: the role of advocacy and coordination in case management. American Journal of Drug and Alcohol Abuse, 21(4), 433-451.

Grant, B., Harford, T.C., Dawson, D.A., Chou, P., Dufour, M., \& Pickering, R. (1994). Prevalence of DSM-IV alcohol abuse and dependence, United States 1992. Alcohol Health \& Research World, 18(3), 243-248.

Grichting, E., Uchtenhagen, A., \& Rehm, J. (2002). Modes and impact of coercive inpatient treatment for drug-related conditions in Switzerland. European Addiction Research, 8(2), 7883.

Hall, J.A., Carswell, C., Walsh, E., Huber, D.L., \& Jampoler, J.S. (2002). Iowa case management: Innovative social casework. Social Work, 47(2), 132-141.

Hansen, W., (1992). School-based substance abuse prevention: a review of the state of the art in curriculum, 1980-1990. Health Education Research, 7, 403-430.

Harm Reduction Coalition (HRC). (2001). Principles of harm reduction: The need for harm reduction. Retrieved November 3, 2001, from http://www.harmreduction.org/prince.html.

Hser, Y.I., Anglin, M.D., Grella, C., Longshore, D., \& Prendergast, M.L. (1997). Drug treatment careers: a conceptual framework and existing research findings. Journal of Substance Abuse Treatment, 14(6), 543-558.

Hubbard, R.L., Craddock, S.G., \& Anderson, J. (2003). Overview of 5-year followup outcomes in the drug abuse treatment outcome studies (DATOS). Journal of Substance Abuse Treatment, 25(3), 125-134.

Institut National d'Assurance Maladie-Invalidité (INAMI). (2001). La rééducation fonctionelle des toxicomanes de 1980 à 1999. Bruxelles: INAMI.

Kinnunen, A., \& Nilson, M. (1999). Recent trends in drug treatment in Europe. European Addiction Research, 5, 145-152.

Kooyman, M. (1993). The therapeutic community for addicts: intimacy, parent involvement and treatment success. Amsterdam - Lisse: Swets \& Zeitlinger.

Leppänen, K., Sullström, R., \& Suoniemi, I. (2001). The consumption of alcohol in fourteen European countries: a comparative econometric analysis. Helsinki, Finland: Stakes, National Research and Development Centre for Welfare and Health.

Maertens, J. (1997). Opbouwen van een zorgcircuit toxicomanie: een probleem zo groot als het werkveld? Hospitalia, 4, 171-180.

Marlatt, G.A., Blume, A., \& Parks, G. (2001). Integrating harm reduction therapy and traditional substance abuse treatment. Journal of Psychoactive Drugs, 33(1), 13-22.

McLellan, A.T. (2002). Have we evaluated addiction treatment corretcly? Implications from a chronic care perspective. Addiction, 97(3), 249-252.

McLellan, A.T., Arndt, I., Metzger, D., Woody, G., \& O'Brien, C. (1993). The effects of psychosocial services in substance abuse treatment. Journal of the American Medical Association, 269, 1953-1959. 
McLellan, A.T., Hagan, T.A., Levine, M., Meyers, K., Gould, F., Bencivengo, M. et al. (1999). Does clinical case management improve outpatient addiction treatment. Drug and Alcohol Dependence, 55, 91-103.

Molnar, M., Pecsteen, D., Hariga, F., Bastin, P., \& Dal, M. (2002). L'usage de drogues en communauté française. Rapport Communauté Française 1999 - 2000. Bruxelles: Eurotox.

Overleg Druggebruik Brussel - Concertation Toxicomanies Bruxelles (ODB-CTB). (2000). Epidemiologische gegevens systematisch in zamelen. Brussel: CTB-ODB.

Paglia, A., \& Room, R. (1999). Preventing substance use problems among youth: a literature review and recommendations. Journal of Primary Prevention, 20, 3-50.

Prochaska, J., DiClemente, C., \& Norcross, J. (1992). In search of how people change: applications to addictive behaviors. American Psychologist, 47(9), 1102-1114.

Rabinowitz, J., Cohen, H., \& Atias, S. (2002). Outcomes of naltrexone maintenance following ultra rapid opiate detoxification versus intensive inpatient detoxification. American Journal of Addictions, 11(1), 52-56.

Raes, V., Lenders, F., \& Geirnaert, M. (1995). Drughulpverlening in Vlaanderen: Feiten en problemen. Brussel: Vereniging voor Alcohol- en andere Drugproblemen.

Raes, V., \& Lombaert, G. (2003). Jaarverslag De Sleutel 2002. Een evaluatie volgens EFQM. (unpublished annual report). Merelbeke: De Sleutel.

Rapp, R.C., Siegal, H.A., Li, L., \& Saha, P. (1998). Predicting post-primary treatment services and drug use outcome: A multivariate analysis. American Journal of Drug and Alcohol Abuse, 24(4), 603-615.

Saleh, S.S., Vaughn, T., Hall, J.A., Levey, S., Fuortes, L., \& Uden-Holmen, T. (2002). Effectiveness of case management in substance abuse treatment. Care Management Journal, 3(4), 172-177.

Sergeant, A., \& Van Havere, T. (2002). Onderzoek naar hoe druggebruikers bun zorgbehoeften en bulpverleningsaanbod ervaren (unpublished Master-dissertation). Gent: Universiteit Gent, Faculteit Psychologie en Pedagogische Wetenschappen.

Siegal, H.A., Rapp, R.C., Kelliher, C.W., Fisher, J.H., Wagner, J.H., \& Cole, P.A. (1995). The strengths perspective of case management: a promising inpatient substance abuse treatment enhancement. Journal of Psychoactive Drugs, 27(1), 67-72.

Simpson, D.D. (1981). Treatment for drug abuse: Follow-up outcomes and length of time spent. Archives of General Psychiatry, 38(8), 875-880.

Sindelar, J.L., \& Fiellin, D.A. (2001). Innovations in treatment for drug abuse: solutions to a public health problem. Annual Review of Public Health, 22, 249-272.

Sleiman, S. (2003). Belgian National Report on Drugs 2003. Brussel: Scientific Institute of Public Health, Epidemiology Unit - Belgian Information Reitox Network (BIRN).

Sleiman, S., \& Sartor, F. (2002). Belgian National Report on Drugs 2002. Brussel: Scientific Institute of Public Health, Epidemiology Unit - Belgian Information Reitox Network (BIRN).

Spooren, D., Van Heeringen, K., \& Jannes, C. (1996). Drug abuse and emergency psychiatry: a comparative study of psychiatric emergencies following illegal and legal drug abuse in Belgium. European Addiction Research, 2, 213-218. 
Stauffacher, M. (Ed.) (1999). Pompidou Group Project on Treatment Demand: final report. Treated drug users in 23 European cities, Data 1997, Trends 1996-1997. Strasbourg: Council of Europe, Cooperation Group to combat drug abuse and illicit trafficking in drugs (Pompidou Group).

Stauffacher, M. \& Kokkevi, A. (1999). The Pompidou Group Treatment Demand Protocol: the first pan-European standard in the field. European Addiction Research, 5(4), 191-196.

Substance Abuse and Mental Health Administration (SAMHSA). (1998). Comprehensive case management for substance abuse treatment (TIP Series 27). Rockville: U.S. Department of health and human services, Public Health Service, Substance abuse and mental health services administration, Center for substance abuse treatment.

Thienpont, J. (2003). Cïfergegevens voor de VVBV centra: 2000, 2001 en 2002. Gent: Vlaamse Vereniging van Behandelingscentra Verslaafdenzorg (VVBV)

Tobler, N. (2001). Prevention is a two-way process. Drug and Alcohol Findings, 5, 25-27.

Tucker, J.A. (1999). Reformulating the addictive behavior change process: changing addictive behavior, historical and contemporary perspectives. In J.A. Tucker, D. Donovan, \& A. Marlatt (Eds.), Changing addictive behavior: Bridging clinical and public health strategies (pp. 1-44). New York: The Guilford Press.

United Nations Office for Drug Control and Crime Prevention (UNDCCP) (2000). World Drug Report 2000. Oxford: Oxford University Press.

van Achterberg, T., Stevens, F., Hekkink, M., Crebolder, H., \& Philipsen, H. (1995). Implementing coordination of care: task performance and problems encountered. Scandinavian Journal of Caring Sciences, 9(4), 209-217.

Van den Brink, W. (2002). Addiction treatment, addiction research, paradigms between day to day work and visions (Symposium devoted to the lifetime contributions of Professor Dr. Ambros Uchtenhagen, 6 September 2002). Zurich: Institut for Suchtforschung.

Van den Brink, W., Hendriks, V.M., Blanken, P., Huijsman, I.A., \& Van Ree, J.M. (2002). Medical coprescription of heroin: two randomized controlled trials. Den Haag: Centrale Commissie Behandeling Heroïneverslaafden (CCBH).

Vandenbussche, E. (2001). Vlaamse Registratie Middelenmisbruik (VRM): registratiegegevens 1999. Brussel: Vereniging voor Alcohol- en andere Drugproblemen (VAD).

Vanderplasschen, W., Colpaert, K., Lievens, K., \& Broekaert, E. (2003). De Oost-Vlaamse drughulpverlening in cijfers: kenmerken, zorggebruik en uitstroom van personen in behandeling (Orthopedagogische Reeks Gent Nummer 15). Gent: Universiteit Gent, Vakgroep Orthopedagogiek.

Vanderplasschen, W., De Donder, E., Lenoir, S., \& Roets, G. (2001). De leerlingenbevraging over een drugbeleid op school: een bruikbaar instrument? Gent - Brussel: Universiteit Gent, Vakgroep Orthopedagogiek - Vereniging voor Alcohol- en andere Drugproblemen (VAD).

Vanderplasschen, W., Derluyn, I., \& Broekaert, E. (2002). Opvoedingsondersteuning van drugverslaafde ouders en hun jonge kinderen. In W. Buisman, et al. (Eds.), Handboek Verslaving: bulpverlening, preventie en beleid (pp. C-3130 1-24). Houten: Bohn Stafleu Van Loghum.

Vanderplasschen, W., \& De Wilde, J. (2002). Satisfaction and needs of drugs users contacting treatment services. In International Harm Reduction Association (Ed.), Book of Abstracts of 
the 13th International Conference on Reduction of Drug Related Harm (pp. 84). Ljubljana, Slovenia: International Harm Reduction Association.

Vanderplasschen, W., Lievens, K., \& Broekaert, E. (2001a). De instroom in de Oost-Vlaamse drughulpverlening: registratie van intakes en aanmeldingen tussen oktober 1999 en mei 2000 (Orthopedagogische Reeks Gent Nummer 13). Gent: Universiteit Gent, Vakgroep Orthopedagogiek.

Vanderplasschen, W., Lievens, K., \& Broekaert, E. (2001b). Implementatie van een methodiek van case management in de drughulpverlening: een proefproject in de provincie Oost-Vlaanderen (Orthopedagogische Reeks Gent Nummer 14). Gent: Universiteit Gent, Vakgroep Orthopedagogiek.

Vanderplasschen, W., Mostien, B., Claeys, P., Raes, V., \& Van Bouchaute, J. (2001). Conceptnota organisatiemodel zorgcircuit middelenmisbruik. (Orthopedagogische Reeks 12). Gent: Universiteit Gent, Vakgroep Orthopedagogiek.

Vandevelde, S., Vanderplasschen, W., \& Broekaert, E. (2003). Cultural responsiveness in substance abuse treatment: a qualitative study using professionals' and clients' perspectives. International Journal of Social Welfare, 12(3), 221-228.

Van Dijck, A., Bruggeman, B., Demey, R., Todts, S., \& Van Hal, G. (2000). Inventarisatie van publiek beschikbare gegevens m.b.t. de gespecialiseerde drughulpverlening in Antwerpen (1996-1999) (ESOC publicatie nr. 34). Antwerpen: Universiteit Antwerpen, Vakgroep Epidemiologie en Sociale Geneeskunde.

Van Epen, J. (1995). De drugs van de wereld, de wereld van de drugs. Houten - Diegem: Bohn, Stafleu, Van Loghum.

Van Gageldonk, A., de Zwart, W., van der Stel, J., \& Donker, M. (1997). De Nederlandse verslavingszorg: overzicht van de kennis over aanbod, vraag en effect. Utrecht: Trimbos-instituut.

van Riet, N., \& Wouters, H. (1996). Casemanagement: een leer-en werkboek over de organisatie en coördinatie van zorg-, bulp-en dienstverlening. Assen: Van Gorcum.

Willenbring, M. (1996). Case management applications in substance use disorders. In H. Siegal, \& R. Rapp (Eds.), Case management and substance abuse treatment: practice and experience (pp. 51-76). New York: Springer Publishing Company.

World Health Organisation (WHO). (2001). The World Health Report 2001: Mental health: new understanding, new hope. Paris, France: Sadag.

Ziguras, S.J., \& Stuart, G.W. (2000). A meta-analysis of the effectiveness of mental health case management over 20 years. Psychiatric Services, 51, 1410-1421. 



\title{
Chapter 2
}

\section{Coordination and continuity of care in substance abuse treatment:}

\author{
an evaluation study in Belgium ${ }^{2}$
}

\begin{abstract}
Considering the complexity of drug dependence and the multiplicity of services for substance abusers, coordination and continuity of care are important prerequisites for the quality of substance abuse treatment. However, several shortcomings concerning cooperation, communication and coordination of care have been reported in most European countries. In this study, different aspects of coordination and continuity of care (e.g., first contact, intake, referral, follow-up) have been studied among all agencies $(n=27)$ that are addressed by substance abusers in a clear-cut region in Belgium. Structured interviews with key informants show a lack of systematic communication between services and a lack of follow-up of clients. A study of 57 client records in 12 of these 27 centers illustrates that relatively little information is registered concerning the course of the treatment process and that only $10 \%$ of all client files contain a treatment plan. Following the introduction of a formalized plan that was regarded as a precondition for systematizing and optimizing communication between services, key informants considered the implementation of a model of case management an appropriate way of improving coordination and continuity of care in this region.
\end{abstract}

\footnotetext{
2 This chapter is based on: Vanderplasschen, W., De Bourdeaudhuij, I., \& Van Oost, P. (2002). Coordination and continuity of care in substance abuse treatment: an evaluation study in Belgium. European Addiction Research, 8(1), 10-21.
} 



\subsection{INTRODUCTION}

\subsubsection{SUBSTANCE ABUSE AND TREATMENT IN BELGIUM}

Although few valid and reliable epidemiological data are available on the extent and evolution of drug use in Belgium (De Donder, 2000), empirical findings from population and utilization studies illustrate some key aspects of substance use. Population studies show that cannabis is the most popular illicit drug, and that the use of amphetamines among youngsters has increased considerably in recent years (BIRN, 1999). As in most European countries, heroin is recorded as being the main substance of problem drug use (EMCDDA, 2000). Most treatment demands in metropolitan Belgian cities (Brussels and Liège) are related to problems with heroin and to a lesser extent with cocaine (Stauffacher, 1999).

Problem drug use dates back to the beginning of the 1970s, when Belgium was confronted with a growing amount of young adults who abused illicit drugs (mainly heroin). As most services in traditional mental health care were at that time rather reluctant to deal with the emerging drug problems, two drug-free therapeutic communities were started during the period 1972-1975 (Maertens, 1997). Over the next few years, while the availability of illicit drugs and the consequent problems grew, other specialized services were established including day-care centers, crisis centers, short-term therapeutic programs and therapeutic communities (Broekaert \& Raes, 1998). The lack of governmental initiatives, the involvement of more than 10 ministries and the fact that substance abuse quickly emerged as an important health issue stimulated the establishment of a number of specific and specialized initiatives for substance abusers. Recently, street corner work, social workplaces and medical-social care centers for drug abusers have completed the range of treatment services, adding outreaching, training and employment, and low threshold facilities, methadone treatment and harm reduction initiatives (e.g., needle exchange), respectively. Other harm reduction initiatives such as controlled heroin trials are still being discussed (Reggers \& Ansseau, 2000).

From the 1980s on, traditional (mental) health care gradually opened its doors to drug addicts: many substance abusers detoxify in emergency wards at general and psychiatric hospitals (Spooren, Van Heeringen, \& Jannes, 1996), some psychiatric and general hospitals started special wards for drug addicts and some mental health care centers specialized in substance abuse treatment. Only a few general practitioners - especially in the French-speaking part of Belgium - are involved in the (methadone) treatment of drug abusers, since most of them are reluctant or feel incompetent to work with these patients (De Donder, 2000).

These changes led to an extended and differentiated quantity of services for substance abusers, including specialized and non-specialized centers (cf. table 2.1., p. 44). Specialized centers exclusively address substance abusers, while non-specialized centers have regular 
contacts with or a specific approach towards substance abusers besides treatment for other target groups. Due to a lack of coordination between these services, substance abuse treatment resembles a patchwork rather than a network (de Weert-van Oene \& Schrijvers, 1992; Maertens, 1997). Recently, coordination and cooperation between all levels (e.g., local, regional, national, and European) and partners involved in the drug policy (e.g., health care, social welfare, criminal justice, education, and specialized substance abuse treatment) has been promoted to overcome this situation (De Ruyver \& Casselman, 2000).

Table 2.1.: Overview of specialized and non-specialized agencies for drug abusers in Belgium, including some of their principal functions (V anderplasschen, Mostien, Claeys, Raes, \& V an Bouchaute, 2001)

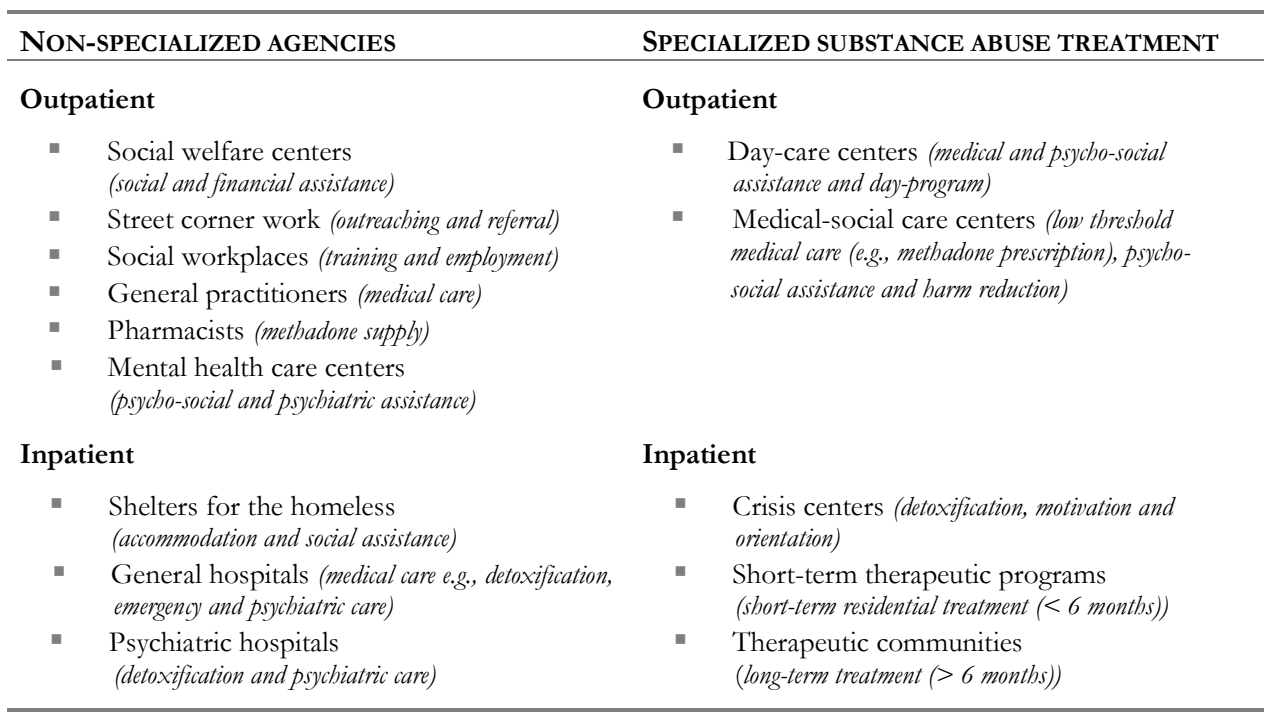

In the past decade, in accordance with EU-agreements, the Belgian drug policy has been basically aimed at the prevention and reduction of any drug use, reduction of the number of new users, the protection of society and its members, care for drug users, and improvement of the quality of these persons' lives (BIRN, 1999). Since 1998, dealing with the possession of small amounts of cannabis has been given "least priority" by the prosecuting authorities (Vanhex, 1998). Recently, the federal government approved of the new policy note on drug problems, which introduces several innovations such as not prosecuting non-problematic use of cannabis, establishing epidemiological and evaluation research and expanding resources for treatment, harm reduction and reintegration (Federale Regering, 2001). Substance abuse is regarded as a public health problem. The associated policy focuses on "normalization" as an alternative for a strictly repressive or a full tolerance policy, and intends to control and reduce drug-related risks. Priority should be given to more and better cooperation in order to realize an integrated drug policy, 
including prevention of (non-) problem drug use, treatment, (re-) integration and harm reduction for problem drug users, and repression of dealers and producers.

\subsubsection{SPECIFIC CHARACTERISTICS OF DRUG ABUSERS}

Drug dependence can be described as a maladaptive pattern of substance use leading to clinically significant impairment or distress (APA, 1996). In order to meet the DSM IV criteria for dependence, at least 3 of the following 7 criteria should occur at any time in the same 12-month period: "tolerance; withdrawal; substance often taken in larger amounts or longer than intended; reinstatement liability; much time spent in activities necessary to obtain or use the substance or to recover; important social, recreational and occupational activities are abandoned or reduced due to drug use; continued substance abuse despite physical or psychological problems caused or exacerbated by drug use".

Dependence is a complex and multiple problem, often including several related problems such as unemployment, problems with the courts, infectious diseases (HCV, HIV), social exclusion, relationship problems, co-morbid psychopathology, and accommodation problems. Moreover, the use of multiple substances is the rule rather than the exception (Yates, 1999). Substance abusers are often reluctant about treatment, and their motivation for change is often low. According to Prochaska and colleagues, change is a prolonged and cyclical process including several stages with maintenance as a final stage, but often followed by lapses and relapses (Prochaska, DiClemente, \& Norcross, 1992). Early dropout and relapse after treatment are known to be relatively high among substance abusers (McMillan \& Cheney, 1992). Although survey research shows that relatively few substance abusers enter treatment (Tucker, 1999), many have a long treatment career and some of them are known to be "treatment tourists" (Kinnunen \& Nilson, 1999).

Given the nature of dependence, treatment objectives cannot be exclusively "cure"oriented, but should also be "care"-oriented. Consequently, substance abuse treatment should not be limited to one single treatment (Willenbring, 1996), but instead consist of different treatment episodes and modalities with continuity of care as an important challenge (Graham, Timney, Bois, \& Wedgerfield, 1995). Integrated and individualized services are needed to address these complex and diverse problems and to improve quality of care.

\subsubsection{QUALITY OF SUBSTANCE ABUSE TREATMENT}

During the past decade, evaluation of substance abuse treatment and several of its components has been an important research topic in most EU-countries (EMCDDA, 1999). In Belgium, evaluation research has mainly been limited to therapeutic communities (Broekaert, Raes, Kaplan, \& Coletti, 1999). This tendency towards evaluation has been inspired by the introduction of economic thinking in all social sectors, including 
the non-profit sector. One of the major goals of treatment evaluation is to improve the quality of treatment services (Merino, 1999). Due to the competitive marketplace, the demand for accountability, the desire to assess return on investments and the need to allocate resources as wisely as possible, the economic aspect (cost-effectiveness) has also been integrated into this evaluation (Hatziandreou, 1999). Monteiro (1999) describes quality of treatment as the cost, delivery and effectiveness of treatment services. According to de Weert-van Oene \& Schrijvers (1992), coordination, continuity, effectiveness and efficiency can be distinguished within quality of care. Effectiveness refers to the relationship between achievements and objectives, while efficiency is the relationship between effects and resources.

In Belgium, the issue of quality of care has been introduced into the field of social welfare and health care during the mid-1990s (VOCA, 1998). In a recent advice, the National Council for Hospital Facilities [Nationale Raad voor Ziekenhuisvoorzieningen (NRZV)] recommended to reorganize the field of mental health care, based on the treatment demand of clients and the establishment of integrated treatment systems for some specific target groups, including substance abusers (Knapen \& Van Holsbeke, 1997). This reorganization does not only aim at more continuity of care and more individualized treatment, but also at better coordination and cooperation. The proposal of the NRZV has recently been further elaborated and concretized in a policy note by the ministers of public health and social affairs (Aelvoet \& Vandenbroucke, 2001).

The quality of the delivery of services within substance abuse treatment has been discussed in several European countries. Koller (1999) referred to the fragmentation and lack of coordination in German substance abuse treatment, which led to institutionrelated thought and action. Nizzoli (1999) criticized the lack of standardized clinical forms in this sector in Reggio Emilia, Italy. Research concerning intake and assessment in Rotterdam (the Netherlands) revealed widely divergent intake and assessment procedures, resulting in duplicated work and redundant information (De Groen \& Van OoyenHouben, 1995). Also in the Netherlands, a lack of coordination, cooperation and communication between treatment centers for drug abusers was observed in Utrecht (de Weert-van Oene \& Schrijvers, 1992).

As the development of substance abuse treatment in most EU-countries first occurred without a great deal of coordination and deliberation, problems encountered in this sector in Belgium will, consequently, serve as examples for the challenges other European countries face or have faced. Since the establishment of services for substance abusers happened without governmental programming, it has led to fragmentation and lack of coordination and created a chaotic and unstructured network with overlapping and parallel structures and missing links (Knapen \& Van Holsbeke, 1997; Maertens, 1997). In recent years, the range of treatment services has been growing as the amount and diversity of treatment demands increased (Nassen, 2001). Cooperation and communication between services seems to be mainly based on personal choices and benevolence (BIRN, 
1999). Due to the broad range of services and the free choice of the client, persons can be registered in several services at the same time as or shortly after they have been in another service (Van Deun \& Figiel, 2000). The subsidizing system, which pays per bed and consultation, unintentionally stimulates competition between services. Finally, a lack of standardized intake procedures and follow-up of clients has been reported (Raes, Lenders, \& Geirnaert, 1995).

Besides these problems encountered in the organization of substance abuse treatment, the multiple and complex problems of substance abusers - which elicit contacts with several caregivers - induce the need for coordination and continuity of care (van Achterberg, Stevens, Hekkink, Crebolder, \& Philipsen, 1995). Alternatively, several solutions are suggested to improve the quality of substance abuse treatment. In several places in the United States, case management has been introduced in substance abuse treatment to address the needs of clients with multiple, complex and chronic problems (Ashery, 1996; Mejta, Bokos, Mickenberg, Maslar, \& Senay, 1997) and to deal with the lack of coordination of care (Graham et al., 1995). According to a German study, agencies should no longer be regarded as separate institutions, but rather as a network of treatment services with clear functions to answer clients' needs (Koller, 1999). Moreover, it was suggested that the demand for successful coordination and cooperation should be placed in a context of local monitoring and steering, in order to give the right help to the right person. Due to the differentiation in substance abuse treatment, the growing complexity of drug problems and the differential effectiveness of treatment modalities for specific subgroups, client matching has recently gained importance in the United States and Europe (Hser, 1997; Kersten, Schippers, Broekman, van Rijswijk, \& Joosten, 1995). Centralized intake procedures have been developed to facilitate access, coordination and continuity of treatment (Rohrer et al., 1996).

\subsubsection{AIMS}

The aim of this study is - according to the advice of the NRZV - to evaluate two core aspects of quality of substance abuse treatment, i.e. coordination and continuity of care. Effectiveness and efficiency of treatment are not our primary focus, as these aspects were not the main incentives for the intended reorganization of treatment and as these are more economic aspects of quality of treatment, closely related to accountability (Merino, 1999). Since some of the above-mentioned solutions might be good alternatives for the present-day situation, different aspects of the treatment process that are related to coordination and continuity of care will be studied. Based on the results, recommendations will be formulated to improve and optimize coordination and continuity of care. These recommendations might also be relevant to and applicable in other countries, as problems concerning the organization of substance abuse treatment dealt with in Belgium are similar to those encountered in other European countries. 
Although coordination is widely recognized as an important function in substance abuse treatment, only few researchers have focused on this aspect (Graham et al., 1995; van Achterberg et al., 1995). Graham and colleagues (1995) view coordination as an integral part of case management and define it as the giving and receiving of information regarding specific clients, such as informing other agencies, obtaining information from other agencies, exchange of information and case discussions involving other services. Coordination of care is clearly situated on the client-level rather than on the system-level. According to van Achterberg and colleagues (1995), coordination consists of five basic tasks: introduction; making a care inventory; making a care plan; executing the care plan and monitoring care; evaluating the implementation of the care plan. Other authors state that coordination of care can be derived from the functional cooperation between services (de Weert-van Oene \& Schrijvers, 1992). In order to study coordination of care at the level of the individual, we will focus on several aspects of the referral process, exchange of information, registration, creation of client files, and cooperation.

Several authors (Bachrach, 1981; de Weert-van Oene \& Schrijvers, 1992) have stressed the importance of continuity of care in substance abuse treatment. However, relatively few information is available on how this concept can be made operational. For this purpose, Bachrach's 7 dimensions of continuity of care provide a useful theoretical framework: longitudinal approach, flexibility, individualization, proximity, accessibility, communication, and comprehensiveness (Bachrach, 1981). Several aspects related to these dimensions, i.e. intake procedure, treatment process, follow-up of clients, and case management will be studied in this article.

Both theoretical frameworks illustrate that aspects of coordination and continuity of care cannot be strictly separated (e.g., communication, case management). However, for pragmatic reasons both dimensions will be distinguished in the chapters "results" and "discussion".

\subsection{METHODS}

\subsubsection{SAMPLE}

The sample for the structured interviews consisted of all 27 (non-specialized and specialized) agencies in the province of East-Flanders, which have a relatively large group of substance abusers among its population. The level of the province was chosen, since provinces are responsible for the coordination of substance abuse treatment in Belgium. Agencies in the province of East-Flanders were studied as this region has the most elaborated and differentiated network of services. The following centers were involved in this study: 7 wards in psychiatric hospitals, 5 mental health care centers, 5 shelters for the 
homeless, 3 drug-free therapeutic communities, 2 specialized outpatient centers, 1 crisis center, 1 day-care center, 1 medical-social care center, and 1 place for sheltered living.

A total of 31 key informants were interviewed, one at each service except 4 services where 2 key informants were interviewed as no single person could adequately answer all interview questions. A key informant was defined as "a person at a center with most knowledge and experience concerning the different aspects of coordination and continuity of care". Most key informants $(\mathrm{n}=16)$ had a supervisory function, while others were working as psychologist $(n=6)$, social worker $(n=6)$, psychiatrist $(n=2)$ or drug counselor $(n=1)$.

For the study of the client files, those agencies that only have a minority of substance abusers among their population were removed from the interview sample $(n=8)$. Moreover, if services were part of a large organization $(n=3)$, information was thought to be redundant after the study of client files in 1 or 2 agencies. Since two centers refused to participate in this second part of the research, the sample for the study of the client files consisted of in total 14 agencies.

From the first 10 clients in each agency who gave their informed consent to participate in this study, a random sample of 5 records was selected. Due to a combination of reasons (small number of drug users among the client population, refusal of clients to participate and caregivers forgetting to ask clients to participate), only two clients in one agency and only one client in two agencies agreed to participate in the study. The latter two centers were removed from the sample. In total, 57 client files have been studied in these 12 agencies $(4$ mental health care centers, 4 wards in psychiatric hospitals, 2 drug-free therapeutic communities, 1 crisis center and 1 medical-social care center).

\subsubsection{INSTRUMENTS}

Based on topics from existing questionnaires (Anker, Delcourt, de Groof, \& Maier, 1990; Öberg, Gerdner, Sallmén, Jansson, \& Segraeus, 1997) and literature concerning coordination of care (Graham et al., 1995; van Achterberg et al., 1995), continuity of care (Bachrach, 1981) and case management (Moxley, 1989; SAMHSA, 1998; van Riet \& Wouters, 1996), a questionnaire was developed for the semi-structured interviews, consisting of open-ended and multiple-choice questions.

The first part of the questionnaire concerned descriptive information about the organizational and structural aspects of treatment (i.e. objectives, target group, treatment program and accessibility), while the second part focused on important aspects of the treatment process (coordination and continuity of care) and on aspects of case management. Questions concerning case management were all open-ended questions, checking experiences, expectations, positions, feasibility and priorities. The prerequisites, strategies, partners involved and communication were questioned as important aspects of the treatment process (first contact, intake, dismissal, referral and cooperation), since these 
aspects are closely related to coordination and continuity of care. In order to understand how information is collected and recorded, some questions concerning registration and client files were integrated in the interview. Due to a lack of precise figures, frequencies were estimated using a 7-point scale from "always" to "never".

For the study of the client records, an interview scheme and checklist were used. The interview scheme was based on a guide for referrals in mental health care (Subregionaal Samenwerkingsverband, 1997) and covered feedback and communication at referral. The checklist consisted of 32 items concerning various aspects of the treatment process and was based on criteria for "good quality" client files (van Riet \& Wouters, 1996). Items could be scored positive or negative (present or absent in the records) and were grouped into 8 categories: first contact, assessment, planning, intervention, evaluation, referral, dismissal and registration. The first category concerned information gathered at the first contact or admission (e.g., treatment demand, name and address of the referring agency), while categories 6 and 7 included information registered at referral or dismissal (e.g., reason for referral, notice of dismissal). Categories 2 to 5 referred to the core functions of case management (Moxley, 1989) e.g., assessment of current and past problems, goals of treatment, treatment planning, description of various interventions, and evaluation of these interventions. The last category contained some residual items (e.g., informed consent).

\subsubsection{PROCEDURE}

The evaluation study was conducted between January 1998 and June 1999. Key informants were interviewed at their workplace between June and October 1998. The duration of the interviews varied between 70 and 120 minutes, with 90 minutes as the average duration. All interviews were tape-recorded and transcribed and then returned to the key informants for a final check.

Client files were studied from December 15, 1998 to January 31, 1999. A short interview with the person responsible for the registration at each center preceded the study of the records. The client files were scored on the presence or absence of the checklist items. Moreover, the researcher noted his findings and remarks concerning the records at the end of the interview.

\subsubsection{DATA ANALYSIS}

The data from the semi-structured interviews and the study of the client files were analyzed by both qualitative and quantitative methods. Multiple-choice questions from the interviews and checklist items from the files study were coded and analyzed using the statistical software package SPSS. Due to the nominal and ordinal level of the variables, analyses were limited to frequency tables and cross tabulations. Answers to open-ended 
questions and additional remarks from key informants during the interviews were grouped according to themes. Comparison of these themes in the total sample led to a more indepth analysis of the interviews. The remarks of the interviewees and the researcher's notes during the study of the client files were analyzed similarly.

During the data analysis we distinguished 4 categories: specialized substance abuse treatment (therapeutic communities, crisis centers, day care centers, medical-social care centers and other specialized out-patient centers); mental health care centers; psychiatric hospitals; and social welfare centers (shelters for the homeless and places for sheltered living).

\subsection{RESULTS}

\subsubsection{COORDINATION OF CARE}

\section{口 REFERRAL}

In most services, clients themselves $(n=14)$ or their surroundings (family, friends) $(n=7)$ usually make the first contact. General practitioners, judicial agencies (e.g., youth court, probation) and specialized services (medical-social care center and crisis center) also regularly initiate the contact with these services. Compared with other agencies, selfreferral is most common in specialized substance abuse treatment.

The amount of referrals is limited and fluctuates over time. Most services only occasionally refer clients, while 5 agencies refer about $50 \%$ of their clients. Direct referral on first contact can be observed in about $25 \%$ of all cases in 7 agencies (particularly social welfare centers). Clients are referred to various specialized (e.g., therapeutic communities, medical-social care centers) and non-specialized services (e.g., mental health care centers, shelters for the homeless, psychiatric wards) without one particular center or clear referral patterns dominating.

The qualitative analysis showed that most services receive referrals from various other centers. Agencies that are part of a network of services tend to refer clients within their own organization. The reason for referral is not always clear: sometimes clients are referred to a specific service for a specific problem; mostly other reasons play a role such as the choice and place of residence of the client $(n=13)$ or caregivers in different centers who know each other or who have been working together before $(n=7)$. It appears from the study of the clients' records that the proper reason for referral could not be retrieved in 1 in 5 files. 


\section{a COMMUNiCATION}

When a client is referred to one of these agencies, about half of all services (48\%) "always" or "nearly always" have contacts with the referring agency within the first days after referral. Mostly, this contact is initiated by the referring agency $(2 / 3$ times), but a systematic and uniform pattern of communication is lacking. Most agencies $(n=19)$ communicate this information by telephone, while 8 centers mainly receive written information, which is complemented by telephone communication.

Qualitative analysis shows that few services have systematic contacts with the referring agency to provide feedback about the result of the referral. Key informants again confirm that communication between services is easier when they know a staff member at the referring agency. Only in 6 centers the communication of client information is always based on the "informed consent" of the client.

When an agency itself refers a client, 18 services "nearly always" exchange information with the center the client is referred to. If information is communicated, almost all services $(n=25)$, as referring agencies, initiate this contact themselves. Most services $(n=15)$ communicate this information through telephone contacts, although 12 services (mental health care centers, social welfare centers, inpatient specialized substance abuse treatment) have telephone contact in addition to the written information they send.

Qualitative analysis of the interviews shows that services usually receive no feedback about the results of their referrals. Alternatively, key informants suggest using standardized forms for communication and also communicating information about the course of treatment. Most key informants prefer to receive written rather than telephone information, since this kind of communication is less transient. Some key informants complain about the lack of basic information they receive about certain clients. Privacy regulations are often cited as a major reason for the lack of or insufficient communication.

The interviews $(\mathrm{n}=12)$ that preceded the study of the clients' records revealed wide variations in communication procedures at different services. After the initial contact about the referral, only one agency reports on the course of treatment and only a quarter of all services communicate important changes in the situation (e.g., suicide attempt) or treatment of the client (e.g., admission to a general hospital) to the referring agency. If a service further refers a client, most centers $(n=7)$ "nearly always" inform the referring agency or the general practitioner.

The study of the client files reveals that information from the referring agency is absent in $25 \%$ of the files of all referred clients. Twelve records contained feedback that was sent to the referring agency after the referral. One third of the files contained information that was communicated by another service, although nearly all clients had been treated in other services. An "informed consent" for the communication of client information was found in only $28 \%$ of all files. 


\section{a Registration}

According to the type of service (e.g., psychiatric wards, mental health care centers, specialized substance abuse treatment), specific registration forms are used in addition to other registration forms developed within these services. From the study of the client records, it appears that the client's treatment demand is registered in most records, but in more than three-quarter of the files there is a lack of information about why a client is coming to this service and why he is doing so at this particular time. Almost all records contain information about physical health, employment, drug and alcohol use, psychological state, and judicial situation.

\section{a Client FILES}

Key informants indicate that client records contain various forms and a large quantity of information. In 10 services, files consist of various parts located at different places. Qualitative analysis reveals that various services use different forms to compose and structure these records, and even within some services structural differences between the records could be observed. Most files do not have a fixed structure, clear or chronological order, table of contents or summary of the most important client information, and consist almost exclusively of hand-written information. Several files also contain duplicated information.

\section{a COOPERATION}

Overall, the cooperation between services is positively evaluated. Five services report problems in cooperating with some specific agencies. Qualitative analysis of the interviews shows that - compared to a few years ago - cooperation and deliberation between services is growing and improving and that services are gradually showing more openness towards other centers. None of the key informants reported systematic cooperation concerning some aspects of the treatment process e.g., time-out, detoxification. According to these informants "good" cooperation depends on persons rather than on services and cooperation seems to improve if caregivers from different services know each other better. Cooperation is hindered by the competition between services due to the co-existence of similar services and programs, the system of allocating subsidies and the conflicting objectives of different services.

Key informants criticize the lack of flexibility, long waits and reluctance to work with substance abusers in some mental health care centers. Most general practitioners also seem to be reluctant to work with this target group. Social welfare centers complain that some specialized centers do not communicate essential information e.g., doses of methadone. According to the key informants, the lack of coordination and cooperation is 
best illustrated by the so-called "drug treatment tourists", who take advantage of the lack of communication between services.

\subsubsection{CONTINUITY OF CARE}

\section{- INTAKE PROCEDURE}

In most services ( $\mathrm{n}=19)$, a treatment demand is followed by an appointment for an intake interview. Restart of treatment with clients who have been previously treated in this particular service is unconditional in 5 centers, while 22 services evaluate on a case-by-case basis whether a client can be treated again or not. Only 6 (residential) agencies regularly use a waiting list, but key informants explain that these waiting lists are mostly temporary and resolve automatically as clients contact other services.

\section{- TREATMENT PROCESS}

Most client records contain a large amount of information about the treatment history (e.g., origin of the problem, coping mechanisms, number of previous treatment periods), but only half of these files contain information about the content, course and result of previous treatment. An extended problem analysis is part of most records, but little information can be found about the client's competencies and about goals and expectations of treatment. A treatment plan could only be found in 6 records (10.5\%). Most files contain a logbook with information about the treatment process, but the lack of structure and order in these logbooks might restrict their utility. In two-thirds of the files, an evaluation of the treatment process was found, but the product offered to the client (strategies and methods) is rarely evaluated.

\section{a FOLLOW-UP}

At the end of treatment, most services ( $\mathrm{n}=17)$ "nearly always" contact the referring agency about the result of treatment. The more contacts during the course of treatment, the greater the chance that the referring agency will be informed about the end of treatment. In cases where a client stops treatment with negative advice from the staff, referring agencies from the judicial sector will "always" be contacted.

Only 7 centers follow up clients after the end of treatment, but this mainly relates to informal contacts after long-term residential programs. In cases where treatment ends with a negative advice, the only thing some services $(n=6)$ do is to send a reminder to clients. The lack of follow-up after treatment is - according to the key informants - due to lack of time and resources to do so. Some of them are reluctant to follow up clients as this might imply acting at the same time other caregivers are involved. Follow-up of clients 
after referral is restricted to those cases in which the referring agency remains involved in the treatment of the client.

\section{- CASE MANAGEMENT}

According to the key informants, experiences with case management are limited to some isolated cases, and only in 2 psychiatric hospitals a model of case management has been utilized to follow up a small number of clients. About half of all key informants ( $\mathrm{n}=$ 12) state that some of the basic functions of case management are already applied in the center where they are employed.

Key informants suggest that the implementation of case management might help to avoid duplicated work, to reduce costs, to guarantee the continuity of care and to centralize information about the client. Moreover, case management can stimulate coordination and cooperation and can help to reduce "shopping". On the other hand, it can limit the free choice of the client and lead to stigmatization. They feel that the implementation of case management will be hindered by the lack of a structural place for this method in the Belgian health care system. The key informants suggest to start with a small pilot project and to use this method to help clients that are addressed by various caregivers at the same time.

\subsection{DISCUSSION}

Structured interviews with key informants in all services involved in substance abuse treatment in the province of East-Flanders $(n=27)$ and a study of client files $(n=57)$ in 12 of these services have been conducted to evaluate coordination and continuity of care. Consequently, two sources of information have been used for this evaluation, the former representing the more subjective interpretations of key informants, the latter giving a more objective analysis of the situation.

According to the theoretical frameworks offered by de Weert-van Oene \& Schrijvers (1992), Graham and colleagues (1995) and van Achterberg and colleagues (1995), several aspects of coordination of care have been evaluated, focusing on the referral, communication, registration, client files and cooperation. Graham and colleagues (1995) have stressed the importance of exchanging information at referral and during the course of treatment and of 'ad hoc' cooperation concerning some specific cases. The importance of monitoring and evaluation is emphasized by van Achterberg and colleagues (1995), while de Weert-van Oene \& Schrijvers (1992) add cooperation, registration and the making of client-files as important indicators of coordination of care. 


\subsubsection{COORDINATION OF CARE}

Analysis of the referral procedures shows that most referrals are self-referrals or referrals by family or friends, which corresponds with the results of the analysis of drug treatment demands in 23 European cities (Stauffacher, 1999). It can be questioned whether clients themselves are able to address the most appropriate service to respond to their problems. If clients are referred by another agency, the reason for referral is not always clear and is based rather on informal mechanisms such as the personal choice of the client and referral to affiliated centers. As long as this referral meets the client's needs, these "subjective" motivations for referral can be a good addition to more objective reasons such as a DSM IV diagnosis or specific problems (Kersten et al., 1995).

The results of both structured interviews and the study of the client files show that information is not systematically communicated and that a standardized pattern of communication at referral is lacking. Particularly feedback about the result of the referral (e.g., client was further referred, client admitted into a hospital) is not often communicated, although a referral can be regarded as an important step in the treatment process. Most of this information is exchanged by telephone, which is more transient and superficial than information in writing. Good informal contacts between caregivers from different agencies improve the exchange of information, which has been characterized as "social services bartering" (SAMHSA, 1998). According to the Belgian privacy regulations, information about clients can only be communicated if they have given their "informed consent". Only a quarter of the client files contained an informed consent, which is opposed to the principle that communication of information should be consistent with confidentiality regulations and professional standards of care (SAMHSA, 1998).

Good cooperation between services is based on positive informal contacts between individual staff members rather than on structural agreements between services. Although cooperation and deliberation have been growing recently, fragmentation and lack of coordination continue and maintain institution-related thought and action due to, among other things, the competition between services for scarce funds (Koller, 1999). This observation is illustrated by the criticism of some key informants that large organizations consisting of different services refer clients within their own organization.

As in Italy and other European countries (Nizzoli, 1999), no standardized registration forms are used by all services involved in substance abuse treatment. Instead, various types of services use specific forms. Several key informants suggested the development and introduction of standardized forms at intake and referral, in order to improve the exchange of information between services.

The records of the clients are well documented, but when compared with some minimal criteria for good qualitative records (van Riet \& Wouters, 1996), some shortcomings can be observed e.g., concerning the presence of a treatment plan, objectives of treatment and evaluation of the treatment process. Moreover, the structure of these records differed 
between and even within services. Little evidence of written communication between services could be found, since only a few files contained information from services previously involved in the treatment of these clients. Surprisingly, it appeared that most records consist of hand-written information and only a few agencies used computers for the registration and creation of client files, although researchers have proven that computers can reduce the costs of health care and may lead to more effective and efficient care (Willenbring, 1996).

\subsubsection{CONTINUITY OF CARE}

Continuity of care has been evaluated based on the dimensions postulated by Bachrach (1981), which stress aspects such as the need for longitudinal and individualized care, accessibility of treatment and good communication between services.

As has been observed in the Netherlands and Italy (De Groen \& Van Ooyen-Houben, 1995; Nizzoli, 1999), each service developed a specific intake procedure to start the treatment process. On the other hand, all services are easily accessible and only some of these centers sometimes use a waiting list. Re-commencement of treatment with recidivist clients who have been treated at a certain agency before is decided on an individual basis. This might increase the risk that some hard core clients who have been treated several times at one or more agencies or who have caused trouble at a particular place are excluded from treatment in some agencies.

Most services contact the referring agency at the end of treatment, but few services follow up clients after treatment. If they do so it cannot be characterized as a proactive followup. Due to the high relapse rates among drug users, continuous treatment has been one of the basic characteristics of case management (Moxley, 1989; van Riet \& Wouters, 1996). Lack of time and resources and reluctance to interfere when other caregivers are involved are recorded as the main reasons for not following up clients after initial treatment.

Experiences with case management in substance abuse treatment are limited to two agencies, and some services report taking up at least some basic functions of case management. According to the key informants, case management is considered to have many advantages - besides some disadvantages - and should be directed to the group of clients with multiple and complex problems who are known at different services.

\subsubsection{IMPLICATIONS OF THE STUDY}

If compared to the indicators of coordination proposed by Graham and colleagues (1995), we can conclude that a lot of information is exchanged at the time of referral, although not systematically. However, little information is communicated about the result of the referral. Cooperation is evaluated positively and is mainly based on informal 
mechanisms, but "ad hoc" cooperation concerning some specific cases is lacking. A lot of work is already done concerning registration and making of client files, but standardization of registration forms and client files is necessary to improve the quality of the registration and client files. Monitoring and evaluation of the treatment process is unusual.

According to indicators for continuity of care (Bachrach, 1981), especially the longitudinal approach and the individualization are not well elaborated, as follow-up of drug abusers after treatment is unusual and as few initiatives can be observed that are directed at the individual. Moreover, some of the core functions of case management (e.g., planning, monitoring and evaluation) are not realized and the so-called "drug treatment tourists" illustrate the lack of individualized and comprehensive treatment. Indicators like flexibility, accessibility and proximity of treatment are evaluated positively as only few services have a waiting list and as re-commencement of treatment is usually possible. As could be derived from indicators of coordination of care, information about the client is exchanged at the time of referral, but little information is communicated concerning the course of treatment.

As key informants asked for more systematization and standardization of communication, the introduction of a formalized stepwise plan was regarded as a prerequisite for systematizing and optimizing communication between services. Following such a stepwise plan, the implementation of a model of case management was considered an appropriate answer to improve coordination and continuity of care in this region. According to the key informants, case management can contribute to the avoidance of duplicated work, reduction of costs, centralization of information and limitation of "treatment tourism", although the risk of stigmatization and restriction of the free choice of the client should be closely monitored.

\section{a SystematizATION OF COMMUNiCATION}

As a consequence of this study, it was proposed to introduce a formalized and stepwise communication system to systematize and optimize the communication between agencies at referral (Subregionaal samenwerkingsverband, 1997). It starts from the observation that services consider that it is important to receive basic information from the referring agency and that a large amount of information is already communicated, but that this often occurs non-systematically and without the informed consent of the client. The introduction of such a system assumes the following prerequisites: respect for the autonomy of each service, referral to the most appropriate service according to the client's needs, exchange of written information and communication of client information based on their informed consent. The proposed procedure primarily consists of systematic communication of a short letter of referral by the referring agency (including the reason for referral, information about the treatment process) and systematic feedback on the 
result of this referral by the agency the client is referred to (Vanderplasschen, De Bourdeaudhuij, \& Van Oost, 1999). Additionally, sending a temporary report and reporting on important changes in the situation or treatment of the client was recommended. The implementation of such a communication system should be accompanied by the introduction of standardized forms.

\section{a A MOdEL Of CASE MANAGEMENT}

The implementation of a comprehensive model of case management can follow the systematization of communication and has been identified by key informants as a potential alternative to improve coordination and continuity of care. A small pilot-project has been established to address those clients that are contacting various services in a relatively short period of time. The project is conceptualized according to the operational features of case management, identified by Robinson and Bergman (as cited in Willenbring, 1996): consumer directedness, range of assessment or focus, program structure, degree of direct service provision, target population, case manager training, service site, staff-to-client ratio, staff credentials, staff availability, intensity/frequency of contact, duration of service provision, administrative authority. This intervention aims at reducing relapse and readmission into treatment, providing individualized and continuous care and preventing social exclusion (Vanderplasschen \& Broekaert, 2000). At a more structural level, this project is intended to improve the coordination of care for substance abusers and the communication between all services involved in the treatment process.

The suggested comprehensive model of case management basically follows the principles of Assertive Community Treatment: long-term commitment, contacts with clients in their natural setting, focusing on practical problems of daily life, small caseloads, frequent contacts with the case manager and a team approach (Stein \& Test, 1980; SAMHSA, 1998). The primary functions of case managers included: assessment, treatment planning, direct (e.g., information, support, advice) and indirect (outreaching, coordination, linking, advocacy) interventions, monitoring and evaluation (Moxley, 1989). The target group consists of drug users with multiple and complex problems, which has been made operational based on following inclusion criteria: persons who are dependent on illicit drugs (and alcohol) for at least 2 years, who have several problems besides their drug dependence (employment, the courts, family relationships and physical and psychological health) and who have been previously treated for their drug problems in at least 3 different agencies.

The following prerequisites are formulated to facilitate the implementation of this intervention: development of a clear program description (Moxley, 1989); introduction of a manual for the case managers (Ridgely \& Willenbring, 1992); predominance of the interest of the client and involvement of general practitioners (Bokos, Mejta, Mickenberg, \& Monks, 1992); involvement of the client's family (van Riet \& Wouters, 1996); use of 
standardized forms for the evaluation (SAMHSA, 1998). The implementation of case management will be evaluated and this evaluation started at the end of the year 1999. An experimental group of 30 drug abusers will be compared with a control group not receiving case management in addition to standard treatment. Both groups will be interviewed at the start of the project and 12 months later, using the European version of the Addiction Severity Index (EuropASI) (McLellan et al., 1992), the Circumstances Motivation and Readiness scale (CMR) (De Leon, Melnick, Thomas, Kressel, \& Wexler, 2000) and an open interview to study the satisfaction of the persons involved. Besides these interviews with clients, all other partners involved will be interviewed: case managers, program directors, and stakeholders. In addition, logbooks and files kept by the case managers will be studied. Finally, as case managers operate from different services, it will be very important to study the characteristics of the units where case managers are working.

ACKNOWLEDGEMENTS. This research project has been carried out with the financial support of the Province of East-Flanders [Provincie Oost-Vlaanderen], Belgium. Special thanks to Mr. Bert Mostien, Regional Board on Substance Abuse of the Province of East-Flanders [Provinciaal Platform Middelenmisbruik, Provincie Oost-Vlaanderen]; Mr. Patrick Claeys, Regional Board on Mental Health Care of East-Flanders [Overlegplatform Geestelijke Gezondheidszorg Oost-Vlaanderen (PoporGGZ)]; all agencies involved in the research project "Case management in substance abuse treatment in EastFlanders". 


\section{REFERENCES}

Aelvoet, M., \& Vandenbroucke, F. (2001). De psyche: mij een zorg?! Geestelijke gezondheidszorg door participatie en overleg. Brussel: Ministerie van Volksgezondheid, Consumentenzaken en Leefmilieu.

American Psychiatric Association (APA). (1996). DSM-IV: Diagnostic and statistical manual of mental disorders, fourth edition. Washington: American Psychiatric Association.

Anker, A., Delcourt, E., de Groof, W., \& Maier, R. (1990). Een nieune ronde: circuitvorming in de Nederlandse verslavingszorg, WGU-cahier 11. Utrecht: Stichting WGU.

Ashery, R.S. (1996). Case management for substance abusers: more issues than answers. In H. Siegal, \& R. Rapp (Eds.), Case management and substance abuse treatment: practice and experience (pp. 141-154). New York: Springer Publishing Company.

Bachrach, L. (1981). Continuity of care for chronic mental patients: A conceptual analysis. The American journal of psychiatry, 138, 1449-1455.

Belgian Information Reitox Network (BIRN). (1999). Belgian National Report on Drugs 1998: National Policy, Epidemiology, Demand Reduction and Early Warning System. Brussels: Scientific Institute of Public Health.

Bokos, P., Mejta, C., Mickenberg, J., \& Monks, R. (1992). Case management: an alternative approach to working with intravenous drug users. In R.S. Ashery (Ed.), Progress and Issues in case management (NIDA Research Monograph 127) (pp. 92-111). Rockville: National Institute on Drug Abuse.

Broekaert, E., \& Raes, V. (1998). Drug abuse treatment in Europe: country reports Belgium. In M. Coletti (Ed.), Evaluation of treatment: an European overview (pp. 10-35). Rome: Cedis Editrice.

Broekaert, E., Raes, V., Kaplan, C., \& Coletti, M. (1999). The design and effectiveness of Therapeutic Community research in Europe: an overview. European Addiction Research, 5, 21 35.

De Donder, E. (2000). Alcohol, illegale drugs \& medicatie: recente ontwikkelingen in Vlaanderen. Leuven: Acco.

De Groen, I., \& Van Ooyen-Houben, M. (1995). Intake en diagnostiek in het Boumanhuis. Rotterdam: Boumanhuis.

De Leon, G., Melnick, G., Thomas, G., Kressel, D., \& Wexler, H. (2000). Motivation for treatment in a prison-based therapeutic community. American Journal of Drug and Alcohol Abuse, 26(1), 33-46.

De Ruyver, B., \& Casselman, J. (2000). Het Belgisch drugbeleid anno 2000: een stand van zaken drie jaar na de aanbevelingen van de parlementaire werkgroep drugs. Leuven - Ghent: Katholieke Universiteit Leuven, Onderzoeksgroep Gerechtelijke geestelijke gezondheidszorg - Universiteit Gent, Onderzoeksgroep Drugbeleid, strafrechtelijk beleid en internationale criminaliteit.

de Weert-van Oene, G., \& Schrijvers, A. (1992). Van lappendeken naar zorgcircuit: circuitvorming in de Utrechtse verslavingszorg. Utrecht: Rijksuniversiteit Utrecht, Vakgroep Algemene gezondheidszorg en epidemiologie. 
European Monitoring Centre for Drugs and Drug Addiction (EMCDDA). (1999). Evaluating the Treatment of Drug Abuse in the European Union, EMCDDA Scientific Monograph Series $N^{\circ} 3$. Luxembourg: Office for Official Publications of the European Communities.

European Monitoring Centre for Drugs and Drug Addiction (EMCDDA). (2000). Annual report on the state of the drugs problem in the European Union 2000. Luxembourg: Office for Official Publications of the European Communities.

Federale Regering. (2001). Beleidsnota van de federale regering in verband met de drugproblematiek. Brussel: Federale regering.

Graham, K., Timney, C., Bois, C., \& Wedgerfield, K. (1995). Continuity of care in addictions treatment: the role of advocacy and coordination in case management. American Journal of Drug and Alcohol Abuse, 21(4), 433-451.

Hatziandreou, E. (1999). Applying economic evaluation in the substance-misuse field. In European Monitoring Centre for Drugs and Drug Addiction (EMCDDA) (Ed.), Evaluating the Treatment of Drug Abuse in the European Union, EMCDDA Scientific Monograph Series $N^{\circ} 3$ (pp. 43-50). Luxembourg: Office for Official Publications of the European Communities.

Hser, Y. (1995). A referral system that matches drug users to treatment programs: existing research and relevant issues. Journal of Drug Issues, 25(1), 209-224.

Kersten, T., Schippers, G., Broekman, T., van Rijswijk, A., \& Joosten, A. (1995). Ontwikkeling en verbetering van indicatiestelling en verwijzing van cliënten met verslavingsproblematiek. Nijmegen: Bureau Bêta.

Kinnunen, A., \& Nilson, M. (1997). Recent trends in drug treatment in Europe. European Addiction Research, 5, 145-152.

Knapen, J., \& Van Holsbeke, J. (1997). Een masterplan voor de organisatie en inhoudelijke vernieuwing van de geestelijke gezondheidszorg. Situering van en toelichting bij twee adviezen van de nationale raad voor ziekenhuisvoorzieningen. Hospitalia, 41(4), 148-154.

Koller, E. (1999). The policy-maker's perspective. In European Monitoring Centre for Drugs and Drug Addiction (EMCDDA) (Ed.), Evaluating the Treatment of Drug Abuse in the European Union, EMCDDA Scientific Monograph Series $N^{\circ} 3$ (pp. 79-84). Luxembourg: Office for Official Publications of the European Communities.

Maertens, J. (1997). Opbouwen van een zorgcircuit toxicomanie: een probleem zo groot als het werkveld? Hospitalia, 4, 171-180.

McLellan, A.T., Kushner, H., Metzger, D., Peters, F., Smith, I., Grissom, G. et al. (1992). The fifth edition of the Addiction Severity Index. Journal of Substance Abuse Treatment, 9, 199-213.

McMillan, D., \& Cheney, R. (1992). Aftercare for formerly homeless recovering women: issues for case management. In R.S. Ashery (Ed.), Progress and Issues in case management (NID A Research Monograph 127) (pp. 274-288). Rockville: National Institute on Drug Abuse.

Mejta, C., Bokos, P., Mickenberg, J., Maslar, M., \& Senay, E. (1997). Improving substance abuse treatment access and retention using a case management approach. Journal of Drug Issues, 27(2), 329-340.

Merino, P. (1999). Treatment-evaluation literature. In European Monitoring Centre for Drugs and Drug Addiction (EMCDDA) (Ed.), Evaluating the Treatment of Drug Abuse in the European Union, EMCDDA Scientific Monograph Series $N^{\circ} 3$ (pp. 25-28). Luxembourg: Office for Official Publications of the European Communities. 
Monteiro, M. (1999). World Health Organisation Programme on Substance Abuse. In European Monitoring Centre for Drugs and Drug Addiction (EMCDDA) (Ed.), Evaluating the Treatment of Drug Abuse in the European Union, EMCDDA Scientific Monograph Series $N^{\circ} 3$ (pp. 89-96). Luxembourg: Office for Official Publications of the European Communities.

Moxley, D. (1989). The practice of case management, Sage Human Services Guides Vol. 58. Newbury Park: Sage publications.

Nassen, E. (2001). Tien stappen in de concretisering van een nieuw begrippenkader voor de geestelijke gezondheidszorg. Tijdschrift Klinische Psychologie, 31(1), 37-48.

Nizzoli, U. (1999). Treatment information systems: the Emilia-Romagna experience. In European Monitoring Centre for Drugs and Drug Addiction (EMCDDA) (Ed.), Evaluating the Treatment of Drug Abuse in the European Union, EMCDDA Scientific Monograph Series $N^{\circ} 3$ (pp. 63-66). Luxembourg: Office for Official Publications of the European Communities.

Öberg, D., Gerdner, A., Sallmén, B., Jansson, I., \& Segraeus, V. (1997). MAP-unit: Monitoring Area and Phase Unit description form, draft version. Stockholm: National Board of Institutional Care (SiS).

Prochaska, J., DiClemente, C., \& Norcross, J. (1992). In search of how people change: applications to addictive behaviours. The American Psychologist, 47(9), 1102-1114.

Raes, V., Lenders, F., \& Geirnaert, M. (1995). Drughulpverlening in Vlaanderen: Feiten en problemen. Brussel: Vereniging voor Alcohol- en andere Drugproblemen.

Reggers, J., \& Ansseau, M. (2000). Recommandations dans le traitement des toxicomanies aux opiacés. Revue Médicale de Liège, 55(5), 409-416.

Ridgely, M.S., \& Willenbring, M. (1992). Application of case management to drug abuse treatment: overview of models and research issues. In R.S. Ashery (Ed.), Progress and Issues in case management (NIDA Research Monograph 127) (pp. 12-33). Rockville: National Institute on Drug Abuse.

Rohrer, J., Vaughan, M., Cadoret, R., Carswell, C., Patterson, A., \& Zwick, J. (1996). Effect of centralized intake on outcomes of substance abuse treatment. Psychiatric Services, 47(11), 1233-1238.

Spooren, D., Van Heeringen, K., \& Jannes, C. (1996). Drug abuse and emergency psychiatry: a comparative study of psychiatric emergencies following illegal and legal drug abuse in Belgium. European Addiction Research, 2, 213-218.

Stauffacher, M. (Ed.). (1999). Treated drug users in 23 European cities, Data 1997, Trends 1996-97: Pompidou Group Project on Treatment Demand, Final Report. Zurich: Council of Europe Publishing.

Stein, L., \& Test, M. (1980). Alternatives to mental hospital treatment: I. Conceptual model, treatment program, and clinical evaluation. Archives of General Psychiatry, 37, 392-397.

Subregionaal Samenwerkingsverband Geestelijke Gezondheidszorg Midden West-Vlaanderen. (1997). Verwijscode geestelijke gezondheidszorg Regio Midden West-Vlaanderen. Pittem: Subregionaal Samenwerkingsverband Geestelijke Gezondheidszorg Midden West-Vlaanderen.

Substance Abuse and Mental Health Services Administration (SAMHSA). (1999). Comprehensive case management for substance abuse treatment, Treatment Improvement Protocol (TIP) Series 27. Rockville: US Department of Health and Human Services, Centre for substance abuse treatment. 
Tucker, J.A. (1999). Reformulating the addictive behavior change process: Changing addictive behavior: Historical and contemporary perspectives. In J.A. Tucker, D. Donovan, \& A. Marlatt (Eds.), Changing addictive behavior: Bridging clinical and public health strategies (pp. 1-44). New York: The Guilford Press.

van Achterberg, T., Stevens, F., Hekkink, M., Crebolder, H., \& Philipsen, H. (1995). Implementing coordination of care: task performance and problems encountered. Scandinavian Journal of Caring Sciences, 9(4), 209-217.

Vanderplasschen, W. \& Broekaert, E. (2000). Using case management to reduce harm among substance abusers with multiple and complex problems. In International Harm Reduction Association (Ed.), Programme \& Abstract book of the 11th International Conference on the Reduction of Drug Related Harm: Integrated approaches to diverse challenges (pp. 160-161). Jersey, Channel Islands, British Isles: International Harm Reduction Association.

Vanderplasschen, W., De Bourdeaudhuij, I., \& Van Oost, P. (1999). Eindrapport onderzoeksproject Case management in de Oost-Vlaamse drughulpverlening. Gent: Universiteit Gent, Vakgroep Gedragstherapie en psychologische begeleiding.

Vanderplasschen, W., Mostien, B., Claeys, P., Raes, V., \& Van Bouchaute, J. (2001). Conceptnota organisatiemodel zorgcircuit middelenmisbruike (Orthopedagogische Reeks 12). Ghent, Belgium: Ghent University, Department of Orthopedagogics.

Van Deun, P., \& Figiel, C. (2000). Aansluiting tussen de diverse hulpverleningsniveaus op lokaal vlak. In B. De Ruyver, G. Vermeulen, A. Flaveau, A. De Leenheer, F. Carlier, A. Noirfailise et al. (Eds.), Drugbeleid 2000: Drugbeleid aan de vooravond van de 21 $1^{\text {ste }}$ eeuw, Zevende Nationaal Congres (pp. 503-522). Antwerpen-Apeldoorn: Maklu Uitgevers.

Vanhex, M. (1998). Die belgische Drogenpolitik im Wandel. Binad-Info, 10, 27-29.

van Riet, N., \& Wouters, H. (1996). Case management: een leer-en werkboek over de organisatie en coördinatie van zorg-, bulp-en dienstverlening. Assen: Van Gorcum.

VOCA Training \& Consult (VOCA). (1998). Totaal kwaliteitsmanagement: Handleiding voor het systematisch werken aan kwaliteit in gezondheids- en welzijnsvoorzieningen. Leuven-Apeldoorn: Garant.

Willenbring, M. (1996). Case management applications in substance use disorders. In H. Siegal, \& R. Rapp (Eds.), Case management and substance abuse treatment: practice and experience (pp. 51-76). New York: Springer Publishing Company.

Yates, R. (1999). Multi-drug use: a new problem or the recognition of how it always was? In E. Broekaert, W. Vanderplasschen, \& V. Soyez (Eds.), Proceedings of the International Symposium on Substance Abuse Treatment and Special Target Groups (pp. 109-112). Ghent: Ghent University, Department of Orthopedagogics. 


\title{
Chapter 3
}

\section{The integration of treatment systems for substance abusers}

\begin{abstract}
This chapter consists of two parts. The first part focuses on similarities and dissimilarities between treatment modalities, and the evolution towards cooperation and integrated models. Based on discussions between practitioners and directors of harm reduction and abstinence-oriented programs during an international symposium, incentives and preconditions are formulated for the integration of treatment systems. The second part starts from discussion groups with practitioners, directors, policymakers and researchers in East-Flanders and describes a step-by-step plan for the establishment of an integrated treatment system for substance abusers.
\end{abstract}





\subsection{TOWARDS THE INTEGRATION OF TREATMENT SYSTEMS FOR SUBSTANCE ABUSERS ${ }^{3}$}

ABSTRACT. The central ideas of this chapter are the result of intensive discussions during a symposium that was organized following structural changes in European substance abuse treatment. Therapeutic communities were concerned about their approach being replaced by other treatment modalities. Participants focused on the question of whether the emerging harm reduction paradigm can be combined with the principle of recovery and how its integration in a comprehensive treatment system can be beneficial or detrimental to therapeutic communities. This article defines integrated treatment systems for substance abusers from a conceptual, etymological, ethical and ideological point of view. In addition it focuses on old but ongoing contradictions and discussions between drug-free, methadone maintenance and harm reduction approaches. Several prerequisites for the integration of treatment systems are discussed, and parallels and discrepancies between the American and European situation are explored. An integrated and comprehensive system of treatment services is put forward as an alternative to the present-day gap between conventional abstinence-oriented programs and harm reduction initiatives. Participants maintain that collaboration between these apparently incompatible treatment paradigms will depend on mutual respect, the introduction of a common language and a thorough analysis of clients' treatment demands.

3 This chapter is based on: Broekaert, E. \& Vanderplasschen, W. (2003). Towards the integration of treatment systems for substance abusers: Report on the Second International Symposium on Substance Abuse Treatment and Special Target Groups. Journal of Psychoactive Drugs, 35(2), 237245. 

THE INTEGRATION OF TREATMENT SYSTEMS FOR SUBSTANCE ABUSERS

\subsubsection{INTRODUCTION}

In some European countries (e.g., Germany, the Netherlands, Norway) attempts have recently been made to reorganize the field of mental health care and substance abuse treatment towards more integrated systems (de Weert-Van Oene \& Schrijvers, 1992; Koller, 1999). A similar evolution can be observed in Belgium, where the National Council of Hospital Facilities [Nationale Raad voor Ziekenbuisvoorzieningen (NRZV)] has proposed establishing integrated treatment systems for special target groups, including substance abusers. In this way, they hope to better meet clients' multiple and complex needs and to improve the continuity of care and coordination and cooperation between treatment services (Vanderplasschen, Mostien, Claeys, Raes, \& Van Bouchaute, 2001).

As this topic has been discussed intensively for the last 2 years in Belgium, the organizing committee of the International Symposium on Substance Abuse Treatment and Special Target Groups (i.e. the European Federation of Therapeutic Communities (EFTC) and the Department of Orthopedagogics, Ghent University) decided to approach the abovementioned theme from an international perspective during the annual symposium in the year 2000 .

During the last decade, the European Federation of Therapeutic Communities experienced a shift of treatment methods and perspectives in most of its membership countries: the therapeutic community approach has been complemented and sometimes even superceded by low threshold methadone centers, free heroin distribution and flexible cooperation between treatment interventions which initially appeared incompatible (Marset, 1999). In certain European countries such as Switzerland (Klingemann, 1996), the Netherlands (Kooyman, 2001), Sweden (Göransson, 1997) and the United Kingdom (Tomlinson, 1994), an important decrease in the number of therapeutic communities has been noted. The only exceptions on this trend are therapeutic communities located within prisons (Turnbull \& Webster, 1998). Moreover, the 1999 annual report of the European Monitoring Center for Drugs and Drugs Addiction (EMCDDA, 1999), which reports on drug problems and their treatment, barely mentioned the drug-free approach.

EFTC was concerned about the adulteration of its value-based and abstinence-oriented approach due to the decline of the recovery principle and the establishment of a new harm reduction paradigm, in which drug use is considered acceptable (Inciardi, 1999; Rosenbaum, 1996). Simultaneously the gap between the United States - where this harm reduction movement remains less influential and is mainly limited to methadone maintenance - and Europe and Australia became apparent (Drucker, 1995; Harm Reduction Coalition, 2001). Moreover, European therapeutic communities had a less prominent tradition of prohibition and - due to the influence of milieu therapy and psychoanalysis - were not as moralistic (Broekaert, van der Straeten, D’Oosterlinck, \& Kooyman, 1999). 
Therapeutic community staff members also affirmed the importance of increased cooperation and more flexible care systems, and strove to enlarge the TC method in order to include such special target groups as prisoners, homeless, dually diagnosed persons, adolescents, etc. (De Leon, 1997a; Martin, 1999; Van der Meer, 1997). Due to the increased prevalence of substance abuse and the complexity and variety of needs presented by substance abusers, therapeutic communities realized that one single treatment modality could not hope to solve all problems. Consequently, substance abuse treatment cannot be limited to one single treatment, but should consist of various phases and diverse modalities with continuity of care presenting an important challenge (Vanderplasschen, De Bourdeaudhuij, \& Van Oost, 2002). Finally, the economic reality has led to structural changes and a demand for more collaboration and a better modulation of different initiatives (Hagedorn, 1998).

During the second International Symposium on Substance Abuse Treatment and Special Target Groups concerning "Integration of different treatment models" in De Haan (Belgium), more than 100 participants discussed the integration of treatment systems for substance abusers from a conceptual, etymological, ethical and ideological point of view. Attempts to bridge the gap between various treatment modalities revealed fundamental differences. Keynote speakers and other participants debated whether the emerging harm reduction paradigm could be combined with the principle of recovery and how a neoliberal approach towards managed care could benefit or damage therapeutic communities (Broekaert, Vanderplasschen, \& Bradt, 2000). In the United States, the debate concerning the integration of harm reduction with traditional substance abuse services is seen as an important challenge (Gleghorn, Rosenbaum, \& Garcia, 2001; Marlatt, Blume, \& Parks, 2001). A comprehensive system of treatment services is proposed as a way of breaching the present-day gap between conventional abstinence-oriented and harm reduction initiatives.

The concept of integrated treatment systems has been implemented in some European countries and seems a satisfying way of dealing with the multiple and often chronic problems of substance abusers, as well as an effective way of unifying the often fragmented services available to this target group. For this reason the findings of this symposium might well be of interest to those facing a similar integration of different treatment models. The participants largely focused on ideas, experiences and concerns expressed by management and staff members of therapeutic communities. However, input from other drug-free programs and harm reduction initiatives is included, as well as feedback from scientists and policymakers. 
THE INTEGRATION OF TREATMENT SYSTEMS FOR SUBSTANCE ABUSERS

\subsubsection{DEFINITION}

The term "integrated treatment systems" is a relatively new concept, and little has been published concerning it. Therefore, the term is defined from etymological, conceptual, ethical and ideological points of view. The combination of these 3 words is particularly noteworthy, as most articles refer to "integrated treatment" or "integrated systems" or "integrated approaches". Sometimes the word "integrated" is replaced by "integrative".

\section{• ETYMOLOGICAL DEFINITION}

"Integration" is derived from the Latin words integer or "whole" and integrare or "renewal". It pursues new unity and can be considered as "alternatively going together where unity is pursued" (Rucker, 1986, p. 218). "Treatment" (from the Latin tractare: "to handle" or "what to do") refers to the content, whilst "system" (derived from the Greek systema or "logical order") refers to the organizational aspects of this integration. Integrated treatment thus differs from a multi- (Latin for "many") or mixed- (mixtus in Latin means "assorted") modality (modus is Latin for "means" and/or "way") approach. The term "multi-modality" stresses the multiplicity of the approach, but not the striving for unity or coordination within that multiplicity. However, the specific meaning of "integrated treatment systems" and "multi-modality approaches" is seldom emphasized in daily reality.

\section{a CONCEPTUAL DEFINITION}

Most articles (cited in the Social Sciences Citation Index of the Institute for Scientific Information) containing the terms "integrated treatment (systems)" and "substance abuse" refer to the integration of mental health care and substance abuse programs for dually diagnosed patients (co-morbidity of substance abuse and severe mental illness). Conceptual definitions of "integrated treatment" are seldom used and the meaning can usually be derived from the context (cf. Bachmann, Moggi, Hirsbrunner, Donati, \& Brodbeck, 1997; De Leon, 1996; Drake, Mercer-McFadden, Mueser, McHugo, \& Bond, 1998; Drake, Yovetich, Bebout, Harris, \& McHugo, 1997; Fiorentine \& Hillhouse 2000; Grella, 1996; Hellerstein, Rosenthal, \& Miner, 2001; Sciacca \& Thompson, 1996; Weisner, Mertens, Parthasarathy, Moore, \& Lu, 2001).

Sciacca and collaborators investigated "Integrated Treatment (Across) Systems for dual diagnosis: Mental Illness, Drug Addiction, and Alcoholism (MIDAA)", as mental health and substance abuse programs were traditionally designed to deal with singular disorders (Sciacca \& Thompson, 1996). Due to conflicting and incompatible philosophies and treatment methods within different systems, IT(A)S aims at providing comprehensive services within each program of each delivery system. The programs are cost-effective, 
make use of existing facilities, train staff in the issues of incompatible treatment interventions, fill the gaps between services and expand referral resources. Clients' needs are met in each phase of their recovery. In the course of time, the program covers comprehensive assessment, motivation, stabilization, education, rehabilitation and relapse prevention. Symptoms of dual or multiple disorders are accepted without demur (Sciacca, 1991; Sciacca \& Thompson, 1996).

De Leon and his colleagues refer to an integrated systems approach and define it as "interrelated clinical interventions and social services that are guided by a common socialpsychological vision of the individual and of recovery" (De Leon, 1997a, p. 268). This shared vision of recovery entails following residents in their recovery process, assessing their needs and providing them with the most effective form of treatment. This integrated system approach, in which the concept of recovery and treatment is seen as primordial, has been applied in a modified therapeutic community for criminal delinquents, for substance abusers suffering from mental illness and for mentally ill homeless abusers referred from shelters. Prescription of methadone or other harm reduction interventions can contribute to the partial or total realization of this goal. The main focus is thus not society, nor the program, setting or modality, but the development of the individual.

During the symposium in De Haan, following definition was used to describe integrated treatment systems (Broekaert, Vanderplasschen, \& Bradt, 2000, p. 3): "Integrated treatment systems refer to sensible action within a global context and are based on the needs of clients on the one hand and on coordination of policy, cooperation of services and availability of a large range of treatment modalities on the other".

\section{口 ETHICAL DEFINITION}

From an ethical point of view, integrated treatment systems are influenced by questions concerning the goals of treatment and the nature of recovery: should substance use be dissuaded or tolerated? This controversy is reflected in a gamma of recovery strategies that vary from total abstinence to controlled heroin distribution. Some of these strategies aim at personal development (e.g., drug-free therapeutic communities (Kooyman, 1993)), others at psychiatric treatment (e.g., psychiatric hospitals), and still others at substitution therapy with methadone, LAAM or buprenorphine (Newman, 1990). Harm reduction initiatives promote, among others, needle exchange, health awareness, prevention of infectious diseases, safe injection rooms and controlled heroin trials (Drucker, 1995). Recently, a new tendency arose whereby the protection of society and concern for the individual were no longer seen as mutually incompatible (Fridell, 1999). Finally, the debate also includes the question of whether substance abuse should be decriminalized, depenalized or even legalized (Inciardi, 1999). 


\section{a IDEOLOGICAL DEFINITION}

The current neo-liberal ideological viewpoint sees integrated treatment systems as part of new managed care. The cornerstones of this approach are satisfaction of the individual, privacy, productivity, efficiency, effectiveness and quality care (Fridell, 1999). Quality must be made explicit and be translated into concrete norms and standards that are measurable at the level of the product, structure and process (Brook, McGlynn, \& Shekelle, 2000). Regular tests and checks are required to ascertain that standards are met (VOCA, 1998).

Due to the introduction of economic thinking in all social sectors, evaluation of substance abuse treatment became an important research topic and one of its main objectives was to improve the quality of care (Vanderplasschen et al., 2002). Coordination, continuity, effectiveness and efficiency are considered vital characteristics of quality care (de Weertvan Oene \& Schrijvers, 1992). Effectiveness denotes the relationship between achievements and objectives, whilst efficiency refers to the relationship between effects and resources. Coordination relates to the functional cooperation between various services, and continuity to the length of treatment and the individual nature of the approach.

\subsubsection{CRITICAL LIMITATIONS}

The integration of different treatment paradigms is impeded by perpetual discussions between abstinence-oriented programs, substitution and harm reduction approaches. Although narrowing the gap between these divergent approaches is a slow process and the debate continues, daily practice proves that many drug abusers make use of several services simultaneously or within a short period of time (Friedman, D'Aunno, Jin, \& Alexander, 2000; Vanderplasschen, Lievens, \& Broekaert, 2001). Both the advantages and disadvantages of the respective approaches are elucidated in this section.

\section{- DRUG-FREE TREATMENT}

The discussion goes back to the late 1960s, when therapeutic communities defined their identity in terms of a drug-free lifestyle and absolute recovery from drugs (Bassin, 1977; Bratter \& Forrest, 1985; Broekaert, Vanderplasschen, Temmerman, Ottenberg, \& Kaplan, 2000; Broekaert \& van der Straeten, 1997; Glaser, 1977; Mowrer, 1976; O’Brien, 1993; Yablonsky, 1965). They severely criticized Dole and Nyswander's "no exit"approach towards heroin addiction. Acampora and Stern (1994, p. 8) reported ironically "how a teaspoon of medicine taken daily in a cup of orange juice is changing former dope addicts into decent law abiding citizens". Bratter (1978) maintained that the individual's belief in recovery worked as a self-fulfilling prophecy: to remove this and replace it with 
the demands of society was to condemn the abuser to relapse. Lennard, Epstein and Rosenthal (1972) saw methadone as an ordinary street drug and considered methadone treatment an illusion: methadone was often used in combination with other substances, led to heavy withdrawal symptoms, and condemned the abuser to lifelong "street psychiatry".

At the same time, the validity of the therapeutic community was questioned. French social workers openly criticized the authoritarian nature of the American hierarchical drug-free therapeutic communities (Ottenberg, 1984). Synanon, the birthplace of the drug-free therapeutic community, gradually became a cult (Deitch \& Zweben 1979; Mitchell, Mitchell, \& Ofshe, 1980).

\section{a Methadone SUbSTITUTION}

On the other hand, proponents of methadone substitution praised Dole and Nyswander's approach which "does not impair an addict's functioning and costs as little as ten cents a day" (Smith \& Luce, 1969, p. 337). They supported the "British system" for "making narcotics legally available and thereby making it unnecessary for addicts to steal in order to support their habits" (Smith \& Luce, 1969, p. 336).

In the seventies, American therapeutic communities reached the peak of their development and expanded to Europe and other continents (Broekaert \& Slater, 2001). From the beginning of the eighties onwards, methadone maintenance gained ground due to the prevalence of HIV and AIDS amongst drug users (Drucker, 1995; Uchtenhagen, 1997). In the ensuing years, methadone proved to be an excellent tool for fighting the enormous increase in substance abuse. Treatment for substance abusers became more clientcentered and, if sufficient psychological and social support was provided, dropout rates in methadone programs were lower than in drug-free programs (De Leon, 1997b). Moreover, methadone programs led to decreased (intravenous) use of heroin (Hartel et al., 1995), less criminal behavior and fewer arrests (Ezard et al., 1999), and higher employment rates (Newman, 1985).

\section{- HARM REDUCTION}

Methadone maintenance became a central intervention of the harm reduction approach, which aims at reducing the negative consequences of drug use and incorporates a spectrum of strategies which range from safer use to managed use and finally to total abstinence (Harm Reduction Coalition, 2001). This harm reduction paradigm no longer focuses exclusively on recovery as the ultimate goal, but views respect for the client's autonomy as a guiding principle (Denning, 2001). Criminal law enforcement and medical treatment are used to optimize drug users' quality of life with or without drugs. 
This ideology contrasted sharply with the drug-free recovery paradigm that was considered as purist, based on belief in dogma-based values and lacking reference to research (Griffin, 2001). Harm reduction is a pragmatic alternative to prohibition (Marlatt et al., 2001), and incorporates a broad range of interventions including:

- Intravenous injection of morphine, methadone and heroin to opiate dependent persons with severe medical and social problems and to those for whom treatment has repeatedly failed in Switzerland (Küng, 1997; Uchtenhagen, 1997).

- Medical prescription of injectable drugs in, among others, Great Britain (Stimson \& Oppenheimer, 1982), the Netherlands (Derks, 1990) and Australia (Bammer \& Gerrard, 1992).

- Needle exchange and syringe distribution programs in, among others, the United States (Des Jarlais et al., 1994), Switzerland (Office of the Chief Medical Officer, 1994) and the Netherlands (Hartgers, Buning, van Santen, Verster, \& Coutinho, 1998).

- Support of liberal laws that accept free availability of certain substances such as cannabis in the Netherlands (Korf, 1990) or the decriminalization of all illicit substances in Portugal and of non-problematic use of cannabis (e.g., Belgium) (EMCDDA, 2001).

- Establishment of drug user organizations (Balian \& White, 1998).

\section{- MANAGED CARE}

As far as the organization of services in the field of substance abuse is concerned, critical issues are service utilization, integration of services and the position of new managed care. Both in the United States and in Europe governments support new forms of cost-effective collaboration.

For example, in the United States the "Integrated treatment and blended funding for cooccurring mental and addictive disorders" (NAMI, 2001) and the "Arizona integrated treatment consensus panel" (Arizona Department of Health Services, 2001) demonstrate this trend. Centralized intake procedures have been developed to facilitate access, coordination and continuity of treatment (Rohrer et al., 1996). Case management has been set up with several target groups who experience similar difficulties in accessing treatment, or who have contacts with a variety of services due to their chronic and multiple problems (SAMHSA, 1998). Matching of clients has become more important both in the United States (Hser, 1995) and in Europe (Kersten, Schippers, Broekman, van Rijswijk, \& Joosten, 1995), due to the differentiation of substance abuse treatment, the growing complexity of drug problems and the varying degrees of success obtained by different treatment modalities.

In Europe, networks of integrated services for substance abusers have been created in the Netherlands (de Weert-van Oene \& Schrijvers, 1992) and Germany (Däumling, 2000; 
Koller, 1999). Case management is frequently applied in the field of mental health care, but was only recently introduced in substance abuse treatment in order to assist, amongst others, drug users with multiple and complex problems (Vanderplasschen \& Broekaert, 2000; EMCDDA, 2001).

These new forms of collaboration and managed care originated in the United States in the early seventies, when the "American Health Maintenance Organization"-act allowed the public sector to receive public funds. Ten years later, this practice was discontinued and the profitmaking aspect penetrated the non-profit sector. This increased emphasis on profit making stimulated the development and application of more stringent cost-control procedures.

Some years later a similar evolution took place in Europe, accelerated by the European Union's struggle for economic power. The principles underlying this tendency are similar in both the United States and Europe and include: meeting clients' needs in every phase of treatment; limiting the negative medical, social and economic consequences of substance abuse; integrating traditional and non-traditional approaches into a continuum of interventions; providing comprehensive services and interventions; creating prevention strategies; providing treatment including primary medical care; acknowledging the strengths and limitations of individual programs, etc. (Gleghorn et al., 2001).

Managed care and all its implications aroused much criticism. Zimmerman (1999, p. 289) noted "how the growing impact of economic thinking leads to an increased denial of the needs of the poor, the elderly, minority groups, the young and disabled". Gould, Levine and McLellan (2000, p. 75) deplored that "Managed Care Organizations have taken the position that they are empowered to provide only those services that are medically necessary". This leads these authors to conclude that Managed Care Organizations (MCOs) contribute to the exclusion of social responsibility. Zarkin and Dunlap (1999, p. 33-34) described the implications of managed care for methadone treatment and concluded: "The treatment programs that we visited speculated that a Medicaid managed care system may limit access to methadone treatment and may adversely influence retention in the program as well as the quality of care provided". They further stated: "Treatment programs are worried that their patients may be required to go through an MCO-gatekeeper in order to gain access to treatment, but MCO-gatekeepers lack appropriate training in identifying substance abuse patients and in directing them to the appropriate treatment". 
THE INTEGRATION OF TREATMENT SYSTEMS FOR SUBSTANCE ABUSERS

\subsubsection{PREREQUisites FOR THE INTEGRATION OF TREATMENT SYSTEMS}

The symposium on the integration of different treatment models should be situated within this context of opposing paradigms and shifting policies. Based on the contribution of several speakers and the ensuing discussions, various prerequisites were formulated for the integration of treatment systems (Broekaert, Vanderplasschen, \& Bradt, 2000).

First of all, it was stipulated that the choice of treatment should be free of moral pressure. Moreover, the system should grant equal support to the medical model, the therapeutic community and the value-based approach. Mutual respect between all partners is crucial and the objectives of each modality should be made explicit. Historical and ideological differences should be taken into account when establishing an integrated treatment system, but it is essential that the network adopts a common and comprehensive approach towards drug abuse and its treatment. It is important to safeguard the uniqueness of each approach when integrating the diverse approaches into a comprehensive system.

A comprehensive treatment system should include various settings and modalities and be characterized by a multidisciplinary approach and continuity of care (Graham, Timney, Bois, \& Wedgerfield, 1995). Outreaching, prevention, early intervention, family involvement, self-help and relapse prevention should all have a place within this system. Depending on the individual and the situation, the treatment can be either care- or cureoriented. Assessment, planning, monitoring and evaluation are all basic elements of the treatment process. Particular attention must be paid to special target groups (e.g., drug abusers with children, immigrants), as they often contact several services and fall through the cracks of the health care and social welfare system.

Dealing with the multiple and complex problems of drug abusers and safeguarding quality of care (i.e. coordination, continuity, efficiency, effectiveness) calls for more integrated and individualized treatment. The importance of networking and case management and the creation of a more centralized intake system have been discussed (Vanderplasschen, Mostien, et al., 2001). Collaboration between different services and coordination of care is indispensable (Ottenberg, 2000). One common language, applicable to all treatment settings and modalities, is essential to the realization of an integrated treatment system. Concepts such as "cure", "care", "network", "method" and "follow-up care" should all be described in the same terminology. Group discussion should determine the choice of terminology and all those involved should be heard, including practitioners, counselors, directors, researchers, policymakers and subsidizing authorities.

All partners involved in the treatment of drug abuse should participate in such a network. Communication between different modalities is very important, as some clients move from one modality to another. Registration and maintenance of client files should be standardized in order to improve communication within and between services. Referral procedures should be clear to all parties and the accessibility of the system should be closely monitored. Although the establishment of an integrated system requires many 
arrangements and agreements, this should not be at the expense of flexibility. Client participation is an important part of creating and monitoring an integrated treatment system.

A thorough qualitative and quantitative analysis of clients' treatment demands is a necessary part of providing the best possible care and creating alternatives to present-day treatment services (Vanderplasschen, Mostien et al., 2001). Treatment should be based on the demands of the client. Treatment adapted to the most prevalent problems would be available on a local or regional basis, whilst the more specialized services would be available only at state- or county level. A regional inventory of all existing treatment facilities and modalities is the first step in the process of reorganizing and integrating treatment services. Further deliberation, based on the registration of treatment demands and following the inventory of existing services, may lead to the abolition of superfluous methods and modalities and the establishment of others not yet in place.

On an organizational level, national, regional and local funding agencies must take many factors into account. The client's treatment demand must be considered as well as the philosophy and objectives of the various services. The transition towards an integrated treatment system will initially create much extra work and the authorities should provide financial support in order to help motivate staff. The development of measurable treatment processes should be closely followed, but utilization studies and cost-benefit comparisons must not aim only at cost reduction or stimulation of competition between services. Finally, cooperation between services should be based on a formal agreement signed by all parties in which individual responsibilities are clearly stated (Vanderplasschen, Mostien et al., 2001).

There are many theories and suggestions pertaining to the integration of treatment systems but many questions remain (Ottenberg, 2000): What is the importance of "recovery" in this integrated system? What are the benefits of a natural health care approach (e.g., acupuncture) and how is it incorporated in an integrated treatment system? Not everything is measurable (e.g., humanistic qualifications). Is this view upheld by the system and, if so, how is it reflected in the philosophy of managed care?

\subsubsection{SIMILARITIES BETWEEN THE AMERICAN AND EUROPEAN SITUATION}

These prerequisites formulated by European workers from therapeutic communities and other services in the field of substance abuse treatment reflect the same ideas as those postulated during the "Bridging the gap"-conferences in San Francisco by American colleagues in the field of traditional substance abuse and harm reduction services (Gleghorn et al., 2001). While the principles for integrating harm reduction with 
THE INTEGRATION OF TREATMENT SYSTEMS FOR SUBSTANCE ABUSERS

traditional substance abuse treatment refer to a common approach shared by all in the network, the "De Haan" prerequisites focus on structural elements necessary for the establishment of an integrated treatment system. Thus, although the European and American situation differ to a certain extent, the "De Haan" conclusions complement those reached by the San Francisco "Bridging the Gap"-conference. This is due not only to a different approach towards "integrated treatment systems", but also to the fact that the American and European situation originate from two distinct paradigms.

Europe and the United States share many of the same principles, although the choice of words differs slightly. Both believe that care should be delivered in a culturally competent, non-judgmental manner with respect for individual dignity (Gleghorn et al., 2001). Interventions should reduce the adverse social, physical, and economic consequences of substance abuse. New strategies should be developed to engage and motivate potential clients and to limit the long-term consequences of substance abuse. Harm reduction interventions should be applied to those unable or unwilling to stop drug use. Relapse should be regarded as an integral part of the recovery process. Treatment should be available to all, including patients requiring medical or psychiatric drugs. Effective collaboration strengthens each separate program or modality (Broekaert, Vanderplasschen, \& Bradt, 2000).

\subsubsection{CONCLUSION}

European professionals working in therapeutic communities and other services within the field of substance abuse treatment observed a shift in treatment paradigms and drug policy. An evolution towards integrated treatment systems for drug abusers was noted and accepted. Economic thinking in today's society makes this evolution inevitable, as do the changing complexity of drug users' treatment needs and the lack of coordination and continuity of care. Moreover, there has been a growing acceptance of methadone substitution and harm reduction initiatives. European TC staff members emphasize individual development and consider it more important than the harm done to society. They favor a recovery paradigm and believe in the durability of their identity. The symposium participants further concluded that prohibition is an intrinsic aspect of American morality and social structures, which may complicate the rapprochement with harm reduction.

An integrated and comprehensive system of treatment modalities and services is put forward as a way of breaching the present-day gap between conventional abstinenceoriented programs and harm reduction initiatives. Collaboration between these two apparently incompatible treatment paradigms will largely depend on mutual respect, the introduction of a common language to describe treatment, and the development of a fair subsidy system. An integrated treatment system for substance abusers should be based on 
a thorough analysis of clients' treatment needs and should safeguard the unique qualities of each approach. Effective communication and collaboration between all services is crucial and should be supported by the authorities. There is still some dissent concerning certain issues (e.g., acceptance of drug use as normal behavior; the question of whether addiction is a disease; the importance of values) and the network must adopt a common approach towards substance abuse and its treatment in order to reconcile philosophical and ideological differences.

ACKNOWLEDGEMENTS. We would like to thank following persons for their contribution to this paper and for discussing the central theme during the symposium: M. Haack (Maastricht University, the Netherlands), C. Kaplan (Maastricht University, the Netherlands), M. Kooyman (Rotterdam, the Netherlands), J. Maertens (De Sleutel, Belgium), D. Ottenberg (Pennsylvania, United States), A. Slater (Phoenix House Haga - EFTC, Norway), D. Vandevelde (De Kiem, Belgium) and R. Yates (University of Stirling, Scotland). L. Bockaert, B. Hofman, D. Reynaert \& K. Wuyts (Master students in Educational Sciences) for revising and editing this paper. 


\section{REFERENCES}

Acampora, A., \& Stern, C. (1994). The evolution of the therapeutic community. In Therapeutic Communities of America (Ed.). Treatment paradigms: Past, present and future. Proceedings of the 1992 national planning conference. Washington, D.C.: Therapeutic Communities of America Publications.

Arizona Department of Health Services (United States). (n.d.). Arizona integrated treatment consensus panel. Home Page. Retrieved November 3, 2001, from http://www.hs.state.az.us/bhs/consensus.htm

Bachmann, K.M., Moggi, F., Hirsbrunner, H.P., Donati, R., \& Brodbeck, J. (1997). An integrated treatment program for dually diagnosed patients. Psychiatric Services, 48(3), 314-316.

Balian, R., \& White, C. (1998). Defining the drug user [electronic version]. Harm Reduction Communication, 7.

Bammer, G., \& Gerrard, G. (Eds.). (1992). Heroin treatment: New alternatives. Proceedings of a seminar beld on 1 November 1991. Canberra, Australia: The Australian National University, National Centre for Epidemology and Population Health.

Bassin, A. (1977). The miracle of the TC From birth to post-partum insanity to full recovery. Second world conference of therapeutic communities. Montreal, Canada: McGill University.

Bratter, T.E. (1978). The negative self-fulfilling prophecy of methadone maintenance. Corrective and Social Psychiatry, 24(1), 1-5.

Bratter, T.E., \& Forrest, G. (Eds.). (1985). Alcoholism and substance abuse: Strategies for clinical intervention. New York: Free Press Macmillan.

Broekaert, E., \& Slater, A. (2001). The development of the therapeutic community in Western and Southern Europe. EFTC newsletter, 7 (July 2001), 16-20.

Broekaert, E., Vanderplasschen, W., \& Bradt, H. (Eds.). (2000). Proceedings of the second international symposium on substance abuse treatment and special target groups. The integration of different treatment models. Ghent, Belgium: Ghent University, Department of Orthopedagogics \& the European Federation of Therapeutic Communities (EFTC).

Broekaert, E., Vanderplasschen, W., Temmerman, I., Ottenberg, D.J., \& Kaplan, C. (2000). Retrospective study of similarities and relations between American drug-free and European therapeutic communities for children and adults. Journal of Psychoactive Drugs, 32(4), 407-417.

Broekaert, E., \& van der Straeten, G. (1997). Histoire, philosophie et développement de la communauté thérapeutique en Europe. Psychotropes: Revue Internationale des Toxicomanies, 3(1), $7-23$.

Broekaert, E., van der Straeten, G., D’Oosterlinck, F., \& Kooyman, M. (1999). The therapeutic community for ex-addicts: A view from Europe. Therapentic Communities: The International Journal for Therapeutic and Supportive Organizations, 20(4), 255-66.

Brook, R., McGlynn, E., \& Shekelle, P. (2000). Defining and measuring the quality of care: a perspective from U.S.-researchers. International Journal for Quality in Health Care, 12(4), 281295. 
Däumling, M. (2000). Integration of different treatment models in the concept of treatment of drug-addicts of the Deutche Orden. In E. Broekaert, W. Vanderplasschen, \& H. Bradt (Eds.), Proceedings of the second international symposium on substance abuse treatment and special target groups. The integration of different treatment models (pp. 67-72). Ghent, Belgium: Ghent University, Department of Orthopedagogics \& the European Federation of Therapeutic Communities (EFTC).

Deitch, D., \& Zweben, J. (1979). Synanon: A pioneering response in drug abuse treatment and a signal for caution. In H. Seymour, \& L. Bambe (Eds.), Proceedings of the fourth world conference of therapeutic communities (pp. 57-70). New York: Daytop Village - ICAA.

De Leon, G. (1996). Integrative recovery: A stage paradigm. Substance Abuse, 17(1), 51-63.

De Leon, G. (1997a). Community as a method: Therapeutic communities for special populations and special settings. Westport, Connecticut: Praeger Publishers.

De Leon, G. (1997b). Passages: A therapeutic community oriented day treatment model for methadone maintained clients. Journal of Drug Issues, 27(2), 341-42.

Denning, P. (2001). Strategies for implementation of harm reduction in treatment settings. Journal of Psychoactive Drugs, 33(1), 23-26.

Derks, J. (1990). The efficacy of the Amsterdam morphine-dispensing program. In H.A. Ghodse, C.D. Kaplan, \& R.D. Mann (Eds.), Drug misuse and Dependence. Park Ridge, New York: Parthenon.

Des Jarlais, D.C., Friedman, S.R., Sotheran, J.L., Wenston, J., Marmor, M., Yancovitz, S.R. et al. (1994). Continuity and change within an HIV epidemic. Injecting drug users in New York City, 1984 trough 1992. Journal of the American Medical Association (JAMA), 271(2), 121-127.

de Weert-van Oene, G., \& Schrijvers, A. (1992). Van lappendeken naar zorgcircuit: circuitvorming in de Utrechtse verslavingszorg. Utrecht, the Netherlands: Rijksuniversiteit Utrecht, Vakgroep Algemene gezondheidszorg en epidemiologie.

Drake, R.E., Mercer-McFadden, C., Mueser, K.T., McHugo, G.J., \& Bond, G.R. (1998). Review of integrated mental health and substance abuse. Schizophrenia Bulletin, 24(4), 589-608.

Drake, R.E., Yovetich, N.A., Bebout, R.R., Harris, M., \& McHugo, G.J. (1997). Integrated treatment for dually diagnosed homeless adults. Journal of Nervous and Mental Disease, 185(5), 298-305.

Drucker, E. (1995). Harm reduction: A public health strategy. Current Issues in Public Health, 1, 64-70.

European Monitoring Centre for Drugs and Drug Addiction (EMCDDA). (1999). Annual report on the state of the drugs problem in the European Union 1999. Luxembourg: Office for Official Publications of the European Communities.

European Monitoring Centre for Drugs and Drug Addiction (EMCDDA). (2001). Annual report on the state of the drugs problem in the European Union 2001. Luxembourg: Office for Official Publications of the European Communities.

Ezard, N., Lintzeris, N., Odgers, P., Koutroulis, G., Muhleisen, P., Stowe, A. et al. (1999). An evaluation of community methadone services in Victoria, Australia: results of a client survey. Drug and Alcohol Review, 18(4), 417-423. 
Fiorentine, R., \& Hillhouse, P. (2000). Drug treatment and 12-step program participation. The additive effects of integrated recovery activities. Journal of Substance Abuse Treatment, 18(1), 6574.

Fridell, M. (1999). Evaluating residential and institutional treatment. In European Monitoring Centre for Drugs and Drug Addiction (EMCDDA) (Ed.), Evaluating the Treatment of Drug Abuse in European Union (EMCDDA Scientific Monograph Series $n^{\circ} 3$ ). Luxembourg: Office for Official publications of the European Communities.

Friedmann, P., D’Aunno, T., Jin, L., \& Alexander, J. (2000). Medical and psychosocial services in drug abuse treatment: Do stronger linkages promote client utilization? Health Services Research, 35(2), 443-465.

Glaser, F. (1977). The origins of the drug-free therapeutic community: A retrospective history. Toronto, Canada: Addiction Research Foundation.

Gleghorn, A., Rosenbaum, M., \& Garcia, B.A. (2001). Bridging the gap in San Francisco: the process of integrating harm reduction and traditional substance abuse services. Journal of Psychoactive Drugs, 33(1), 1-7.

Göransson, B. (1997). Treatment and rehabilitation in Sweden. Integration of national policy at community level. In S. Sollbakken (Ed.), Proceedings from the third European conference on rehabilitation and drug policy. Oslo, Norway: Norwegian Directory for the Prevention of Alcohol and Drug Problems.

Gould, F., Levine, M., \& McLellan, A.T. (2000). Treating the substance- abusing patient in the public sector: "Medical necessity" versus "social necessity and social responsibility" in the Philadelphia target cities demonstration project. Journal of Substance Abuse Treatment, 18(1), 7577.

Graham, K., Timney, C., Bois, C., \& Wedgerfield, K. (1995). Continuity of care in addictions treatment: the role of advocacy and coordination in case management. American Journal of Drug and Alcohol Abuse, 21(4), 433-451.

Grella, C.E. (1996). Background and overview of mental health and substance abuse treatment systems: Meeting the needs of women who are pregnant or parenting. Journal of Psychoactive Drugs, 28(4), 319-43.

Griffin, S. (2001). Do no harm. San Diego: Griffen \& Wong Institute. Retrieved November 3, 2001, from http://www.realsolutions.org/donoharm.htm.

Hagedorn, J. (1998). The business of drug dealing in Milwaukee. Wisconsin Policy Research Institute report, 11(5), 1-33.

Harm Reduction Coalition (HRC). (2001). Principles of harm reduction: The need for harm reduction. Retrieved November 3, 2001, from http://www.harmreduction.org/prince.html.

Hartel, D.M., Schoenbaum, E.E., Selwyn, P.A., Kline, J., Davenny, K., Klein, R.S. et al. (1995). Heroin use during methadone maintenance: The importance of methadone dose and cocaine use. American Journal of Public Health, 85(1), 83-88.

Hartgers, C., Buning, E.C., van Santen, G.W., Verster, A.D., \& Coutinho, R.A. (1998). The impact of the needle and syringe exchange programme in Amsterdam on injecting risk behaviour. AIDS, 3(9), 571-76.

Hellerstein, D.J., Rosenthal, R.N., \& Miner, C.R. (2001). Integrating services for schizophrenia and substance abuse. Psychiatric Quarterly, 72(4), 291-306. 
Hser, Y. (1995). A referral system that matches drug users to treatment programs: existing research and relevant issues. Journal of Drug Issues, 25(1), 209-224.

Inciardi, J. (1999). The drug legalization debate. Thousand Oaks, California: Sage Publications, Inc.

Kersten, T., Schippers, G., Broekman, T., van Rijswijk, A., \& Joosten, A. (1995). Ontwikekeling en verbetering van indicatiestelling en verwijzing van cliënten met verslavingsproblematiek. Nijmegen, the Netherlands: Bureau Bêta.

Klingemann, H.K.H. (1996). Drug treatment in Switzerland: Harm reduction, decentralization and community response. Addiction, 91(5), 723-36.

Koller, E. (1999). The policy-maker's perspective. In European Monitoring Centre for Drugs and Drug Addiction (EMCDDA) (Eds.), Evaluating the Treatment of Drug Abuse in the European Union (EMCDDA Scientific Monograph Series $N^{\circ} 3$ ) (pp. 79-84). Luxembourg: Office for Official publications of the European Communities.

Kooyman, M. (1993). The therapeutic community for addicts: Intimacy, parent involvement and treatment success. Amsterdam, the Netherlands: Swets \& Zeitlinger.

Kooyman, M. (2001). The history of therapeutic communities. A view from Europe. In B. Rawlings, \& R. Yates (Eds.), Therapeutic communities for the treatment of drug users. London, United Kingdom: Jessica Kingsley Publishers.

Korf, D. (1990). Cannabis retail markets in Amsterdam. International Journal of Drug Policy, 2(1), 2327.

Küng, M. (1997). Drug prevention in the light of a changing drug policy. In S. Sollbakken (Ed.), Proceedings from the third European conference on rehabilitation and drug policy. Oslo, Norway: Norwegian directorate for the prevention of alcohol and drugs problems.

Lennard, H.I., Epstein, L.J., \& Rosenthal, M.S. (1972). The methadone illusion. Science, 176(37), 881-84.

Marlatt, G.A., Blume, A., \& Parks, G. (2001). Integrating harm reduction therapy and traditional substance abuse treatment. Journal of Psychoactive Drugs, 33(1), 13-22.

Marset, M. (1999). Programmes of controlled prescription of heroin: Drug addict integration into a process of change. In C. Hernandes Gil (Ed.), Proceedings of the fourth European conference on rehabilitation and drug policy. Marbella, Spain: Spanish national plan on drugs.

Martin, P. (1999). Flexibility in treatment provisions. Programs of controlled prescription of heroine: Drug addict integration into a process of change. In C. Hernandes Gil (Ed.). Proceedings of the fourth European conference on rehabilitation and drug policy. Marbella, Spain: Spanish national plan on drugs.

Mitchell, D., Mitchell, C., \& Ofshe, R. (1980). The light on Synanon. New York: Seaview Books.

Mowrer, O.H. (1976). Therapeutic groups and communities in retrospect and prospect. Paper at the the First World Conference on Therapeutic Communities. Katrineholm, Sweden: Vallmotorp Foundation. Unpublished.

The Nation's Voice on Mental Illness (NAMI). (2001). Integrated treatment and blended funding for cooccurring mental and addictive disorders. Retrieved November 3, 2001, from http://www.nami.org/update/unitedintegrate.html.

Newman, R.G. (1985). Narcotic addiction and methadone treatment in Hong Kong: Lessons for the United States. Journal of Public Health Policy [Southeast Asian Edition], 6(4), 526-38. 
THE INTEGRATION OF TREATMENT SYSTEMS FOR SUBSTANCE ABUSERS

Newman, R.G. (1990). Advocacy for methadone treatment. Annals of Internal Medicine, 113(11), 81920.

O’Brien, W.B. (1993). You can't do it alone. New York: Simon and Schuster.

Office of the Chief Medical Officer. (1994). AIDS prevention statistics on needle exchange 1992/1993. Zurich, Switzerland: Health Department of the City of Zurich.

Ottenberg, D.J. (1984). Therapeutic community and the danger of the cult phenomena. In L. Bremberg (Ed.), Proceedings of the first world conference on therapeutic communities. Katrineholm, Sweden: Vallmotorp Foundation.

Ottenberg, D.J. (2000). Conclusions of the plenary meeting and workshops. In E. Broekaert, W. Vanderplasschen, \& H. Bradt (Eds.), Proceedings of the second international symposium on substance abuse treatment and special target groups. The integration of different treatment models (pp. 79-84). Ghent, Belgium: Ghent University, Department of Orthopedagogics \& the European Federation of Therapeutic Communities (EFTC).

Rohrer, J., Vaughan, M., Cadoret, R., Carswell, C., Patterson, A., \& Zwick, J. (1996). Effect of centralized intake on outcomes of substance abuse treatment. Psychiatric Services, 47(11), 1233-1238.

Rosenbaum, M. (1996). Kids, drugs, and drug education: A harm reduction approach. San Francisco: The national council on crime and delinquency.

Rucker, R. (1986). Oneindigheid, filosofie en wetenschap van het oneindige. Amsterdam, the Netherlands: Contact.

Sciacca, K. (1991). An integrated treatment approach for severely mentally ill individuals with substance disorders. In K. Minkoff, \& R. Drake (Eds.), New directions for mental health services, no. 50. Dual diagnosis of major mental illness and substance disorder (pp. 69-84). San Francisco: Jossey-Bass Publishers.

Sciacca, K., \& Thompson, C.M. (1996). Program development and integrated treatment across systems for dual diagnosis: Mental illness, drug addiction and alcoholism (MIDAA). Journal of Mental Health Administration, 23(3), 288-97.

Smith, D., \& Luce, J. (1969). Love needs care: A bistory of the Haight Ashbury Free Medical Clinic. Boston, Toronto: Little, Brown and Company.

Stimson, G.V., \& Oppenheimer, E. (1982). Heroin addiction: Treatment and control in Britain. London, UK: Tavistock.

Substance Abuse and Mental Health Services Administration (SAMHSA). (1998). Comprehensive case management for substance abuse treatment (Treatment Improvement Protocol (TIP) Series 27). Rockville: US Department of Health and Human Services, Center for substance abuse treatment.

Tomlinson, D. (1994). Presidents message. Newsletter. In P. Zafiridis (Ed.), European Federation of Therapeutic Communities. Athens, Greece: Kethea.

Turnbull, P.J., \& Webster, R. (1998). Demand reduction activities in the criminal justice system in the European Union. Drugs: education, prevention and policy, 5(2), 177-84.

Uchtenhagen, A. (1997). Maintenance treatment. In S. Sollbakken (Ed.), Proceedings from the third European conference on rehabilitation and drug policy. Oslo, Norway: Norwegian directory for the prevention of alcohol and drugs problems. 
Van der Meer, C. (1997). Inpatient treatment and update. In S. Sollbakken (Ed.), Proceedings from the third European conference on rehabilitation and drug policy. Oslo, Norway: Norvegian Directorat for the Prevention of Alcohol and Drug Problems.

Vanderplasschen, W., \& Broekaert, E. (2000). Using case management to reduce harm among substance abusers with multiple and complex problems. In International Harm Reduction Association (Ed.), Program \& Abstract book of the 11th International Conference on the Reduction of Drug Related Harm (pp. 160-161). Jersey, Channel Islands: International Harm Reduction Association.

Vanderplasschen, W., De Bourdeaudhuij, I., \& Van Oost, P. (2002). Co-ordination and continuity of care in substance abuse treatment: an evaluation study in Belgium. European Addiction Research, 8, 10-21

Vanderplasschen, W., Lievens, K., \& Broekaert, E. (2001). “Drug treatment tourism” in specialised treatment facilities. In International Council on Alcohol and Addiction (Ed.), Programme and abstract book of the $44^{\text {th }}$ International ICAA Conference on the prevention and treatment of dependencies "Science meets practice" (pp. 133). Heidelberg, Germany: International Council on Alcohol and Addiction.

Vanderplasschen, W., Mostien, B., Claeys, P., Raes, V., \& Van Bouchaute, J. (2001). Conceptnota organisatiemodel zorgcircuit middelenmisbruike (Orthopedagogische Reeks 12). Ghent, Belgium: Ghent University, Department of Orthopedagogics.

VOCA Training \& Consult (VOCA). (1998). Totaal Kwaliteitsmanagement: Handleiding voor het systematisch werken aan kwaliteit in gezondheids- en welzijnsvoorzieningen. Leuven-Apeldoorn: Garant.

Weisner, C., Mertens, J., Parthasarathy, S., Moore, C., \& Lu, Y. (2001). Integrating primary medical care with addiction treatment. Journal of the American Medical Association (JAMA), 286(14), $1715-23$.

Yablonsky, L. (1965). Synanon: The tunnel back. Baltimore: Penguin Books.

Zarkin, G.A., \& Dunlap, L.J. (1999). Implications of managed care for methadone treatment. Findings from five case studies in New York State. Journal of Substance Abuse Treatment, 17(12), 25-35.

Zimmerman, D. (1999). Scientism and managed care: The betrayal of group and individual treatment for children. Therapeutic Communities, 20(4), 281-300. 


\subsection{COORDINATION OF CARE IN SUBSTANCE ABUSE TREATMENT: THE GRADUAL ESTABLISHMENT OF AN INTEGRATED TREATMENT SYSTEM FOR SUBSTANCE ABUSERS ${ }^{4}$}

ABSTRACT. During the last decade, an evolution towards more cooperation and networking as well as to more individualized and continuous care can be observed in health care and social welfare in several countries. In Belgium, the reorganization of mental health care is intended to establish integrated treatment systems for several target groups, including substance abusers. Despite various publications and policy documents, only few concrete recommendations have been given concerning the actual implementation of such systems. Based on our experiences and procedure followed while implementing an integrated treatment system for substance abusers in the province of East-Flanders, we will highlight five crucial steps in this process in this chapter. The development of a common language and a concerted approach to drug problems is regarded as a first prerequisite. Second, a theoretical model should be elaborated about how such an integrated system can be organized and which services should be offered. Third, an inventory should be made revealing which services treatment centers offer at present, followed by a comparative analysis of missing links and duplicated work in the existing system and, consequently, the elaboration of an action-plan for the abolition, addition or adaptation of certain services. Fourth, theoretical preparations make room for putting the elaborated system into practice. The fifth and last step, which should be repeated regularly, includes monitoring, evaluating and - if necessary - guiding the implementation. Finally, several recommendations are formulated for anticipating possible obstacles, as one might be confronted with resistance and practical problems at several points during the implementation process.

\footnotetext{
${ }^{4}$ This chapter is based on: Vanderplasschen, W., Lievens, K., Van Bouchaute, J., Mostien, B., Claeys, P., \& Broekaert, E. (2004). Zorgcoördinatie in de verslavingszorg: de stapsgewijze uitbouw van een zorgcircuit middelenmisbruik. Tijdschrift voor Geneeskunde, 60(11), 773-787.
} 

THE INTEGRATION OF TREATMENT SYSTEMS FOR SUBSTANCE ABUSERS

\subsubsection{INTRODUCTION}

In 1997, the future organization and structure of mental health care was presented for the first time in an advisory note of the permanent working group concerning "psychiatry" of the National Council of Hospital Facilities [Nationale Raad voor Ziekenhuisvoorzieningen (NRZV)] (Knapen \& Van Holsbeke, 1997; NRZV, 1997). This intended reform starts from clients' treatment demands and the characteristics of being "mentally ill'. In their advice to the Belgian policymakers, the NRZV suggested moving away from the present-day institution-based organization of services towards regional integrated treatment systems for specific target groups. In addition to the traditional target groups (children and adolescents; adults; elderly people), a number of specific and emerging populations have been distinguished in the field of mental health care: forensic patients, substance abusers and people with intellectual disabilities (Knapen \& Van Holsbeke, 1997). Meanwhile, this proposal has been confirmed in the respective policy notes on "mental health care" (Aelvoet \& Vandenbroucke, 2001) and "drugs" (Federale Regering, 2001) and in the Hospital Act of January 14, 2002 (Wet, 2002). Moreover, in December 2002, care coordinators were assigned to nearly all regional boards on mental health care [overlegplatforms geestelijke gezondheidszorg] in order to facilitate the establishment of regional integrated treatment systems for persons with substance-related disorders (FOD Volksgezondheid, 2002).

The ultimate objective of the introduction of function-oriented thought and action and of the organization of integrated treatment systems is to guarantee individualized and continuous care and to respond to the growing diversity of treatment demands by means of more cooperation and networking (De Meulemeester, Molenberghs, Nassen \& Bellings, 1998; Nassen, 1999; van Achterberg, Stevens, Hekkink, Crebolder \& Philipsen, 1995). The transition from institution-based care towards a more client-centered organization of care is not limited to the field of substance abuse treatment, but also appears from evolutions among other mental health populations and in other sectors, such as social welfare and youth care (Claeys \& Lievens, 2003; Vanderplasschen, Mostien, Claeys, Raes \& Van Bouchaute, 2001).

These evolutions are also consistent with international tendencies towards more cooperation and networking (Broekaert \& Vanderplasschen, 2003). In the United States, this is illustrated by the system of "managed care". This cooperation between treatment providers and insurance companies mainly aims at cost containment in the health care system (Galanter, Keller, Dermatis \& Egelko, 2000). Several adverse consequences have been reported, such as growing competition between treatment providers, and attenuation of the availability and accessibility of services as a result of cutting back on expensive and long-term treatment and maintaining strict eligibility criteria (Vanderplasschen, Mostien et al., 2001). Another tendency concerns the integration of different treatment modalities ("integrated treatment"), particularly for clients with severe mental illness and cooccurring substance use disorders (DiNitto, Webb \& Rubin, 2002; Minkoff, 2000). 
Integrated treatment has generated positive effects concerning the organization as well as the treatment outcomes (Drake, Mercer-McFadden, Mueser, McHugo \& Bond, 1998).

From the mid-1980s, numerous innovative projects have been set up in the field of mental health care in the Netherlands. These were characterized by a community-based approach, functional organization of care, administrative decentralization, and the application of economic principles (Wolf, 1995). Integrated treatment systems that provide comprehensive and individualized care were established all over the country for several target groups. In Germany, mental health care has been reformed based on clients' treatment demand (Koller, 1999). The appointment of regional care coordinators in substance abuse treatment has contributed significantly to the programming and matching of services to clients' needs (Oliva, Görgen, Schlanstedt, Schu, \& Sommer, 2001).

Despite the above-mentioned evolutions and publications, clear and concrete guidelines for the establishment of integrated treatment systems are not available at present. Such concrete information is almost completely lacking in the international literature, or is very context-specific. Therefore, we will try to describe systematically the steps that are necessary to establish such an integrated treatment system. This description is based on our experiences and working methods in the province of East-Flanders, where a group of practitioners, management staff, policymakers and researchers prepares and supervises the implementation of an integrated treatment system for substance abusers (Vanderplasschen, Mostien, et al., 2001). Other Belgian provinces have also been faced with the same challenge and we think they can benefit from our expertise concerning this issue. We believe that the step-by-step plan we describe might also be relevant for persons with other mental health problems, as the proposed modulation and gradual establishment of an integrated treatment system will be analogous for other target groups.

\subsubsection{THE DEVELOPMENT OF INTEGRATED TREATMENT SYSTEMS FOR SUBSTANCE ABUSERS}

Drug dependence has been characterized as a chronic and relapsing disorder and is often accompanied by other problems such as physical and mental health problems, unemployment, social exclusion, relational and financial problems (Brindis \& Theidon, 1997). Consequently, substance abusers are in need of several services which are offered by various (fragmented) agencies (cf. table 2.1., p. 44). These include specialized substance abuse treatment (e.g., medical-social care centers, drug-free therapeutic communities) as well as non-specialized agencies such as general practitioners, emergency or psychiatric wards in general hospitals, or shelters for the homeless. The complexity of these persons' problems and dropout during or relapse after treatment may cause substance abusers to seek help through several agencies within a relatively short period of time. Cooperation, networking, coordination and continuity of care will be needed to improve the 
THE INTEGRATION OF TREATMENT SYSTEMS FOR SUBSTANCE ABUSERS

effectiveness of substance abuse treatment (Graham, Timney, Bois, \& Wedgerfield, 1995; SAMHSA, 1998; Vanderplasschen, De Bourdeaudhuij, \& Van Oost, 2002).

However, several publications have demonstrated shortcomings in the programming and delineation of services and in the cooperation and treatment matching in Belgian substance abuse treatment (De Ruyver \& Casselman, 2000; Maertens, 1997). Treatment services for substance abusers are more like a patchwork than a coherent network, with little attention to continuity of care, centralized intake procedures or standardized registration systems (Raes, Lenders \& Geirnaert, 1995). These bottlenecks and the increased stress on quality of care have recently stimulated the search for adequate interventions (e.g., case management) and structural approaches (e.g., integrated treatment systems) to resolving these problems (de Weert-van Oene \& Schrijvers, 1992; Vanderplasschen, et al., 2002). While case management intends to provide comprehensive, continuous and individualized care on the client level, the integration of different treatment systems aims at structural changes at the organizational level. Within such an integrated treatment system, case management will be a crucial intervention to guarantee the coordination and continuity of care (Broekaert \& Vanderplasschen, 2003).

\subsubsection{A STEP-BY-STEP PLAN FOR THE ESTABLISHMENT OF AN INTEGRATED TREATMENT SYSTEM}

The establishment of an integrated treatment system for substance abusers is a long-term process, consisting of several steps:

1. developing a common approach and language;

2. elaborating a theoretical model for the organization of an integrated treatment system;

3. mapping existing treatment services (including missing links and duplications), followed by laying out an action plan;

4. applying and implementing the developed model;

5. monitoring and evaluating the implemented model.

In this chapter, we will illustrate and discuss these distinct steps. At present, our experiences and findings mainly relate to the first three steps in this process. The final steps still have to be taken, but we have already developed a clear vision and plan how these steps can be realized. 


\section{STEP 1: DEVELOPING A COMMON APPROACH AND LANGUAGE}

\section{a A COMMON APPROACH}

A common approach by the network of treatment agencies regarding the structural and functional organization is a first prerequisite for establishing an integrated treatment system. Policymakers have stipulated some broad guidelines and conditions: the client and his or her social network as starting point; guaranteed accessibility, flexibility and quality of care; application of one common language in all institutions; and a psychiatric hospital, mental health care center and general hospital as minimal partners in a network (Knapen \& Van Holsbeke, 1997; NRZV, 1997). In close collaboration with various treatment agencies, the Union for Alcohol and Drug Problems [Vereniging voor Alcohol en andere Drugproblemen (VAD)], which is the Flemish umbrella organization of treatment centers and prevention initiatives concerning alcohol and drug problems, has elaborated a specific approach regarding the development of integrated treatment systems for problematic drug users (VAD, 2001). The principles outlined by the NRZV are listed in this document, as well as some additional conditions: continuity of care, continuous exchange of information, an inventory of existing services, quantitative and qualitative analysis of treatment demands, case management, regional demarcation, formal agreements between treatment agencies, adaptation of existing (financial) regulations among others. In anticipation of the formal cooperation between substance abuse treatment agencies in the province of East-Flanders, the above-mentioned working group has devised a common approach (Vanderplasschen, Mostien, et al., 2001). These are the core elements of this common approach to substance abuse problems: the principal right to treatment; accessibility and availability of treatment services; individualized care after consulting with clients and their social network; participation and emancipation; (partial) freedom of choice for clients and caregivers; continuity of care; professional, interdisciplinary and qualitative care; involvement of all relevant partners; shared responsibility; one common language; a comprehensive and community-based problem approach; and priority of effective and least-impressive interventions. This common approach may include distinct therapeutic approaches and abstinence as well as harm reduction-oriented modules. An explicit and formal agreement concerning such a common approach that is subscribed to by all partners in the network is the first important step toward the development of an integrated treatment system (Claeys \& Lievens, 2003).

\section{a A COMMON LANGUAGE}

In order to communicate unambiguously about existing treatment agencies and the services they offer, a common language is required (Knapen \& Van Holsbeke, 1997). The initial impetus for such a common language has been the description of a "new 
THE INTEGRATION OF TREATMENT SYSTEMS FOR SUBSTANCE ABUSERS

framework of concepts for mental health care" [Nieun begrippenkader geestelijke gezondheidszorg] (Nassen, Theunis, Du Laing \& Van Holsbeke, 1999). The hospital Act of January 14, 2002 officially defined the concepts "integrated treatment system" [zorgcircuit] and "network" [netwerk] (Wet, 2002). An integrated treatment system refers to all treatment programs - consisting of modules - organized by a network that represents all necessary treatment services for a certain target group and guarantees continuous and individualized care (Nassen, 1999). A network is defined as all treatment providers who organize an integrated treatment system for a certain target group within a clear-cut region, based on a judicially formalized cooperation between several institutions (Wet, 2002).

An integrated treatment system consists of the content of treatment [zorginhoud] (or management of different treatment modules) and the organization of treatment [zorgorganisatie] (or management of personnel and resources for operating the treatment program) (cf. figure 3.1., p. 94). Treatment agencies [zorgeenheden] are the smallest organizational units within an integrated treatment system (e.g., detoxification ward in a psychiatric hospital; alcohol team of a mental health care center; therapeutic community) and are responsible for offering certain treatment modules. Modules [modules] are the core elements of an integrated treatment system and can be described as a global offer of treatment services. A module consists of a combination of one or more treatment functions [zorgfuncties] that are organized in a certain way (mode) [modus] and are oriented toward a well-defined objective (Nassen, 1999) (cf. table 3.1.). Several modules can be connected to a treatment trajectory [rorgtraject], which is a global response to a certain situation or to the problems of a certain target group (e.g., trajectory "emergency and crisis care", "dual diagnosis").

Nassen (2001) has developed a step-by-step plan for making these modules and trajectories more concrete, based on the "new framework of concepts for mental health care" [Nieuw begrippenkader geestelijke gezondheidszorg] ((Nassen, Theunis, Du Laing \& Van Holsbeke, 1999). In this plan, treatment services are described according to three dimensions: age (children and adolescents, adults, elderly people), main treatment function (engagement, assessment, nursing, counseling, treatment, psycho-education, activation, and provision of services), and mode (location, duration, periodicity, and degree of protection) (Nassen, 2001).

However, this classification brings about two problems. First, the fact that all treatment agencies separately designate the modules that they organize may cause confusion and ambiguity. When establishing an integrated treatment system for substance abusers in the province of East-Flanders, we decided to designate the distinct modules in advance and limited their number. After some deliberation, the above-mentioned group decided on about 32 modules that can be offered to substance abusers, such as substitution treatment, detoxification, long-term treatment, housing, and employment (Vanderplasschen, Mostien, et al., 2001). Second, the dimensions proposed do not allow sufficient 
differentiation of treatment services for specific target groups, such as substance abusers. Therefore, we added some dimensions with the intention to describe the target group and the treatment modules more accurately (Vanderplasschen, Mostien, et al., 2001).

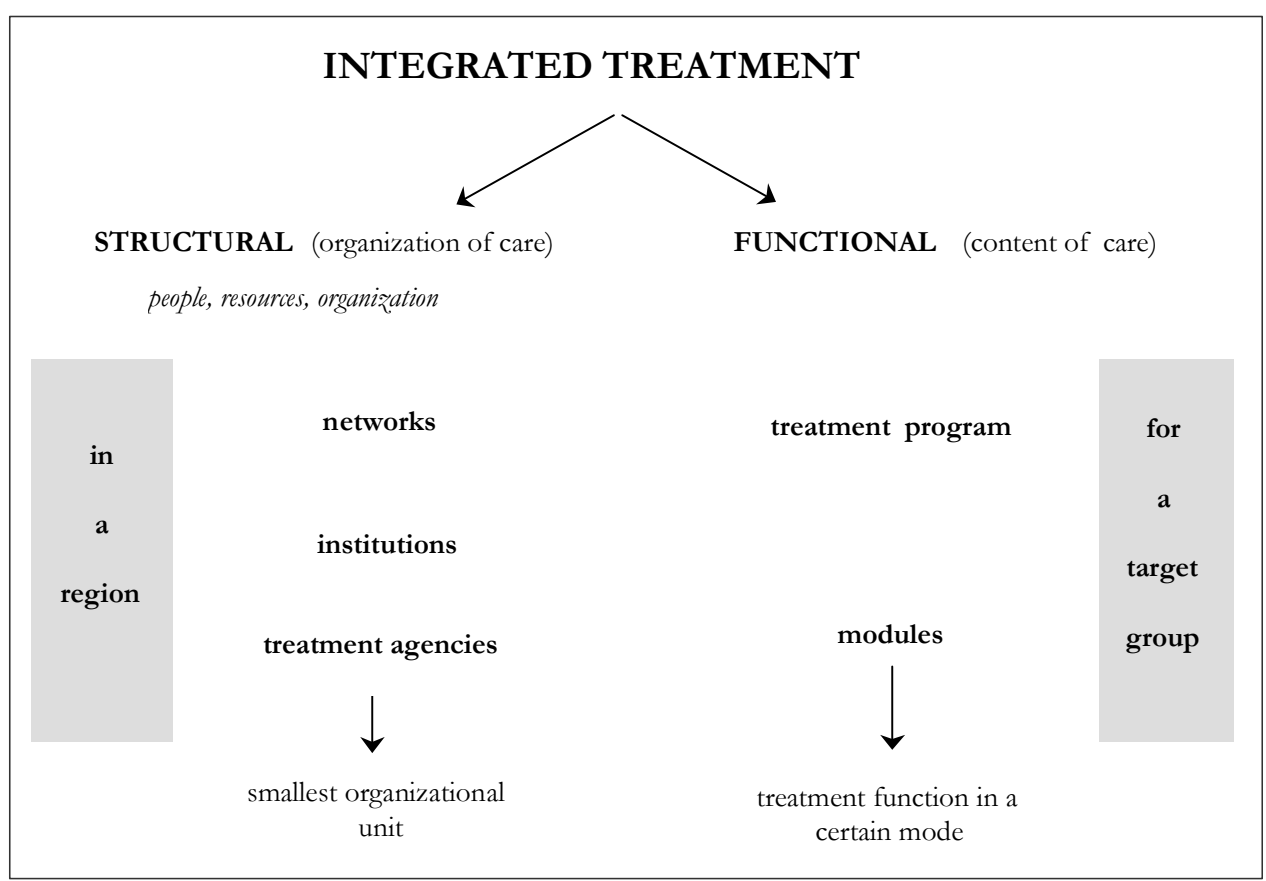

Figure 3.1.: Overview of core elements of an integrated treatment system and how these relate to one another

(Nassen et al., 1999)

Regarding the target group, we maintained "age" as one dimension, but further differentiated according to the following dimensions: problem severity, substance of (ab)use, and specific population. Problem severity was categorized according to the DSM IV classification (APA, 1996), but the category "use" was added to indicate each form of substance use that cannot be regarded as "abuse" or "dependence". The DSM IV classification of substance-related disorders was used for specifying the target group based on the specific substance used, if any. The dimension "specific population" was added due to the growing interest in the literature and daily practice of so-called special target groups (Broekaert, Vandevelde, Vanderplasschen, Soyez, \& Poppe, 2002).

Modules are differentiated according to the dimensions suggested by Nassen (2001) (treatment function and mode), but we added the "focus" and "objectives" of the module (cf. table 3.1., p. 98). The main treatment function [hoofdzorgfunctie] indicates which treatment function (a series of related activities with a clear objective in response to clients' treatment demand) predominates within a certain module. The mode denotes in which way a module is organized and we added the intensity (how long?) and degree of 
THE INTEGRATION OF TREATMENT SYSTEMS FOR SUBSTANCE ABUSERS

urgency (how quickly accessible?) of the module to the indicators already formulated by Nassen and colleagues (2001): location, total duration, periodicity, and degree of protection. The focus reveals at which life domains the intervention is aimed and is based on the seven life domains of the Addiction Severity Index (physical health, training and employment, alcohol and drugs, justice and police, family and social relations, psychological and emotional complaints, and gambling) (Hendriks, Kaplan, van Limbeek, \& Geerlings, 1990), complemented with "living situation" and "leisure time". Finally, the objectives describe the goals of modules at client level: basic care, readiness for change, control, recovery, or relapse prevention (Öberg, Gerdner, Sallmén, Jansson, \& Segraeus, 2000; Prochaska, DiClemente, \& Norcross, 1992)

\section{STEP 2: ELABORATING A THEORETICAL MODEL FOR THE ORGANIZATION OF AN INTEGRATED TREATMENT SYSTEM}

A second, partly parallel step is the response to the theoretical question: How should the regional development and coordination of an integrated treatment system be organized (Claeys \& Lievens, 2003)? In order to meet the specific questions and needs of various regions, a region-oriented approach in interaction with the local and provincial level seems most appropriate (Vanderplasschen, Mostien, et al., 2001). By doing so, regional differences concerning availability of treatment services and differential familiarity with this innovative concept should be taken into account. The theoretical model developed may in no way confirm or strengthen existing regional inequalities.

The ultimate goal is to establish within a clear-cut region (e.g., a province) a wellcoordinated integrated treatment system for substance abusers, including three levels: local connection, regional development, and provincial coordination (Vanderplasschen, Mostien, et al., 2001). Local connection means that someone with drug problems should be able to receive at least primary care in his or her immediate surroundings, and this should fit perfectly with more specialized substance abuse treatment agencies at regional or provincial levels. General practitioners will not only be the referring agency, but can also be responsible for organizing specific modules themselves (e.g., substitution treatment, aftercare). The regional development refers to the establishment of a comprehensive network of treatment agencies that offer specific services regarding substance abuse problems so that clients and their social network may receive adequate treatment in their own region. The provincial level predominantly concerns more specialized modules, some of which can even be organized on an inter-provincial level if they only serve a small target group. The coordination and support of the integrated treatment system should be established at provincial level, as this might facilitate matching and cooperation with integrated treatment systems in other regions or for other target groups.

Subsequently, a theoretical model should be elaborated that includes a list of modules and trajectories that are theoretically needed on the different levels of an integrated treatment 
system (Claeys \& Lievens, 2003). This is an ideal representation of types of services required in a specific region. Given the fact that clients' treatment demands and needs largely depend on contextual factors, available international literature only provides general indications about what types of services are needed. Also, data from national and regional monitoring studies seem insufficient for this purpose. A large-scale study of clients' needs and satisfaction is needed, as well as ethnographic research to reach populations that are now insufficiently or not served at all by existing agencies.

Such a theoretical model should be based on available data concerning treatment demand, utilization, and length of stay in existing agencies (VAD, 2001; Vanderplasschen, Mostien, et al., 2001). Monitoring and cohort studies may provide further insight into treatment aspects that could be improved e.g., the effectiveness of intake procedures and referrals. Besides the standardization of intake procedures and improved exchange of information, case management and other methods for stimulating coordination of care, centralized intake units can be an alternative for improving client treatment matching and for tracking and monitoring clients (de Weert-van Oene \& Schrijvers, 1992). In addition, centralization can contribute to the transparency of substance abuse treatment for clients, referring agencies and providers by creating one or a few clear gates to treatment, and by attuning divergent intake procedures. On the other hand, such a centralized intake unit limits the freedom of choice of clients and caregivers, and may be confusing for everyone who was accustomed to the previous system. Research has shown that centralized intake units mainly affect the organization of substance abuse treatment rather than clients' functioning (Scott \& Foss, 2002; Sears, Davis, \& Guydish, 2002).

Case management is regarded as an adequate method to monitor and coordinate the trajectory that clients follow in an integrated treatment system (SAMHSA, 1998; Drake, Yovetich, Bebout, Harris, \& McHugo, 1997). The case manager acts as contact person and is responsible for a proactive follow-up and a planned and comprehensive approach to the problems (Vanderplasschen, Lievens \& Broekaert, 2001). Research has demonstrated that this intervention contributes to increased and more adequate service utilization, and treatment participation and retention are enhanced, which increases the chance of positive treatment outcomes (Siegal, Rapp, Li, Saha, \& Kirk, 1997; Vaughn, Sarrazin, Saleh, Huber, \& Hall, 2002). As case management is a very intensive intervention, it will only be possible to track a limited number of clients (Vanderplasschen, Lievens \& Broekaert, 2001). Moreover, independent case managers (e.g., employed by the network that manages the integrated treatment system) seem most appropriate, because they can mediate at times of conflict or can add new methods to the treatment process (SAMHSA, 1998). A good demarcation of case managers' tasks is needed to avoid conflicts with other caregivers involved in the treatment process. One of the most important obstacles is the risk that clients stick to this type of intervention and become dependent on their case manager, at the expense of their autonomy (Vanderplasschen, Lievens \& Broekaert, 2001). 
THE INTEGRATION OF TREATMENT SYSTEMS FOR SUBSTANCE ABUSERS

Finally, the recruitment area and authorities of treatment agencies and the network need to be delineated so that clear agreements can be made with other integrated treatment systems in this or neighboring regions (Claeys \& Lievens, 2003). Furthermore, a feasible timing and operational goals, including measurable indicators, should be part of the proposed model.

\section{STEP 3: MAPPING EXISTING TREATMENT SERVICES (INCLUDING MISSING LINKS AND DUPLICATIONS), FOLLOWED BY LAYING OUT AN ACTION PLAN}

Whereas the second step particularly intended to reach a consensus concerning the modules that are theoretically required in a specific region and how such an integrated treatment system can be organized in practice, the objective of this third step is to look at the availability and accessibility of services and how this relates to the ideal representation detailed in step 2.

In order to map all available services in a certain region, each treatment agency independently from other agencies - needs to describe all its treatment modules based on a common language (cf. step 1). Due to the complex organization of treatment services and the need for unambiguous communication, we chose to describe only the main treatment activities and modules (not services that are offered exceptionally), based on the following dimensions: target group, function, mode, focus, and objectives. Table 3.1. shows one module for some hypothetical treatment agencies, including the target group, and a description of the above-mentioned dimensions.

The subjective interpretation by various treatment agencies needs to be made more objective. For this purpose, the results of this inventory can be compared with objective data about the region concerned, its treatment agencies, and the services they offer. Since such information is only available to a limited extent in most regions, data about services offered can be looked at objectively through critical discussion and analysis by a number of independent experts and representatives of the agencies involved in so-called "focus groups". This is a qualitative research method, including a limited number of persons who have an in-depth discussion concerning some selected topics (Greenbaum, 2000). More specifically, the goal of these focus groups is for experts who are familiar with these treatment agencies (representatives of the treatment agencies and of similar services, referring agencies, policymakers, research institutes among others) to evaluate and compare the inventory of the modules made up by the respective treatment agencies. The critical comments and recommendations that result from the focus group discussions lead to a revision of the descriptions of the services offered that is more congruent with the inventories by other treatment agencies. Consequently, the inter-subjectivity and, therefore, the reliability and validity of the modules inventoried can be improved (Swanborn, 1994). 
Table 3.1.: Hypothetical inventory of modules offered by substance abuse treatment agencies

\begin{tabular}{|c|c|c|c|c|c|c|c|c|c|}
\hline \multirow{2}{*}{$\begin{array}{l}\text { Treatment } \\
\text { agency }\end{array}$} & \multicolumn{5}{|l|}{ Module } & \multicolumn{4}{|c|}{ Target group } \\
\hline & & $\begin{array}{l}\text { Main } \\
\text { treatment } \\
\text { function }\end{array}$ & Mode & Focus & Objectives & Age & Substance & Severity & $\begin{array}{l}\text { Specific target } \\
\text { group }\end{array}$ \\
\hline $\begin{array}{l}\text { Youth team of a } \\
\text { mental health care } \\
\text { center }\end{array}$ & $\begin{array}{l}\text { early } \\
\text { intervention }\end{array}$ & assessment & $\begin{array}{l}\text { location: within the treatment unit } \\
\text { total duration: } 1 \text { to } 4 \text { weeks } \\
\text { intensity: } 1 \text { hour } \\
\text { periodicity: once a week } \\
\text { degree of protection: no supervision } \\
\text { degree of ungengy: within } 3 \text { days }\end{array}$ & $\begin{array}{l}\text { - illicit drugs } \\
\text { - alcohol } \\
\text { - gambling }\end{array}$ & $\begin{array}{l}\text { - readiness to } \\
\text { change } \\
\text { - control }\end{array}$ & adolescents & $\begin{array}{l}\text { - alcohol } \\
\text { - medication } \\
\text { - illicit drugs }\end{array}$ & $\begin{array}{l}\text { - use } \\
\text { - abuse }\end{array}$ & \\
\hline $\begin{array}{l}\text { Emergency unit } \\
\text { of a general } \\
\text { hospital }\end{array}$ & $\begin{array}{l}\text { emergency } \\
\text { care }\end{array}$ & care & $\begin{array}{l}\text { location: within the treatment unit } \\
\text { total duration: } 1 \text { to } 3 \text { days } \\
\text { intensity: } 24 \text { hours } \\
\text { periodicity: daily } \\
\text { degree of protection: intensive protection } \\
\text { degree of urgency): immediate }\end{array}$ & $\begin{array}{l}\text { - alcohol } \\
\text { - illicit drugs } \\
\text { - physical health }\end{array}$ & - basic care & adults & $\begin{array}{l}\text { - alcohol } \\
\text { - medication } \\
\text { - illicit drugs }\end{array}$ & $\begin{array}{l}\text { - abuse } \\
\text { - dependence }\end{array}$ & \\
\hline $\begin{array}{l}\text { Medical-social care } \\
\text { centre }\end{array}$ & $\begin{array}{l}\text { substitution } \\
\text { treatment }\end{array}$ & counseling & $\begin{array}{l}\text { location: within the treatment unit } \\
\text { total duration: from } 3 \text { to } 6 \text { months to } \\
\text { more than } 2 \text { years } \\
\text { intensity: < } 30 \text { minutes } \\
\text { periodicity: daily } \\
\text { degree of protection: no supervision } \\
\text { degree of ungengy: within } 3 \text { days }\end{array}$ & $\begin{array}{l}\text { - illicit drugs } \\
\text { - physical health }\end{array}$ & $\begin{array}{l}- \text { control } \\
\text { - recovery }\end{array}$ & adults & - opiates & $\begin{array}{l}\text { - abuse } \\
\text { - dependence }\end{array}$ & \\
\hline $\begin{array}{l}\text { Therapeutic } \\
\text { community }\end{array}$ & $\begin{array}{l}\text { long-term } \\
\text { group } \\
\text { program }\end{array}$ & treatment & $\begin{array}{l}\text { location: within the treatment unit } \\
\text { totat luaration: } 1 \text { to } 2 \text { years } \\
\text { intensity: } 24 \text { hours } \\
\text { periodicity: daily } \\
\text { degree of protection: limited supervision } \\
\text { degree of ungengy: within a week }\end{array}$ & $\begin{array}{l}\text { - illicit drugs } \\
\text { - family, social } \\
\text { relations } \\
\text { - living situation }\end{array}$ & $\begin{array}{l}\text { - recovery } \\
\text { - relapse prevention }\end{array}$ & adults & $\begin{array}{l}\text { - alcohol } \\
\text { - medication } \\
\text { - illicit drugs }\end{array}$ & $\begin{array}{l}\text { - abuse } \\
\text { - dependence }\end{array}$ & $\begin{array}{l}\text { mothers with } \\
\text { children/pregnant } \\
\text { women }\end{array}$ \\
\hline $\begin{array}{l}\text { Day care clinic } \\
\text { of a psychiatric } \\
\text { hospital }\end{array}$ & $\begin{array}{l}\text { part-time } \\
\text { treatment }\end{array}$ & $\begin{array}{l}\text { psycho- } \\
\text { education }\end{array}$ & $\begin{array}{l}\text { location: within the treatment unit } \\
\text { total duration: } 3 \text { to } 6 \text { months } \\
\text { intensity: } 3 \text { hours } \\
\text { periodicity: several times a week } \\
\text { degree of protection: none } \\
\text { degree of urgengy: within a month }\end{array}$ & $\begin{array}{l}\text { - alcohol } \\
\text { - illicit drugs } \\
\text { - psychological } \\
\text { and emotional } \\
\text { problems } \\
\text { - leisure time }\end{array}$ & $\begin{array}{l}\text { - recovery } \\
\text { - relapse prevention }\end{array}$ & adults & $\begin{array}{l}\text { - alcohol } \\
\text { - medication } \\
\text { - illicit drugs }\end{array}$ & $\begin{array}{l}\text { - abuse } \\
\text { - dependence }\end{array}$ & $\begin{array}{l}\text { psychiatric } \\
\text { patients }\end{array}$ \\
\hline
\end{tabular}


THE INTEGRATION OF TREATMENT SYSTEMS FOR SUBSTANCE ABUSERS

Since much information is collected during this inventory, and since this is a timeconsuming activity for the treatment agencies involved, it should be determined at the start how data will be processed. Data processing must be set up to provide feedback to participating agencies. But, on the other hand, the ultimate goal should be taken into account: mapping available services, missing links, and duplications in the treatment services. In the province of East-Flanders, we used an adjusted version of the Spiller database for this purpose. This database was developed through the Collaboration of Psychiatric Services in Limburg [Samenwerking Psychiatrische Initiatieven Limburg (SPIL)], the regional board on mental health care in the province of Limburg, the university of Limburg [Limburgs Universitair Centrum (LUC)], and the Province of Limburg. This computerized database is based on the "new framework of concepts for mental health care" [Nieuw begrippenkader geestelijke gezondheidszorg] and allows - through a combination of the above-mentioned dimensions - a search of the services offered by treatment agencies inventoried. At the moment, the description of treatment services for substance abusers in East-Flanders is only available on CD-ROM, although we intend to use more accessible and flexible data carriers in the near future.

To be able to detect missing links and duplications in current treatment services, the information from the inventory needs to be confirmed formally by all treatment agencies involved and must be confronted with the theoretical model (cf. step 2) and empirical data about these treatment services. Based on this comparison, an action plan is elaborated that indicates whether certain modules need to be developed, deleted, or converted and whether it is necessary to cooperate for this purpose with another (level of the) integrated treatment system (Claeys \& Lievens, 2003). Matching available services to the needs and demands of the target group is not limited to a one-off event, since the network that manages the integrated treatment system is responsible for continuously monitoring whether treatment services respond to clients' needs and for eliminating missing or duplicated services (De Meulemeester et al., 1998).

\section{STEP 4: APPLYING AND IMPLEMENTING THE DEVELOPED MODEL}

The fourth step is without a doubt the most crucial and tangible step in the implementation process, since the theoretical preparations make room for the practical application of the model that has been developed. Authorities should sketch the general outlines for this implementation, but ultimately a bottom-up approach is needed for establishing an integrated treatment system (Vanderplasschen, Mostien et al., 2001). The proposed step-by-step plan should not be followed too strictly, since in practice certain steps will partly overlap or one may have to go back one or more steps (Claeys \& Lievens, 2003). After all, it is impossible to assess and discuss all aspects in advance, and sometimes the rules will have to be changed or determined during the implementation. 
If we assume that treatment trajectories provide an answer to the specific treatment demands of a target group (Nassen et al., 1999), the development of an integrated treatment system trajectory by trajectory is probably the most feasible strategy. One should start with a number of clearly defined, high-priority modules, which can be implemented and evaluated within a relatively short period of time (Vanderplasschen, Mostien, et al., 2001). Existing initiatives can be fit into such an integrated treatment system.

In order to establish concrete projects concerning "integrated treatment systems", authorities should create more openness and flexibility so that agencies and networks can prepare themselves for this innovation (Claeys \& Lievens, 2003). Pooling personnel and resources may be a good solution for preparing this transition (Claeys \& Lievens, 2003). Authorities can support networks that anticipate this innovation by providing financial resources for coordination and other expenses related to organizational shift. The complex and delicate character of this conversion requires pilot projects to evaluate the establishment of integrated treatment systems. Such projects should have a minimum duration of three to five years and leave room for experimentation (Claeys \& Lievens, 2003). Evaluation of these projects based on measurable indicators will be essential to verify if the objectives that were postulated have actually been realized. If this is the case, experiments can be further extended. If not, the project should be adjusted or, if necessary, discontinued.

The implementation of an integrated treatment system is preferable when all partners voluntarily sign an agreement of mutual cooperation to formalize their commitment (SAMHSA, 1998). Such a formal agreement was signed in the province of East-Flanders by most treatment agencies with specific services for substance abusers. The implementation process is facilitated by the appointment of a coordinator who closely follows the implementation and makes corrections, if necessary. The coordinator further supervises the agreements that were made, mediates conflicts, and monitors the data collection. A certain degree of standardization (e.g., procedures, protocols, and registration systems) is required in order to stimulate cooperation and communication between treatment agencies (Graham et al., 1995; SAMHSA, 1998). Exchange of information should always be based on clients' informed consent (Vanderplasschen et al., 2002). The coordinator consults with responsible persons from other sectors or integrated treatment systems and monitors the entry to and exit from this system, in order to guarantee its accessibility as well as to ensure that clients do not become disoriented in the integrated treatment system (Vanderplasschen, Mostien, et al., 2001). Ultimately, the coordinator monitors the overall quality of the services offered by the network. The establishment of an integrated treatment system may not lead to reduced availability or accessibility of services (e.g., waiting lists), which is a potential danger given the developments and experiences in the Netherlands and in the United States (Galanter et al., 2000; Wolf, 1995). 
THE INTEGRATION OF TREATMENT SYSTEMS FOR SUBSTANCE ABUSERS

\section{STEP 5: MONITORING AND EVALUATING THE IMPLEMENTED MODEL}

The final step evaluates whether the implemented model has additional value and leads to the postulated goals (Claeys \& Lievens, 2003; Vanderplasschen, Mostien, et al., 2001). Monitoring data give an indication about the degree to which the different modules are utilized, which are the most common treatment demands, and which evolutions can be observed concerning clients' functioning. Therefore, it is desirable to have a common, computerized monitoring system that allows the analysis of these data rapidly and accurately (de Weert-van Oene \& Schrijvers, 1992). It is recommended to collect qualitative data in addition to quantitative data (Broekaert et al., 2002), as these can provide insight into how professionals and clients evaluate the transition and how satisfied they are with the services delivered. For this purpose, organizing interviews and/or focus groups with several persons involved as well as filling out satisfaction questionnaires by clients, their social networks, and referring agencies are regarded to be adequate research methods (SAMHSA, 1998). Such monitoring and evaluation activities may lead to the adjustment of the treatment program or its organization and should be repeated regularly (Vanderplasschen, Mostien, et al., 2001).

\subsubsection{DISCUSSION AND CONCLUSION}

In this chapter, we have demonstrated that coordination of care and the establishment of integrated treatment systems for substance abusers are necessary for several reasons, especially due to some characteristics of the target group and the treatment system for this population. In the Netherlands, the establishment of integrated treatment systems, begun in the early 1990s, has led to the fusion of several specialized substance abuse treatment agencies in most big cities (e.g., Rotterdam, Amsterdam, the Hague), resulting in one large organization that provides services for substance abusers (de Weert-van Oene \& Schrijvers, 1992; Parnassia, 2003; Wolf, 1995). Available literature shows that the development of networks and integrated treatment systems can contribute to, among others, increased transparency of treatment services, avoidance of duplicated efforts, more efficient allocation of available resources, more individualized care and improved client satisfaction with services provided (de Weert-van Oene \& Schrijvers, 1992; Drake et al., 1997; Galanter et al., 2000; Parnassia, 2003; SAMHSA, 1998). On the

other hand, a number of obstacles have been identified: far-reaching formalization of care, fewer personal contacts between client and professional, longer waiting times, and cutbacks concerning expensive treatment modules. When establishing integrated treatment systems for substance abusers in Belgium, we should not make the same mistakes. 
Despite the advantages demonstrated and the faith of several caregivers and policymakers, the announced implementation of integrated treatment systems raises numerous questions and remarks. In several regions, especially in the French-speaking part of Belgium, this proposal elicits resistance both among practitioners and managers. These people are afraid that such reorganization would cause increased interference by the authorities, a restriction of the therapeutic freedom of the caregiver and freedom of choice for the client, and a health care system based on economic principles. In spite of this resistance, recent policy decisions unmistakably show an evolution towards networking and modulation (Aelvoet \& Vandenbroucke, 2001; FOD Volksgezondheid, 2002; Wet, 2002).

In order to meet some of the concerns of practitioners and to create a dialogue between the policy and practice level concerning the implementation process, it is recommended to anticipate top-down decisions and to prepare practitioners for the conversion of existing services towards integrated treatment systems. The step-by-step plan that has been described can be a directive for this implementation, but several bottlenecks and potential obstacles should be taken into account. Based on our own research and the available literature, these obstacles will be discussed.

\section{口 INSTITUTION-BASED ORGANIZATION OF TREATMENT}

The notion of integrated treatment systems and client-oriented care clashes with the current, institution-based organization of treatment (De Meulemeester et al., 1998; Nassen, 1999). Starting from this contrast, developing and implementing a common language and approach based on consensus will be difficult. Information and training will be necessary so that this unambiguous language can become commonly accepted. Moreover, the common approach should respect the identity and diversity of the different partners, but it should not remain too vague or general at the expense of its practical applicability (Vanderplasschen, Mostien, et al., 2001).

\section{a MOdUlation OF TREATMENT SERVICES}

The inventory of existing treatment services is intended to map all modules that are offered by one or more treatment agencies. Apparently, the treatment agencies that were inventoried agreed with the description of modules as it was initially conceptualized (cf. step 1), since none of the treatment agencies added other modules. Also, a limited number of categories were available to choose from to describe the other dimensions, which contributed to the uniformity of the information (cf. table 3.1.). On the other hand, the limited number of categories did not allow the mapping of specific aspects of the services offered. For example, although the inventory provides insight into the target groups that are addressed by a certain module, it does not show for whom this module is not or only exceptionally accessible (e.g., exclusion criteria). In order to analyze the availability of treatment services, it will also be necessary to map the capacity of each module. However, 
THE INTEGRATION OF TREATMENT SYSTEMS FOR SUBSTANCE ABUSERS

assessing the capacity of a treatment module is rather difficult because, within the current organization of care, the capacity ("beds") is linked with an architectonic or organizational unit and not with modules. Finally, the inventory has revealed that several treatment agencies try to fit all of their treatment activities into one of the modules in order to offer as many modules as possible, which is explained by the present-day "fee-for-service" funding system (Clark \& Fox, 1993; Maertens, 1997). However, the inventory of treatment services does not intend to relocate subsidies. Its primary objective is to map which treatment agencies offer which services for which target group and which aspects are missing or duplicated in the services offered (Vanderplasschen, Mostien, et al., 2001).

\section{a ASSESSING TREATMENT DEMAND}

For the realization of one of the basic principles of the re-organization of mental health care (clients' treatment demands), an objective measurement of the needs of this target group is assumed (Nassen, 2001). For this purpose, a combination of qualitative and quantitative research methods is required with a longitudinal design and a large, representative sample, including clients, their social network, treatment providers, subsidizing authorities, and policymakers. Furthermore, while mapping existing services and while assessing the postulated indicators, one may be confronted with methodological problems. Triangulation, a strategy from the qualitative research tradition, can help to realize maximal inter-subjectivity and to increase validity and reliability of the research, as this supposes that the research question is addressed by applying several data sources and methods (Swanborn, 1994).

\section{口 DIFFERENTIATION OF TREATMENT SERVICES}

The development of a specialized integrated treatment system for substance abusers contrasts with recent advice from an "ad hoc" working group regarding substance abuse treatment within the National Council of Hospital Facilities [Nationale Raad voor Ziekenhuisvoorzieningen (NRZV)] (NRZV, 2002). As opposed to other proposals and decisions (Aelvoet \& Vandenbroucke, 2001; FOD Volksgezondheid, 2002; NRZV, 1997; Wet, 2002), this working group suggested not to develop a separate and specialized integrated treatment system for substance abusers, but to integrate this in treatment programs for the traditional target groups: "children and adolescents", "adults", and "elderly". Indeed, the establishment of integrated treatment systems for specific target groups may not result in stigmatization. On the other hand, one might think that an all-encompassing integrated treatment system would become a ponderous system that lacks dynamism and flexibility. Also, for the following additional reasons, specialized services for substance abusers seems the most adequate choice: the growing complexity of drug problems (SAMHSA, 1998; Willenbring, 1996), stigmatization of substance abusers by health care and welfare centers due to manipulative and inappropriate behavior (Vanderplasschen et al., 2002), 
development of specific knowledge and "evidence-based" interventions (SAMHSA, 1998), and elaboration of trajectories for specific target groups or situations (Vanderplasschen, Mostien, et al., 2001). Moreover, we decided in favor of a specialized integrated treatment system in order to create comprehensive services for substance abusers in each region. During the experimental phase, the use of a specialized integrated treatment system for substance abusers needs to be tested and should be compared with advantages and disadvantages of a non-specialized integrated treatment system for the general target group "adults". Ultimately, it will be important to develop trajectories and modules across the boundaries of an integrated treatment system for substance abusers (e.g., for adolescents, dually diagnosed persons). Moreover, some modules (e.g., emergency care, orientation) and treatment functions (e.g., psycho-education, activation) should be jointly organized for several target groups.

\section{a PRECONDITIONS FOR IMPLEMENTATION}

During the implementation process a number of preconditions can be formulated. First, finalizing the first three steps should not be delayed before implementing the theoretical model. It is recommended to complete this step-by-step plan in close

collaboration with all partners involved. One should start with the content-related aspects of an integrated treatment system, and then move on to the organizational aspects; otherwise, one might get stuck in practical and administrative arrangements (Vanderplasschen, Mostien et al., 2001). Moreover, improvements concerning the content of treatment can strengthen the trust between participating parties, which facilitates such administrative arrangements. Flexibility is required when implementing the action plan, which means that treatment agencies can be involved in the integrated system for a limited number of modules or can quit when they choose to (Claeys \& Lievens, 2003). Too many partners in the network may be counterproductive. Finally, sufficient availability of treatment services and some room for experiments are important preconditions.

\section{口 DYNAMICS OF THE SYSTEM}

The metaphor of a "system" suggests closeness and lack of dynamics, which contrasts with the idea of an integrated treatment system as a dynamic concept that needs to be monitored and adjusted on a regular basis (Vanderplasschen, Mostien, et al., 2001). Therefore, an integrated treatment system will never be "finished". Depending on the needs and demands in the region, specific modules or trajectories will need to be adjusted, added, or deleted. Ultimately, the dynamism of an integrated treatment system should be clear to the clients themselves: the services offered are a client-oriented response of the network of treatment agencies to every treatment demand of individuals in a specific region. 
With this systematic overview of five steps that should be taken when implementing an integrated treatment system, we have attempted to outline how the establishment of an integrated treatment system can be realized. However, theoretical preparations and hypotheses will have to make room for the practical elaboration, in order to assess the feasibility of integrated treatment systems for substance abusers. Monitoring and evaluating this process is required, based on quantitative and qualitative indicators, to test whether the establishment of integrated treatment systems is an adequate method for more and better coordination of care in substance abuse treatment.

ACKNOWLEDGEMENTS. We would like to thank all practitioners, directors, policymakers and researchers who have contributed in one way or another to the realization of the "Conceptualization of the organization of an integrated treatment system for substance abusers" [Conceptnota organisatiemodel zorgcircuit middelenmisbruike]. In particular, we would like to thank Veerle Raes (De Sleutel), a co-author of this publication. Furthermore, we express our thanks to everyone who has participated in the discussions concerning networking in substance abuse treatment in the province of East-Flanders and/or contributed to a number of realizations in this area (e.g., Spiller inventory, implementation of case management and care coordination, cooperation agreement between substance abuse treatment agencies). 


\section{REFERENCES}

Aelvoet, M., \& Vandenbroucke, F. (2001). De psyche: mij een zorg?! Geestelijke gezondheidszorg door participatie en overleg. Brussel: Ministerie van Volksgezondheid, Consumentenzaken en Leefmilieu.

American Psychiatric Association (APA). (1996). DSM-IV: Diagnostic and statistical manual of mental disorders (fourth edition). Washington: American Psychiatric Association.

Brindis, C.D., \& Theidon, K.S. (1997). The role of case management in substance abuse treatment services for women and their children. Journal of Psychoactive Drugs, 29(1), 79-88.

Broekaert, E., \& Vanderplasschen, W. (2003). Towards an integrated treatment system for substance abusers: report on the second international symposium on substance abuse treatment and special target groups. Journal of Psychoactive Drugs, 35(2), 237-245.

Broekaert, E., Vandevelde, S., Vanderplasschen, W., Soyez, V., \& Poppe, A. (2002). Two decades of "research-practice" encounters in the development of European therapeutic communities for substance abusers. Nordic Journal of Psychiatry, 56, 371-377.

Claeys, P., \& Lievens, K. (2003). Zorgcircuits st(r)ikken in netwerken: ervaringen en dromen vanuit een overlegplatform geestelijke gezondheidszorg. Psychiatrie en Verpleging: Tijdschrift voor hulpverleners in de geestelijke gezondheidszorg, 79(4), 210-232.

Clark, R.E., \& Fox, T.S. (1993). A framework for evaluating the economic impact of case management. Hospital and Community Psychiatry, 44(5), 469-473.

De Meulemeester, P., Molenberghs, G., Nassen, E., \& Bellings, P. (1998). Een pragmatisch en patiëntgericht raamkader voor de geestelijke gezondheidszorg. Acta Hospitalia, 38(3), 29-44.

De Ruyver, B., \& Casselman, J. (2000). Het Belgisch drugbeleid anno 2000: een stand van zaken drie jaar na de anbevelingen van de parlementaire werkgroep drugs. Leuven - Ghent: Katholieke Universiteit Leuven, Onderzoeksgroep Gerechtelijke Geestelijke Gezondheidszorg - Universiteit Gent, Onderzoeksgroep Drugbeleid, Strafrechtelijk Beleid en Internationale Criminaliteit.

de Weert-van Oene, G., \& Schrijvers, A. (1992). Van lappendeken naar zorgcircuit: circuitvorming in de Utrechtse verslavingszorg. Utrecht: Rijksuniversiteit Utrecht, Vakgroep Algemene Gezondheidszorg en Epidemiologie.

DiNitto, D.M., Webb, D., \& Rubin, A. (2002). The effectiveness of an integrated treatment approach for clients with dual diagnoses. Research on Social Work Practice, 12(5), 621-641.

Drake, R.E., Mercer-McFadden, C., Mueser, K.T., McHugo, G.J., \& Bond, G.R. (1998). Review of integrated mental health and substance abuse. Schizophrenia Bulletin, 24(4), 589-608.

Drake, R.E., Yovetich, N.A., Bebout, R.R., Harris, M., \& McHugo, G.J. (1997). Integrated treatment for dually diagnosed homeless adults. Journal of Nervous and Mental Disease, 185(5), 298-305.

Federale Regering. (2001). Beleidsnota van de federale regering in verband met de drugproblematiek. Brussel: Federale regering.

FOD Volksgezondheid, Veiligheid van de Voedselketen en Leefmilieu. (2002). Implementatie van de functie zorgcoördinator binnen de overlegplatforms geestelijke gezondheidszorg met betrek.king tot de behandeling van personen met een middelengerelateerde stoornis (niet-gepubliceerde 
THE INTEGRATION OF TREATMENT SYSTEMS FOR SUBSTANCE ABUSERS

samenwerkingsovereenkomst). Brussel: Directoraat-generaal Organisatie Gezondheidsvoorzieningen, Dienst Geestelijke Gezondheidszorg, Cel Gezondheidszorg Drugs.

Galanter, M., Keller, D., Dermatis, H., \& Egelko, S. (2000). The impact of managed care on substance abuse treatment: A report of the American Society of Addiction Medicine. Journal of Addictive Diseases, 19(3), 13-34.

Graham, K., Timney, C., Bois, C., \& Wedgerfield, K. (1995). Continuity of care in addictions treatment: the role of advocacy and coordination in case management. American Journal of Drug and Alcohol Abuse, 21(4), 433-451.

Greenbaum, T. (2000). Moderating focus groups: a practical guide for group facilitation. Thousand Oaks: Sage.

Hendriks, V., Kaplan, C.D., van Limbeek, J., \& Geerlings, P. (1989). The Addiction Severity Index: Reliability and validity in a Dutch addict population. Journal of Substance Abuse Treatment, 6(2), 133-141.

Knapen, J., \& Van Holsbeke, J. (1997). Een masterplan voor de organisatie en inhoudelijke vernieuwing van de geestelijke gezondheidszorg. Situering van en toelichting bij twee adviezen van de nationale raad voor ziekenhuisvoorzieningen. Hospitalia, 41(4), 148-154.

Koller, E. (1999). The policy-maker's perspective. In European Monitoring Centre for Drugs and Drug Addiction (EMCDDA) (Eds.), Evaluating the Treatment of Drug Abuse in the European Union (EMCDDA Scientific Monograph Series No3) (pp. 79-84). Luxembourg: Office for Official publications of the European Communities.

Maertens, J. (1997). Opbouwen van een zorgcircuit toxicomanie: een probleem zo groot als het werkveld. Hospitalia, 41(4), 171-180.

Minkoff, K. (2000). An integrated model for the management of co-occurring psychiatric and substance disorders in managed-care systems. Disease Management \& Health Outcomes, 8(5), 251-257.

Nassen, E. (1999). Nieuwe begrippen voor een nieuwe toekomst van de geestelijke gezondheidszorg. Hospitalia, 43(3), 111-124.

Nassen, E. (2001). Tien stappen in de concretisering van een nieuw begrippenkader voor de geestelijke gezondheidszorg. Tijdschrift voor Klinische Psychologie, 31(1), 37-48.

Nassen, E., Theunis, K., Du Laing, L., \& Van Holsbeke, J. (1999). Nieun beschrijvend begrippenkader Geestelijke gezondheidszorg. Brussel: Licap.

Nationale Raad voor Ziekenhuisvoorzieningen (NRZV). (1997). Advies (2 ${ }^{\text {de }}$ deel) van de permanente werkgroep "psychiatrie" inzake toekomstige organisatie en ontwikkeling van de geestelijke gezondheidszorg. Brussel: Ministerie van Sociale Zaken, Volksgezondheid en Leefmilieu, Bestuur Gezondheidszorg, Nationale Raad voor Ziekenhuisvoorzieningen.

Nationale Raad voor Ziekenhuisvoorzieningen (NRZV). (2002). Advies betreffende de opvang van verslaafden. Brussel: Ministerie van Sociale Zaken, Volksgezondheid en Leefmilieu, Bestuur Gezondheidszorg, Nationale Raad voor Ziekenhuisvoorzieningen.

Öberg, D., Gerdner, A., Sallmén, B., Jansson, I., \& Segraeus, V. (2000). Monitoring Area Phase System - Unit (unpublished questionnaire). Stockholm: National Board of Institutional Care (SiS). 
Oliva, H., Görgen, W., Schlanstedt, G., Schu, M., \& Sommer, L. (2001). Case management in der Suchtkranken- und Drogenhilfe: Ergebnisse des Kooperationsmodells nachgehende Sozialarbeit Modellbestandteil Case management, Berichtsұeitraum 1995-2000. Köln: Fogs, Gesellschaft für Forschung und Beratung in Gesundheits- und Sozialbereich $\mathrm{mbH}$.

Parnassia. (2003). Bedrijfsplan Parnassia 2002-2003 (unpublished business plan). Retrieved July 23, 2003, from http://www.parnassia.nl/algemeen/bedrijfsplan/.

Prochaska, J., DiClemente, C., \& Norcross, J. (1992). In search of how people change: applications to addictive behaviors. American Psychologist, 47(9), 1102-14.

Raes, V., Lenders, F., \& Geirnaert, M. (1995). Drughulpverlening in Vlaanderen: Feiten en problemen. Brussel: Vereniging voor Alcohol- en andere Drugproblemen.

Rapp, R. C., Siegal, H. A., Li, L., \& Saha, P. (1998). Predicting post-primary treatment services and drug use outcome: A multivariate analysis. American Journal of Drug and Alcohol Abuse, 24(4), 603-615.

Scott, C., \& Foss, M. (2002). Impact of centralized intake on drug and alcohol treatment placement decisions. Journal of Psychoactive Drugs, 34(1), 7-15.

Sears, C., Davis, T., \& Guydish, J. (2002). Effects of treatment history and centralized intake on drug treatment outcomes. Journal of Psychoactive Drugs, 34(1), 87-95.

Siegal, H., Rapp, R., Li, L., Saha, P., \& Kirk, K. (1997). The role of case management in retaining clients in substance abuse treatment: an exploratory analysis. Journal of Drug Issues, 27(4), 821 831.

Substance Abuse and Mental Health Services Administration (SAMHSA). (1998). Comprehensive case management for substance abuse treatment, TIP Series 27. Rockville: U.S. Department of health and human services, Public Health Service, Substance Abuse and Mental Health Services Administration, Center for Substance Abuse Treatment.

Swanborn, P.G. (1994). Methoden van sociaal-wetenschappelijk onderzoek. Boom: Meppel-Amsterdam.

van Achterberg, T., Stevens, F., Hekkink, M., Crebolder, H., \& Philipsen, H. (1995). Implementing coordination of care: task performance and problems encountered. Scandinavian Journal of Caring Sciences, 9(4), 209-217.

Vanderplasschen, W., De Bourdeaudhuij, I., \& Van Oost, P. (1999). Eindrapport onderzoeksproject case management in de Oost-Vlaamse drughulpverlening (unpublished research report). Gent: Universiteit Gent, Vakgroep Gedragstherapie en Psychologische begeleiding.

Vanderplasschen, W., De Bourdeaudhuij, I., \& Van Oost, P. (2002). Coordination and continuity of care in substance abuse treatment: an evaluation-study in Belgium. European Addiction Research, 8, 10-21.

Vanderplasschen, W., Lievens, K., \& Broekaert, E. (2001). De instroom in de Oost-Vlaamse drughulpverlening: registratie van intakes en aanmeldingen tussen oktober 1999 en mei 2000 (Orthopedagogische Reeks Gent Nummer 13). Gent: Universiteit Gent, Vakgroep Orthopedagogiek.

Vanderplasschen, W., Lievens, K., \& Broekaert, E. (2001). Implementatie van een methodiek van case management in de drughulpverlening: een proefproject in de provincie Oost-Vlaanderen (Orthopedagogische Reeks Gent Nummer 14). Gent: Universiteit Gent, Vakgroep Orthopedagogiek. 
THE INTEGRATION OF TREATMENT SYSTEMS FOR SUBSTANCE ABUSERS

Vanderplasschen, W., Mostien, B., Claeys, P., Raes, V., \& Van Bouchaute, J. (2001). Conceptnota organisatiemodel zorgcircuit middelenmisbruik (Orthopedagogische Reeks 12). Ghent, Belgium: Ghent University, Department of Orthopedagogics.

Vaughn, T., Sarrazin, M.V., Saleh, S.S., Huber, D.L., \& Hall, J.A. (2002). Participation and retention in drug abuse treatment services research. Journal of Substance Abuse Treatment, 23(4), 387-397.

Vereniging voor Alcohol- en andere Drugproblemen (VAD). (2001). Visietekst Zorgcircuit 'Problematisch middelengebruik'. Brussel: Vereniging voor Alcohol- en andere Drugproblemen.

Wet houdende maatregelen inzake gezondheidszorg (2002, 14 januari). Belgisch Staatsblad 22/2/2002; 172(61): 6777-6797.

Willenbring, M. (1996). Case management applications in substance use disorders. In H. Siegal, \& R. Rapp (Eds.), Case management and substance abuse treatment: practice and experience (pp. 51-76). New York: Springer Publishing Company.

Wolf, J. (1995). Zorgvernieuning in de GGZ: Evaluatie van achttien zorgvernieuningsprojecten. Utrecht: Nederlands Centrum Geestelijke Volksgezondheid. 



\title{
Chapter 4
}

\section{Comparative review of the development and implementation of case management for substance use disorders in North America and Europe ${ }^{5}$}

\begin{abstract}
Case management has been adapted to work with persons with substance use disorders in several countries, expecting a positive impact on treatment participation and retention, the coordination of services and drug-related outcomes. As deliberate implementation has been identified as a powerful determinant of successful case management, this paper focuses on six key questions concerning implementation and applies a comparative perspective (based on experiences from the United States, the Netherlands and Belgium). First, we look at the motives, objectives and target populations of this intervention. Second, the integration of case management in the system of services is studied. Third, four distinct models, their core features and effects are reviewed. Fourth, skills and qualifications of case managers and essential support they need are highlighted. Fifth, funding and continuity of programs are discussed. Finally, we focus on adequate evaluation methods and aspects of case management that require further research.
\end{abstract}

5 This chapter is based on: Vanderplasschen, W., Rapp, R.C., Wolf, J., \& Broekaert, E. (in press). Comparative review of the development and implementation of case management for substance use disorders in North America and Europe. Psychiatric Services (accepted for publication, May 13, 2004). 



\subsection{INTRODUCTION}

Case management is regarded to be one of the most important innovations in mental health and community care of the last decade (Holloway \& Carson, 2001). It is a clientcentered strategy to improve coordination and continuity of care, especially for persons with multiple needs (Moxley, 1989). Regardless the controversy whether, in what form(s) and to what extent case management is effective, this intervention has a long history for the treatment of several mental health populations in the United States, Australia, Canada and several European countries (Burns, Fioritti, Holloway, Malm, \& Rossler, 2001; Erdmann \& Wilson, 2001; Rochefort \& Goering, 1998; Rosen \& Teesson, 2001; Ziguras \& Stuart, 2000).

From the 1980s onwards, case management was adapted to work with persons with substance use disorders (Graham \& Birchmore-Timney, 1990; Ogborne \& Rush, 1983; Rush \& Ekdahl, 1990), as this problem became increasingly recognized as a multi-faceted, chronic and relapsing disorder requiring a comprehensive and continuous approach (Brindis \& Theidon, 1997; McLellan, 2002). Although modeled after mental health examples, case management for substance abusers was developed rather separately, illustrating the - originally strong - distinction between mental health care and substance abuse treatment in several countries (Ridgely \& Jerrell, 1996; SAMHSA, 1998; Broekaert \& Vanderplasschen, 2003). Lightfoot and colleagues (1982) were the first to show that this intervention could reduce attrition from treatment and improve both psychosocial and drug and alcohol outcomes among substance abusers. Since the 1990s, hundreds of programs in Canada and the United States and some in Europe (e.g., Germany, the Netherlands, and Belgium) have implemented case management (EMCDDA, 2001; SAMHSA, 1998), expecting a positive impact on treatment participation and retention, the coordination of services and drug-related outcomes. The increased need for case management has been attributed to the growing complexity of individuals' problems and systems of care (Brindis \& Theidon, 1997; Willenbring, 1996).

Despite its widespread application and popularity, case management is not unanimously defined and its practice varies from place to place due to diverging objectives, distinct target populations, program and system variables, and other immediate local concerns (Ridgely, 1996; Ridgely \& Willenbring, 1992; Wolf, Mensink, \& van der Lubbe, 2002). One of the first definitions described this intervention as "that part of substance abuse treatment that provides ongoing supportive care to clients and facilitates linking with appropriate helping resources in the community" (Birchmore-Timney \& Graham, 1989). A more accurate way to characterize this intervention is postulating its basic functions: assessment, planning, linking, monitoring and advocacy (SAMHSA, 1998). Further, some broad principles are true of almost every application: community-based, client-driven, pragmatic, flexible, anticipatory, culturally sensitive and offering a single point of contact. 
As deliberate conceptualization and implementation have been identified as powerful determinants of successful practice and outcomes (Burns et al., 2001; Inciardi, Martin, Butzin, Hooper, \& Harrison, 1996; Jerrell \& Ridgely, 1999; Perl \& Jacobs, 1992; Wolf et al., 2002), we made a comparative review of available literature focusing on issues concerning the implementation of case management for substance use disorders. The goal of this review is to provide insight into some of the "do's" and "don'ts" when developing this intervention as can be derived from the experiences in North America (the United States) and Europe (the Netherlands and Belgium), loosely representing three points on a continuum. This comparison started from exploring similarities and dissimilarities between the selected countries during a workshop concerning case management at the "Third International Symposium on Substance Abuse Treatment and Special Target Groups" (Blankenberge, Belgium, March 5-6, 2001) (Broekaert, Vandevelde, Vanderplasschen, Soyez, \& Poppe, 2002). Discussions between researchers from these countries led to the joint identification of six key questions, which are elaborated in this article, based on available literature and empirical evidence. Information was accessed through repeated searches in Medline, Psyclit and the Web of Science.

\subsection{KEY QUESTIONS CONCERNING THE IMPLEMENTATION OF CASE MANAGEMENT}

\section{- WHICH PROBLEMS ARE ADDRESSED WITH CASE MANAGEMENT AND WHAT ARE THE OBJECTIVES AND TARGET GROUP OF THIS INTERVENTION?}

The observation that many substance abusers have significant problems in addition to abusing substances has been the main impetus for using case management as an enhancement and supplement to substance abuse treatment (Oppenheimer, Sheehan, \& Taylor, 1988; Sullivan, Hartmann, Dillon, \& Wolk, 1994; Vanderplasschen, De Bourdeaudhuij, \& Van Oost, 2002; Westermeyer, 1989; Wolf \& Planije, 2002). In the United States, the paucity and selective accessibility of available services, shortcomings in the overall quality of service delivery (accountability, continuity, comprehensiveness, coordination, effectiveness, efficiency) and cost containment were further incentives for implementing this intervention (Hall, Carswell, Walsh, Huber, \& Jampoler, 2002; SAMHSA, 1998; Ridgely \& Willenbring, 1992; Willenbring, 1996). Its implementation in the Netherlands was not merely driven by economic concerns, but rather by the poor quality of life of many chronic addicts and the nuisance they cause in city centers (Wolf \& Planije, 2002). In Belgium, the chronic and complex problems of many substance abusers and the lack of coordination and continuity of care were the main reasons for introducing case management (Vanderplasschen et al., 2002). 
Unlike in the United States, where hundreds of programs and government units have implemented case management since the early 1990s, this intervention has not been applied as widely among substance abusers in Europe. This was due to, among others, higher availability and accessibility of services, less stress on cost containment and conflicting outcomes concerning the effectiveness of case management for mentally ill persons. However, recent reforms in substance abuse treatment (e.g., in the Netherlands, Germany, and Belgium) have shifted the focus towards accessibility, continuity, costeffectiveness and efficiency and stimulated the interest in case management (Broekaert \& Vanderplasschen, 2003; De Weert-van Oene \& Schrijvers, 1992; Oliva, Görgen, Schlanstedt, Schu, \& Sommer, 2001). Since 1995, more than 50 projects have been developed in the Netherlands that make use of this intervention (Wolf \& Planije, 2002), while the number of case management projects for this population in Belgium is limited to 5 or 10 (Vanderplasschen, 2002).

In the United States, case management has been implemented successfully for enhancing treatment participation and retention among substance abusers in general (McLellan et al,, 1999; Saleh et al., 2002; Shwartz, Baker, Mulvey, \& Plough, 1997; Siegal, Rapp, Li, Saha, \& Kirk, 1997) and for populations with multiple needs experiencing specific barriers in accessing or keeping in touch with services, such as pregnant women, mothers, adolescents, chronic public inebriates, dually diagnosed and HIV-infected persons (Braucht et al., 1995; Brindis \& Theidon, 1997; Drake \& Noordsey, 1994; Godley, Godley, Pratt, \& Wallace, 1994; Laken \& Ager, 1996; Sorensen et al., 2003; Willenbring, Whelan, Dahlquist, \& O'Neal, 1990). Most of these programs intend to promote abstinence, while European programs rather apply a harm reduction perspective. In the Netherlands, the implementation of case management has mainly been directed at severely addicted persons (e.g., street prostitutes, mothers with young children, homeless and dually diagnosed persons), who are frequently not (adequately) served by existing services. Evaluation of this intervention among treatment providers has shown that case management contributes to the stabilization of these persons' situation (Broër \& Noyon, 1999). In Belgium, case management has been reserved for substance abusers with multiple and complex problems and several previous treatment episodes, resulting in improved client outcomes and coordination of service delivery (Vanderplasschen, Lievens, \& Broekaert, 2001).

Target populations may also include substance abusers involved in the criminal justice system (e.g., the United States and the Netherlands), which has been associated with reduced drug use and recidivism and with increased service utilization, but uncertainty remains about the differential effect of coercion in case management (Cook, 1992; De Koning \& Hessing, 2000; Martin \& Scarpitti, 1993; Rhodes \& Gross, 1996; Van Stelle, Mauser, \& Moberg, 1994). This intervention has further often been utilized to address "the most problematic clients". The choice for this population has been related to adverse outcomes in the field of mental health care (Burns et al., 2001), while various studies 
among substance abusers have shown cost-effectiveness and beneficial outcomes (Bearman, Claydon, Kincheloe, \& Lodise, 1997; Cox et al., 1998; Jerrell, 1996; Jerrell, Hu, \& Ridgely, 1994; Lightfoot et al., 1982; Okin et al., 2000). Still, several authors have reported practical problems e.g., the difficulty of long-term planning, increased risk of burnout among case managers, and clients becoming totally dependent on their case manager (Bearman et al., 1997; Vanderplasschen et al., 2001; Wolf et al., 2002; Yates \& Gilman, 1990).

An overview of recently (1997-2003) published peer-reviewed studies concerning case management reveals that this intervention has been relatively successful for achieving several of the postulated goals (cf. table 4.1., pp. 129-131). Almost all outcome studies have been conducted in the United States, while similar studies are still forthcoming in Europe. We chose to restrict this overview to studies that have included at least 100 substance abusers, as such studies have more statistical power and also allow detecting small or modest effects (Orwin, Sonnefeld, Garrison-Mogren, \& Smith, 1994). Several uncontrolled studies have shown significant improvements among case managed-clients when compared with baseline assessments (Evenson, Binner, Cho, Schicht, \& Topolski, 1998; Levy, Strenski, \& Amick, 1995; Oliva et al., 2001; Shwartz et al., 1997; Vanderplasschen et al., 2001). In addition, some randomized and controlled studies have demonstrated significant increases in treatment access, participation and retention or service utilization compared with clients receiving standard treatment (Conrad et al., 1998; Godley, Godley, Dennis, Funk, \& Passetti, 2002; McLellan et al., 1999; Mejta, Bokos, Mickenberg, Maslar, \& Senay, 1997; Rapp, Siegal, Li, \& Saha, 1998; Scott, Sherman, Foss, Godley, \& Hristova, 2002; Siegal, Li, \& Rapp, 2002; Siegal et al., 1997; Vaughan-Sarrazin, Hall, \& Rick, 2000). Effects of case management concerning drug-related outcomes are still conflicting, but generally indicate moderate improvements for the case management group (Drake et al., 1998; Huber, Sarrazin, Vaughn, \& Hall, 2003; Mejta, Bokos, Mickenberg et al., 1997; Okin et al., 2000; Sarrazin, Huber, \& Hall, 2001). However, effects tend to decline over time (after 9 to 12 months) (Conrad et al., 1998; Saleh et al., 2002) and often do not differ significantly from these of similar control interventions (e.g., behavioral skills training, other models of case management) (Ridgely \& Jerrell, 1996; Sarrazin et al., 2001; Sorensen et al., 2003; Vaughan-Sarrazin et al., 2000).

\section{- WHAT IS THE POSITION OF CASE MANAGEMENT IN THE SYSTEM OF SERVICES AND HOW CAN THE COOPERATION AND COORDINATION BETWEEN SERVICES BE ENHANCED?}

Several authors have argued that the success of case management largely depends on its integration in a comprehensive network of services (Ashery, 1996; Graham \& Birchmore-Timney, 1990; Graham, Timney, Bois, \& Wedgerfield, 1995; Kirby \& Braucht, 1993; Wolf et al., 2002). This intervention risks being just one more of the fragmented 
pieces of the system of services, if it is not exquisitely sensitive to potential system-related barriers such as waiting lists, inconsistent diagnoses, opposing views, and lack of housing and transportation (Godley et al., 2000). McLellan and colleagues (1999) found no effects of case management 12 months after implementation, but did so after 26 months. They concluded there was a strong influence of various system variables (e.g., program fidelity, availability and accessibility of services) and recommended extensive training and supervision to foster collaboration and pre-contracting of services to ascertain their availability. Access to treatment can be markedly improved when case managers have funds with which to pay for treatment (Mejta, Bokos, Mickenberg et al., 1997). In addition, formal agreements and protocols are needed concerning tasks, responsibilities and authorities of case managers and other services involved, the use of common assessment and planning tools, and exchange and management of client information (Mejta, Bokos, Maslar, Mickenberg, \& Senay, 1997; Ridgely \& Jerrell, 1996; SAMHSA, 1998; Wolf et al., 2002; Yates \& Gilman, 1990).

Case management can be implemented as a module provided by or attached to a specific organization (e.g., hospital, detoxification center) or as a specific service organized together by several providers to link clients to other services. The former program structure has been widely applied in the United States for enhancing participation and retention and reducing relapse, while the latter is frequently utilized in Belgium and the Netherlands to address populations at risk of falling through the cracks of the system. Vaughn-Sarrazin and colleagues (2000) studied the differential impact of programs' location and compared the effectiveness of 3 types of case management with a control condition. The variant with case managers housed inside the facility led to significantly higher service utilization as opposed to the other conditions, which suggests that the accessibility and availability of case management programs mediate their success.

\section{- What MODEL OF CASE MANAGEMENT SHOULD BE UTILIZED AND WHICH ARE CRUCIAL ASPECTS OF EFFECTIVE CASE MANAGEMENT?}

Although most practical examples only vaguely resemble the pure version of a model, four models of case management are usually distinguished for working with substance use disorders: the brokerage/generalist model, strengths perspective, assertive community treatment/intensive case management and clinical case management (Ridgely \& Willenbring, 1992; SAMHSA, 1998). Selection of a model should be dictated by what services are already available, the objectives and target population, and, if any, empirical evidence.

Assertive Community Treatment and especially intensive case management, with their focus on a comprehensive (team) approach and providing assertive outreach and direct counseling services, have been utilized for reintegrating incarcerated offenders in the United States, among others. A randomized study of 135 parolees, half of them receiving 
case management, showed little effect concerning drug use but some improvement was found concerning risk behavior and recidivism (Inciardi et al., 1996). Random assignment to intensive case management compared to two other interventions, resulted in a decline in drug use and criminal involvement and increased treatment participation among almost 1400 arrestees (Rhodes \& Gross, 1996). In Belgium and the Netherlands, intensive case management has been the predominant model and it is associated with the provision of more comprehensive and individualized services and improved outcomes (Vanderplasschen et al., 2001; Wolf and Planije, 2002).

Two large NIDA-sponsored studies in Dayton, Ohio and Iowa have applied strengthsbased case management among substance abusers entering initial treatment (cf. table 4.1.). The former study found evidence for improved employment functioning and enhanced retention, in turn positively affecting outcomes concerning drug use and criminal involvement (Rapp et al., 1998; Siegal et al., 1996; Siegal et al., 1995; Siegal et al., 2002; Siegal et al., 1997). According to clients, retention was promoted by the client-driven nature of goal setting and facilitated by case managers' assistance in teaching clients how to set goals (Brun \& Rapp, 2001). The Iowa study showed an impact on utilization of substance abuse and medical services and moderate, but fading effects concerning legal, employment, and psychiatric problems (Hall et al., 2002; Huber et al., 2003; Saleh et al., 2002; Sarrazin et al., 2001; Vaughan-Sarrazin et al., 2000).

Brokerage models and other brief approaches to case management have usually failed to find any discernable benefits of this intervention compared to non-case managed control groups (Falck, Siegal, \& Carlson, 1992; Lidz, Bux, Platt, \& Iguchi, 1992). However, recent studies have shown a positive impact on service utilization and access to treatment and equal effectiveness compared with intensive case management (Scott et al., 2002; Sorensen et al., 2003). Generalist or standard case management has been associated with a significant positive influence on treatment participation and retention and relapse (Mejta, Bokos, Mickenberg et al., 1997; Shwartz et al., 1997). Clinical case management, which combines resource acquisition and clinical activities, has rarely been applied among substance abusers, but was successful in at least one study (McLellan et al., 1999). Others have stated that combining the role of counselor and case manager is problematic, since it dilutes both aspects of the program (Inciardi et al., 1996).

After all, as opposed to case management for mentally ill persons (Barry, Zeber, Blow, \& Valenstein, 2003; Burns et al., 2001; Teague, Bond, \& Drake, 1998; Ziguras \& Stuart, 2000), little information is available concerning crucial features of distinct models and their effectiveness for specific substance abusing populations. 


\section{- WHICH QUALIFICATIONS AND SKILLS SHOULD CASE MANAGERS HAVE AND WHICH SUPPORT SHOULD BE PROVIDED?}

Several authors assume that previous work experience, extensive training, knowledge about the health care and social welfare system, and communication and interpersonal skills are at least as important as formal qualifications or degrees (Oliva et al., 2001; SAMHSA, 1998; Wolf \& Planije, 2002). Only some programs have involved recovered addicts as case managers (Levy, Gallmeier, Weddington, \& Wiebel, 1992), but no information is available concerning the differential impact of case management by professionals or peers. The client-case manager relationship has been identified as crucial for promoting case management participation and related outcomes and the application of a strength-based approach can stimulate clients' involvement (Brun \& Rapp, 2001; Oliva et al., 2001; Siegal et al., 1995; Vanderplasschen et al., 2001).

Analyses of case management activities and program fidelity have shown large variations among case managers, not only within, but also across programs (Huber et al., 2003; Jerrell \& Ridgely, 1999; Ridgely \& Jerrell, 1996; SAMHSA, 1998; Shwartz et al., 1997; Sorensen et al., 2003). Poor program fidelity has been associated with worse outcomes and can be optimized by extensive initial training, regular supervision, administrative support, application of protocols and manuals, treatment planning and a team approach (Jerrell \& Ridgely, 1999; McLellan et al., 1999; Ridgely \& Jerrell, 1996). Variety across programs has resulted in attempts to standardize and guide this practice in the United States, quickly approaching the degree of sanctioned legitimacy. The National Association of Alcoholism and Drug Abuse identified case management as one of eight counseling skills and the commonly cited case management functions have been incorporated into the referral and service coordination practice dimensions of the Addiction Counseling Competencies (California Addiction Technology Transfer Center, 1997; NAADAC, 1986). In the Netherlands, a Delphi study was organized to reach a broad consensus concerning the core features of this intervention, resulting in a manual that will serve as a touchstone for future development, implementation and evaluation of case management (Ontwikkelcentrum Sociaal Verslavingsbeleid, 2003; Wolf \& Planije, 2002). The Delphi method comprises a series of questionnaires sent to a pre-selected group of experts (e.g., clients, case managers, and program directors), who respond to the problems posed individually and who are enabled to refine their views as the group's work progresses (Fiander \& Burns, 2000). It is believed that the group will converge toward the best response through this consensus process, based on structuring of the information flow and feedback to the participants.

Case managers' caseloads vary, but usually do not exceed 15 to 20 clients when providing intensive contacts to substance abusers with multiple and complex problems (Cox et al., 1998; Godley et al., 1994; Oliva et al., 2001; Ridgely \& Jerrell, 1996; Wolf et al., 2002). A team-approach helps to deal with large and difficult caseloads, but also to extend 
availability and guarantee case managers' safety (Oliva et al., 2001; Wingerson \& Ries, 1999). Only some studies have focused on the impact of high versus low caseloads and results are conflicting. As for mental health case management, some have found no effect of the intensity of this intervention (Burns et al., 2001; Shwartz et al., 1997; Sorensen et al., 2003), while others have related higher case management dosage with improved or even adverse outcomes (Huber et al., 2003; Oliva et al., 2001).

\section{- HOW SHOULD CASE MANAGEMENT PROJECTS BEST BE FINANCED AND HOW CAN ITS CONTINUITY BE GUARANTEED?}

The burgeoning interest in managed care financing structures has caused an explosive growth of case management initiatives in the US in the 1990s (Hall et al., 2002). Most programs have been set up as experiments, but - despite positive results - only some have been integrated on a long-term basis into the system of services. On the other hand, case management programs in the Netherlands became part of the system of services, shortly after their implementation and without any indication about its effectiveness (Wolf \& Planije, 2002). Both observations illustrate that continued funding might be predicted on issues that have little or nothing to do with success or failure of the intervention itself.

Developing projects should be given sufficient time (3 to 5 years) to realize their objectives, as it has been shown that it may take up to two years before case management is generating the intended outcomes (McLellan et al., 1999). Alternative or flexible forms of reimbursement need to be negotiated with insurance companies, as case managers' activities are often departures from traditional interventions in substance abuse treatment (Powell, 2001). In addition, a budget for occasional client expenses (e.g., child care, clothes, and public transport) can facilitate case management (Laken \& Ager, 1996; McLellan et al., 1999; Yates \& Gilman, 1990). Ultimately, continued funding should be based on a thorough evaluation of the postulated goals.

\section{- WHICH STANDARDS SHOULD BE USED TO EVALUATE CASE MANAGEMENT?}

Effectiveness needs to be evaluated according to scientific standards, but also requirements from commissioning and subsidizing authorities should be taken into account (SAMHSA, 1998). Evaluation should start from an accurate representation of what the intervention entails (Perl \& Jacobs, 1992). Without this knowledge, it is only possible to vaguely search for outcomes that might be more or less attributable to case management. Besides outcome indicators, process data should be collected that describe to what degree the planned intervention is actually delivered, what is the impact of other 
factors on the intervention, and which outcomes are attributable to what was actually delivered (Martin \& Scarpitti, 1993; SAMHSA, 1998).

Researchers have identified several potential confounding factors (e.g., case managers' personality, clients' characteristics, motivation or legal status, retention) that affect the direct impact of case management on clients' functioning (Block, Bates, \& Hall, 2003; Rapp et al., 1998; Siegal et al., 1997; Siegal \& Rapp, 2002; Vaughn, Sarrazin, Saleh, Huber, \& Hall, 2002). Contextual differences cause further methodological problems when evaluating this intervention. To extend the current knowledge about the effectiveness of case management for substance abusers, more randomized and controlled studies among large samples are needed, especially in Europe. Also a longitudinal scope and (qualitative) research focusing on specific aspects of case management and the role of mediating variables could provide further insight into the factors that make this intervention work (or not).

\subsection{CONCLUSION}

Both in the United States and Europe, case management is regarded to be an important supplement to traditional substance abuse services, as it provides an innovative approach (e.g., client-centered, comprehensive, community-based) and contributes to treatment access, participation and retention, service utilization, and client outcomes. Still, its implementation in Europe is limited to a few projects and most empirical data are based on American examples. Compared with case management for mentally ill persons, fairly little evidence is available concerning the effectiveness of this intervention. Contextual differences, specific target populations, diverging objectives, less tradition of community care, few randomized and controlled trials, and unrealistic expectations about its effects may account for this lack of evidence. Especially in Europe, more randomized and controlled trials including large samples are needed, but also qualitative studies in order to better understand distinct aspects of case management and their impact on client outcomes and system variables.

Case management for substance use disorders is no panacea, but it affects the delivery of services positively and can help to stabilize or improve persons' complex situation. Based on empirical findings from the United States, the Netherlands and Belgium, several prerequisites for a well-conceptualized implementation of this intervention can be mentioned. Integration of the program in a comprehensive network of services, accessibly and availability, providing direct services, using a team approach, applying a strengths perspective, intensive training, and regular supervision all contribute to successful outcomes. Still, the variety of case management practices within and across programs remains a major concern. Development of program protocols and manuals and the 
identification of key features of distinct models can contribute to a more consistent application of this intervention.

Finally, although case management for substance abusers has evolved somehow independently, many similarities can be observed with mental health case management. Therefore, further evolutions in this field should be closely followed, especially for identifying the crucial aspects of this intervention. Moreover, a comparison of case management for both populations may reveal unique aspects of each intervention and thus optimize case management practices with mentally ill patients (with secondary substance abuse), substance abusers and dually diagnosed persons.

ACKNOWLEDGEMENTS. The "Third International Symposium on Substance Abuse Treatment and Special Target Groups" (Blankenberge, Belgium, March 3-5, 2001) was financially supported by the Province of East-Flanders (Belgium) and the European Federation of Therapeutic Communities (EFTC). 


\section{REFERENCES}

Ashery, R.S. (1996). Case management for substance abusers: more issues than answers. In H. Siegal, \& R. Rapp (Eds.), Case management and substance abuse treatment: practice and experience (141-154). New York: Springer Publishing Company.

Barry, K.L., Zeber, J.E., Blow, F.C., \& Valenstein, M. (2003). Effect of strengths model versus assertive community treatment model on participant outcomes and utilization: two-year follow-up. Psychiatric Rehabilitation Journal, 26(3), 268-277.

Bearman, D., Claydon, K., Kincheloe, J., \& Lodise, C. (1997). Breaking the cycle of dependency: dual diagnosis and AFDC families. Journal of Psychoactive Drugs, 29(4), 359-367.

Birchmore-Timney, C., \& Graham, K. (1989). A survey of case management practices in addictions programs. Alcoholism Treatment Quarterly, 6(3/4), 103-127.

Block, R.I., Bates, M.E., \& Hall, J.A. (2003). Relation of premorbid cognitive abilities to substance users' problems at treatment intake and improvements with substance abuse treatment and case management. American Journal of Drug and Alcohol Abuse, 29(3), 515-538.

Braucht, G.N., Reichardt, C.S., Geissler, L.J., Bormann, C.A., Kwaitkowski, C.F., \& Kirby, M.W. (1995). Effective services for homeless substance abusers. Journal of Addictive Diseases, 14(4), 87-109.

Brindis, C.D., \& Theidon, K.S. (1997). The role of case management in substance abuse treatment services for women and their children. Journal of Psychoactive Drugs, 29(1), 79-88.

Broekaert, E., \& Vanderplasschen, W. (2003). Towards an integrated treatment system for substance abusers: report on the second international symposium on substance abuse treatment and special target groups. Journal of Psychoactive Drugs, 35(2), 237-245.

Broekaert, E., Vandevelde, S., Vanderplasschen, W., Soyez, V., \& Poppe, A. (2002). Two decades of "research-practice" encounters in the development of European therapeutic communities for substance abusers. Nordic Journal of Psychiatry, 56, 371-377.

Broër, C., \& Noyon, R. (1999). Over last en beleid: Regioplan Stad en Land. Amsterdam: Regioplan Stad en Land.

Brun, C., \& Rapp, R. (2001). Strengths-based case management: individuals' perspectives on strengths and the case manager relations. Social Work, 46(3), 278-288.

Burns, T., Fioritti, A., Holloway, F., Malm, U., \& Rossler, W. (2001). Case management and assertive community treatment in Europe. Psychiatric Services, 52(5), 631-636.

California Addiction Technology Transfer Center. (1997). Addiction Counseling Competencies: The knowledge, skills, and attitudes of professional practice. La Jolla, CA: California Addiction Technology Transfer Center.

Conrad, K.J., Hultman, C.I., Pope, A.R., Lyons, J.S., Baxter, W.C., Daghestani, A.N. et al. (1998). Case managed residential care for homeless addicted veterans: results of a true experiment. Medical Care, 36, 40-53.

Cook, F. (1992). Case management models linking criminal justice and treatment. In R.S. Ashery (Ed.), Progress and issues in case management (NIDA Research Monograph 127) (pp. 368-382). Rockville, MD.: National Institute on Drug Abuse. 
Cox, G.B., Walker, R.D., Freng, S.A., Short, B.A., Meijer, L., \& Gilchrist, L. (1998). Outcome of a controlled trial of the effectiveness of intensive case management for chronic public inebriates. Journal of Studies on Alcohol, 59(5), 523-532.

De Koning, P.J., \& Hessing, D.J. (2000). De kosten van het drugbeleid. Recht der Werkelijkheid, 1, 124.

de Weert-van Oene, G., \& Schrijvers, A. (1992). Van lappendeken naar zorgcircuit: circuitvorming in de Utrechtse verslavingszorg. Utrecht: Rijksuniversiteit Utrecht, Vakgroep Algemene Gezondheidszorg en Epidemiologie.

Drake, R., McHugo, G., Clark, R., Teague, G., Xie, H., Miles, K. et al. (1998). Assertive community treatment for patients with co-occurring severe mental illness and substance use disorder: a clinical trial. American Journal of Orthopsychiatry, 68(2), 201-215.

Drake, R. E., \& Noordsey, D. L. (1994). Case management for people with coexisting severe mental disorder and substance use disorder. Psychiatric Annals, 24(8), 427-431.

Erdmann, Y., \& Wilson, R. (2001). Managed care: a view from Europe. Annual Review of Public Health, 22, 273-291.

European Monitoring Centre for Drugs and Drug Addiction (EMCDDA) (2001). Annual report on the state of the drug problem in the European Union. Luxembourg: Office for Official Publications of the European Communities.

Evenson RC, Binner PR, Cho DW, Schicht, W.W., \& Topolski, J.M. (1998). An outcome study of Missouri's CSTAR alcohol and drug abuse programs. Journal of Substance Abuse Treatment, 15, $143-150$

Falck, R., Siegal, H. A., \& Carlson, R. G. (1992). Case management to enhance AIDS risk reduction for injection drug users and crack users: Theoretical and practical considerations. In R.S. Ashery (Ed.), Progress and issues in case management (NIDA Research Monograph 127) (pp. 167180). Rockville, MD.: National Institute on Drug Abuse.

Fiander, M., \& Burns, T. (2000). A Delphi approach to describing service models of community mental health practice. Psychiatric Services, 51(5), 656-658.

Godley, S.H., Finch, M., Dougan, L., McDonnell, M., McDermeit, M., \& Carey, A. (2000). Case management for dually diagnosed individuals involved in the criminal justice system. Journal of Substance Abuse Treatment, 18(2), 137-148.

Godley, M.D., Godley, S.H., Dennis, M.L., Funk, R., \& Passetti, L.L. (2002). Preliminary outcomes from the assertive continuing care experiment for adolescents discharged from residential treatment. Journal of Substance Abuse Treatment, 23(1), 21-32.

Godley S.H., Godley, M.D., Pratt, A., \& Wallace, J.L. (1994). Case management services for adolescent substance abusers: a program description. Journal of Substance Abuse Treatment, 11(4), 309-317.

Graham, K., \& Birchmore-Timney, C. (1990). Case management in addictions treatment. Journal of Substance Abuse Treatment, 7(3), 181-188.

Graham, K., Timney, C., Bois, C., \& Wedgerfield, K. (1995). Continuity of care in addictions treatment: the role of advocacy and coordination in case management. American Journal of Drug and Alcohol Abuse, 21(4), 433-451. 
Hall, J.A., Carswell, C., Walsh, E., Huber, D.L., \& Jampoler, J.S. (2002). Iowa case management: Innovative social casework. Social Work, 47(2), 132-141.

Holloway, F., \& Carson, J. (2001). Case management: an update. International Journal of Social Psychiatry, 47(3), 21-31.

Huber, D.L., Sarrazin, M.V., Vaughn, T., \& Hall, J.A. (2003). Evaluating the impact of case management dosage. Nursing Research 52(5), 276-288.

Inciardi, J. A., Martin, S. S., Butzin, C. A., Hooper, R. M., \& Harrison, L.D. (1996). An effective model of prison-based treatment for drug-involved offenders. Journal of Drug Issues, 27(2), 261-278.

Jerrell, J. M. (1996). Toward cost-effective care for persons with dual diagnoses. Journal of Mental Health Administration, 23(3), 329-337.

Jerrell, J.M., Hu, T., \& Ridgely, M.S. (1994). Cost-effectiveness of substance disorder interventions for people with severe mental illness. Journal of Mental Health Administration, 21(3), 283-297.

Jerrell, J.M., \& Ridgely, M.S. (1999). Impact of robustness of program implementation on outcomes of clients in dual diagnosis programs. Psychiatric Services, 50(1), 109-112.

Kirby, M.W., \& Braucht, G.N. (1993). Intensive case management for homeless people with alcohol and other drug problems. Alcoholism Treatment Quarterly, 10, 187-200.

Laken, M.P., \& Ager, J.W. (1996). Effects of case management on retention in prenatal substance abuse treatment. American Journal of Drug and Alcohol Abuse, 22(3), 439-448.

Levy, J.A., Gallmeier, C.P., Weddington, W.W., \& Wiebel, W. (1992). Delivering case management using a community-based service model of drug intervention. In R.S. Ashery (Ed.), Progress and issues in case management (NID A Research Monograph 127) (pp. 145-165). Rockville, MD.: National Institute on Drug Abuse.

Levy, J.A., Strenski, T., \& Amick, D.J. (1995). Community-based case management for active injecting drug users. Advances in Medical Sociology, 6, 183-206.

Lidz, V., Bux, D. A., Platt, J. J., \& Iguchi, M. Y. (1992). Transitional case management: A service model for AIDS outreach projects. In R.S. Ashery (Ed.), Progress and issues in case management (NID A Research Monograph 127) (pp. 112-144). Rockville, MD.: National Institute on Drug Abuse.

Lightfoot, L., Rosenbaum, P., Ogurzsoff, S., Laverty, G., Kusiar, S., Barry, K. et al. (1982). Final Report of the Kingston Treatment Programmed Development Research Project. Canada: Department of Health and Welfare Health Promotion Directorate.

Martin, S. S., \& Scarpitti, F. R. (1993). An intensive case management approach for paroled iv drug users. Journal of Drug Issues, 23(1), 43-59.

McLellan, A.T. (2002). Have we evaluated addiction treatment corretcly? Implications from a chronic care perspective. Addiction, 97(3), 249-252.

McLellan, A.T., Hagan, T.A., Levine, M., Meyers, K., Gould, F., Bencivengo, M. et al. (1999). Does clinical case management improve outpatient addiction treatment. Drug and Alcohol Dependence, 55, 91-103.

Mejta, C., Bokos, P., Maslar, E. M., Mickenberg, J. H., \& Senay, E. C. (1997). The effectiveness of case management in working with intravenous drug users. In F.M. Tims, J.A. Inciardi, B.W. 
Fletcher, \& A.M. Horton (Eds.), The effectiveness of innovative approaches in the treatment of drug abuse (pp. 101-114). Westport, CN: Greenwood Press.

Mejta, C., Bokos, P., Mickenberg, J. Maslar, M., \& Senay, E. (1997). Improving substance abuse treatment access and retention using a case management approach. Journal of Drug Issues, 27(2), 329-340.

Moxley, D. (1989). The practice of case management (Sage Human Services Guides Vol. 58). Newbury Park: Sage publications.

National Association of Alcoholism and Drug Abuse Counselors (NAADAC). (1986). Certification Commission Oral Exam Guidelines. Arlington: National Association of Alcoholism and Drug Abuse Counselors.

Ogborne, A. C., \& Rush, B. R. (1983). The coordination of treatment services for problem drinkers: Problems and prospects. British Journal of Addiction, 78, 131-138.

Okin, R.L., Boccellari, A., Azocar, F., Shumway, M., O'Brien, K., Gelb, A. et al. (2000). The effects of clinical case management on hospital service use among ED frequent users. American Journal of Emergency Medicine, 18(5), 603-608.

Oliva, H., Görgen, W., Schlanstedt, G., Schu, M., \& Sommer, L. (2001). Case management in der Suchtkranken- und Drogenbilfe: Ergebnisse des Kooperationsmodells nachgehende Sozialarbeit Modellbestandteil Case management, Berichtszeitraum 1995-2000. Köln: Fogs, Gesellschaft für Forschung und Beratung in Gesundheits- und Sozialbereich mbH.

Ontwikkelcentrum Sociaal Verslavingsbeleid. (2003). Handreiking voor casemanagers in de sociale verslavingszorg. Utrecht: Resultaten Scoren.

Oppenheimer, E., Sheehan, M., \& Taylor, C. (1988). Letting the client speak: Drug misusers and the process of help seeking. British Journal of Addiction, 83, 635-647.

Orwin, R.G., Sonnefeld, L.J., Garrison-Mogren, R., \& Smith, N.G. (1994). Pitfalls in evaluating the effectiveness of case management programs for homeless persons: lessons from the NIAAA Community Demonstration Program. Evaluation Review, 18(2), 153-207.

Perl, H.I., \& Jacobs, M.L. (1992). Case management models for homeless persons with alcohol and other drug problems: An overview of the NIAAA research demonstration program. In R.S. Ashery (Ed.), Progress and issues in case management (NIDA Research Monograph 127) (pp. 208222). Rockville: National Institute on Drug Abuse.

Powell, S. (2000). Case management: a practical guide to success in managed care. Baltimore - Philadelphia: Lippincott Williams \& Wilkins.

Rapp, R. C., Siegal, H. A., Li, L., \& Saha, P. (1998). Predicting post-primary treatment services and drug use outcome: A multivariate analysis. American Journal of Drug and Alcohol Abuse, 24(4), 603-615.

Rhodes, W., \& Gross, M. (1996). Case management reduces drug use and criminality among drug-involved arrestees: An experimental study of an HIV prevention intervention NIJ Research Report. Washington, D.C.: Office of Justice Programs.

Ridgely, M.S. (1996). Practical issues in the application of case management to substance abuse treatment. In H. Siegal, \& R. Rapp (Eds.), Case management and substance abuse treatment: practice and experience (pp. 1-20). New York: Springer Publishing Company.

Ridgely, M.S., \& Jerrell, J.M. (1996). Analysis of three interventions for substance abuse treatment of severely mentally ill people. Community Mental Health Journal, 32(6), 561-572. 
Ridgely, M.S., \& Willenbring, M. (1992). Application of case management to drug abuse treatment: overview of models and research issues. In R.S. Ashery (Ed.), Progress and Issues in case management (NID A Research Monograph 127) (pp. 12-33). Rockville: National Institute on Drug Abuse.

Rochefort, D.A., \& Goering, P. (1998). "More a link than a division": How Canada has learned from US Mental Health Policy. Health Affairs, 17(5), 110-127.

Rosen, A., \& Teesson, M. (2001). Does case management work? The evidence and the abuse of evidence-based medicine. Australian and New Zealand Journal of Psychiatry, 35(6), 731-746.

Rush, B., \& Ekdahl, A. (1990). Recent trends in the development of alcohol and drug treatment services in Ontario. Journal of Studies on Alcohol, 51(6), 514-522.

Saleh, S.S., Vaughn, T., Hall, J.A., Levey, S., Fuortes, L., \& Uden-Holmen, T. (2002). Effectiveness of case management in substance abuse treatment. Care Management Journal, 3(4), 172-177.

Sarrazin, M.V., Huber, D.L., \& Hall, J.A. (2001). Impact of Iowa case management on family functioning for substance abuse treatment clients. Adolescent \& Family Health, 2(3), 132-140.

Scott, C.K., Sherman, R.E., Foss, M.A., Godley, M., \& Hristova, L. (2002). Impact of centralized intake on case management services. Journal of Psychoactive Drugs 34(1):51-57, 2002

Shwartz, M., Baker, G., Mulvey, K. P., \& Plough, A. (1997). Improving publicly funded substance abuse treatment: The value of case management. American Journal of Public Health, 87, 16591664.

Siegal, H. A., Fisher, J. A., Rapp, R. C., Kelliher, C. W., Wagner, J. H., O'Brien, W. F. et al. (1996). Enhancing substance abuse treatment with case management: Its impact on employment. Journal of Substance Abuse Treatment, 13(2), 93-98.

Siegal, H. A., Li, L., \& Rapp, R. C. (2002). Case management as a therapeutic enhancement: Impact on post-treatment criminality. Journal of Addictive Diseases, 21(4), 37-46.

Siegal, H. A., Rapp, R. C., Kelliher, C. W., Fisher, J. H., Wagner, J. H., \& Cole, P. A. (1995). The strengths perspective of case management: A promising inpatient substance abuse treatment enhancement. Journal of Psychoactive Drugs, 27(1), 67-72.

Siegal, H., Rapp, R., Li, L., Saha, P., \& Kirk, K. (1997). The role of case management in retaining clients in substance abuse treatment: an exploratory analysis. Journal of Drug Issues, 27(4), 821831.

Sorensen, J.L., Dilley, J., London, J, Okin, R.L., Delucchi, K.L., \& Phibbs, C.S. (2003). Case management for substance abusers with HIV/AIDS: a randomized clinical trial. American Journal of Drug and Alcohol Abuse, 29(1), 133-150.

Substance Abuse and Mental Health Services Administration (SAMHSA). (1998). Comprehensive case management for substance abuse treatment, TIP Series 27. Rockville: U.S. Department of health and human services, Public Health Service, Substance Abuse and Mental Health Services Administration, Center for Substance Abuse Treatment.

Sullivan, W., Hartmann, D., Dillon, D., \& Wolk, J. (1994). Implementing case management in alcohol and drug treatment. Families in Society: the Journal of Contemporary Social Services, 75(2), 67-73. 
Teague, G.B., Bond, G.R., \& Drake, R.E. (1998). Program fidelity in assertive community treatment: development and use of a measure. American Journal of Orthopsychiatry, 68(2), 216231.

Vanderplasschen, W. (2002). Case management in de drughulpverlening: le beaujolais nouveau of gewoon oude wijn in nieuwe zakken? In Vereniging voor Alcohol- en andere Drugproblemen (Ed.), Referatenbundel VAD-studiedag Alcohol \& Drugs 21-11-2002 (pp. 18-27). Brussel: Vereniging voor Alcohol- en andere Drugproblemen (VAD).

Vanderplasschen, W., De Bourdeaudhuij, I., \& Van Oost, P. (2002). Co-ordination and continuity of care in substance abuse treatment: an evaluation-study in Belgium. European Addiction Research, 8, 10-21.

Vanderplasschen, W., Lievens, K., \& Broekaert, E. (2001). Implementatie van een methodiek van case management in de drughulpverlening: een proefproject in de provincie Oost-Vlaanderen (Orthopedagogische Reeks Gent Nummer 14). Gent: Universiteit Gent, Vakgroep Orthopedagogiek.

Van Stelle, K. R., Mauser, E., \& Moberg, D. P. (1994). Recidivism to the criminal justice system of substance- abusing offenders diverted into. Crime and Delinquency, 40(2), 175-196.

Vaughan-Sarrazin, M.S., Hall J.A., \& Rick, G.S. (2000). Impact of Iowa case management on use of health services by rural clients in substance abuse treatment. Journal of Drug Issues, 30(2), 435463.

Vaughn, T., Sarrazin, M.V., Saleh, S.S., Huber, D.L., \& Hall, J.A. (2002). Participation and retention in drug abuse treatment services research. Journal of Substance Abuse Treatment, 23(4), 387-397.

Westermeyer, J. (1989). Non-treatment factors affecting treatment outcome in substance abuse. American Journal of Substance Abuse, 15(1), 13-29.

Willenbring, M. (1996). Case management applications in substance use disorders. In H. Siegal, \& R. Rapp (Eds.), Case management and substance abuse treatment: practice and experience (pp. 51-76). New York: Springer Publishing Company.

Willenbring, M. L., Whelan, J. A., Dahlquist, J. S., \& O'Neal, M. E. (1990). Community treatment of the chronic public inebriate I: Implementation. Alcoholism Treatment Quarterly, 7(2), 79-97.

Wingerson, D., \& Ries, R. (1999). Assertive community treatment for patients with chronic and severe mental illness who abuse drugs. Journal of Psychoactive Drugs, 31(1), 13-18.

Wolf, J., Mensink, C., \& van der Lubbe, P. (2002). Case management voor langdurig verslaafden met meervoudige problemen: een systematisch overzicht van interventie en effect. Utrecht: Trimbos-instituut, Ontwikkelcentrum Sociaal Verslavingsbeleid.

Wolf, J., \& Planije, M. (2002). Case management voor langdurig verslaafden met meervoudige problemen. Utrecht: Trimbos-instituut, Ontwikkelcentrum Sociaal Verslavingsbeleid.

Yates, R., \& Gilman, M. (1990). Seeing more drug users: outreach work and beyond: a lifeline project policy report. Manchester: Lifetime project.

Ziguras, S.J., \& Stuart, G.W. (2000). A meta-analysis of the effectiveness of mental health case management over 20 years. Psychiatric Services, 51, 1410-1421. 
Table 4.1.: Overview of main results of recently (1997-2003) published studies in peer-reviewed journals about case management for substance abusers ( $n>100)$

\begin{tabular}{|c|c|c|c|c|c|c|c|c|}
\hline \multirow[t]{2}{*}{ Authors } & \multirow[t]{2}{*}{ Place } & \multirow[t]{2}{*}{ Type of study } & \multirow[t]{2}{*}{$N$} & \multirow[t]{2}{*}{ Target population } & \multirow[t]{2}{*}{ Type of intervention } & \multicolumn{3}{|c|}{ Results } \\
\hline & & & & & & $\begin{array}{l}\text { Access, participation } \\
\text { and retention }\end{array}$ & Service utilization & Drug-related outcomes \\
\hline $\begin{array}{l}\text { Mejta, et al. } \\
(1997)\end{array}$ & Chicago & $\begin{array}{l}\text { Randomized and } \\
\text { controlled trial }\end{array}$ & 316 & Intravenous drug users & $\begin{array}{l}\text { Generalist case } \\
\text { management vs. no case } \\
\text { management }\end{array}$ & $\begin{array}{l}\text { Increased access to and } \\
\text { retention in treatment }\end{array}$ & & Reduced drug and alcohol use \\
\hline $\begin{array}{l}\text { Shwartz et al. } \\
(1997)\end{array}$ & $\begin{array}{l}\text { Boston, } \\
\text { Massachusetts }\end{array}$ & $\begin{array}{l}\text { Retrospective } \\
\text { cohort study }\end{array}$ & 21,207 & $\begin{array}{l}\text { Substance abusers in } 4 \\
\text { types of treatment }\end{array}$ & $\begin{array}{l}\text { Generalist case } \\
\text { management }\end{array}$ & $\begin{array}{l}\text { Increased retention } \\
\text { and post-primary } \\
\text { treatment participation }\end{array}$ & & Reduced relapse-rates \\
\hline $\begin{array}{l}\text { Conrad et al. } \\
(1998)\end{array}$ & Hines, Illinois & $\begin{array}{l}\text { Randomized and } \\
\text { controlled trial }\end{array}$ & 358 & $\begin{array}{l}\text { Homeless addicted } \\
\text { veterans }\end{array}$ & $\begin{array}{l}\text { Case managed residential } \\
\text { care vs. 21-day hospital } \\
\text { program }\end{array}$ & $\begin{array}{l}\text { Increased treatment } \\
\text { retention }\end{array}$ & & $\begin{array}{l}\text { Improved medical, alcohol, } \\
\text { employment and housing status }\end{array}$ \\
\hline $\begin{array}{l}\text { Cox et al. } \\
(1998)\end{array}$ & $\begin{array}{l}\text { King County, } \\
\text { Seattle, } \\
\text { Washington }\end{array}$ & $\begin{array}{l}\text { Randomized and } \\
\text { controlled trial }\end{array}$ & 193 & $\begin{array}{l}\text { Homeless chronic } \\
\text { public inebriates }\end{array}$ & $\begin{array}{l}\text { Intensive case } \\
\text { management vs. standard } \\
\text { treatment }\end{array}$ & & $\begin{array}{l}\text { Increased utilization } \\
\text { of substance abuse } \\
\text { services }\end{array}$ & $\begin{array}{l}\text { Reduced alcohol use, less days of } \\
\text { homelessness, increased income from } \\
\text { public sources }\end{array}$ \\
\hline $\begin{array}{l}\text { Evenson et al. } \\
\text { (1998) }\end{array}$ & $\begin{array}{l}\text { Saint-Louis, } \\
\text { Missouri }\end{array}$ & $\begin{array}{l}\text { Retrospective } \\
\text { study }\end{array}$ & 280 & $\begin{array}{l}\text { Substance abusers in a } \\
\text { treatment and } \\
\text { rehabilitation program }\end{array}$ & $\begin{array}{l}\text { Intensive case } \\
\text { management }\end{array}$ & $\begin{array}{l}\text { Positive association } \\
\text { between program- } \\
\text { retention and } \\
\text { outcomes }\end{array}$ & $\begin{array}{l}\text { High degree of } \\
\text { satisfaction with } \\
\text { services received }\end{array}$ & $\begin{array}{l}\text { Improved functioning on } 11 \text { domain } \\
\text { (e.e. drug use, employment, legal } \\
\text { problems, psychological and social } \\
\text { situation) }\end{array}$ \\
\hline
\end{tabular}




\begin{tabular}{|c|c|c|c|c|c|c|c|c|}
\hline \multirow[t]{2}{*}{ Authors } & \multirow[t]{2}{*}{ Place } & \multirow[t]{2}{*}{$\begin{array}{l}\text { Type of } \\
\text { study }\end{array}$} & \multirow[t]{2}{*}{$N$} & \multirow[t]{2}{*}{ Target population } & \multirow[t]{2}{*}{ Type of intervention } & \multicolumn{3}{|c|}{ Results } \\
\hline & & & & & & $\begin{array}{l}\text { Access, participation } \\
\text { and retention }\end{array}$ & Service utilization & Drug-related outcomes \\
\hline $\begin{array}{l}\text { Rapp et al. } \\
\text { (1998) }\end{array}$ & Dayton, Ohio & $\begin{array}{l}\text { Randomized and } \\
\text { controlled trial }\end{array}$ & 444 & $\begin{array}{l}\text { Veterans with } \\
\text { substance abuse } \\
\text { problems }\end{array}$ & $\begin{array}{l}\text { Strengths-based case } \\
\text { management vs. standard } \\
\text { primary and aftercare } \\
\text { treatment }\end{array}$ & $\begin{array}{l}\text { Increased retention in } \\
\text { post-primary treatment }\end{array}$ & & $\begin{array}{l}\text { Reduced drug use after } 6 \text { months, } \\
\text { mediated by treatment retention }\end{array}$ \\
\hline $\begin{array}{l}\text { McLellan et al. } \\
(1999)\end{array}$ & Philadelphia & $\begin{array}{l}\text { Controlled study } \\
\text { (no } \\
\text { randomization) }\end{array}$ & 537 & $\begin{array}{l}\text { Substance abusers in } \\
\text { outpatient treatment }\end{array}$ & $\begin{array}{l}\text { Clinical case management } \\
\text { vs. standard outpatient } \\
\text { treatment }\end{array}$ & & $\begin{array}{l}\text { Increased utilization } \\
\text { of alcohol, medical } \\
\text { employment and } \\
\text { legal services }\end{array}$ & $\begin{array}{l}\text { Improved alcohol, drug, psychiatric, } \\
\text { employment, and medical status }\end{array}$ \\
\hline $\begin{array}{l}\text { Vaughan- } \\
\text { Sarrazin et al. } \\
(2000)\end{array}$ & $\begin{array}{l}\text { Johnson } \\
\text { County, Iowa }\end{array}$ & $\begin{array}{l}\text { Randomized and } \\
\text { controlled trial }\end{array}$ & 229 & $\begin{array}{l}\text { Substance users starting } \\
\text { residential treatment }\end{array}$ & $\begin{array}{l}\text { Strengths-based case } \\
\text { management ( } 3 \\
\text { experimental conditions } \\
\text { (inside facility, at social } \\
\text { service agency, } \\
\text { telecommunication), and } \\
1 \text { control condition) }\end{array}$ & $\begin{array}{l}\text { Slightly increased } \\
\text { treatment participation } \\
\text { and retention }\end{array}$ & $\begin{array}{l}\text { Increased use of } \\
\text { medical and } \\
\text { substance use } \\
\text { services (not } \\
\text { of mental health } \\
\text { services) among } \\
\text { inside CM-group }\end{array}$ & \\
\hline $\begin{array}{l}\text { Sarrazin et al. } \\
(2001)\end{array}$ & $\begin{array}{l}\text { Johnson } \\
\text { County, Iowa }\end{array}$ & $\begin{array}{l}\text { Randomized and } \\
\text { controlled trial }\end{array}$ & 494 & $\begin{array}{l}\text { Substance users starting } \\
\text { outpatient or residential } \\
\text { treatment }\end{array}$ & $\begin{array}{l}\text { Strengths-based case } \\
\text { management ( } 3 \\
\text { experimental conditions } \\
\text { (inside facility, at social } \\
\text { service agency, } \\
\text { telecommunication), and } \\
1 \text { control condition) }\end{array}$ & $\begin{array}{l}\text { No difference in } \\
\text { participation and } \\
\text { retention across } \\
\text { conditions }\end{array}$ & & $\begin{array}{l}\text { Improved family relations and } \\
\text { parental attitudes after } 6 \text { months in all } \\
\text { CM-conditions } \\
\text { No effect on perceptions of partner } \\
\text { abuse } \\
\text { No difference between } 3 \text { case } \\
\text { management-conditions }\end{array}$ \\
\hline $\begin{array}{l}\text { Godley et al. } \\
(2002)\end{array}$ & Central Illinois & $\begin{array}{l}\text { Randomized and } \\
\text { controlled trial }\end{array}$ & 114 & $\begin{array}{l}\text { Adolescent substance } \\
\text { abusers in short-term } \\
\text { residential treatment }\end{array}$ & $\begin{array}{l}\text { Assertive continuing care, } \\
\text { including case } \\
\text { management vs. usual } \\
\text { continuing care }\end{array}$ & $\begin{array}{l}\text { No differences in } \\
\text { length of stay }\end{array}$ & $\begin{array}{l}\text { More likely to } \\
\text { initiate and receive } \\
\text { continuing care } \\
\text { services }\end{array}$ & $\begin{array}{l}\text { Less marijuana use and less days of } \\
\text { alcohol use after } 3 \text { months }\end{array}$ \\
\hline $\begin{array}{l}\text { Saleh et al. } \\
(2002)\end{array}$ & $\begin{array}{l}\text { Johnson } \\
\text { County, Iowa }\end{array}$ & $\begin{array}{l}\text { Randomized and } \\
\text { controlled trial }\end{array}$ & 662 & $\begin{array}{l}\text { Substance users starting } \\
\text { residential treatment }\end{array}$ & $\begin{array}{l}\text { Strengths-based case } \\
\text { management }(3 \\
\text { experimental conditions } \\
\text { (inside facility, at social } \\
\text { service agency, } \\
\text { telecommunication) and } \\
1 \text { control condition) }\end{array}$ & & & $\begin{array}{l}\text { Improved employment and legal } \\
\text { status (CM inside) } \\
\text { Drugs and psychiatric status slightly } \\
\text { better (CM in social service) } \\
\text { No differential effects for } \\
\text { telecommunication-group }\end{array}$ \\
\hline
\end{tabular}




\begin{tabular}{|c|c|c|c|c|c|c|c|c|}
\hline \multirow[t]{2}{*}{ Authors } & \multirow[t]{2}{*}{ Place } & \multirow[t]{2}{*}{ Type of study } & \multirow[t]{2}{*}{$N$} & \multirow[t]{2}{*}{ Target population } & \multirow[t]{2}{*}{ Type of intervention } & \multicolumn{3}{|c|}{ Results } \\
\hline & & & & & & $\begin{array}{l}\text { Access, participation } \\
\text { and retention }\end{array}$ & Service utilization & Drug-related outcomes \\
\hline $\begin{array}{l}\text { Scott et al. } \\
(2002)\end{array}$ & Chicago & $\begin{array}{l}\text { Randomized and } \\
\text { controlled trial }\end{array}$ & 692 & $\begin{array}{l}\text { Substance abusers } \\
\text { contacting a centralized } \\
\text { intake facility }\end{array}$ & $\begin{array}{l}\text { Brokerage case } \\
\text { management vs. no case } \\
\text { management }\end{array}$ & $\begin{array}{l}\text { Improved treatment } \\
\text { access and } \\
\text { participation, but not } \\
\text { retention }\end{array}$ & $\begin{array}{l}\text { More referrals to } \\
\text { ancillary services }\end{array}$ & \\
\hline $\begin{array}{l}\text { Siegal et al. } \\
(2002)\end{array}$ & Dayton, Ohio & $\begin{array}{l}\text { Randomized and } \\
\text { controlled trial }\end{array}$ & 453 & $\begin{array}{l}\text { Veterans with } \\
\text { substance abuse } \\
\text { problems }\end{array}$ & $\begin{array}{l}\text { Strengths-based case } \\
\text { management vs. standard } \\
\text { primary and aftercare } \\
\text { treatment }\end{array}$ & $\begin{array}{l}\text { Increased after-care } \\
\text { participation }\end{array}$ & & $\begin{array}{l}\text { Less criminal behavior and more } \\
\text { employment after } 12 \text { months, related } \\
\text { to longer length of stay }\end{array}$ \\
\hline $\begin{array}{l}\text { Huber et al. } \\
\text { (2003) }\end{array}$ & $\begin{array}{l}\text { Johnson } \\
\text { County, Iowa }\end{array}$ & $\begin{array}{l}\text { Randomized and } \\
\text { controlled trial }\end{array}$ & 437 & $\begin{array}{l}\text { Substance users starting } \\
\text { outpatient or residential } \\
\text { treatment }\end{array}$ & $\begin{array}{l}\text { Strengths-based case } \\
\text { management ( } 3 \\
\text { experimental conditions } \\
\text { (inside facility, at social } \\
\text { service agency, } \\
\text { telecommunication), and } \\
1 \text { control condition) }\end{array}$ & & & $\begin{array}{l}\text { Increased legal and family problems } \\
\text { associated with higher case } \\
\text { management-dosage }\end{array}$ \\
\hline $\begin{array}{l}\text { Sorensen et al. } \\
(2003)\end{array}$ & $\begin{array}{l}\text { San Francisco, } \\
\text { California }\end{array}$ & $\begin{array}{l}\text { Randomized and } \\
\text { controlled trial }\end{array}$ & 190 & $\begin{array}{l}\text { Substance abusers with } \\
\text { HIV/AIDS }\end{array}$ & $\begin{array}{l}\text { Brokerage vs. intensive } \\
\text { case management }\end{array}$ & & $\begin{array}{l}\text { No differences in } \\
\text { service utilization }\end{array}$ & $\begin{array}{l}\text { No differences in drug-related } \\
\text { outcomes } \\
\text { Equal improvement among both } \\
\text { groups after } 6 \text { months, but effects } \\
\text { reducing after } 12 \text { and } 18 \text { months } \\
\text { Less sexual risk behavior (ICM) }\end{array}$ \\
\hline
\end{tabular}





\section{Chapter 5}

\section{Implementation of case management for substance abusers:}

an exploratory study in Belgium ${ }^{6}$

ABSTRACT. Case management has a long tradition for the treatment of mentally ill persons. Recently, case management has been applied in some European countries to guide substance abusers through the complex network of services. As evaluation of this intervention in the United States has led to conflicting results, this exploratory study was set up to provide further insight concerning its implementation among substance abusers in Europe. The sample consisted of 24 substance abusers with multiple and chronic problems who had been in treatment frequently. This group was selected from all persons in treatment $(n=459)$ in one of the participating services $(n=13)$. Case managers assisted these clients during a 12-month period using an ACT-like model of case management. Implementation of case management was evaluated positively and contributed to more individualized and continuous care, less attrition, and better coordination. Twelve months later, clients' problem severity concerning drug use, legal status, employment, and family relations was reduced or stabilized, but treatment was still indicated for some persons. It was assumed that case management had a direct impact on the organization of service delivery and an indirect influence on clients' functioning by enhancing treatment participation and retention.

\footnotetext{
${ }^{6}$ This chapter is based on: Vanderplasschen, W., Lievens, K., Broekaert, E. \& Rapp, R.C. (2004). Implementation of case management for substance abusers: an exploratory study in Belgium. Manuscript submitted for publication.
} 



\subsection{INTRODUCTION}

Case management has a long tradition for the treatment of several mental health populations in the United States, Canada, Australia, and some European countries (e.g., United Kingdom, Sweden, Italy, Germany and the Netherlands) (Burns, Fioritti, Holloway, Malm, \& Rossler, 2001; Holloway, Oliver, Collins, \& Carson, 1995). Since the 1990s, this intervention has been adapted to deal with substance use disorders in the United States and Canada (Graham \& Birchmore-Timney, 1990; SAMHSA, 1998). It is described as a variety of individualized services to improve accessibility, coordination, and continuity of care, especially among persons with multiple and complex problems (Willenbring, 1996). Case managers' basic functions may vary, but they usually include assessment, planning, various direct (information, advice, crisis intervention) and indirect interventions (advocacy, coordination, linking, outreaching), monitoring, and evaluation (Moxley, 1989). Case management is further characterized by a client-driven nature, community-based interventions, the realization of a single point of contact within the system of services, and an anticipatory, pragmatic, and flexible approach (SAMHSA, 1998).

Despite its widespread application and popularity, case management is not unanimously defined nor is it the sole domain of one single profession (Ridgely \& Willenbring, 1992; Wolf, Mensink, \& van der Lubbe, 2002). Four models of case management for substance abusers are frequently cited, including: the brokerage and generalist model, strengthsbased case management, assertive community treatment and intensive case management, and the clinical/rehabilitation model (Ridgely \& Willenbring, 1992; SAMHSA, 1998). As most practical examples only vaguely resemble the theoretical version of a model, it may not be surprising that these models have been applied with varying effectiveness. While the brokerage model has usually failed to show any discernable benefits, various positive effects have been associated with generalist, strengths-based, ACT, and intensive models of case management. Most of these effects concern drug-related outcomes, such as drug use, criminal activity and employment (McLellan et al., 1999; Rapp, Siegal, Li, \& Saha, 1998; Siegal et al., 1996; Siegal, Li, \& Rapp, 2002), but also treatment participation and retention (Inciardi, Martin, Butzin, Hooper, \& Harrison, 1997; Siegal, Rapp, Li, Saha, \& Kirk, 1997), and coordination of care (Graham, Timney, Bois, \& Wedgerfield, 1995; Siegal et al., 2002). Yet, lack of sufficient controlled and randomized studies causes controversy over whether, in what form(s) and to what extent case management is effective. Moreover, few studies have focused on process variables, clients' satisfaction, or other qualitative aspects of evaluation.

In Europe, case management has only recently been implemented to guide substance abusers through the complex system of services (e.g., in Germany, the Netherlands and Belgium) (EMCDDA, 2001; Oliva, Görgen, Schlanstedt, Schu, \& Sommer, 2001; Vanderplasschen, De Bourdeaudhuij, \& Van Oost, 2002; Wolf \& Planije, 2002). This 
intervention is mostly targeted at persons with multiple and chronic problems and the objective often is to improve accessibility and continuity of services and to promote quality of life and social integration of substance abusers. Also, social control and reduction of drug-related nuisance have inspired its implementation (Wolf \& Planije, 2002).

Due to obvious differences between the American and European health care system and the one-dimensional approach of most studies, thorough evaluation of developing projects in Europe can provide further insight into some of the effects of the implementation of case management. Up to now, few publications have focused on its implementation for substance abusers in Europe, except for dually diagnosed patients (Kellinghaus, Eikelmann, Ohrmann, \& Reker, 1999).

This paper examines the implementation of case management in Belgian substance abuse treatment, using both qualitative and quantitative methods and taking into account several mediating factors. Although the comprehensive and in-depth approach of this study did not allow for a large sample size, this exploratory article might be of interest to others implementing case management as it provides insight into its impact on clients' functioning and the organization of service delivery.

\subsection{MATERIALS AND METHODS}

\subsubsection{SAMPLE}

In order to select substance abusers with multiple and chronic problems in the region of Ghent (Belgium), the total sample of persons that followed treatment for substance use disorders in this area during the first week of October $1999(\mathrm{n}=459)$ was screened on three eligibility criteria: substance dependence for more than two years according to DSM IV-criteria (APA, 1996); problems on at least three ASI life domains (McLellan et al., 1992); at least two previous treatment episodes for drug-related problems. About a quarter of all registered persons $(\mathrm{n}=125 ; 27.2 \%)$ met all three criteria. This group was significantly older and more often dependent on several substances than the noneligible group.

In each service $(\mathrm{n}=13)$, all clients that matched the eligibility criteria were randomly divided into an experimental and control group. They were then asked if they consented to participate in either condition. A case manager could only follow one to three clients per service, because case management was conceptualized as an additional task for one caregiver in each service due to scarce financial resources. This resulted in a sample of 24 case managed-clients. Few clients refused to be followed by a case manager, while just 11 persons were willing to participate in the control condition. 
Case management was implemented in all specialized in- and outpatient services ( $\mathrm{n}=13$ ) that address substance abusers around Ghent, including 4 psychiatric hospitals, 3 drugfree therapeutic communities, 2 mental health care centers, 1 medical-social care centre, 1 day-care centre, 1 detoxification centre and 1 social workplace. Case managers $(n=13)$ were all experienced professionals, who were trained to do this intervention and were also regularly supervised. An assertive community treatment-like model of case management was implemented, characterized by case managers planning and coordinating service delivery, but also providing direct services and assertive outreach (SAMHSA, 1998). The main objectives of the project were to prevent and reduce relapse, to offer individualized and continuous care and to improve coordination and communication between services. Clients were followed during a 12-month period and had at least weekly contact(s) with their case manager. On average, case managers spent 45 minutes a week per client.

\subsubsection{PROCEDURE AND INSTRUMENTS}

The total sample was screened using a common registration form, including administrative and socio-demographical data, variables concerning drug use and treatment started, and the eligibility criteria. Case management and control group clients were interviewed both at the start of the project (November - December 1999) and 12 months later (November - December 2000), using the Dutch translation of the European version of the Addiction Severity Index (EuropASI) (Keymeulen \& Raes, 1999). Clients' motivation was measured in both time periods with De Leon's Circumstances-, Motivation- and Readiness-scales (CMR) (De Leon, Melnick, Thomas, Kressel, \& Wexler, 2000). At follow-up, 22 case managed-clients could be reached for a second interview, while this was only possible for half of the control group $(n=6)$. Differential attrition in the control group was attributed to the lack of tracking of these clients and the absence of a financial incentive for participating in the study (Orwin, Sonnefeld, Garrison-Mogren, \& Smith, 1994; Vaughn, Sarrazin, Saleh, Huber, \& Hall, 2002). Due to the small and disproportionate size of the control group, data about clients in this condition were not analyzed in this study.

Qualitative data for evaluating the treatment process included case managers' logbooks, clients' individual treatment plans and case managers' overview of changes in clients' states. Moreover, all case managers were interviewed individually after 6 and 12 months, using a semi-structured interview concerning the implementation and practice of case management (Jerrell \& Ridgely, 1999; Moxley, 1989). At follow-up, clients were interviewed to measure their satisfaction concerning this intervention and other services received and to evaluate their situation as compared to the start of the project. Also reports of supervision meetings were analyzed. Finally, preliminary results and recommendations were debated in two parallel discussion groups to monitor if our findings and advice matched the experiences of the case managers. 


\subsubsection{DATA ANALYSIS}

Both quantitative and qualitative data have been combined in this study. Quantitative data (EuropASI and CMR) were analyzed using the statistical software program SPSS. Also, data from logbooks were imported into SPSS after they had been categorized by two independent groups of Masters students in Educational Sciences. In cases of incongruence, coding was discussed till a consensus was reached. Due to the small sample size and the nominal and ordinal level of most variables, data analyses were mainly limited to frequency tables, cross-tabs and non-parametric significance tests. T-tests were used for comparing means for scale variables, while associations between variables were assessed using Pearson's and Spearman's correlation coefficients (Moore \& McCabe, 1999). Qualitative analysis of interviews, logbooks, treatment plans, client files, reports, and discussion groups consisted of coding and comparing text segments, based on a hierarchical coding structure. From this comparison emerged several themes that will be discussed in the following chapter. The software package WinMAX 98 Pro was used for this content analysis (Kuckartz, 1998).

\subsection{RESULTS}

\subsubsection{ADDICTION SEVERITY AT START (T0)}

The total sample $(\mathrm{n}=24)$ consisted of 16 males and 8 females, with an average age of 29 years. All of them had problems on several ASI life domains, especially concerning drug use, psychological health, family and social relations, and employment (cf. table 5.1., p. 140). A clear association was found between drug and psychological problems ( $\mathrm{r}=0.48$; $\mathrm{p}<0.05)$, psychological and family problems $(\mathrm{r}=0.46 ; \mathrm{p}<0.05)$, and drug and relational problems $(\mathrm{r}=0.75 ; \mathrm{p}<0.01)$.

All of them had been regularly using several licit and illicit substances for at least 6 years. The vast majority $(n=21)$ had injected drugs and more than half of them $(n=15)$ had had an overdose. These drug problems had caused numerous treatment episodes (18 on average), including detoxification and drug-free programs, psychiatric treatment, and substitution therapy. Frequent previous treatment episodes were associated with more severe family problems $(\mathrm{r}=0.59 ; \mathrm{p}<0.01)$. Only 7 clients had been sober for more than 6 months following previous treatment. As opposed to drug problems, relatively few clients reported problems and/or treatment due to alcohol abuse. Analysis of the family and social situations revealed intergenerational alcohol and drug problems $(\mathrm{n}=17)$, lack of contact with significant others $(n=20)$, conflicts with parents $(n=18)$ or partner $(n=14)$, dissatisfaction with their living situation $(n=10)$ and leisure activities $(n=14)$, and past emotional or physical abuse $(n=10)$. Consequently, these clients had a high prevalence of 
psychological problems, which appeared from depressive feelings $(\mathrm{n}=17)$, previous treatment for psychological problems $(\mathrm{n}=17)$, suicidal ideation $(\mathrm{n}=17)$ and parasuicide $(\mathrm{n}=15)$.

The weak employment situation became apparent from the fact that 15 persons had no degree at all, half of them had never worked for more than 12 months, and a majority $(n=14)$ lived on disability benefits. Moreover, 3 out of 4 clients had debts (on average 6,200 euro). Clients' judicial problems were estimated to be relatively high: nearly all of them had been arrested and convicted for drug-related crimes and about half of them $(\mathrm{n}=11)$ were referred by the criminal justice system. Only 6 had never been imprisoned. Physical problems appeared from the high number of persons who had been admitted to a general hospital $(\mathrm{n}=22)$. Many had chronic physical complaints (e.g., liver, stomach or, heart problems) $(n=12)$ or were infected with HCV $(n=9)$. Poor physical health was related to psychological problems $(\mathrm{r}=0.43 ; \mathrm{p}<0.05)$, employment problems $(\mathrm{r}=0.48$; $\mathrm{p}<0.05)$ and alcohol abuse $(\mathrm{r}=0.46 ; \mathrm{p}<0.05)$.

\subsubsection{ADDICTION SEVERITY 12 MONTHS LATER (T1)}

Follow-up a year later showed a significant reduction in drug, legal and family problems (cf. table 5.1., p. 140), but little changed concerning alcohol use, physical health and social relations. Severity of employment and psychological problems dropped significantly according to clients' ratings (severity scores), while the composite scores didn't change much. Both the trouble caused by drug-related problems and clients' need for help reduced, although (further) assistance was still indicated for several persons concerning psychological health, drug use, family and social relations, and employment.

Although the use of heroin, cocaine, and amphetamines was limited to a few persons, most clients were still using cannabis, sedatives, and alcohol regularly. Most case managedclients had been in at least 2 treatment centers during the previous 12 months and 5 persons still attended outpatient treatment. More severe drug problems at follow-up were related with medical $(\mathrm{r}=.57 ; \mathrm{p}<0.01)$, psychological $(\mathrm{r}=.72 ; \mathrm{p}<0.01)$, and family problems $(\mathrm{r}=.53 ; \mathrm{p}<0.05)$. The more treatment episodes during the previous 12 months, the worse the outcome concerning employment $(\mathrm{r}=.43 ; \mathrm{p}<0.05)$, drug use $(\mathrm{r}=.58 ; \mathrm{p}<0.01)$, family relations $(\mathrm{r}=.53 ; \mathrm{p}<0.01)$, and psychological state $(\mathrm{r}=.45 ; \mathrm{p}<0.05)$. Also the more treatment episodes, the more drug problems at follow-up $(\mathrm{r}=.44 ; \mathrm{p}<0.05)$. On the other hand, longer length of stay in treatment correlated with reduced severity of drug $(\mathrm{r}=-.73$; $\mathrm{p}<0.01)$, family $(\mathrm{r}=-.62 ; \mathrm{p}<0.01)$, legal $(\mathrm{r}=-.49 ; \mathrm{p}<0.05)$, and medical $(\mathrm{r}=-.44 ; \mathrm{p}<0.05)$ problems.

Clients' economic situation improved significantly: Thirteen persons had been working (6 for more than 6 months), fewer persons were dependent on disability benefits and the average amount of debts decreased. On the other hand, one third had not been working and about half had been living in a controlled environment (psychiatric hospital or therapeutic community) for a longer period. Employment during the 30 days before the 
second interview was associated with better physical $(\mathrm{r}=-.49 ; \mathrm{p}<0.05)$ and psychological states $(\mathrm{r}=-.49 ; \mathrm{p}<0.05)$. The family and social situation also ameliorated, since fewer persons $(\mathrm{n}=5)$ were dissatisfied with their living situation and/or leisure activities and more persons reported having two or more good friends $(\mathrm{n}=16)$. Alcohol abuse among clients' mothers was associated with negative outcomes concerning alcohol (rho=.50; $\mathrm{p}<0.05)$ and drug use $(\mathrm{rho}=.47 ; \mathrm{p}<0.05)$, employment $(\mathrm{rho}=.52 ; \mathrm{p}<0.05)$, and physical $(\mathrm{rho}=.48 ; \mathrm{p}<0.05)$ and psychological health $(\mathrm{rho}=.51 ; \mathrm{p}<0.05)$. Judicial problems improved significantly and only a few clients were arrested or incarcerated for drug-related crimes (such as dealing or theft) during the project. No differences were observed at start and follow-up between clients referred by the criminal justice system $(\mathrm{n}=11)$ and other clients, except that the former had more family problems (rho=-0.54; $\mathrm{p}<0.01$ ). Psychological complaints decreased only slightly, but feelings of tension $(\mathrm{n}=14)$ were reported. Moreover, four persons attempted suicide and 17 persons were treated for psychological problems during the previous 12 months. Feelings of depression and/or tension at the start of the project correlated with physical (rho=0.43; $\mathrm{p}<0.05$ ), psychological $($ rho $=0.67 ; \mathrm{p}<0.01)$, and drug problems (rho $=0.48 ; \mathrm{p}<0.05)$ at follow-up.

Table 5.1.: Comparison of clients' functioning at start and 12 months later, based on EuropASI severity and composite scores $(n=22)$

\begin{tabular}{|c|c|c|c|c|}
\hline & TO & $T 1$ & t-value & $p$ \\
\hline \multicolumn{5}{|l|}{ Physical health } \\
\hline Average interviewers' severity score medical status & 3.45 & 2.23 & 2.78 & 0.14 \\
\hline Average composite score medical status & 0.42 & 0.26 & 2.66 & 0.11 \\
\hline \multicolumn{5}{|l|}{ Employment and support status } \\
\hline Average interviewers' severity score economic situation & 4.58 & 3.14 & 3.26 & $0.004^{* *}$ \\
\hline Average composite score economic situation & 0.87 & 0.69 & 1.53 & 0.140 \\
\hline \multicolumn{5}{|l|}{ Alcohol use } \\
\hline Average interviewers' severity score alcohol use & 3.45 & 2.68 & 1.77 & 0.091 \\
\hline Average composite score alcohol use & 0.20 & 0.14 & 1.76 & 0.093 \\
\hline \multicolumn{5}{|l|}{ Drug use } \\
\hline Average interviewers' severity score drug use & 6.23 & 3.86 & 7.11 & $0.000 * *$ \\
\hline Average composite score drug use & 0.20 & 0.13 & 3.32 & $0.003^{* *}$ \\
\hline \multicolumn{5}{|l|}{ Legal status } \\
\hline Average interviewers' severity score legal status & 3.77 & 2.36 & 3.49 & $0.002^{* *}$ \\
\hline Average composite score legal status & 0.24 & 0.11 & 2.92 & $0.008^{* *}$ \\
\hline \multicolumn{5}{|l|}{ Family and social relations } \\
\hline Average interviewers' severity score family and social relations & 4.86 & 3.64 & 3.25 & $0.004 * *$ \\
\hline Average composite score family relations & 0.17 & 0.07 & 2.42 & $0.025^{*}$ \\
\hline Average composite score social relations & 0.14 & 0.14 & -0.08 & 0.937 \\
\hline \multicolumn{5}{|l|}{ Psychological health } \\
\hline Average interviewers' severity score psychological status & 4.91 & 4.00 & 2.27 & $0.034^{*}$ \\
\hline Average composite score psychological status & 0.29 & 0.27 & 0.44 & 0.665 \\
\hline
\end{tabular}




\section{a Motivation}

The CMR scale showed both low and highly motivated persons in the case management group. Both persons dropping out of the project were among the least motivated. Motivation did not correlate with changes on any life domain at follow-up, but was related with a bad economic situation at start $(r=0.43 ; \mathrm{p}<0.05)$.

\section{a Clients' EVOLUTION ACCORDING TO CASE MANAGERS AND CLIENTS}

After 12 months of case management, most clients evaluated their situation as stable or even improved $(n=19)$. Most of these persons $(n=12)$ identified the treatment program they had followed as the major cause for change.

Several persons $(\mathrm{n}=16)$ had contacted three or more services during the previous year, including substance abuse and mental health care services, employment offices, general hospitals, probation offices. Clients reported their improved functioning mainly concerned employment, physical health, and drug use. Clients' files showed that most (negative) changes concerned family relations and drug use, while most positive changes were associated with employment. Treatment planning was mainly concentrated on family and social relations $(n=24)$, employment $(n=19)$, and alcohol and drug use $(n=18)$. Clients themselves primarily identified goals and strategies concerning family relations, while case managers did so concerning drug use.

\section{a EVALUATION BY CASE MANAGERS AND CLIENTS}

Evaluation of the implemented model among clients, case managers, and stakeholders revealed both positive and negative experiences. First, case managers $(n=11)$ and clients $(n=19)$ strongly appreciated the regular contacts that resulted in greater commitment and positively affected the continuity of the treatment process.

"You feel even more responsible for the client than before (...) You are more aware of this responsibility." (Case manager)

Clients liked being able to fall back on one caregiver $(n=12)$ and associated this with a positive influence on their functioning $(n=9)$. They identified treatment planning, monitoring and outreaching as crucial aspects of this intervention.

"I think it's good to set goals as you work towards an end result. (...) Then you can see how you're making progress." (Client) 
On the other hand, clients thought case management should not be terminated after 12 months $(\mathrm{n}=7)$. In addition, they pointed out that they needed case management during their transition towards a situation of more independent living rather than during longterm residential treatment.

"Now [after finishing residential treatment] I really need this (...), when I go back, to the community and try to find a job." (Client)

Case managers especially appreciated the comprehensive approach $(\mathrm{n}=8)$, including attention to all life domains and clients' strengths and weaknesses.

"Case managers have a total view of their clients' situation (...), not only the clinical aspect or drug use, but the person as a whole." (Case manager)

Moreover, clients were more involved in the treatment process and its planning, which led to the provision of services better suited to individuals needs. Case managers and clients evaluated outreaching as innovative, since it stimulated clients' commitment, was highly appreciated by clients, and could provide important additional information concerning clients' states.

"I liked that he [the case manager] often came by (...). When I saw him last week, I asked him: "When are you coming again for a cup of coffee"?" (Client)

According to case managers $(\mathrm{n}=6)$, their role in preventing relapse and re-admission was limited and any effects could be attributed rather to the treatment followed. Still, it led to more continuous and individualized care and improved (informal) contacts and communication between services involved. Most criticism concerned the actual implementation of case management, such as lack of time and means, demarcation issues, and case managers' responsibilities.

\subsection{DisCUSSION}

The selected sample of substance abusers $(n=24)$ had multiple and complex problems and a long treatment career, characterized by dropout and relapse. Despite their long-standing and severe problems, a low dropout rate was found among case managedclients $(n=2)$. This low attrition rate can probably be attributed to the client-oriented, continuous, and outreaching character of this intervention (SAMHSA, 1998; Wolf et al., 2002). Moreover, different data sources indicate a relative improvement of several problems after 12 months, resulting in more employment, less use of illicit substances, fewer criminal acts, and an improved living situation (cf. Shwartz, Baker, Mulvey, \& Plough, 1997; Siegal et al., 1996; Siegal et al., 2002). On the other hand, psychological problems remained among many clients, and illicit drug use was sometimes replaced by 
more socially accepted drugs, such as alcohol, cannabis, and (prescribed) medication. Similar outcomes have been found concerning case management for mentally ill persons (Kroon, van Hoof, \& Wolf, 1999), suggesting its contribution to the stabilization - rather than to recovery - of chronic disorders. It can be further remarked that clients' perspectives concerning drug-related problems (severity scores based on "trouble caused" and "need for help") were more positive than the composite scores, which also take into account past experiences. This observation is probably due to the fact that substance abusers tend to deny or underestimate their problems (Prochaska, DiClemente, \& Norcross, 1992).

Various factors may have contributed to clients' improved functioning (Vaughn et al., 2002). Most clients and case managers associated improvements with the treatment program they followed, while receiving case management. A clear association was found between long treatment retention and positive outcomes, while various (short) treatment episodes led to adverse outcomes. Treatment participation and retention have been identified as important mediating variables for positive changes among case managedclients (Siegal et al., 1996; Siegal et al., 1997). Therefore, it was recommended to focus on skills and strategies for increasing treatment participation and retention during case managers' training.

Although several studies have shown a relationship between motivation and outcomes (Miller, 1996), we didn't find any association between motivation and clients' functioning at follow-up. This may be due to the CMR scales' orientation on residential treatment, while about one third followed outpatient treatment. Moreover, motivation might have changed during the 12-month period, as case managers addressed denial and resistance (Brun \& Rapp, 2001). For further research, it was suggested to use the TCU motivation scales for measuring motivation (de Weert-van Oene, Schippers, De Jong, \& Schrijvers, 2002; Siegal et al., 1996).

Clients' legal status can also mediate treatment retention and success, but no association was found between both variables. The role of judicial pressure or coercion in case management remains unclear (Inciardi et al., 1997; SAMHSA, 1998; Vaughn et al., 2002). Despite a potential positive influence, this intervention may be complicated if case managers are both clients' advocate and evaluator of compliance with judicial conditions.

Improved functioning was clearly related to treatment planning, as most changes concerned life domains for which goals and strategies had been formulated. Fewer drug and family problems can be associated with the fact that most services focus their interventions on these domains. A more direct relation can be assumed with employment (McLellan et al., 1999), given case managers' specific attention to this aspect.

The lack of changes concerning psychological problems associated with problem severity at follow-up illustrates the need for extensive psychiatric screening and the provision of direct counseling services. 
Originally, a control group was created to measure the effect of case management compared with a condition without coordination of care. However, only a few persons could be motivated to participate in this condition $(\mathrm{n}=11)$, which was associated with the lack of intervention and financial compensation (Orwin et al., 1994; Vaughn et al., 2002). Moreover, despite several trials, far fewer control persons could be retrieved for a followup interview $(\mathrm{n}=6)$. Due to the small and disproportionate size of the control group, these data were excluded from further analyses.

It was recommended to stimulate the participation of these substance abusers with chronic and complex problems in either condition by using a reward or compensation. If not, the feasibility of a randomized, controlled trial with this population will be seriously hampered (Rapp et al., 1998). The relatively high dropout in the control condition shows case management's role in tracking even extremely problematic clients (Orwin et al., 1994).

The low budget and small sample were certainly a handicap, resulting in many case managers following a minimal number of clients. The great number of case managers may have led to variation, but it was countered by extensive training, regular supervision, and a manual including objectives, case managers' tasks and responsibilities (SAMHSA, 1998; Siegal et al., 2002; Wolf et al., 2002). Afterwards, it was recommended to appoint a multidisciplinary case management team, operating independently from other services and with a caseload of 15 to 20 clients per case manager (SAMHSA, 1998; Wolf et al., 2002). Resources should also cover occasional client expenses to facilitate the treatment process (e.g., child care, clothes, public transport) (Siegal et al., 2002). Still, the project has shown that it is feasible to meet the needs of clients requiring coordination of services for a longer period with minimal efforts and limited resources. Based on the experiences from this pilot study, it was further suggested to formalize communication and cooperation between services, to integrate this intervention in the existing system of services, to appoint a project coordinator, to involve clients' social networks, and to guarantee the accessibility and availability of the case managers (Vanderplasschen, Rombauts, Derluyn, \& Broekaert, 2003).

The implementation of case management particularly affected the organization and delivery of services and was regarded as an important addition to existing services (Graham \& Birchmore-Timney, 1990). Its innovative character appeared from systematic treatment planning, outreach activities, and clients' involvement in the treatment process. During the discussions that followed the presentation of the preliminary results, it was recommended to increase the frequency of the latter activities, since both case managers and clients considered these to be valuable. A strengths perspective may help clients to identify their strengths and assert direct control over their search for resources and could also support client-driven goal planning and monitoring (Brun \& Rapp, 2001).

Given the chronic nature of substance use disorders, several clients might have needed case management for more than 12 months. However, research among mental health 
populations has shown a fading effect of this intervention after 18 to 24 months (Kroon et al., 1999). Moreover, clients might become dependent on their case manager if case management is continued too long. Therefore, a minimal period of six to 12 months was suggested, which can be terminated or continued, based on the realization of postulated goals.

\subsection{Conclusion}

Case management is a relatively new intervention for substance abusers in Europe, and its implementation has been limited to a few countries. Case managers, clients, and other stakeholders participating in this small-scale project in Belgium evaluated this intervention positively. It led to more continuous and individualized care and clients' functioning relatively improved on several life domains. Still, the contribution of case management to the latter changes remains unclear. While case management may have a direct influence on the organization of substance abuse treatment, its impact on clients' functioning is probably mediated by its role in enhancing treatment participation and retention.

Hypotheses from this exploratory study should be further explored during longitudinal, randomized, and controlled trials among larger samples that are controlled for potential mediating variables. Meanwhile, it was suggested to adapt and extend case management to become an integral part of the system of services for substance abusers in Belgium, as it has a supporting role in service utilization and resource acquisition and can thus indirectly affect treatment outcomes.

ACKNOWLEDGEMENTS. We would like to thank all clients, case managers, and services participating in this project. Further, we are grateful to the Province of East-Flanders and PopovGGZ for financial support. 


\section{REFERENCES}

American Psychiatric Association (APA). (1996). Diagnostic and statistical manual of mental disorders. Fourth edition. Washington: American Psychiatric Association.

Brun, C., \& Rapp, R. (2001). Strengths-based case management: individuals' perspectives on strengths and the case manager relations. Social Work, 46(3), 278-288.

Burns, T., Fioritti, A., Holloway, F., Malm, U., \& Rossler, W. (2001). Case management and assertive community treatment in Europe. Psychiatric Services, 52(5), 631-636.

De Leon, G., Melnick, G., Thomas, G., Kressel, D., \& Wexler, H. (2000). Motivation for treatment in a prison-based therapeutic community. American Journal of Drug and Alcohol Abuse, 26(1), $33-46$.

de Weert-van Oene, G., Schippers, G., De Jong, C., \& Schrijvers, G. (2002). Motivation for treatment in substance-dependent patients. European Addiction Research, 8(1), 2-9.

European Monitoring Centre for Drugs and Drug Addiction (EMCDDA) (2001). Annual report on the state of the drug problem in the European Union. Luxembourg: Office for Official Publications of the European Communities.

Graham, K., \& Birchmore-Timney, C. (1990). Case management in addictions treatment. Journal of Substance Abuse Treatment, 7(3), 181-188.

Graham, K., Timney, C., Bois, C., \& Wedgerfield, K. (1995). Continuity of care in addictions treatment: the role of advocacy and coordination in case management. American Journal of Drug and Alcohol Abuse, 21(4), 433-451.

Holloway, F., Oliver, N., Collins, E. \& Carson, J. (1995). Case management: a critical review of the outcome literature. European Psychiatry, 10(3), 113-128.

Inciardi, J. A., Martin, S. S., Butzin, C. A., Hooper, R. M., \& Harrison, L.D. (1996). An effective model of prison-based treatment for drug-involved offenders. Journal of Drug Issues, 27(2), 261-278.

Jerrell, J.M., \& Ridgely, M.S. (1999). Impact of robustness of program implementation on outcomes of clients in dual diagnosis programs. Psychiatric Services, 50(1), 109-112.

Kellinghaus, C., Eikelmann, B., Ohrmann, P. \& Reker, T. (1999). Homeless and mentally ill: a review of recent research on a double disadvantaged minority. Fortschritte der Neurologie Psychiatrie, 67(3), 108-121.

Kroon, H., van Hoof, F. \& Wolf, J. (1999). Praktijk en opbrengsten van case management op de lange termijn. Utrecht: Trimbos-instituut.

Kuckartz, U. (1998). WinMAX: Scientific text analysis for the social sciences (User's guide). Berlin: Udo Kuckartz, BSS.

McLellan, A.T., Hagan, T.A., Levine, M., Meyers, K., Gould, F., Bencivengo, M. et al. (1999). Does clinical case management improve outpatient addiction treatment? Drug and Alcohol Dependence, 55, 91-103.

McLellan, A.T., Kushner, H., Metzger, D., Peters, F., Smith, I., Grissom, G. et al. (1992). The fifth edition of the Addiction Severity Index. Journal of Substance Abuse Treatment, 9, 199-213. 
Miller, W.R. (1996). Motivational interviewing: research, practice, and puzzles. Addictive Behaviors, 21(6), 835-842.

Moore, D. \& McCabe, G. (1999). Introduction to the practice of statistics, Third edition. New York: WH Freeman and Company.

Moxley, D. (1989). The practice of case management, Sage Human Services Guides Vol. 58. Newbury Park: Sage publications.

Oliva, H., Görgen, W., Schlanstedt, G., Schu, M., \& Sommer, L. (2001). Case management in der Suchtkranken- und Drogenhilfe: Ergebnisse des Kooperationsmodells nachgehende Sozialarbeit Modellbestandteil Case management, Berichtszeitraum 1995-2000. Köln: Fogs, Gesellschaft für Forschung und Beratung in Gesundheits- und Sozialbereich $\mathrm{mbH}$.

Orwin, R.G., Sonnefeld, L.J., Garrison-Mogren, R., \& Smith, N.G. (1994). Pitfalls in evaluating the effectiveness of case management programs for homeless persons: lessons from the NIAAA Community Demonstration Program. Evaluation Review, 18(2), 153-207.

Prochaska, J., DiClemente, C., \& Norcross, J. (1992). In search of how people change: applications to addictive behaviours. American Psychologist, 47(9), 1102-1114.

Raes, V. (1999). European Addiction Severity Index (EuropASI). Handleiding De Sleutel. Merelbeke: De Sleutel.

Rapp, R. C., Siegal, H. A., Li, L., \& Saha, P. (1998). Predicting post-primary treatment services and drug use outcome: A multivariate analysis. American Journal of Drug and Alcohol Abuse, 24(4), 603-615.

Ridgely, M.S., \& Willenbring, M. (1992). Application of case management to drug abuse treatment: overview of models and research issues. In R.S. Ashery (Ed.), Progress and Issues in case management (NID A Research Monograph 127) (pp. 12-33). Rockville: National Institute on Drug Abuse.

Shwartz, M., Baker, G., Mulvey, K. P., \& Plough, A. (1997). Improving publicly funded substance abuse treatment: The value of case management. American Journal of Public Health, 87, 16591664.

Siegal, H. A., Fisher, J. A., Rapp, R. C., Kelliher, C. W., Wagner, J. H., O'Brien, W. F. et al. (1996). Enhancing substance abuse treatment with case management: Its impact on employment. Journal of Substance Abuse Treatment, 13(2), 93-98.

Siegal, H. A., Li, L., \& Rapp, R. C. (2002). Case management as a therapeutic enhancement: Impact on post-treatment criminality. Journal of Addictive Diseases, 21(4), 37-46.

Siegal, H., Rapp, R., Li, L., Saha, P., \& Kirk, K. (1997). The role of case management in retaining clients in substance abuse treatment: an exploratory analysis. Journal of Drug Issues, 27(4), 821831.

Substance Abuse and Mental Health Services Administration (SAMHSA). (1998). Comprehensive case management for substance abuse treatment, TIP Series 27. Rockville: U.S. Department of health and human services, Public Health Service, Substance Abuse and Mental Health Services Administration, Center for Substance Abuse Treatment.

Vanderplasschen, W., De Bourdeaudhuij, I., \& Van Oost, P. (2002). Co-ordination and continuity of care in substance abuse treatment: an evaluation-study in Belgium. European Addiction Research, 8, 10-21. 
Vanderplasschen, W., Rombauts, D., Derluyn, I., \& Broekaert, E. (2003). Case management for substance abusing parents and their children: a view from Europe. The Source, 12, 1-4.

Vaughn, T., Sarrazin, M.V., Saleh, S.S., Huber, D.L., \& Hall, J.A. (2002). Participation and retention in drug abuse treatment services research. Journal of Substance Abuse Treatment, 23(4), 387-397.

Willenbring, M. (1996). Case management applications in substance use disorders. In H. Siegal, \& R. Rapp (Eds.), Case management and substance abuse treatment: practice and experience (pp. 51-76). New York: Springer Publishing Company.

Wolf, J., Mensink, C., \& van der Lubbe, P. (2002). Case management voor langdurig verslaafden met meervoudige problemen: een systematisch overzicht van interventie en effect. Utrecht: Trimbos-instituut, Ontwikkelcentrum Sociaal Verslavingsbeleid.

Wolf, J., \& Planije, M. (2002). Case management voor langdurig verslaafden met meervoudige problemen. Utrecht: Trimbos-instituut, Ontwikkelcentrum Sociaal Verslavingsbeleid. 


\section{Chapter 6}

\section{Review of the effectiveness of different models of case management for substance abusers ${ }^{7}$}

ABSTRACT. The field of substance abuse treatment is characterized by a constant search for new methods and interventions that yield better outcomes and decrease costs. Case management is one of these interventions that has been implemented to improve (cost-)effectiveness, but controversy exists about its potential to realize these objectives. A systematic and comprehensive review of peer-reviewed articles $(n=48)$ published within the last 10 years (1993-2003) is presented, focusing on the effects of different models of case management among various substance abusing populations. Four models were distinguished: the brokerage/generalist model, assertive community treatment/intensive case management, the clinical/rehabilitation model, and strengths-based case management. Results show that several studies have reported positive effects, but only some randomized and controlled trials have demonstrated the effectiveness of case management compared with other interventions. Longitudinal effects of this intervention remain unclear. Although we found no compelling evidence for the effectiveness of case management, some evidence is available about the (differential) effectiveness of intensive, strengths-based and generalist case management. Most positive effects concern reduced use of inpatient services and increased utilization of community-based services, prolonged treatment retention, improved quality of life, and high client satisfaction. Effects concerning drug use and psychosocial functioning are less consistent, but seem to be mediated by retention in treatment and case management. Further research is required to learn more about the extent of the effects of this intervention, how long these are sustained and what specific elements cause particular effects.

\footnotetext{
7 This chapter is based on: Vanderplasschen, W., Wolf, J., Rapp, R.C., \& Broekaert, E. (2004). Review of the effectiveness of different models of case management for substance abusers. Manuscript submitted for publication.
} 



\subsection{INTRODUCTION}

\subsubsection{EFFECTIVENESS OF SUBSTANCE ABUSE TREATMENT}

Evaluation of the effectiveness of substance abuse treatment services has shown that such interventions work for many clients, particularly for reducing drug use and associated problems such as unemployment and criminality (Gossop, Marsden, Stewart, \& Kidd, 2003; McLellan, Luborsky, O’Brien, Woody, \& Druley, 1982; Mejta, Bokos, Mickenberg, Maslar, \& Senay, 1997; Miller \& Wilbourne, 2002; Simpson, 1981; Simpson, Joe, Fletcher, Hubbard, \& Anglin, 1999; Sindelar, Jofre-Bonet, French, \& McLellan, 2004). Positive outcomes were found across treatment modalities (methadone maintenance, drug-free outpatient, short-term inpatient, and long-term residential) (Hser, Anglin, \& Fletcher, 1998; Hubbard, Craddock, \& Anderson, 2003) and cost-effectiveness was demonstrated for several interventions, especially when compared with no treatment or incarceration (McLellan et al., 1996; Barnett, 1999). A strong relationship exists between time in treatment (retention) and successful outcomes (Gossop, Marsden, Stewart, \& Rolfe, 1999; Hubbard et al., 2003; Simpson, 1981). Consequently, several programs have focused on strategies to extend the length of treatment e.g., by enhancing motivation and identifying the crucial elements of particular interventions (EMCDDA, 2002).

Despite several positive outcomes, some observations question the effectiveness of substance abuse treatment: limited accessibility of treatment agencies (Willenbring, 1996; Brindis \& Theidon, 1997; SAMHSA, 1998), relatively high dropout and low completion rates (Sindelar \& Fiellin, 2001), frequent and multiple service utilization (Cox et al, 1998; Thornquist, Biros, Olander, \& Sterner, 2002), and long treatment careers (Hser, Anglin, Grella, Longshore, \& Prendergast, 1997; Moos, 2003). Although longitudinal studies showed effects up to five years after treatment, relapse is often reported and tends to increase over time (Friedmann, Lemon, Anderson, \& Stein, 2002; Gossop, Stewart, Browne, \& Marsden, 2002; Simpson, Joe, \& Broome, 2002).

In spite of the chronic, relapsing character of substance abuse problems, most evaluation studies have looked at the effects of specific interventions, while a continuing care perspective may be more imperative (McLellan, 2002). Some authors have demonstrated some evidence of a cumulative effect of various treatment episodes (Hser et al., 1997).

\subsubsection{IMPLEMENTATION OF CASE MANAGEMENT}

Due to the partial and limited success of substance abuse treatment, this field is characterized by a constant search for new interventions that yield better outcomes and decrease costs (Saleh et al., 2002). Several strategies were developed to increase access and participation and to reduce attrition from treatment, such as motivational interviewing, low threshold programs, harm reduction initiatives, relapse prevention techniques, client- 
treatment matching, centralized intake units, integrated treatment, and contingency management (Broekaert \& Vanderplasschen, 2003; Drake, Mercer-McFadden, Mueser, McHugo, \& Bond, 1998; EMCDDA, 2002; Godley, Godley, Dennis, Funk, \& Passetti, 2002; Griffith, Rowan-Szal, Roark, \& Simpson, 2000; Miller, 1996). Also, case management was implemented to improve (cost-)effectiveness of substance abuse treatment (Brindis \& Theidon, 1997; McLellan et al., 1999; Mejta et al., 1997; SAMHSA, 1998). This intervention was adapted to work with substance abusers after it had been successfully applied among mentally ill persons (Rubin, 1992; Solomon, 1992).

Following de-institutionalization in mental health care, case management was implemented to help people access the resources they needed for living and functioning in the community (Hall, Carswell, Walsh, Huber, \& Jampoler, 2002). The role of case management for achieving these objectives has been studied extensively and generally indicates positive outcomes such as reduced hospitalization, increased use of outpatient and community services, improved quality of life, and high client satisfaction (Rosen \& Teesson, 2001; Ziguras \& Stuart, 2000; Ziguras, Stuart, \& Jackson, 2002). However, conflicting results have been reported across various countries and models (Burns, Fioritti, Holloway, Malm, \& Rossler, 2001), and the impact of case management on clients' functioning remains especially unclear (Drake, McHugo et al., 1998; Marshall, Gray, Lockwood, \& Green, 2000; Ziguras \& Stuart, 2000).

The first implementation of case management for substance abusing populations goes back to the beginning of the 1980s and was based on the recognition that these persons often have significant problems in addition to their substance abuse (Vanderplasschen, Rapp, Wolf, \& Broekaert, in press). This intervention is regarded as an important supplement to traditional substance abuse agencies, since it provides an array of wraparound services that are usually not part of standard treatment (SAMHSA, 1998). Case management is generally described as a coordinated and integrated approach to service delivery, intended to provide ongoing supportive care and to facilitate clients linking with appropriate helping resources (Birchmore-Timney \& Graham, 1989; Bokos, Mejta, Mickenberg, \& Monks, 1992). Its actual practice is characterized most accurately by its core functions: assessment, planning, linking, monitoring, and advocacy (SAMHSA, 1998). During the last decade, case management has been applied among several specific target groups such as substance abusing mothers, dually diagnosed persons, chronic public inebriates, HIV-infected individuals, offenders, and homeless persons (Brindis \& Theidon, 1997; Jerrell, Hu, \& Ridgely, 1994; Martin \& Scarpitti, 1993; Orwin, Sonnefield, GarrisonMogren, \& Smith, 1994; Willenbring, Whelan, Dahlquist, \& O’Neill, 1990).

Four models of case management are usually distinguished for working with substance abusers: the brokerage/generalist model, assertive community treatment/intensive case management, the clinical/ rehabilitation model, and strengths-based case management (Ridgely \& Willenbring, 1992; SAMHSA, 1998; Vanderplasschen et al., in press). The brokerage model is a very brief approach to case management in which case workers 
attempt to help clients identify their needs and broker ancillary or supportive services in one or two contacts (SAMHSA, 1998; Stahler, Shipley, Bartelt, DuCette, \& Shandler, 1995). Generalist or standard models utilize the commonly accepted functions of case management and are characterized by a closer involvement between case manager and client (Woodside \& McClam, 2002). Assertive Community Treatment assumes a comprehensive role for (a team of) case managers by providing assertive outreach and direct counseling services, including skills-building, family consultations and crisis intervention (Stein \& Test, 1980). Similarly, intensive case management applies the same principles, usually with a smaller caseload. Clinical or rehabilitation approaches combine resources acquisition (case management) and clinical or rehabilitation activities, which might include psychotherapy for clients and their families or teaching of specific skills (Kanter, 1989). Finally, strengths-based case management focuses on clients' strengths, self-direction, and the use of informal help networks (as opposed to agency resources) (Brun \& Rapp, 2001; Siegal et al., 1995). It further stresses the primacy of the client-case manager relationship and applies an active form of outreach.

\subsubsection{EFFECTIVENESS OF CASE MANAGEMENT}

The first publications concerning case management for substance abusers mainly focused on implementation and intervention issues (Birchmore-Timney \& Graham, 1989; Graham \& Timney, 1990; Ogborne \& Rush, 1983; Ridgely \& Willenbring, 1992; Rush \& Ekdahl, 1990; Sullivan, Hartmann, Dillon, \& Wolk, 1994; Sullivan, Wolk, \& Hartmann, 1992), and only some included an evaluation component. One of the first studies showed that case management could reduce attrition and improve both psychosocial and drug and alcohol outcomes, especially among the most problematic clients (Lightfoot et al., 1982). Willenbring and his colleagues also demonstrated the effectiveness of case management as it helped to keep public inebriates engaged in treatment, to stabilize their situation, to improve access to service providers, to reduce clinical deterioration, and to provide continuity of care (Willenbring, Ridgely, Stinchfield, \& Rose, 1991). On the other hand, Pearlman (1984) found case management had no effect on reducing the dropout rate among clients entering treatment, but observed a substantial increase in the proportion of persons entering treatment after intake. Other authors (Falck, Siegal, \& Carlson, 1992; Lidz, Bux, Platt, \& Iguchi, 1992) have reported few or no effects of this intervention, when compared with non-case managed control groups.

As these early studies illustrate, controversy exists about the effectiveness of this intervention, resulting in a lack of evidence about which model should be applied for what population (Sorensen et al., 2003; Vanderplasschen et al., in press). Moreover, most publications refer only selectively to available literature, which may result in the underreporting of particular outcomes. Therefore, we made a systematic and comprehensive review of available research, focusing on the effectiveness of different models of case 
management among various substance abusing populations. Effectiveness refers to the ability of this intervention to achieve the postulated goals (Vanderplasschen, De Bourdeaudhuij, \& Van Oost, 2002). Objectives of case management can be established on the client level as well as on the system level and may include ameliorating client outcomes, service utilization, clients' satisfaction, and quality of life, and improving accessibility, accountability, coordination and continuity of care, and cost containment, respectively (SAMHSA, 1998; Willenbring, 1996).

\subsection{METHOD}

For assessing the effectiveness of case management, we restricted our review to articles published in peer-reviewed journals within the last ten years (1993-2003). Peer review was postulated as a minimal guarantee for the quality of the selected studies and 1993 seemed an appropriate starting date, since no evaluation studies were published before that date in these types of journals (Mejta et al., 1997). Although the selected articles have been published since 1993, the research itself may have been performed before this period. In order to be included, a study had to evaluate at least one model of case management, focus on substance abusers (possibly with mental illness as a cooccurring, but not a secondary disorder), and report at least one outcome variable. While controlled trials are generally regarded as the strongest form of evidence of treatment efficacy (Miller \& Wilbourne, 2002; Ziguras \& Stuart, 2000), we chose not to restrict our review to studies that include a comparison condition and use a procedure to yield equivalent groups before treatment (randomization), since the number of randomized and controlled studies concerning this intervention is still relatively small (Vanderplasschen et al., in press).

We used the terms "case management", "substance abuse/drug abuse/addiction" and "evaluation/outcomes/effects/effectiveness" for computer keyword searches in following comprehensive but partly overlapping databases: (Social) Sciences Databases of the Institute of Scientific Information, Medline, PsycInfo, and PubMed. Further, we made hand searches of the cited references from selected articles. After eliminating double counts, we identified 87 articles that contained all three search criteria. Based on an initial analysis of the abstract and/or full text of these articles, it appeared that 38 articles were not eligible for our review: some did not concern outcome studies, but rather an evaluation of implementation issues $(n=12)$; the primary focus was people with severe mental illness ( $n=11)$; case management was part of a comprehensive intervention and the authors did not report on the effects of this intervention separately $(n=7)$; no outcome measure was included $(\mathrm{n}=5)$; or it concerned a review article of which the original article was already included in our review $(\mathrm{n}=3)$. A group of experts examined the preliminary list of references and made suggestions for outcome studies that had been missed. One study 
was added that is frequently cited in peer-reviewed articles but was only published as a research report (Rhodes \& Gross, 1997). The paper or electronic versions of four selected articles could not be accessed, even after contacting the principal author, and were thus not included in our study. Finally, we selected 46 articles that will be further analyzed in this manuscript.

Peer-reviewed journals as a data source may induce a publication bias since these journals are usually edited in English (Miller \& Wilbourne, 2002). Consequently, evaluation studies by non-English-speaking authors may be under-represented in the international peerreviewed literature. Despite the increased implementation of case management in Europe (Vanderplasschen et al., in press), we could not find any English-language article that evaluated the effectiveness of this intervention for substance abusers on this continent. We compensate for this possible bias by including two original research reports that focused on this issue in Germany and Belgium (Oliva, Görgen, Schlanstedt, Schu, \& Sommer, 2001; Vanderplasschen, Lievens, \& Broekaert, 2001). Moreover, selection of peer-reviewed published material may have resulted in an analysis of studies that have demonstrated significant outcomes, while insignificant or even adverse outcomes tend to remain unpublished (Rosen \& Teeson, 2001). To partly meet this potential bias, we did not focus exclusively on studies with a rigorous design, but also included results from descriptive and retrospective studies. While reporting on the effectiveness of different models of case management, we will examine the quality of the research design (type and extent of the study) and the direction and significance of reported effects but not the size of these effects.

\subsection{RESULTS}

Analysis of the selected articles (cf. table 6.1., p. 156) shows that most studies have evaluated the effectiveness of intensive case management $(n=20)$. Strengths-based $(n=11)$ and generalist case management $(=10)$ have been evaluated to a lesser extent, while relatively few studies have focused on the effects of assertive community treatment $(n=4)$, clinical $(n=2)$, and brokerage $(n=1)$ case management. No studies were retrieved that utilized a rehabilitation model. We identified several articles $(n=18)$ that referred to only six original studies, resulting in the analysis of a total of 36 unique studies. Further, some studies have applied brokerage $(n=2)$ or generalist case management $(n=2)$ as a control condition for evaluating more specialized models of case management.

Most methodological rigor (randomized and controlled trials) is associated with studies focusing on the effects of assertive community treatment (100\%), brokerage $(100 \%)$ and strengths-based case management $(90.9 \%)$. Half of all studies concerning generalist case management (50\%) and 35\% of the articles concerning intensive case management applied 
an experimental design, while no studies concerning clinical case management utilized such a design.

Table 6.1.: Overview of selected articles, according to study design and model of case management $(n=48)$

\begin{tabular}{|c|c|c|c|c|c|}
\hline & $\begin{array}{c}\text { experimental } \\
\text { study } \\
\text { (randomized and } \\
\text { controlled trial) }\end{array}$ & $\begin{array}{c}\text { quasi- } \\
\text { experimental } \\
\text { study } \\
\text { (controlled trial) }\end{array}$ & $\begin{array}{c}\text { retrospective } \\
\text { study }\end{array}$ & $\begin{array}{c}\text { descriptive } \\
\text { study }\end{array}$ & total \\
\hline Brokerage case management & 1 & 0 & 0 & 0 & 1 \\
\hline Generalist case management & 5 & 1 & 4 & 0 & 10 \\
\hline Assertive community treatment & $4(2)^{*}$ & 0 & 0 & 0 & $4(2)$ \\
\hline Intensive case management & 7 & $5(2)^{*}$ & 2 & 6 & $20(18)^{*}$ \\
\hline Clinical case management & 0 & 1 & 0 & 1 & 2 \\
\hline $\begin{array}{l}\text { Strengths-based case } \\
\text { management }\end{array}$ & $10(2)^{*}$ & 0 & 0 & 1 & $11(3)^{*}$ \\
\hline Total & $27(18)^{*}$ & $7(4)^{*}$ & 6 & 8 & $48(36)^{*}$ \\
\hline
\end{tabular}

\subsubsection{ASSERTIVE COMMUNITY TREATMENT AND INTENSIVE CASE MANAGEMENT}

Several randomized and controlled studies have tested the effectiveness of intensive case management/assertive community treatment for assisting diverse populations, such as offenders, homeless persons, chronic public inebriates, and dually diagnosed individuals (cf. table 6.2., pp. 179-182). Moreover, quasi-experimental and descriptive studies and one retrospective study provide further information about the effects of this intervention.

\section{口 OFFENDERS}

One of the early experimental studies looked at case management's potential for reducing recidivism and relapse among parolees with a drug use history, but found little difference between assertive community treatment and conventional parole for affecting drug use, sexual risk behavior, and recidivism (Martin \& Scarpitti, 1993). Subsequent analyses also showed only modest effects of assertive community treatment, and it was concluded that this intervention was of limited value for clients who were not merely unable to access services (Inciardi, Martin, \& Scarpitti, 1994). Among a similar population of drug-involved arrestees, Rhodes and Gross (1997) demonstrated significant reductions in drug use at one site and reduced recidivism and increased treatment participation at both sites, when intensive case management was compared with two control conditions. However, this intervention was not more effective for reducing injecting and sexual risk behavior. 
REVIEW OF THE EFFECTIVENESS OF DIFFERENT MODELS OF CASE MANAGEMENT

Two descriptive studies have associated intensive case management with positive outcomes. Godley and colleagues (2000) found a significant reduction of legal problems after six months among dually diagnosed persons involved in the criminal justice system, and their other problems also improved, but not significantly. Although relapse and reincarceration occurred, intensive case management helped to link HIV-positive exoffenders to a variety of (medical) services and to maintain them in the program (Rich et al., 2001).

\section{a HOMELESS SUBSTANCE ABUSERS}

Orwin and colleagues (1994) assessed the effectiveness of intensive case management among homeless substance abusers in three cities (Boston, Louisville, and Minneapolis), but only one project showed indications of effectiveness relative to the standard treatment control group. Moreover, differential effectiveness (i.e., improved housing) could only be demonstrated if it was assumed that persons who dropped out of the control group deteriorated. Also, other authors (Stahler et al., 1995) found no differential effects between intensive case management and control conditions (except for treatment satisfaction). Still, all three groups improved significantly over time concerning alcohol and cocaine use, employment, and housing stability. Similarly, Braucht and colleagues (1995) demonstrated positive but not differential effects of case management in addition to a comprehensive program of substance abuse and rehabilitation services. They concluded that intensive case management only marginally increased clients' contacts with outside services and had little effect on the tailoring of services to clients' needs and, consequently, on client outcomes.

On the other hand, Cox and colleagues (1998) did find support in an experimental study for the effectiveness of intensive case management among chronic public inebriates. Although both groups improved over time, the case management group had significantly better outcomes concerning income from public sources, nights spent in own place, and days of drinking. The authors assumed that the amount of (substance abuse) services mediated these effects. Others have demonstrated that intensive case management significantly improved patients' level of psychosocial functioning, decreased the utilization of emergency services, and led to substantial cost savings among chronically addicted, mentally ill homeless individuals who frequently utilize emergency services (Witbeck, Hornfeld, \& Dalack, 2002). A retrospective study revealed that this intervention was as successful as and more cost-effective than supportive housing for reducing the median of detoxification, emergency and medical visits, and charges among chronic public inebriates, but the mean medical charges did not diminish substantially due to some extremely catastrophic cases (Thornquist et al., 2002). 


\section{a DUALLy Diagnosed PATIENTS}

Jerrell, Ridgely, and colleagues compared the (cost-)effectiveness of three substance abuse interventions - 12-step recovery program, intensive case management, and behavioral skills training - for severely mentally ill persons with co-occurring substance use disorders over a 24-month period in a (partially) randomized and controlled trial (Ridgely \& Jerrell, 1996). They showed an impressive - though insignificant - impact of the latter two interventions on the use of (sub)acute inpatient services (reduced), involvement with outpatient supportive services (increased), and total health care costs (decreased), without transferring the burden to the family or legal system (Jerrell et al., 1994). However, robustness of program implementation across different sites affected these outcomes significantly (Ridgely \& Jerrell, 1996). Robustly implemented case management led to clients having significantly better psychosocial functioning, fewer alcohol and drug symptoms, and lowering of the costs of intensive services, while nonrobust case management was regarded to be the least efficient intervention (Jerrell \& Ridgely, 1999).

Relatively few differences appeared from a comparison of the effectiveness of assertive community treatment and standard case management in a three-year outcome study among patients with dual disorders, except that the ACT group improved more on some measures of substance abuse and quality of life (Drake, McHugo et al., 1998). Both groups ameliorated equally over time on several outcome measures, which was explained by the relatively small differences between both interventions. Clark and colleagues (1998) compared the cost-effectiveness of these interventions and found no differences, except that standard case management was more efficient during the first two years and that assertive community treatment was more cost-effective the third year.

Both studies confirmed the early observations of Durell and colleagues that severely mentally ill substance abusers can benefit from intensive and outreach case management and concurrent treatment of both disorders (Durell, Lechtenberg, Corse, \& Frances, 1993).

\section{a OTHER TARGET GROUPS}

Sorensen and colleagues (2003) found no support for the hypothesis that intensive case management improved outcomes among substance abusers with HIV/AIDS more than a brokerage model. Despite significantly reduced problem severity within both groups after six months, these changes disappeared after 12 and 18 months. Godley and colleagues (2002) showed the effectiveness of intensive case management compared with standard continuing care for adolescent substance abusers, since case managed adolescents were more likely to initiate and receive continuing care, stay longer in continuing care, abstain from marijuana, and use less alcohol at the 3-month follow-up. 
In a quasi-experimental study, Kilbride and colleagues only detected some effects of intensive family case management for term or near-term infants of cocaine abusing women (Kilbride, Castor, Hoffman, \& Fuger, 2000). Cognitive development at six months and verbal scores at 36 months were significantly better among case managed infants, but case managed and non-case managed parents were as likely to lose custody of their children. Uncontrolled studies have associated intensive case management for pregnant and postpartum women with significant improvements across several outcome indicators (substance use, employment, arrests, incarceration, baby's birth weight, and social agency support) by the time case management ended (Lanehart, Clark, Rollings, Haradon, \& Scrivner, 1996). Also, Evenson, Binner, Cho, Schicht and Topolski (1998) found a consistent positive impact of a community program with wrap-around services and intensive case management on several drug-related problems (e.g., global functioning, substance use, interpersonal relations, legal difficulties, employment, and parenting). These outcomes improved with longer lengths of stay.

Implementation of intensive case management for multi-impaired chronic addicts in Germany helped to retain these clients under supervision and to improve or stabilize the overall situation of most clients (Oliva et al., 2001). Positive outcomes were related with longer retention in case management and the vast majority of clients were satisfied or very satisfied with this intervention. A small-scale study among substance abusers with multiple and complex problems in Belgium revealed that intensive case management contributed significantly to the reduction and stabilization of substance use and legal, employment, and family problems (Vanderplasschen et al., 2001).

\subsubsection{STRENGTHS-BASED CASE MANAGEMENT}

Although various articles have focused on the effects of strengths-based case management, these publications relate almost exclusively to two large NIDA-funded studies in Iowa and Ohio (cf. table 6.3., pp. 183-184).

The Iowa case management study compared the differential effectiveness of three variations of strengths-based case management for substance abusers entering (residential) treatment in a rural area. These researchers demonstrated a significant impact of inside case management on the utilization of medical and substance abuse services during a 12month period (Vaughan-Sarrazin, Hall, \& Rick, 2000). Saleh and colleagues (2002) found few differential effects concerning client outcomes: inside case management led to significantly better legal outcomes after six months and an improved employment situation after 12 months, while outside case management contributed to reduced drug use at the 3-month follow-up and decreased psychological problems at the 3-and 12-month follow-up. However, most effects - especially concerning drug use - tended to decline over time (Saleh et al., 2002; Vaughan-Sarrazin et al., 2000). All three modalities had a significant impact on family relationships and parental attitudes after six months, but these 
effects were not apparent after 3 and 12 months (Sarrazin, Huber, \& Hall, 2001). Face-toface case management was associated with superior outcomes as compared to telecommunication case management (Saleh et al., 2002). Clients in the latter group received significantly higher dosages (amount, frequency, breadth, duration) of case management and high doses were significantly related to more severe legal and family problems at the 12-month follow-up (Huber, Sarrazin, Vaughn, \& Hall, 2003). Persons with higher premorbid cognitive abilities benefited most from telecommunication case management (Block, Bates, \& Hall, 2003). Finally, Iowa case management appeared to be particularly effective for improving employment among amphetamine users, although this intervention did not impact this subgroup any differently than clients reporting abuse of other drugs (Cretzmeyer, Sarrazin, Huber, Block, and Hall, 2003).

Another experimental study among veterans with substance abuse problems following primary treatment associated strengths-based case management with improved employment functioning after six months (Siegal et al., 1996). Case management further contributed significantly to treatment retention, which was in turn related to less drug use and improved legal outcomes (Rapp, Siegal, Li, \& Saha, 1998; Siegal, Li, \& Rapp, 2002; Siegal, Rapp, Li, Saha, \& Kirk, 1997). This intervention also promoted after-care participation at the 12-month follow-up, which was positively related to post-treatment criminality (Siegal et al., 2002). Multivariate analyses revealed that case management had no direct impact on drug use severity, but that this effect was mediated by its role in enhancing treatment participation and retention (Rapp et al., 1998).

Zanis and Coviello (2001) adopted the strength-based principles to assist a small sample of chronically unemployed methadone clients with their employment situation, and found that this intervention helped most of them to acquire and maintain a job during an 8month period. Although participants evaluated this intervention as effective and valuable, they regarded six months as too short a period of time for stabilizing employment functioning.

\subsubsection{GENERALIST OR STANDARD CASE MANAGEMENT}

Generalist or standard case management has been applied among various substance abusing populations, namely among intravenous drug users, homeless persons, and pregnant women and mothers (cf. table 6.4., pp. 185-186).

Mejta and colleagues (1997) demonstrated in a clinical trial that treatment access and retention improved significantly among case managed intravenous drug users, especially when case managers had money to purchase treatment. A longitudinal study of injecting drug users randomly assigned to case management or a control intervention showed that

drug use had decreased markedly among case managed individuals after 36 months, and to a lesser extent among the control group (Levy, Strenski, \& Amick, 1995). 
Homeless addicted veterans who received case management following residential care were retained significantly longer in treatment and had better alcohol, medical, employment, and housing scores the first nine months after admission than clients who followed usual treatment, although these effects diminished after 12 months (Conrad et al., 1998). Lapham, Hall and Skipper (1995) found no differential effectiveness between case management and (peer-supervised) housing among homeless alcoholics after ten months, but found significant within-group differences concerning days of alcohol use, housing stability, and employment status, especially among program graduates. The difficulty to maintain positive changes over time was also shown in a descriptive study among homeless substance abusing women, since the observed effects plateaued or even deteriorated after 12 months (Mercier \& Racine, 1993).

Comparison of the effects of psychosocially enhanced treatment and standard case management for cocaine dependent mothers showed a significant time effect of both interventions (Volpicelli, Markman, Monterosso, Filing, \& O'Brien, 2000), but women in the former condition had superior treatment attendance and greater reductions in cocaine use, though equal psychosocial functioning.

Others have shown that case management, particularly the availability of transportation, helped pregnant substance abusing women to overcome barriers to treatment and contributed significantly to retention in substance abuse treatment (Laken \& Ager, 1996). Eisen, Keyser-Smith, Dampeer, and Sambrano (2000) revealed that standard case management - rather than day treatment - was associated with significantly reduced use of illicit drugs between intake and 30 days after delivery among this population, but these effects were not maintained six months later.

Although a retrospective study revealed that a substantial number of offenders who had followed a TASC program had been rearrested during the 18-month study period, standard case management was regarded as an effective intervention for reducing recidivism, since treatment non-completers were significantly more likely to be rearrested than treatment completers (Van Stelle, Mauser, \& Moberg, 1994). This intervention was more cost-effective than incarceration and also successful among offenders with extensive criminal records.

Finally, a large retrospective study among substance abusers discharged from different treatment settings has shown that case managed clients were significantly more likely to stay longer in treatment and to follow post-primary treatment, and they were less likely to be readmitted to a detoxification program after discharge (Shwartz, Baker, Mulvey, \& Plough, 1997). 


\subsubsection{CLinical CASE MANAGEMENT}

McLellan and colleagues (1999) have associated clinical case management with an increase in the provision of services concerning alcohol, employment, medical, and legal problems and significant improvements concerning alcohol and drug use, medical and psychiatric status, and employment functioning after six months (cf. table 6.5., p. 187). However, no differential outcomes and similar patterns of service utilization were observed during the first 12 months of the study. This was attributed to a lack of training and pre-contracting of services. Clinical case management appeared to be a cost-effective service for frequent users of emergency services, since this intervention led to significant reductions in the median of emergency visits and inpatient and emergency costs, and an increase in the use of primary care services and improved psychosocial functioning (Okin et al., 2000).

\subsubsection{BROKERAGE CASE MANAGEMENT}

The only study that has evaluated the effectiveness of brokerage case management revealed that case managed-clients were significantly more likely to show up for treatment after initial assessment than non-case managed clients, and that they were also more often referred to ancillary services (Scott, Sherman, Foss, Godley, \& Hristova, 2002) (cf. table 6.5., p. 187). However, no differences appeared in the number of services received and retention in substance abuse treatment. Other studies (Stahler et al., 1995; Sorensen et al., 2003) have utilized a brokerage model as control condition for more specialized models of case management and demonstrated that this intervention was equally effective for affecting client outcomes and service utilization.

\subsection{DisCUSSION}

This review of peer-reviewed articles that have evaluated the effectiveness of case management does not show compelling evidence for the effectiveness of this intervention, although several studies have reported positive effects concerning client outcomes, service utilization, treatment access and retention, quality of life, consumers' satisfaction, and cost savings. It appears that especially descriptive, retrospective, and quasi-experimental studies have shown beneficial outcomes, while studies applying a methodologically stronger design (randomized and controlled trials) have often failed to prove the effectiveness of case management compared with other interventions, particularly over a longer period of time. Still, other authors have shown longitudinal effects of this intervention. 


\subsubsection{EFFECTIVENESS OF DIFFERENT MODELS OF CASE MANAGEMENT}

Irrespective of any specific population, five out of nine randomized and controlled trials have shown significant differential effects of intensive case management/assertive community treatment when compared with other interventions: reduced recidivism, less alcohol and drug use, housing stability, improved quality of life and psychosocial functioning, increased treatment participation and retention, less use of inpatient services, and reduced costs (Cox et al., 1998; Drake, McHugo et al., 1998; Godley et al., 2002; Rhodes \& Gross, 1997; Witbeck et al., 2002). However, few studies have repeated the findings of other studies, and usually only some significant differences were found. Also, quasi-experimental studies have shown inconsistent results (Kilbride et al., 2000; Orwin et al., 1994), but robustly implemented intensive case management has been identified as a cost-effective intervention (Jerrell \& Ridgely, 1999). Uncontrolled studies applying a prepost design have consistently reported positive results, mainly concerning psychosocial functioning, client satisfaction and service utilization (Durell et al., 1993; Evenson et al., 1998; Godley et al., 2000; Lanehart et al., 1996; Oliva et al., 2001; Rich et al., 2000; Thornquist et al., 2000; Vanderplasschen et al., 2001). We conclude that intensive case management appears to be most effective for extremely problematic substance abusers such as chronic public inebriates and dually diagnosed individuals, since this intervention helps to stabilize and improve psychosocial functioning and to reduce utilization of expensive inpatient services (Drake, McHugo et al., 1998; Thornquist et al., 2000; Witbeck et al., 2002). This intervention might also be effective for other populations, but we found insufficient evidence of such effects except in uncontrolled studies.

As only two experimental studies have evaluated the effectiveness of strengths-based case management, little evidence is available about the effects of this intervention. Both studies have demonstrated significant effects on service utilization and legal and employment outcomes (Saleh et al., 2002; Siegal et al., 1996; Siegal et al., 2002; Siegal et al., 1997; Vaughan-Sarrazin et al., 2000). Strengths-based case management's potential for improving employment functioning also appeared from a case study (Zanis \& Coviello, 2001). However, effects tended to fade after 12 months in the Iowa study (Saleh et al., 2002), while these were maintained in the other study (Siegal et al., 2002). The latter researchers also showed that outcomes concerning psychosocial functioning were significantly affected by treatment retention (Rapp et al., 1998). Given its role in addressing denial and resistance, its appreciation among clients and its potential positive effects (Brun \& Rapp, 2001), it is recommended this strengths-perspective be applied in other studies, mainly to enhance treatment participation and retention among persons with little motivation for change.

Although two out of five randomized and controlled trials utilizing generalist case management have reported differential effects concerning drug and alcohol abuse compared with the control group, these effects were marginal or decreased over time 
(Conrad et al., 1998). Effects of standard case management rather concern improved treatment participation and retention (Conrad et al., 1998; Mejta et al., 1997), but psychosocially enhanced treatment (including individual psychotherapy) was still superior to this intervention (Volpicelli et al., 2002). Uncontrolled studies also have demonstrated positive effects on treatment access and retention, substance abuse, and recidivism (Laken \& Ager, 1996; Shwartz et al., 1997; Van Stelle et al., 1994), but effects could not always be maintained over time (Eisen et al., 2000; Mercier \& Racine, 1993). However, some authors have shown such effects over a 36-month period (Clark et al., 1998; Drake, McHugo et al., 1998). Standard case management might be appropriate for enhancing treatment participation and retention among several substance abusing populations, but probably needs to be combined over time with more intensive or specialized models of case management or with other interventions (Clark et al., 1998).

Although brokerage models of case management include a very brief intervention, available research showed that this method was not inferior to more specialized models for reducing drug-related problems and stimulating service utilization (Sorensen et al, 2003; Stahler et al., 1995). On the other hand, brokerage case management only seems to affect initial treatment participation and linking to services, but not subsequent retention and/or service utilization (Scott et al., 2002). Further research is needed concerning brief models of case management, since such interventions can lead to some positive outcomes and might be cost-effective.

Little empirical data are available about the effectiveness of clinical case management, but the results from non-experimental studies are promising (McLellan et al., 1999; Okin et al., 2002). The combination of psychotherapy and resource acquisition significantly affected substance abusers' psychosocial functioning and service utilization and was more costeffective than standard treatment, particularly for frequent users of inpatient services (Okin et al., 2002; Sindelar et al., 2004).

\subsubsection{EVIDENCE OF EFFECTIVENESS}

Based on a systematic review of randomized and controlled studies of interventions for alcohol use disorders, Miller and Wilbourne (2002) concluded that case management is one of the psychosocial interventions for alcohol use disorders with the strongest evidence of efficacy. The inconsistent and modest effects of different models of case management we found do not really support this conclusion.

Sufficient evidence for the effectiveness of a certain intervention is usually concluded when five or more randomized and controlled studies have shown particular effects (Van Gageldonk, de Zwart, van der Stel, \& Donker, 1997; Wolf, Mensink, \& van der Lubbe, 2002). Some evidence is available if two to four experimental studies have demonstrated such effects, and insufficient evidence exists if only one experimental study or non- 
experimental studies have found these effects. Based on this assumption, we conclude that some evidence is available for an effect of intensive case management/assertive community treatment on psychosocial functioning (alcohol use, housing, employment) and service utilization. Some evidence also exists of the effectiveness of strengths-based case management for improving employment functioning and treatment participation and retention, and of the effectiveness of standard case management for enhancing participation and retention. Insufficient or no evidence is available about the effectiveness of brokerage and clinical case management, which is mainly due to a lack of randomized and controlled trials. The scarcity of experimental studies also explains the overall lack of sufficient evidence of the effectiveness of this intervention. Moreover, the use of multiple and inconsistent outcome measures and contextual differences have hampered the duplication of findings from earlier studies (Wolf et al., 2002). We conclude that some evidence is available about the effectiveness of case management. This conclusion confirms the observation that most social interventions have modest effects at best (Lipsey, 1990), but the effectiveness of case management might be relatively high compared with other interventions (Miller and Wilbourne, 2002).

Although several studies have failed to demonstrate a significant between-group effect favoring the case management condition, several (quasi-)experimental studies have revealed significant positive effects when compared with baseline assessments e.g., concerning substance abuse, housing, employment, quality of life, psychological functioning, and service utilization (Braucht et al., 1995; Drake, McHugo et al., 1998; Jerrell \& Ridgely, 1995; Lapham et al., 1995; Siegal et al., 1997; Stahler et al., 1995; Witbeck et al., 2002). Without a control condition, authors may have wrongly assigned such time effect to case management, while other factors, such as motivation, retention, and client characteristics, may have accounted for these positive outcomes. Others have suggested "spontaneous remission" or the hypothesis of a "regression to the mean", since most substance abusers start with case management at a very low level in their functioning and a certain degree of improvement may be part of the natural course of substance abuse problems. Several authors have rejected these hypotheses, based on the observation that persons receiving less intensive services showed far less improvement (Braucht et al., 1995; Lapham et al., 1995; Stahler et al., 1995).

According to Orwin and colleagues (1994), the lack of evidence for the differential effectiveness of case management may have more to do with the way it is evaluated than with the intervention itself. Treatment that has been compared primarily with other viable treatment - not with minimal or no treatment - may seem less effective since the latter studies have usually found (more) significant differences (Miller \& Wilbourne, 2002). Generally, models of case management have been compared with control conditions that include standard treatment, another innovative intervention, or another model of case management, thus reducing the chance of observing significant differential effects. 
Also, other sources of bias may have obscured the differential effectiveness of this intervention.

First, bias may occur due to lower attrition rates in the case management group (Drake, McHugo et al., 1998; Kilbride et al., 2000; Vaughn, Sarrazin, Saleh, Huber, \& Hall, 2002). Due to the nature of the case management process itself, case managers can track even the most difficult cases that would normally be lost at follow-up when receiving standard treatment (Orwin et al., 1994). In the Iowa case management study, lower attrition rates were related to female gender, greater social support, longer distance, and higher motivation, while involvement with the criminal justice system and older age negatively affected initial participation and subsequent retention in case management (Vaughn et al., 2002).

Second, partial, or incomplete implementation and low intensity of the intervention due to staffing problems, lack of training and inexperience of case managers, and staff turnover may account for limited or no effectiveness (Orwin et al., 1994). Robust implementation of case management was significantly more cost-effective than other interventions, but non-robust case management was the least efficient intervention (Jerrell \& Ridgely, 1999). Moreover, McLellan and colleagues (1999) could only demonstrate the effectiveness of a case management program 26 months after initial implementation. Usually much shorter periods are adhered to for piloting and fine-tuning new programs, which may result in a lack of or underestimation of particular effects (Lapham et al., 1995).

Third, differential effects between groups can hardly be demonstrated if the comparison group receives more services than planned or if other programs or the control condition adopt principles of the innovative intervention (Drake, McHugo et al., 1998; Orwin et al., 1994). From an ethical and practical point of view, it may be unwarranted to keep a potentially effective intervention from individuals in need of it (especially high-risk populations), and this might invite other caregivers to provide similar services (Inciardi et al., 1994). The drift of one intervention toward another can also happen in the opposite direction, when experimental conditions begin to resemble the comparison group as case managers settle into their jobs and lose their initial enthusiasm (Ridgely \& Willenbring, 1992).

Finally, despite the fact that results from experimental studies concerning case management have been biased to a certain extent, it is unlikely that (particular models of) case management is significantly more effective than other interventions for substance abusers. Perhaps this should not be surprising, since this intervention was originally designed to provide ongoing and supportive care to clients and to link them with community resources and existing agencies (Birchmore-Timney \& Graham, 1989; Rapp et al., 1998). Expecting significant and lasting effects on clients' functioning has probably also been too optimistic an objective. 
REVIEW OF THE EFFECTIVENESS OF DIFFERENT MODELS OF CASE MANAGEMENT

\subsubsection{LIMITATIONS OF THIS REVIEW}

As opposed to the field of mental health care (Marshall et al., 2000; Ziguras \& Stuart, 2000), no comprehensive review has yet been published about the effectiveness of case management for substance abusers, despite numerous empirical studies that have evaluated the effectiveness of this intervention. This review may contribute to our present-day knowledge about the effects of this intervention and to its further implementation, and can be the starting point for a meta-analysis of the effectiveness of case management for substance abusers. However, some shortcomings were observed concerning the methodology of this review.

First, this review was based on articles published in peer-reviewed journals, which may have contributed to the under-representation of non-American studies and studies that have reported insignificant or even adverse outcomes. The former limitation was addressed by including the original reports of two European studies, the latter by including different types of studies. Since we found various and inconsistent effects and several studies that reported insignificant effects, we assume that our review was not merely affected by such a publication bias. It can also be that published articles only contain the strongest findings of each study, while other insignificant observations were not reported. Analysis of the original research reports and data could address this problem, but this information is usually difficult to access at the expense of its comprehensiveness and quality. Further, the conceptualization of this review may have led to the underexposure of particular effects, since various articles that have been published concerning one large study were regarded as one single study.

Second, this review starts from four different models of case management that have been accepted by a consensus panel of American specialists (SAMHSA, 1998). Due to contextual differences and lack of program fidelity, most of the practical applications only vaguely resemble the pure version of each model (Jerrell et al., 1994; Vanderplasschen et al., in press). As opposed to the field of mental health care, few indicators exist about the core elements of different models (Teague, Bond, \& Drake, 1998). Still, most authors state explicitly which case management model was utilized, and articles were grouped based on this information. If insufficient details were given about the actual intervention or no specialized model was mentioned, the intervention was classified as generalist case management. This may have resulted in an over-representation of the latter category and a lack of evidence concerning its effectiveness due to increased heterogeneity.

Finally, contextual differences affect the implementation - and consequently the evaluation - of case management to a large extent (SAMHSA, 1998). Due to the distinct organization of social welfare and health care in the United States and Europe, it can be questioned whether the results from these predominantly American studies can be easily transferred to the European situation (Oliva et al., 2001; Wolf et al., 2002). Available findings from European studies suggest similar outcomes, but further evaluation is needed 
to generalize these results. An extensive description of the intervention that has been evaluated and the development of indicators to measure the program fidelity of different models of case management may help to improve the comparability of different case management programs (Godley et al., 2000; Orwin et al., 1994).

\subsubsection{LIMITATIONS OF THE PRESENTED STUDIES AND GUIDELINES FOR FURTHER RESEARCH}

Any firm conclusions about the effectiveness of case management are premature and even unwarranted, given the relative scarcity of randomized and controlled studies, especially concerning some specific models of case management (clinical, brokerage, and strengths-based). Additional studies are needed - mainly outside the United States - that apply a strong methodology among a sufficiently large sample. Small samples have accounted for limited power and reduce the chance of detecting small or medium effects (Orwin et al., 1994).

The lack of a longitudinal scope in most studies debilitates any conclusion about the longterm effects of this intervention. Most of the selected studies have applied case management interventions that do not last longer than six to 12 months and clients were usually not followed up with for more than six months after termination of the program. Studies that have utilized case management over a 24- to 36-month period have demonstrated long-term positive effects and even cost-effectiveness (Clark et al., 1998; Drake, McHugo et al., 1998; Jerrell \& Ridgely, 1999; Lanehart et al., 1996; Levy et al., 1996; Oliva et al., 2001). However, others showed that effects plateaued or even deteriorated after a while (Conrad et al., 1998; Jerrell \& Ridgely, 1995; Mercier \& Racine, 1993; Sorensen et al., 2003).

Several authors have shown a positive association between the length and completion of case management and client outcomes (Evenson et al., 1998; Lanehart et al., 1996; Oliva et al., 2001; Siegal et al., 1997). Given the chronic and relapsing nature of substance abuse problems and some promising results from available longitudinal studies, application of a longitudinal approach to case management is probably indicated. We need to know if the value of case management declines over time and when, if ever, case management efforts should be reduced or terminated (Clark et al., 1998). The combination or alternation of intensive and less intensive interventions from a chronic care perspective (including case management) may yield the best results.

Outcomes cannot always be easily compared due to the use of different instruments and outcome measures. The use of self-report as the sole indicator for clients' substance abuse has been criticized by several authors, since this may lead to substantial under-reporting at pre-test due to denial, minimization, or socially desirable answers, and to over-reporting at follow-up due to increased problem insight and the perceived availability of helping 
resources (Drake, McHugo et al., 1998; Lapham et al., 1995; Orwin et al., 1994; Vaughn et al., 2002). Still, most studies have included the Addiction Severity Index (ASI), as the validity and reliability of this self-report questionnaire has been demonstrated in numerous studies among substance abusers (Godley et al., 2002; Hendriks, Kaplan, van Limbeek, \& Geerlings, 1989; Zanis, McLellan, Cnaan, \& Randall, 1994). Although it is unlikely that the use of self-report measures has contributed to the lack of differential effectiveness of case management, it is recommended to complement self-report data about substance use with additional and more objective measures, such as urine analysis or breath or hair tests, especially among dually diagnosed individuals (Drake, McHugo et al., 1998; Jerrell \& Ridgely, 1995; Zanis et al., 1997).

The use of multiple outcome measures is further suggested, since multiple outcomes of clients' functioning are not always consistent, and focusing on one single outcome may consequently lead to inadequate and possibly incorrect policy inferences (Sindelar et al., 2004). Moreover, not only socially acceptable changes, but also indicators concerning quality of life and clients' subjective perceptions that may provide further insight in the effectiveness of this intervention should be studied.

Evaluation of the effectiveness of case management should also include process variables, as these can reveal which aspects of case management work. Up to now, little information has been available about the crucial features of this intervention: What specific aspects contribute to specific outcomes? Since the identification of these elements has been suggested as the most important research issue for the next decade in the field of mental health care, insights in this field should be closely followed (Burns et al., 2001). A team approach, monitoring, treatment planning, outreaching, and focusing on strengths and good relationships with case managers have been associated with positive outcomes among substance abusers (Brun \& Rapp, 2001; Jerrell \& Ridgely, 1999; Vanderplasschen et al., in press). In-depth qualitative research is required to explore the elements that contribute to the effectiveness of case management, but the more comprehensive the intervention, the more difficult the evaluation (Ho et al., 1999). The general nature of the elements identified in qualitative studies can be tested in randomized and controlled trials.

Finally, additional research is needed concerning the cost-effectiveness of different models of case management. Although some studies have demonstrated that intensive and clinical case management are cost-effective, insufficient evidence is available about its efficiency (Clark et al., 1998; Jerrell \& Ridgely, 1999; Okin et al., 2000; Sindelar et al., 2004; Witbeck et al., 2002). Moreover, such information is lacking for other models of case management and it remains unclear how case management affects costs (Clark \& Fox, 1993). 


\subsection{CONCLUSION}

Based on this review of published articles, we conclude that at least some evidence is available for the effectiveness of some models of case management. These effects are small or modest at best and do not differ significantly from those of most other interventions in the field of substance abuse treatment. As in the field of mental health care, obvious positive effects concern reduced use of inpatient services and increased utilization of outpatient and community-based services, prolonged treatment retention, improved quality of life, high client satisfaction, and stabilization or even improvement of the situations of - often problematic - substance abusers. Retention in and completion of case management programs has consistently been associated with positive outcomes, but overall effects concerning clients' functioning are less consistent. Various authors have found significant effects over time concerning several drug-related outcomes, but these usually did not differ from outcomes among clients receiving less intensive or even minimal interventions. Longitudinal effects are still unclear, but at least some studies have shown long-term effects.

Several aspects of the effectiveness of this intervention need to be studied further. The extent of the effects was beyond the scope of this article, but should be included in a meta-analysis of the effectiveness of case management for substance abusers. Although some studies have shown that this intervention works, it is still unclear what exactly makes this intervention work and how long its effects are sustained. Given the increased acceptance that substance abuse is a chronic and relapsing disorder, the role of case management should be discussed from a chronic care perspective. Ultimately, the effectiveness of this intervention for affecting clients' functioning should not be overestimated; its effect primarily lies in supporting clients in their daily lives and linking them to adequate services. Providing direct services or psychotherapy as part of case management may contribute more substantially to the stabilization or improvement of clients' situations, but such support probably needs to be sustained over time to produce long-term effects. 


\section{REFERENCES}

Barnett, P.G. (1999). The cost-effectiveness of substance abuse treatment. Current Psychiatry Reports, 1(2), 166-171.

Birchmore-Timney, C., \& Graham, K. (1989). A survey of case management practices in addictions programs. Alcoholism Treatment Quarterly, 6(3/4), 103-127.

Block, R.I., Bates, M.E., \& Hall, J.A. (2003). Relation of premorbid cognitive abilities to substance users' problems at treatment intake and improvements with substance abuse treatment and case management. American Journal of Drug and Alcohol Abuse, 29(3), 515-538.

Bokos, P., Mejta, C., Mickenberg, J., \& Monks, R. (1992). Case management: an alternative approach to working with intravenous drug users. In R.S. Ashery (Ed.), Progress and Issues in case management (NIDA Research Monograph 127) (pp. 92-111). Rockville: National Institute on Drug Abuse.

Braucht, G.N., Reichardt, C.S., Geissler, L.J., Bormann, C.A., Kwaitkowski, C.F., \& Kirby, M.W. (1995). Effective services for homeless substance abusers. Journal of Addictive Diseases, 14(4), 87-109.

Brindis, C.D., \& Theidon, K.S. (1997). The role of case management in substance abuse treatment services for women and their children. Journal of Psychoactive Drugs, 29(1), 79-88.

Broekaert, E., \& Vanderplasschen, W. (2003). Towards an integrated treatment system for substance abusers: report on the second international symposium on substance abuse treatment and special target groups. Journal of Psychoactive Drugs, 35(2), 237-245.

Brun, C., \& Rapp, R.C. (2001). Strengths-based case management: individuals' perspectives on strengths and the case manager relations. Social Work, 46(3), 278-288.

Burns, T., Fioritti, A., Holloway, F., Malm, U., \& Rossler, W. (2001). Case management and assertive community treatment in Europe. Psychiatric Services, 52(5), 631-636.

Clark, R.E., \& Fox, T.S. (1993). A framework for evaluating the economic impact of case management. Hospital and Community Psychiatry, 44(5), 469-473.

Clark, R.E., Teague, G.B., Ricketts, S.K., Bush, P.W., Xie, H., McGuire, T.G. et al. (1998). Costeffectiveness of assertive community treatment versus standard case management for persons with co-occurring severe mental illness and substance use disorders. Health Services Research, 33(5), 1285-1308.

Conrad, K.J., Hultman, C.I., Pope, A.R., Lyons, J.S., Baxter, W.C., Daghestani, A.N. et al. (1998). Case managed residential care for homeless addicted veterans: results of a true experiment. Medical Care, 36, 40-53.

Cox, G.B., Walker, R.D., Freng, S.A., Short, B.A., Meijer, L., \& Gilchrist, L. (1998). Outcome of a controlled trial of the effectiveness of intensive case management for chronic public inebriates. Journal of Studies on Alcohol, 59(5), 523-532.

Cretzmeyer, M., Sarrazin, M.V., Huber, D.L., Block, R.I., \& Hall, J.A. (2003). Treatment of methamphetamine abuse: research findings and clinical directions. Journal of Substance Abuse Treatment, 24, 267-277. 
Drake, R.E., McHugo, G., Clark, R., Teague, G.B., Xie, H., Miles, K. et al. (1998). Assertive community treatment for patients with co-occurring severe mental illness and substance use disorder: a clinical trial. American Journal of Orthopsychiatry, 68(2), 201-215.

Drake, R.E., Mercer-McFadden, C., Mueser, K.T., McHugo, G.J., \& Bond, G.R. (1998). Review of integrated mental health and substance abuse treatment for patients with dual disorders. Schirophrenia Bulletin, 24(4), 589-608.

Durell, J., Lechtenberg, B., Corse, S., \& Frances, R.J. (1993). Intensive case management of persons with chronic mental illness who abuse substances. Hospital and Community Psychiatry, 44(5), 415-416, 428.

Eisen, M., Keyser-Smith, J., Dampeer, J., \& Sambrano, S. (2000). Evaluation of substance use outcomes in demonstration projects for pregnant and postpartum women and their infants: findings from a quasi-experiment. Addictive Behaviors, 25(1), 123-129

European Monitoring Centre for Drugs and Drug Addiction (EMCDDA) (2002). Annual report on the state of the drug problem in the European Union and Norway. Luxembourg: Office for Official Publications of the European Communities.

Evenson, R.C., Binner, P.R., Cho, D.W., Schicht, W.W., \& Topolski, J.M. (1998). An outcome study of Missouri's CSTAR alcohol and drug abuse programs. Journal of Substance Abuse Treatment, 15, 143-150.

Falck, R., Siegal, H.A., \& Carlson, R.G. (1992). Case management to enhance AIDS risk reduction for injection drug users and crack users: Theoretical and practical considerations. In R.S. Ashery (Ed.), Progress and Issues in case management. (NID A Research Monograph 127) (pp. 167180). Rockville: National Institute on Drug Abuse.

Friedmann, P.D., Lemon, S.C., Anderson, B.J., \& Stein, M.D. (2003). Predictors of follow-up health status in the Drug Abuse Treatment Outcome Study (DATOS). Drug and Alcohol Dependence, 69(3), 243-251.

Godley, S.H., Finch, M., Dougan, L., McDonnell, M., McDermeit, M., \& Carey, A. (2000). Case management for dually diagnosed individuals involved in the criminal justice system. Journal of Substance Abuse Treatment, 18(2), 137-148.

Godley, M.D., Godley, S.H., Dennis, M.L., Funk, R., \& Passetti, L.L. (2002). Preliminary outcomes from the assertive continuing care experiment for adolescents discharged from residential treatment. Journal of Substance Abuse Treatment, 23(1), 21-32.

Gossop, M., Marsden, J., Stewart, D., \& Kidd, T. (2003). The National Treatment Outcome Research Study (NTORS): 4-5 year follow-up results. Addiction, 98(3), 291-303.

Gossop, M., Marsden, J., Stewart, D., \& Rolfe, A. (1999). Treatment retention and 1 year outcomes for residential programmes in England. Drug and Alcohol Dependence, 57(2), 89-98.

Gossop, M., Stewart, D, Browne, N., \& Marsden, J. (2002). Factors associated with abstinence, lapse or relapse to heroin use after residential treatment: protective effect of coping responses. Addiction, 97(10), 1259-1267.

Graham, K., \& Timney, C. (1990). Case management in addictions treatment. Journal of Substance Abuse Treatment, 7(3), 181-188.

Griffith, J.D., Rowan-Szal, G.A., Roark, R.R., \& Simpson, D.D. (2000). Contingency management in outpatient methadone treatment: a meta-analysis. Drug and Alcohol Dependence, 58(1-2), 5566. 
Hall, J.A., Carswell, C., Walsh, E., Huber, D.L., \& Jampoler, J.S. (2002). Iowa case management: Innovative social casework. Social Work, 47(2), 132-141.

Hendriks, V., Kaplan, C.D., van Limbeek, J., \& Geerlings, P. (1989). The Addiction Severity Index: Reliability and validity in a Dutch addict population. Journal of Substance Abuse Treatment, 6(2), 133-141.

Ho, A.P., Tsuang, J.W., Liberman, R.P., Wang, R., Wilkins, J.N., Eckman, T.A. et al. (1999). Achieving effective treatment of patients with chronic psychotic illness and comorbid substance dependence. American Journal of Psychiatry, 156(11), 1765-1770.

Hser, Y.I., Anglin, M.D., \& Fletcher, B. (1998). Comparative treatment effectiveness: effects of program modality and client drug dependence history on drug use reduction. Journal of Substance Abuse Treatment, 15(6), 513-523.

Hser, Y.I., Anglin, M.D., Grella, C., Longshore, D., \& Prendergast, M.L. (1997). Drug treatment careers: a conceptual framework and existing research findings. Journal of Substance Abuse Treatment, 14(6), 543-558.

Hubbard, R.L., Craddock, S.G., \& Anderson, J. (2003). Overview of 5-year followup outcomes in the drug abuse treatment outcome studies (DATOS). Journal of Substance Abuse Treatment, 25(3), 125-134.

Huber, D.L., Sarrazin, M.V., Vaughn, T., \& Hall, J.A. (2003). Evaluating the impact of case management dosage. Nursing Research 52(5), 276-288.

Inciardi, J.A., Martin, S.S., \& Scarpitti, F.R. (1994). Appropriateness of assertive case management for drug-involved prison releasees. Journal of Case Management, 3(4), 145-149.

Jerrell, J.M., Hu, T., \& Ridgely, M.S. (1994). Cost-effectiveness of substance disorder interventions for people with severe mental illness. Journal of Mental Health Administration, 21(3), 283-297.

Jerrell, J.M., \& Ridgely, M.S. (1995). Evaluating changes in symptoms and functioning of dually diagnosed clients in specialized treatment. Psychiatric Services, 46(3), 233-238.

Jerrell, J.M., \& Ridgely, M.S. (1999). Impact of robustness of program implementation on outcomes of clients in dual diagnosis programs. Psychiatric Services, 50(1), 109-112.

Kanter, J. (1989). Clinical case management: Definition, principles, components. Hospital and Community Psychiatry, 40(4), 361-368.

Kilbride, H., Castor, C., Hoffman, E., \& Fuger, K.L. (2000). Thirty-six month outcome of prenatal cocaine exposure for term or near-term infants: Impact of early case management. Journal of Developmental and Behavioral Pediatrics, 21(1), 19-26.

Laken, M.P., \& Ager, J.W. (1996). Effects of case management on retention in prenatal substance abuse treatment. American Journal of Drug and Alcohol Abuse, 22(3), 439-448.

Lanehart, R.E., Clark, H.B., Rollings, J.P., Haradon, D.K., \& Scrivner, L. (1996). The impact of intensive case-managed intervention on substance-using pregnant and postpartum women. Journal of Substance Abuse, 8(4), 487-495.

Lapham, S.C., Hall, M., \& Skipper, B.J. (1995). Homelessness and substance use among alcohol abusers following participation in project H\&ART. Journal of Addictive Diseases, 14(4), 41-55.

Levy, J.A., Strenski, T., \& Amick, D.J. (1995). Community-based case management for active injecting drug users. Advances in Medical Sociology, 6, 183-206. 
Lidz, V., Bux, D.A., Platt, J.J., \& Iguchi, M.Y. (1992). Transitional case management: A service model for AIDS outreach projects. In R.S. Ashery (Ed.), Progress and Issues in case management (NID A Research Monograph 127) (pp. 112-144). Rockville: National Institute on Drug Abuse.

Lightfoot, L., Rosenbaum, P., Ogurzsoff, S., Laverty, G., Kusiar, S., Barry, K. et al. (1982). Final Report of the Kingston Treatment Programmed Development Research Project. Ottawa, Canada: Department of Health and Welfare, Health Promotion Directorate.

Lipsey, M. (1990). Design sensitivity: statistical power for experimental research. Newbury Park: Sage.

Marshall, M., Gray, A., Lockwood, A., \& Green, R. (2000). Case management for people with severe mental disorders. The Cochrane Library, Systematic Review (2). Oxford: Cochrane Library, Update software.

Martin, S.S., \& Scarpitti, F.R. (1993). An intensive case management approach for paroled iv drug users. Journal of Drug Issues, 23(1), 43-59.

McLellan, A.T. (2002). Have we evaluated addiction treatment corretcly? Implications from a chronic care perspective. Addiction, 97(3), 249-252.

McLellan, A.T., Hagan, T.A., Levine, M., Meyers, K., Gould, F., Bencivengo, M. et al. (1999). Does clinical case management improve outpatient addiction treatment? Drug and Alcohol Dependence, 55, 91-103.

McLellan, A.T., Luborsky, L., O'Brien, C.P., Woody, G.E., \& Druley, K.A. (1982). Is treatment for substance abuse effective? Journal of the American Medical Association (JAMA), 247(10), 14231428.

McLellan, A.T., Woody, G.E., Metzger, D., McKay, J., Durrell, J., Alterman, A.I. et al. (1996). Evaluating the effectiveness of addiction treatments: reasonable expectations, appropriate comparisons. Milbank Quarterly, 74(1), 51-85.

Mejta, C.L., Bokos, P.R., Mickenberg, J., Maslar, M., \& Senay, E. (1997). Improving substance abuse treatment access and retention using a case management approach. Journal of Drug Issues, 27(2), 329-340.

Mercier, C., \& Racine, G. (1993). A follow-up study of homeless women. Journal of Social Distress and the Homeless, 2(3), 207-222.

Miller, W.R. (1996). Motivational interviewing: research, practice, and puzzles. Addictive Behaviors, 21(6), 835-842.

Miller, W.R., \& Wilbourne, P.L. (2002). Mesa Grande: a methodological analysis of clinical trials of treatments for alcohol use disorders. Addiction, 97(3), 265-277.

Moos, R.H. (2003). Addictive disorders in context: principles and puzzles of effective treatment and recovery. Psychology of Addictive Behaviors, 17(1), 3-12.

Ogborne, A.C., \& Rush, B.R. (1983). The coordination of treatment services for problem drinkers: problems and prospects. British Journal of Addiction, 78, 131-138.

Okin, R.L., Boccellari, A., Azocar, F., Shumway, M., O'Brien, K., Gelb, A. et al. (2000). The effects of clinical case management on hospital service use among ED frequent users. American Journal of Emergency Medicine, 18(5), 603-608.

Oliva, H., Görgen, W., Schlanstedt, G., Schu, M., \& Sommer, L. (2001). Case management in der Suchtkranken- und Drogenhilfe: Ergebnisse des Kooperationsmodells nachgehende Sozialarbeit - 
Modellbestandteil Case management, Berichtszeitraum 1995-2000. Köln: Fogs, Gesellschaft für Forschung und Beratung in Gesundheits- und Sozialbereich $\mathrm{mbH}$.

Orwin, R.G., Sonnefeld, L.J., Garrison-Mogren, R., \& Smith, N.G. (1994). Pitfalls in evaluating the effectiveness of case management programs for homeless persons: lessons from the NIAAA Community Demonstration Program. Evaluation Review, 18(2), 153-207.

Pearlman, S. (1984). Early experiences with primary care. In F.B. Glaser, H.M. Annis, \& H.A. Skinner (Eds.). A system of health care delivery: Volume II Primary Care Asssessment. Toronto: Addiction Research Foundation.

Rapp, R.C., Siegal, H.A., Li, L., \& Saha, P. (1998). Predicting post-primary treatment services and drug use outcome: A multivariate analysis. American Journal of Drug and Alcohol Abuse, 24(4), 603-615.

Rhodes, W., \& Gross, M. (1997). Case management reduces drug use and criminality among drug-involved arrestees: an experimental study of an HIV prevention intervention. NIJ Research Report. Washington DC: National Institute of Justice.

Rich, J.D., Holmes, L., Salas, C., Macalino, G., Davis, D., Ryczek, J. et al. (2001). Successful linkage of medical care and community services for HIV-positive offenders being released from prison. Journal of Urban Health: Bulletin of the New York Academy of Medicine, 78(2), 279-289.

Ridgely, M.S., \& Jerrell, J.M. (1996). Analysis of three interventions for substance abuse treatment of severely mentally ill people. Community Mental Health Journal, 32(6), 561-572.

Ridgely, M.S., \& Willenbring, M. (1992). Application of case management to drug abuse treatment: overview of models and research issues. In R.S. Ashery (Ed.), Progress and Issues in case management (NIDA Research Monograph 127) (pp. 12-33). Rockville: National Institute on Drug Abuse.

Rosen, A., \& Teesson, M. (2001). Does case management work? The evidence and the abuse of evidence-based medicine. Australian and New-Zealand Journal of Psychiatry, 35(6), 731-746.

Rubin, A. (1992). Is case management effective for people with serious mental illness? A research review. Health and Social Work, 17(2), 138-150.

Rush, B., \& Ekdahl, A. (1990). Recent trends in the development of alcohol and drug treatment services in Ontario. Journal of Studies on Alcohol, 51(6), 514-522.

Saleh, S.S., Vaughn, T., Hall, J.A., Levey, S., Fuortes, L., \& Uden-Holmen, T. (2002). Effectiveness of case management in substance abuse treatment. Care Management Journal, 3(4), 172-177.

Sarrazin, M.V., Huber, D.L., \& Hall, J.A. (2001). Impact of Iowa case management on family functioning for substance abuse treatment clients. Adolescent \& Family Health, 2(3), 132-140.

Scott, C.K., Sherman, R.E., Foss, M.A., Godley, M., \& Hristova, L. (2002). Impact of centralized intake on case management services. Journal of Psychoactive Drugs 34(1):51-57, 2002

Shwartz, M., Baker, G., Mulvey, K.P., \& Plough, A. (1997). Improving publicly funded substance abuse treatment: the value of case management. American Journal of Public Health, 87, 16591664.

Siegal, H.A., Fisher, J.H, Rapp, R.C., Kelliher, C.W., Wagner, J.H., O'Brien, W.F. et al. (1996). Enhancing substance abuse treatment with case management: its impact on employment. Journal of Substance Abuse Treatment, 13(2), 93-98. 
Siegal, H.A., Li, L., \& Rapp, R.C. (2002). Case management as a therapeutic enhancement: Impact on post-treatment criminality. Journal of Addictive Diseases, 21(4), 37-46.

Siegal, H.A., Rapp, R.C., Kelliher, C.W., Fisher, J.H., Wagner, J.H., \& Cole, P.A. (1995). The strengths perspective of case management: a promising inpatient substance abuse treatment enhancement. Journal of Psychoactive Drugs, 27(1), 67-72.

Siegal, H.A., Rapp, R.C., Li, L., Saha, P., \& Kirk, K. (1997). The role of case management in retaining clients in substance abuse treatment: an exploratory analysis. Journal of Drug Issues, 27(4), 821-831.

Simpson, D.D. (1981). Treatment for drug abuse: Follow-up outcomes and length of time spent. Archives of General Psychiatry, 38(8), 875-880.

Simpson, D.D., Joe, G.W., \& Broome, K.M. (2002). A national 5-year follow-up of treatment outcomes for cocaine dependence. Archives of General Psychiatry, 59(6), 538-544.

Simpson, D.D., Joe, G.W., Fletcher, B.W., Hubbard, R.L., \& Anglin, M.D. (1999). A national evaluation of treatment outcomes for cocaine dependence. Archives of General Psychiatry, $56(6), 507-514$

Sindelar, J.L., \& Fiellin, D.A. (2001). Innovations in treatment for drug abuse: solutions to a public health problem. Annual Review of Public Health, 22, 249-272.

Sindelar, J.L., Jofre-Bonet, M., French, M.T., \& McLellan, A.T. (2004). Cost-effectiveness analysis of addiction treatment: paradoxes of multiple outcomes. Drug and Alcohol Dependence, 73(1), 41-50.

Solomon, P. (1992). The efficacy of case management services for severely mentally disabled clients. Community Mental Health Journal, 28(3), 163-180.

Sorensen, J.L., Dilley, J., London, J, Okin, R.L., Delucchi, K.L., \& Phibbs, C.S. (2003). Case management for substance abusers with HIV/AIDS: a randomized clinical trial. American Journal of Drug and Alcohol Abuse, 29(1), 133-150.

Stahler, G.J., Shipley, T.F., Bartelt, D., DuCette, J.P., \& Shandler, I.W. (1995). Evaluating alternative treatments for homeless substance-abusing men: outcomes and predictors of success. Journal of Addictive Diseases, 14(4), 151-167.

Stein, L.I., \& Test, M.A. (1980). Alternative to mental hospital treatment: Conceptual model, treatment program and clinical evaluation. Archives of General Psychiatry, 37(4), 392-397, 1980.

Substance Abuse and Mental Health Administration (SAMHSA). (1998). Comprehensive case management for substance abuse treatment (TIP Series 27). Rockville: U.S. Department of health and human services, Public Health Service, Substance abuse and mental health services administration, Center for substance abuse treatment.

Sullivan, W., Hartmann, D., Dillon, D., \& Wolk, J.L. (1994). Implementing case management in alcohol and drug treatment. Families in Society: the Journal of Contemporary Social Services, 75(2), 67-73.

Sullivan, W., Wolk, J.L., \& Hartmann, D.J. (1992). Case management in alcohol and drug treatment: improving client outcomes. Families in Society: the Journal of Contemporary Social Services, 73(2), 195-204. 
Teague, G.B., Bond, G.R., \& Drake, R.E. (1998). Program fidelity in assertive community treatment: development and use of a measure. American Journal of Orthopsychiatry, 68(2), 216231.

Thornquist, L., Biros, M., Olander, R., \& Sterner, S. (2002). Health care utilization of chronic inebriates. Academic Emergency Medicine, 9(4), 300-308.

Vanderplasschen, W., De Bourdeaudhuij, I., \& Van Oost, P. (2002). Co-ordination and continuity of care in substance abuse treatment: an evaluation-study in Belgium. European Addiction Research, 8, 10-21.

Vanderplasschen, W., Lievens, K., \& Broekaert, E. (2001). Implementatie van een methodiek van case management in de drughulpverlening: een proefproject in de provincie Oost-Vlaanderen (Orthopedagogische Reeks Gent Nummer 14). Gent: Universiteit Gent, Vakgroep Orthopedagogiek.

Vanderplasschen, W., Rapp, R.C., Wolf, J., \& Broekaert, E. (in press). Comparative review of the development and implementation of case management for substance use disorders in North America and Europe. Psychiatric Services (accepted for publication, May 13, 2004).

Van Gageldonk, A., de Zwart, W., van der Stel, J., \& Donker, M. (1997). De Nederlandse verslavingszorg: overzicht van de kennis over aanbod, vraag en effect. Utrecht: Trimbos-instituut.

Van Stelle, K.R., Mauser, E., \& Moberg, D.P. (1994). Recidivism to the criminal justice system of substance-abusing offenders diverted into treatment. Crime and Delinquency, 40(2), 175-196.

Vaughan-Sarrazin, M.S., Hall, J.A., \& Rick, G.S. (2000). Impact of Iowa case management on use of health services by rural clients in substance abuse treatment. Journal of Drug Issues, 30(2), 435-463.

Vaughn, T., Sarrazin, M.V., Saleh, S.S., Huber, D.L. \& Hall, J.A. (2002). Participation and retention in drug abuse treatment services research. Journal of Substance Abuse Treatment, 23(4), 387397.

Volpicelli, J.R., Markman, I., Monterosso, J., Filing, J., \& O’Brien, C.P. (2000). Psychosocially enhanced treatment for cocaine-dependent mothers: evidence of efficacy. Journal of Substance Abuse Treatment, 18(1), 41-49.

Willenbring, M. (1996). Case management applications in substance use disorders. In H. Siegal \& R. Rapp (Eds.), Case management and substance abuse treatment: practice and experience (pp. 51-76). New York: Springer Publishing Company.

Willenbring, M.L., Ridgely, M.S., Stinchfield, R., \& Rose, R. (1991). Application of case management in alcohol and drug dependence: matching techniques and populations. Rockville: National Institute on Alcohol Abuse and Alcoholism.

Willenbring, M.L., Whelan, J.A., Dahlquist, J.S., \& O’Neil, M. (1990). Community treatment of the chronic public inebriate: 1 Implementation. Alcoholism Treatment Quarterly, 7(2), 79-97.

Witbeck, G., Hornfeld, S., \& Dalack, G.W. (2000). Emergency room outreach to chronically addicted individuals: A pilot study. Journal of Substance Abuse Treatment, 19(1), 39-43.

Wolf, J., Mensink, C., \& van der Lubbe, P. (2002). Case management voor langdurig verslaafden met meervoudige problemen: een systematisch overzicht van interventie en effect. Utrecht: Trimbos-instituut, Ontwikkelcentrum Sociaal Verslavingsbeleid.

Woodside, M., \& McClam, T. (2002). Generalist case management: a method of human service delivery (2 ${ }^{\text {nd }}$ edition). Florence: Thomson Learning. 
Zanis, D.A., \& Coviello, D. (2001). A case study of employment case management with chronically unemployed methadone maintained clients. Journal of Psychoactive Drugs, 33(1), 67-73.

Zanis, D.A., McLellan, A.T., Cnaan, R.A., \& Randall, M. (1994). Reliability and validity of the Addiction Severity Index with a homeless sample. Journal of Substance Abuse Treatment, 11(6), 541-548.

Ziguras, S.J., \& Stuart, G.W. (2000). A meta-analysis of the effectiveness of mental health case management over 20 years. Psychiatric Services, 51, 1410-1421.

Ziguras, S.J., Stuart, G.W., \& Jackson, A.C. (2002). Assessing the evidence on case management. British Journal of Psychiatry, 181, 17-21. 
Table 6.2.: Overview of studies that have focused on the effectiveness of intensive case management $(I C M)$ / assertive community treatment (ACT), including study design, sample, type of intervention and direction and significance of effects

\begin{tabular}{|c|c|c|c|c|}
\hline Authors & Type of study & Sample & Intervention & Effects \\
\hline $\begin{array}{l}\text { Martin \& } \\
\text { Scarpitti (1993) }\end{array}$ & $\begin{array}{l}\text { Randomized and } \\
\text { controlled trial }\end{array}$ & $\begin{array}{l}\text { Parolees with history of } \\
\text { drug use and HIV-risk } \\
\text { behavior }(\mathrm{n}=135)\end{array}$ & $\begin{array}{l}\text { ACT compared with conventional } \\
\text { parole } \\
6 \text {-month intervention }\end{array}$ & $\begin{array}{l}\text { Few differences between both groups (NS) } \\
\text { ACT-clients: worse outcomes concerning drug use, but slightly better outcomes concerning sexual } \\
\text { risk behavior and recidivism (NS) } \\
\text { Length of treatment related with self-report of weekly drug use (S) }\end{array}$ \\
\hline $\begin{array}{l}\text { Inciardi et al. } \\
\text { (1994) }\end{array}$ & $\begin{array}{l}\text { Randomized and } \\
\text { controlled trial }\end{array}$ & $\begin{array}{l}\text { Drug-involved parolees } \\
\text { with HIV-risk behavior } \\
(\mathrm{n}=258)\end{array}$ & Cf. Martin \& Scarpitti & $\begin{array}{l}\text { Modest effects, ACT not superior for reducing relapse or rearrest (NS) } \\
\text { ACT not valuable for clients who were not merely unable to access services, but rather assertive in } \\
\text { their unwillingness to make use of services }\end{array}$ \\
\hline $\begin{array}{l}\text { Orwin et al. } \\
\text { (1994) }\end{array}$ & $\begin{array}{l}\text { (Partially) randomized } \\
\text { and controlled trial }\end{array}$ & $\begin{array}{l}\text { Individuals with substance } \\
\text { abuse problems, homeless } \\
\text { or at risk of becoming } \\
\text { homeless ( } \mathrm{n}=930 \text { ) }\end{array}$ & $\begin{array}{l}\text { ICM compared with standard care in } 3 \\
\text { cities (Boston, Louisville, and } \\
\text { Minneapolis) } \\
\text { 9-month intervention }\end{array}$ & $\begin{array}{l}\text { ICM more effective for improving housing (S)+ substance abuse and employment (NS) in Boston; } \\
\text { only significant differences if it was assumed that clients who were not followed up did not improve } \\
\text { No differential between-group effects of ICM in Louisville and Minneapolis }\end{array}$ \\
\hline $\begin{array}{l}\text { Braucht et al. } \\
\text { (1995) }\end{array}$ & $\begin{array}{l}\text { Randomized and } \\
\text { controlled trial }\end{array}$ & $\begin{array}{l}\text { Homeless individuals with } \\
\text { substance abuse problems } \\
(\mathrm{n}=323)\end{array}$ & $\begin{array}{l}\text { Comprehensive array of substance } \\
\text { abuse and rehabilitation services } \\
\text { compared with the same condition } \\
\text { receiving additional ICM } \\
\text { 4-month intervention + 6-month } \\
\text { follow-up }\end{array}$ & $\begin{array}{l}\text { Small differences between ICM and comprehensive treatment group (NS) } \\
\text { Significant improvements within both groups concerning alcohol and drug abuse, housing status, } \\
\text { physical and mental health, employment and quality of life after } 4 \text { and } 10 \text { months } \\
\text { Improvements decreased during the 6-month follow-up period } \\
\text { Persons receiving more services improved more than those receiving less services } \\
\text { ICM only marginally increased clients' contacts and had little effect on amount of services received, } \\
\text { tailoring of services, and outcomes (NS) }\end{array}$ \\
\hline $\begin{array}{l}\text { Stahler et al. } \\
\text { (1995) }\end{array}$ & $\begin{array}{l}\text { Randomized and } \\
\text { controlled trial }\end{array}$ & $\begin{array}{l}\text { Homeless male substance } \\
\text { abusers from a homeless } \\
\text { shelter }(\mathrm{n}=722)\end{array}$ & $\begin{array}{l}\text { Comparison of: integrated } \\
\text { comprehensive residential treatment; } \\
\text { shelter-based ICM (peers); usual } \\
\text { shelter services including brokerage } \\
\text { CM } \\
6-9 \text { month intervention + 6-month } \\
\text { follow-up }\end{array}$ & $\begin{array}{l}\text { Significant improvements at follow-up among all three groups concerning cocaine and alcohol use, } \\
\text { employment and housing, but no differential effects between groups (NS) } \\
\text { Subgroups did not respond differently to } 3 \text { interventions (NS) } \\
\text { Subjects in the first and second condition most satisfied with treatment provided (S) } \\
\text { Clients with more severe substance use histories usually showed poorer outcomes (S) }\end{array}$ \\
\hline $\begin{array}{l}\text { Rhodes \& Gross } \\
\text { (1997) }\end{array}$ & $\begin{array}{l}\text { Randomized and } \\
\text { controlled trial }\end{array}$ & $\begin{array}{l}\text { Drug-involved arrestees } \\
(\mathrm{n}=1400) \text {, in Portand, } \\
\text { Oregon and Washington } \\
\text { DC }\end{array}$ & $\begin{array}{l}\text { Comparison of: ICM, intermediate } \\
\text { CM (session with specialist for } \\
\text { referral), control condition } \\
\text { (motivational tape + referral guide) } \\
6 \text {-month period }\end{array}$ & $\begin{array}{l}\text { Significantly reduced drug use at one site (Washington) and reduced recidivism and increased } \\
\text { treatment participation at both sites (S); the latter effect was only observed in Portland for CM- } \\
\text { clients who received more intensive services } \\
\text { ICM not more successful than other interventions for reducing injecting and sexual risk behavior } \\
\text { (NS) }\end{array}$ \\
\hline
\end{tabular}




\begin{tabular}{|c|c|c|c|c|}
\hline Authors & Type of study & Sample & Intervention & Effects \\
\hline Cox et al. (1998) & $\begin{array}{l}\text { Randomized and } \\
\text { controlled trial }\end{array}$ & $\begin{array}{l}\text { Homeless chronic public } \\
\text { inebriates }(\mathrm{n}=193)\end{array}$ & $\begin{array}{l}\text { ICM compared with standard } \\
\text { treatment } \\
18 \text {-month intervention }\end{array}$ & $\begin{array}{l}\text { Both groups improved over time (S) } \\
\text { Significant differences favoring IIM-group: total income from public sources, nights spent in own } \\
\text { place and days of drinking; effects were small and varied over time (except for drinking outcomes); } \\
\text { effects not generalized to other life domains } \\
\text { ICM-group received more substance abuse and other services ( }(\mathrm{S}) \text {, which was related with improved } \\
\text { drinking outcomes } \\
\text { Drinking and housing outcomes consistently worse for persons with more extensive histories of } \\
\text { homelessness and medical problems }\end{array}$ \\
\hline $\begin{array}{l}\text { Witbeck et al. } \\
(2000)\end{array}$ & $\begin{array}{l}\text { Randomized and } \\
\text { controlled trial }\end{array}$ & $\begin{array}{l}\text { Chronically addicted and } \\
\text { mentally ill homeless } \\
\text { individuals who frequently } \\
\text { utilize emergency services } \\
(\mathrm{n}=18)\end{array}$ & $\begin{array}{l}\text { ICM compared with no-CM control } \\
\text { group } \\
\text { 12-month intervention }\end{array}$ & $\begin{array}{l}\text { Use of emergency services decreased by } 58 \% \text { compared to preceding year ( } \mathrm{S} \text { ) } \\
\text { No decrease in emergency service use among control group } \\
\text { Significant decrease in the use of emergency and ambulance ervices } \\
\text { Substantial cost-savings and enhanced recovery and psychosocial functioning (NS) }\end{array}$ \\
\hline $\begin{array}{l}\text { Jerrell et al. } \\
\text { (1994) }\end{array}$ & $\begin{array}{l}\text { Partially randomized } \\
\text { and controlled trial }\end{array}$ & $\begin{array}{l}\text { Persons with severe mental } \\
\text { illness and co-occurring } \\
\text { substance use disorders } \\
(\mathrm{n}=143)\end{array}$ & $\begin{array}{l}\text { Comparison of } 3 \text { interventions: ICM, } \\
\text { behavioral skills training (BST) and 12- } \\
\text { step recovery program } \\
18 \text {-month hintervention }+6 \text {-month } \\
\text { follow-up }\end{array}$ & $\begin{array}{l}\text { All } 3 \text { interventions reduced acute and subacute service use and increased involvement with } \\
\text { outpatient and community-based treatment, especially among clients with more prior } \\
\text { hospitalizations ( } \mathrm{S} \text { ) } \\
\text { ICM and BST reduced total health care costs more than } 12 \text { step-recovery program (NS) } \\
\text { Costs for society were reduced with } 43 \% \text {, without transferring the burden to family or criminal } \\
\text { justice system } \\
\text { No differences between groups concerning level of functioning or social adjustment }\end{array}$ \\
\hline $\begin{array}{l}\text { Ridgely \& Jerrell } \\
\text { (1996) }\end{array}$ & $\begin{array}{l}\text { Partially randomized } \\
\text { and controlled trial }\end{array}$ & $\begin{array}{l}\text { Persons with severe mental } \\
\text { illness and co-occurring } \\
\text { substance use disorders } \\
(\mathrm{n}=132)\end{array}$ & Cf. Jerrell et al. (1994) & $\begin{array}{l}\text { BST: highest ratings of psychosocial adjustment and higher levels of functioning and symptom } \\
\text { reduction (S) } \\
\text { ICM: highest satisfaction with quality of life, most substance abuse symptoms, lowest costs of } \\
\text { mental health services + lowest burden for family (NS) } \\
\text { Significant variations from the model across sites }\end{array}$ \\
\hline $\begin{array}{l}\text { Jerrell \& Ridgely } \\
(1999)\end{array}$ & $\begin{array}{l}\text { Cf. Ridgely \& Jerrell } \\
(1996)\end{array}$ & Cf. Ridgely \& Jerrell (1996) & $\begin{array}{l}\text { Comparison of } 3 \text { interventions, } \\
\text { controlling for robust and non-robust } \\
\text { implementation }\end{array}$ & $\begin{array}{l}\text { Robust ICM associated with higher rates of psychosocial functioning, less alcohol and drug } \\
\text { symptoms and lower cost of intensive services }(\mathrm{S}) \\
\text { Non-robust ICM generated significantly higher costs than other non-robust interventions }\end{array}$ \\
\hline $\begin{array}{l}\text { Drake et al. } \\
(1998)\end{array}$ & $\begin{array}{l}\text { Randomized and } \\
\text { controlled trial }\end{array}$ & $\begin{array}{l}\text { Patients with dual disorders } \\
(\mathrm{n}=203)\end{array}$ & $\begin{array}{l}\text { ACT compared with standard CM } \\
\text { 36-month intervention }\end{array}$ & $\begin{array}{l}\text { ACT: greater improvement on some measures of substance abuse and quality of life (S), but } \\
\text { equivalent improvements concerning most measures: stable community days, hospital days, } \\
\text { psychiatric symptoms and remission (NS) } \\
\text { Substantial improvement on all measures over } 3 \text { years, especially concerning treatment retention, } \\
\text { substance abuse and stable days in community (S) } \\
\text { Standard CM-clients receeived more outpatient services, which was related with the lack of } \\
\text { differential effects between both groups }\end{array}$ \\
\hline
\end{tabular}




\begin{tabular}{|c|c|c|c|c|}
\hline Authors & Type of study & Sample & Intervention & Effects \\
\hline $\begin{array}{l}\text { Clark et al. } \\
(1998)\end{array}$ & $\begin{array}{l}\text { Randomized and } \\
\text { controlled trial }\end{array}$ & $\begin{array}{l}\text { Persons with dual disorders } \\
(\mathrm{n}=193)\end{array}$ & $\begin{array}{l}\text { Comparison of cost-effectiveness } \\
\text { between ACT and SCM } \\
\text { 36-month intervention }\end{array}$ & $\begin{array}{l}\text { Significant reductions in substance use in both groups over time } \\
\text { No difference in cost-effectiveness over } 3 \text { year-period when focusing on substance abuse and quality } \\
\text { of life (NS) } \\
\text { Longitudinal analyses showed SCM was more efficient during first } 2 \text { years, while ACT was more } \\
\text { efficient the last year of the study (NS) }\end{array}$ \\
\hline $\begin{array}{l}\text { Sorensen et al. } \\
(2003)\end{array}$ & $\begin{array}{l}\text { Randomized and } \\
\text { controlled trial }\end{array}$ & $\begin{array}{l}\text { Substance abusers with } \\
\text { HIV/AIDS }(\mathrm{n}=190)\end{array}$ & $\begin{array}{l}\text { ICM compared with a brief contact } \\
\text { condition (brokerage CM) } \\
\text { 12-month intervention }+6 \text { month } \\
\text { follow-up }\end{array}$ & $\begin{array}{l}\text { No significant differences between brief contact and ICM-condition concerning service utilization } \\
\text { and drug-related outcomes, except more sexual risk behavior in BCM-group } \\
\text { Amount of CM was not related to improved outcomes } \\
\text { Both groups improved over time: equal, significant reduction in problem severity first } 6 \text { months, but } \\
\text { these reductions were no longer significant after } 12 \text { and } 18 \text { months }\end{array}$ \\
\hline $\begin{array}{l}\text { Godley et al. } \\
\text { (2002) }\end{array}$ & $\begin{array}{l}\text { Randomized and } \\
\text { controlled trial }\end{array}$ & $\begin{array}{l}\text { Adolescents in residential } \\
\text { substance abuse treatment } \\
(\mathrm{n}=114)\end{array}$ & $\begin{array}{l}\text { Usual continuing care (UCC) } \\
\text { compared with UCC and additional } \\
\text { assertive continuing care (ACC), } \\
\text { including ICM } \\
\text { 3-month intervention }\end{array}$ & $\begin{array}{l}\text { No differences between groups in length of stay and treatment completion status } \\
\text { ACC more likely to initiate and receive continuing care services ( }(\mathrm{S}) \\
\text { ACC more likely to be abstinent from marijuana and less days of alcohol use } 3 \text { months after } \\
\text { discharge (S) }\end{array}$ \\
\hline $\begin{array}{l}\text { Kilbride et al. } \\
(2000)\end{array}$ & $\begin{array}{l}\text { Controlled study (no } \\
\text { random assignment) }\end{array}$ & $\begin{array}{l}\text { Term- or near-term infants } \\
\text { of cocaine abusing women } \\
(\mathrm{n}=70)\end{array}$ & $\begin{array}{l}\text { Comparison of intensive family } \mathrm{CM} \\
\text { (n=70) and routine follow-up } \mathrm{n}=48) \text {; } \\
\text { additional control group of matched } \\
\text { non-drug exposed children }(\mathrm{n}=41) \\
36 \text {-month intervention }\end{array}$ & $\begin{array}{l}\text { Few differences in neuro-developmental outcomes among all three groups (NS) } \\
\text { ICM-infants had higher mean scores than routine follow-up group for cognitive development after } 6 \\
\text { months (S), but not at later assessments } \\
\text { ICM-group better verbal scores than routine follow-up group after } 36 \text { months (S) } \\
\text { Both groups of cocaine abusing women lost custody of their child to a similar extent (NS) }\end{array}$ \\
\hline $\begin{array}{l}\text { Thornquist et al. } \\
\text { (2002) }\end{array}$ & $\begin{array}{l}\text { Retrospective study } \\
\text { of medical databases }\end{array}$ & $\begin{array}{l}\text { Chronic inebriates who } \\
\text { often utilize emergency } \\
\text { services }(\mathrm{n}=92)\end{array}$ & $\begin{array}{l}\text { Comparison of } 3 \text { programs: ethnic and } \\
\text { gender-specific supportive housing } \\
\text { and intensive street CM } \\
\text { Min. } 4 \text {-month intervention } \\
\text { 24-month study period }\end{array}$ & $\begin{array}{l}\text { Reduction in median number of detox and medical visits }(\mathrm{S}) \\
\text { Reduction in median of medical and total health care charges (S), but mean charges were not } \\
\text { reduced due to some extremely catastrophic cases } \\
\text { Reduced health care use (NS) } \\
\text { ICM most cost-effective, since results were similar and costs were not as high as for supportive } \\
\text { housing }\end{array}$ \\
\hline $\begin{array}{l}\text { Evenson et al. } \\
(1998)\end{array}$ & $\begin{array}{l}\text { Retrospective study } \\
\text { of CSTAR databases }\end{array}$ & $\begin{array}{l}\text { Persons in CSTAR- } \\
\text { program (n=280) }\end{array}$ & $\begin{array}{l}\text { Community program including wrap- } \\
\text { around services and ICM } \\
\text { Min. 4-month intervention } \\
\text { 10-month study period }\end{array}$ & $\begin{array}{l}\text { Consistent positive results across several domains typically affected by substance abuse: global } \\
\text { functioning, felt distresss, substance use, interpersonal problems, legal difficulties, costs of addiction, } \\
\text { productivity, parenting skills, and independent living (S) } \\
\text { High degree of satisfaction with treatment services } \\
\text { Longest length of stay associated with more favorable outcomes (NS) }\end{array}$ \\
\hline $\begin{array}{l}\text { Durell et al. } \\
(1993)\end{array}$ & $\begin{array}{l}\text { Pre-post test } \\
\text { (uncontrolled study) }\end{array}$ & $\begin{array}{l}\text { Severely mentally ill ( } \mathrm{n}=84) \text {, } \\
\text { some with co-occuring } \\
\text { substance abuse }(\mathrm{n}=43)\end{array}$ & $\begin{array}{l}\text { ICM } \\
\text { 18-month intervention + 6-month } \\
\text { follow-up }\end{array}$ & $\begin{array}{l}\text { Modest improvements: reduced substance abuse and changing patterns of service utilization (NS) } \\
\text { No differential effects for substance abusers compared with mentally ill persons }\end{array}$ \\
\hline
\end{tabular}




\begin{tabular}{|c|c|c|c|c|}
\hline Authors & Type of study & Sample & Intervention & Effects \\
\hline $\begin{array}{l}\text { Lanehart et al. } \\
(1996)\end{array}$ & $\begin{array}{l}\text { Pre-post test } \\
\text { (uncontrolled study) }\end{array}$ & $\begin{array}{l}\text { Substance abusing pregnant } \\
\text { and postpartum women } \\
(\mathrm{n}=152)\end{array}$ & $\begin{array}{l}\text { Wide array of intensive case } \\
\text { management-services and supports } \\
\text { Min. 6-month intervention }\end{array}$ & $\begin{array}{l}\text { Significant improvements across all outcome indicators: substance use, employment, rearrest, } \\
\text { incarceration, children's birth weight, and social support } \\
\text { Longer length of stay in the program was associated with more substance-free days }(\mathrm{S})\end{array}$ \\
\hline $\begin{array}{l}\text { Godley et al. } \\
(2000)\end{array}$ & $\begin{array}{l}\text { Pre-post test } \\
\text { (uncontrolled study) }\end{array}$ & $\begin{array}{l}\text { Individuals with substance } \\
\text { abuse and mental health } \\
\text { problems, involved in the } \\
\text { criminal justice system } \\
(\mathrm{n}=54)\end{array}$ & $\begin{array}{l}\text { ICM }(2 \text { case managers/person: TASC } \\
\text { and MISA case manager) } \\
\text { Min 4-month intervention }\end{array}$ & $\begin{array}{l}\text { Significantly reduced legal problems at 6-month follow-up + also other drug-related problems } \\
\text { improved (N) } \\
\text { Improved quality of life (NS) } \\
\text { Most subjects found "life now" was better than last year and were generally very satisfied with the } \\
\text { program } \\
\text { Clients more successful in accessing substance abuse than mental health services }\end{array}$ \\
\hline $\begin{array}{l}\text { Rich et al. } \\
\text { (2001) }\end{array}$ & $\begin{array}{l}\text { Pre-post test } \\
\text { (uncontrolled study) }\end{array}$ & $\begin{array}{l}\text { HIV-positive ex-offenders } \\
\text { released from prison } \\
(\mathrm{n}=97)\end{array}$ & $\begin{array}{l}\text { ICM } \\
18 \text {-month intervention }\end{array}$ & $\begin{array}{l}\text { Relapse and re-incarceration did occur, but clients were maintained in a variety of services and } 100 \% \\
\text { received HIV-related medical services } \\
\text { Almost all subjects were maintained in the program for } 18 \text { months } \\
\text { Intervention was perceived to be beneficial by most clients }\end{array}$ \\
\hline $\begin{array}{l}\text { Oliva et al. } \\
(2001)\end{array}$ & $\begin{array}{l}\text { Pre-post test } \\
\text { (uncontrolled study) }\end{array}$ & $\begin{array}{l}\text { Multi-impaired chronic } \\
\text { addicts in } 16 \text { counties } \\
(\mathrm{n}=1660)\end{array}$ & $\begin{array}{l}\text { ICM } \\
12 \text {-month intervention }\end{array}$ & $\begin{array}{l}\text { According to case managers, overall situation of the clients had improved ( } 47 \%) \text { or was stabilized } \\
(20 \%) \text {, especially living situation, judicial problems, health status, social problems, and financial } \\
\text { situation } \\
\text { Positive outcomes were related with longer retention } \\
85.1 \% \text { of the clients thought their situation had improved and most were very satisfied }(74.2 \%) \text { or } \\
\text { satisfied }(21.5 \%) \text { with this intervention }\end{array}$ \\
\hline $\begin{array}{l}\text { Vanderplasschen } \\
\text { et al. } \\
(2001)\end{array}$ & $\begin{array}{l}\text { Pre-post test } \\
\text { (uncontrolled study) }\end{array}$ & $\begin{array}{l}\text { Substance abusers with } \\
\text { multiple and complex } \\
\text { problems }(\mathrm{n}=24)\end{array}$ & $\begin{array}{l}\text { ICM } \\
12 \text { month-intervention }\end{array}$ & $\begin{array}{l}\text { Reduction and stabilization of substance use, legal, employment and family problems after } 12 \\
\text { months ( }) \\
\text { Improvements related with treatment retention }\end{array}$ \\
\hline
\end{tabular}


Table 6.3.: Overview of studies that have focused on the effectiveness of strengths-based case management (SBCM), including study design, sample, type of intervention and direction and significance of effects

\begin{tabular}{|c|c|c|c|c|}
\hline Authors & Type of study & Sample & Intervention & Effects \\
\hline $\begin{array}{l}\text { Siegal et al. } \\
(1996)\end{array}$ & $\begin{array}{l}\text { Randomized and } \\
\text { controlled trial }\end{array}$ & $\begin{array}{l}\text { Veterans with substance } \\
\text { abuse problems seeking } \\
\text { treatment }(\mathrm{n}=632)\end{array}$ & $\begin{array}{l}\text { Usual primary and aftercare treatment } \\
\text { compared with condition with } \\
\text { additional SBCM } \\
6 \text {-month intervention }\end{array}$ & $\begin{array}{l}\text { Both groups improved significantly concerning employment, but SBCM led to additional } \\
\text { improvement: more days employed, fewer employment problems and less troubles about } \\
\text { employment situation (S) } \\
\text { Improved employment outcomes correlated with improvements concerning other life domains } \\
\text { (medical, alcohol, drugs, legal, social, psychiatric) (S) }\end{array}$ \\
\hline $\begin{array}{l}\text { Siegal et al. } \\
(1997)\end{array}$ & Cf. Siegal et al. (1996) & $\begin{array}{l}\text { Veterans with substance } \\
\text { abuse problems seeking } \\
\text { treatment }(\mathrm{n}=258)\end{array}$ & Cf. Siegal et al. (1996) & $\begin{array}{l}\text { Positive relation between length of time in treatment and outcomes (S) } \\
\text { Persons who dropped out from SBCM and usual care: lowest levels of functioning (S) } \\
\text { SBCM-retainees: less criminality (S) and more employment (NS) } \\
\text { Clients receiving SBCM and usual care: additional improvement concerning drug use and self-help } \\
\text { group attendance (S) }\end{array}$ \\
\hline $\begin{array}{l}\text { Siegal et al. } \\
(2002)\end{array}$ & Cf. Siegal et al. (1996) & $\begin{array}{l}\text { Veterans with substance } \\
\text { abuse problems seeking } \\
\text { treatment }(\mathrm{n}=453)\end{array}$ & $\begin{array}{l}\text { Cf. Siegal et al. (1996) } \\
\text { 12-month follow-up }\end{array}$ & $\begin{array}{l}\text { SBCM-stayed longer in after-care services (S), which was related with better outcomes concerning } \\
\text { post-treatment criminality (S) } \\
\text { Length of after-care participation also associated with employment outcomes and readiness for } \\
\text { treatment (S) }\end{array}$ \\
\hline $\begin{array}{l}\text { Vaughan- } \\
\text { Sarrazin et al. } \\
(2000)\end{array}$ & $\begin{array}{l}\text { Randomized and } \\
\text { controlled trial }\end{array}$ & $\begin{array}{l}\text { Substance abusers admitted } \\
\text { in residential treatment } \\
(\mathrm{n}=229)\end{array}$ & $\begin{array}{l}\text { Standard treatment control condition } \\
\text { compared with } 3 \text { modalities of Iowa } \\
\text { CM (based on strengths-based } \\
\text { principles): CM inside the facility, CM } \\
\text { in social agency (outside CM), } \\
\text { telecommunication CM } \\
\text { 12-month intervention }\end{array}$ & $\begin{array}{l}\text { Inside SBCM: significant impact on utilization of medical and substance abuse services (outpatient } \\
\text { or aftercare treatment), compared with other conditions } \\
\text { SBCM: no impact on use of mental health services (NS) } \\
\text { Face-to-face SBCM greater impact on service utilization than telecommunication SBCM (S) } \\
\text { Utilization of treatment services declined steadily from start to last quarter in all modalities (NS) }\end{array}$ \\
\hline
\end{tabular}




\begin{tabular}{|c|c|c|c|c|}
\hline Authors & Type of study & Sample & Intervention & Effects \\
\hline $\begin{array}{l}\text { Saleh et al. } \\
\text { (2002) }\end{array}$ & $\begin{array}{l}\text { Cf. Vaughan-Sarrazin } \\
\text { et al. (2000) }\end{array}$ & $\begin{array}{l}\text { Substance abusers admitted } \\
\text { in residential treatment } \\
(\mathrm{n}=662)\end{array}$ & Cf. Vaughan-Sarrazin et al. (2000) & $\begin{array}{l}\text { No differential effectiveness between modalities for reducing substance use (NS) } \\
\text { Outside CM: improved drug use at } 3 \text { months and better psychiatric status at } 3 \text { and } 12 \text { months (S), } \\
\text { compared with control group } \\
\text { Inside CM: improved legal status at } 3 \text { and } 6 \text { months; improved employment status at } 12 \text { months (S), } \\
\text { compared with control group } \\
\text { Telecommunication CM: no differences with control group concerning any life domain }\end{array}$ \\
\hline $\begin{array}{l}\text { Block et al. } \\
(2003)\end{array}$ & $\begin{array}{l}\text { Cf. Vaughan-Sarrazin } \\
\text { et al. (2000) }\end{array}$ & $\begin{array}{l}\text { Substance abusers admitted } \\
\text { in residential treatment } \\
(\mathrm{n}=213)\end{array}$ & Cf. Vaughan-Sarrazin et al. (2000 & $\begin{array}{l}\text { Telecommunication CM: better outcomes concerning alcohol, legal and psychiatric problems for } \\
\text { clients with higher premorbid cognitive abilities }(\mathrm{S})\end{array}$ \\
\hline $\begin{array}{l}\text { Cretzmeyer et al. } \\
(2003)\end{array}$ & $\begin{array}{l}\text { Cf. Vaughan-Sarrazin } \\
\text { et al. (2000) }\end{array}$ & $\begin{array}{l}\text { Substance abusers admitted } \\
\text { in residential treatment, } \\
\text { with metamphetamine as } \\
\text { primary drug }(\mathrm{n}=41)\end{array}$ & Cf. Vaughan-Sarrazin et al. (2000) & $\begin{array}{l}\text { Improved employment outcomes (S) and lower incidence of depression (NS) compared with control } \\
\text { group } \\
\text { SBCM does not impact metamphetamine abusers any differently than clients reporting primary } \\
\text { abuse of other drugs (NS) }\end{array}$ \\
\hline $\begin{array}{l}\text { Huber et al. } \\
\text { (2003) }\end{array}$ & $\begin{array}{l}\text { Cf. Vaughan-Sarrazin } \\
\text { et al. (2000) }\end{array}$ & $\begin{array}{l}\text { Substance abusers admitted } \\
\text { in residential treatment } \\
(\mathrm{n}=437)\end{array}$ & Cf. Vaughan-Sarrazin et al. (2000) & $\begin{array}{l}\text { Dosage of SBCM differed across modalities (S), favoring telecommunication CM (greater breadth } \\
\text { and frequency of services) } \\
\text { Case management dose was related with more severe legal and family problems (S) } \\
\text { Highest dosage in first quarter, which declined steadily in subsequent months }\end{array}$ \\
\hline $\begin{array}{l}\text { Zanis \& Coviello } \\
(2001)\end{array}$ & Case study & $\begin{array}{l}\text { Chronically unemployed } \\
\text { methadone maintained } \\
\text { clients }(\mathrm{n}=10)\end{array}$ & $\begin{array}{l}\text { Employment SBCM } \\
\text { 6-month intervention (8-month } \\
\text { follow-up) }\end{array}$ & $\begin{array}{l}\text { Positive employment outcomes ( } 9 \text { employed after } 2 \text { months, } 6 \text { maintained employment after } 8 \\
\text { months) } \\
\text { SBCM regarded as effective and valuable intervention by the participants } \\
\text { Discontinuation of SBCM, led to unemployment among } 3 \text { persons } \\
\text { Employment did not interfere with participation in substance abuse treatment }\end{array}$ \\
\hline
\end{tabular}


Table 6.4.: Overview of studies that have focused on the effectiveness of generalist or standard case management (SCM), including study design, sample, type of intervention and direction and significance of effects

\begin{tabular}{|c|c|c|c|c|}
\hline Authors & Type of study & Sample & Intervention & Effects \\
\hline $\begin{array}{l}\text { Mejta et al. } \\
(1997)\end{array}$ & $\begin{array}{l}\text { Randomized and } \\
\text { controlled trial }\end{array}$ & $\begin{array}{l}\text { Intravenous drug users } \\
\text { who seek treatment } \\
\text { through a centralized intake } \\
\text { facility }(\mathrm{n}=316)\end{array}$ & $\begin{array}{l}\text { SCM compared with control } \\
\text { condition, including limited referral } \\
\text { information } \\
3 \text { year-intervention }\end{array}$ & $\begin{array}{l}\text { SCM-group accessed treatment in greater numbers and more rapidly than control group (S), } \\
\text { especially when case managers had access to service dollars } \\
\text { SCM-clients remained nearly twice as long in treatment (S) } \\
\text { SCM: better treatment outcomes, including reduced alcohol and drug use (NS) }\end{array}$ \\
\hline $\begin{array}{l}\text { Conrad et al. } \\
(1998)\end{array}$ & $\begin{array}{l}\text { Randomized and } \\
\text { controlled trial }\end{array}$ & $\begin{array}{l}\text { Homeless addicted male } \\
\text { veterans }(n=358)\end{array}$ & $\begin{array}{l}\text { SCM in addition to residential care } \\
\text { program compared with 21-day } \\
\text { hospital program } \\
\text { 12-month intervention + 24-month } \\
\text { follow-up }\end{array}$ & $\begin{array}{l}\text { SCM-group: significant differential effects concerning medical, alcohol, employment and housing } \\
\text { status after } 24 \text { months, but these differences were mainly observed in first year and diminished } \\
\text { during second year } \\
\text { Both groups improved on these } 4 \text { measures over time }(\mathrm{S}) \\
\text { Control group had also access to and used substantial amounts of services }\end{array}$ \\
\hline $\begin{array}{l}\text { Lapham et al. } \\
(1995)\end{array}$ & $\begin{array}{l}\text { Randomized and } \\
\text { controlled trial }\end{array}$ & $\begin{array}{l}\text { Homeless alcohol abusers } \\
(\mathrm{n}=469)\end{array}$ & $\begin{array}{l}\text { Comparison of } 3 \text { interventions: SCM } \\
\text { plus peer-supervised housing, peer- } \\
\text { supervised housing alone and a housed } \\
\text { an non-housed control group } \\
\text { 4-month intervention + 10-month } \\
\text { follow-up }\end{array}$ & $\begin{array}{l}\text { Significant within group improvements (alcohol use, housing, employment), but no between-group } \\
\text { differences } \\
\text { Program graduates had more favorable substance use and housing outcomes than dropouts (S) } \\
\text { Motivation rather than program factors affected outcomes (NS) }\end{array}$ \\
\hline $\begin{array}{l}\text { Volpicelli et al. } \\
(2000)\end{array}$ & $\begin{array}{l}\text { Randomized and } \\
\text { controlled trial }\end{array}$ & $\begin{array}{l}\text { Cocaine dependent } \\
\text { mothers }(\mathrm{n}=84)\end{array}$ & $\begin{array}{l}\text { SCM compared with psychosocially } \\
\text { enhanced treatment program (PET), } \\
\text { including individual psychotherapy } \\
\text { 12-month intervention }\end{array}$ & $\begin{array}{l}\text { No difference in service utilization among both groups, except for individual therapy } \\
\text { Progfam retention significantly better for clients in PET-condition } \\
\text { Cocaine used decreased among both groups (S), but the PET-group showed significantly greater } \\
\text { decrease } \\
\text { Psychosocial functioning improved among both groups (S), but no differential effects }\end{array}$ \\
\hline
\end{tabular}




\begin{tabular}{|c|c|c|c|c|}
\hline Authors & Type of study & Sample & Intervention & Effects \\
\hline $\begin{array}{l}\text { Shwartz et al. } \\
(1997)\end{array}$ & $\begin{array}{l}\text { Retrospective cohort } \\
\text { design }\end{array}$ & $\begin{array}{l}\text { Clients discharged from } \\
\text { short }(\mathrm{n}=3112) \text { or long- } \\
\text { term residential treatment } \\
(\mathrm{n}=2888) \text {, outpatient } \\
\text { treatment }(\mathrm{n}=7431) \text { or } \\
\text { residential detoxification } \\
(\mathrm{n}=7776)\end{array}$ & Program-based SCM & $\begin{array}{l}\text { CM-clients stayed } 1.6 \text { (outpatient) to } 3.6 \text { (short-term residential) times longer in treatment (S) } \\
\text { CM-clients were less likely to be readmitted to detox after discharge (except outpatient clients) (S) } \\
\text { CM-clients followed } 1.7 \text { times more post-primary treatment (S) } \\
\text { Length of stay correlated with improved outcomes (S), but no relation found between intensity of } \\
\text { CM and outcomes }\end{array}$ \\
\hline $\begin{array}{l}\text { Van Stelle et al. } \\
(1994)\end{array}$ & $\begin{array}{l}\text { Retrospective study } \\
\text { of criminal justice } \\
\text { records }\end{array}$ & $\begin{array}{l}\text { Offenders admitted to a } \\
\text { Treatment Alternatives } \\
\text { Program }(\mathrm{n}=259)\end{array}$ & $\begin{array}{l}\text { SCM } \\
\text { 12-month intervention } \\
\text { 18-month study period }\end{array}$ & $\begin{array}{l}58 \% \text { rearrested during } 18 \text {-month follow-up, but rearrest and reconviction rates varied significantly } \\
\text { by program completion status } 43 \% \text { of completers arrested; } 74 \% \text { of fon-completers) } \\
\text { TAP also successful for criminals with extensive arrest histories } \\
\text { SCM more cost-effective than incarceration (NS) }\end{array}$ \\
\hline $\begin{array}{l}\text { Laken \& Ager } \\
\text { (1996) }\end{array}$ & $\begin{array}{l}\text { Retrospective study } \\
\text { of client charts }\end{array}$ & $\begin{array}{l}\text { Pregnant women who } \\
\text { contacted a case } \\
\text { management program } \\
(\mathrm{n}=225)\end{array}$ & $\begin{array}{l}\text { Community-based SCM } \\
\text { 18-month intervention }\end{array}$ & $\begin{array}{l}\text { SCM helped to overcome barriers to treatment and to promote retention }(S) \\
\text { SCM, including availability of transportation, correlated significantly with treatment attendance and } \\
\text { retention }\end{array}$ \\
\hline $\begin{array}{l}\text { Mercier \& } \\
\text { Racine (1993) }\end{array}$ & $\begin{array}{l}\text { Retrospective analysis } \\
\text { of client files }\end{array}$ & $\begin{array}{l}\text { Homeless women with } \\
\text { substance abuse problems } \\
(\mathrm{n}=25)\end{array}$ & $\begin{array}{l}\text { SCM } \\
\text { Min. 6-month intervention } \\
\text { 12- and 36-month follow-up }\end{array}$ & $\begin{array}{l}\text { SCM led to improved or stabilized living conditions for most clients after } 12 \text { months, but } \\
\text { acquistions not maintained over time } 36 \text { monthss } \\
\text { Most improvements concerned housing, financial situation, substance abuse; deterioration related } \\
\text { with physical and mental health problems } \\
\text { Women who were followed longer showed most deterioration and had more severe problems }\end{array}$ \\
\hline
\end{tabular}


Table 6.5.: Overview of studies that have focused on the effectiveness of clinical (CCM) or brokerage case management (BCM), including study design, sample, type of intervention and direction and significance of effects

\begin{tabular}{|c|c|c|c|c|}
\hline Authors & Type of study & Sample & Intervention & Effects \\
\hline Scott et al. (2002) & $\begin{array}{l}\text { Randomized and } \\
\text { controlled trial }\end{array}$ & $\begin{array}{l}\text { Clients presenting at } \\
\text { centralized intake unit } \\
(\mathrm{n}=692)\end{array}$ & $\begin{array}{l}\mathrm{BCM} \text { compared with no case } \\
\text { management }\end{array}$ & $\begin{array}{l}\text { CM-group more likely to show up for treatment (especially younger clients) (S) } \\
\text { CM-clients received more referrals to ancillary services (S) } \\
\text { No differences in amount of services and length of substance abuse treatment } \\
\text { Increased possibility that assessed clients will present at program they were referred to (S) }\end{array}$ \\
\hline $\begin{array}{l}\text { McLellan et al. } \\
(1999)\end{array}$ & $\begin{array}{l}\text { Quasi-experimental } \\
\text { study }\end{array}$ & $\begin{array}{l}\text { Substance abusers } \\
\text { attending outpatient } \\
\text { treatment }(\mathrm{n}=537)\end{array}$ & $\begin{array}{l}\text { CCM compared with standard } \\
\text { outpatient treatment } \\
6 \text {-month intervention }\end{array}$ & $\begin{array}{l}\text { Wave } 1 \text { (12 months after implementation): within group improvements concerning substance use, } \\
\text { psychiatric and family problems (S); both groups received very similar services, resulting in no } \\
\text { differential effects between groups } \\
\text { Wave } 2 \text { (26 months after implementation): CCM-group received more medical services (S), and } \\
\text { alcohol, employment and legal services (NS) } \\
\text { Significant improverements concerning alcohol, drug, medical, psychiatric and employment status } \\
\text { Extensive training to foster collaboration and pre-contracting of services to ascertain their } \\
\text { availability essential for success }\end{array}$ \\
\hline Okin et al. (2000) & Pre-post design & $\begin{array}{l}\text { Patients who used the } \\
\text { emergency department at } \\
\text { least } 5 \text { times in past } 12 \\
\text { months ( } \mathrm{n}=53 \text { ) }\end{array}$ & $\begin{array}{l}\text { Intensive CCM } \\
\text { 12-month intervention }\end{array}$ & $\begin{array}{l}\text { Median of ED visits and costs decreased and number of outpatient visits increased (S) } \\
\text { Homelessness decreased by } 57 \% \text {, alcohol use by } 22 \% \text { and drug use by } 26 \% \text { (S) } \\
\text { Increased linkage to primary care and reduction in acute services and hospital costs (S) } \\
\text { For each dollar invested in program, } 1.44 \$ \text { reduction in hospital costs }\end{array}$ \\
\hline
\end{tabular}





\title{
Chapter 7
}

\section{Qualitative study on the effectiveness of case management for multiple service users in Belgian substance abuse treatment ${ }^{8}$}

\begin{abstract}
Frequent and multiple service users make disproportionate use of available services and resources in substance abuse treatment. Standard treatment for these clients has been described as frustrating and ineffective. Intensive case management was implemented among a small sample of multiple service users to decrease inpatient service utilization, to optimize matching to treatment services, to improve clients' functioning, to enhance treatment retention, and to improve satisfaction with the services received. We present the results of a qualitative study that explored whether intensive case management initially generated the intended outcomes and which elements elicited such effects. Standardized instruments, interviews with clients and case managers, and case managers' logbooks were used to assess the effectiveness of this intervention. Case-by-case comparison of 6-month outcomes of the first 20 clients who participated in this project $(n=20)$ showed that intensive case management helped to stabilize and reduce most clients' problems of drug use, employment and family functioning, and physical and psychological health. Persons who received more intensive case management services generally showed greater improvement in drug and physical health problems. Service utilization was considerably high, especially among clients receiving more intensive case management services, while treatment retention was enhanced among only a few cases. We concluded that intensive case management was an effective intervention for improving communication and coordination of care and for reducing or at least stabilizing drug-related problems among multiple service users, and that nearly all participants viewed case management as an effective and valuable intervention.
\end{abstract}

\footnotetext{
8 This chapter is based on: Vanderplasschen, W., Lievens, K., Franssen, A. \& Broekaert, E. (2004). Qualitative study on the effectiveness of case management for multiple service users in Belgian substance abuse treatment. Manuscript submitted for publication.
} 

QUALITATIVE STUDY ON THE EFFECTIVENESS OF CASE MANAGEMENT

\subsection{INTRODUCTION}

Frequent and multiple service utilization has been reported as an increasing problem, particularly in emergency wards, crisis and detoxification centers, and other acute services (Cox et al., 1998; Kinnunen \& Nilson, 1999; Okin et al., 2000; Thornquist, Biros, Olander, \& Sterner, 2002; Witbeck, Hornfeld, \& Dalack, 2000). Among other reasons, this phenomenon is due to the growing complexity of health problems and systems of care (Nassen, 2001; Willenbring, 1996). Frequent service utilization has primarily been associated with homelessness, substance abuse, unemployment, social exclusion, lack of insurance entitlement, medical and psychological problems, suicidal behavior, and increased risk of mortality (Keene, Bailey, Swift, \& Janacek, 2000; Langdon, Yagüez, Brown, \& Hope, 2001; Okin et al., 2000; Witbeck et al., 2000).

Despite much anecdotal evidence about persons who repeatedly use the same agencies or a range of different agencies, relatively sparse empirical data are available about these socalled "revolving door clients", "shared clients" or "treatment tourists" (Keene, Swift, Bailey, \& Janacek, 2001; Kertesz, Horton, Friedmann, Saitz, \& Samet, 2003; Kinnunen \& Nilson, 1999; McCarty, Caspi, Panas, Krakow, \& Mulligan, 2000). This can be attributed to the lack of a common definition, little specialist interest in this multi-problem population, and the lack of adequate research methods (Keene et al., 2001).

Only some authors have focused on the extent of frequent and multiple service utilization among substance abusing populations (Keene et al. 2000; Thornquist et al., 2002). Thornquist and colleagues (2002) have demonstrated that the number of chronic public inebriates who frequently and repeatedly use emergency departments for medical care accounted for $5.6 \%$ of all yearly emergency visits. A large study concerning repeated service use and shared clients in East England has shown that about half of all clients (49\%) contacting alcohol and drug agencies had also been registered at least once in another social or health care agency within a two-year period (Keene et al., 2000).

In our study of multiple and repeated service use in specialized substance abuse agencies in the region of Ghent (Belgium) we estimated the percentage of substance abusers starting treatment in three or more agencies within a 6-and 8-month registration period to be 2.9 and 4\%, respectively (Vanderplasschen, Lievens, \& Broekaert, 2001a; Vanderplasschen, Colpaert, Lievens, \& Broekaert, 2003). Although these cases do not represent a numerically large group of substance abusers, this subgroup was involved in $9.9 \%$ and $14 \%$ of all registrations during the respective periods. This observation illustrates the disproportionate use these persons make of available services and resources (Keene et al., 2001; McCarty et al., 2000; Okin et al., 2000; Thornquist et al., 2002).

The care of this particular group of substance abusers has been described as frustrating and challenging (Thornquist et al., 2002). Interviews with caregivers from the agencies that participated in our research revealed a lack of adequate strategies and interventions to deal with these clients (Vanderplasschen, De Bourdeaudhuij, \& Van Oost, 2002). Traditional 
substance abuse treatment services have proven to be relatively ineffective for this target population, resulting in clients receiving episodic, non-continuous, and inadequate care (Cox et al., 1998; Okin et al., 2000; Thornquist et al., 2002; Vanderplasschen, Rapp, Wolf, $\&$ Broekaert, in press). When comprehensive and long-term interventions are available, substantial improvements have been observed in clients' functioning (Braucht et al., 1995; Cox et al., 1998). Intensive case management has been applied successfully among frequent service users (e.g., chronic public inebriates) to reduce the use of expensive inpatient services, to promote participation in community-based services, and to stabilize and improve clients' functioning (Okin et al., 2000; Thornquist et al. 2002; Witbeck et al., 2000). However, only a limited number of randomized and controlled trials provide some evidence for the differential effectiveness of case management when compared with usual care (Vanderplasschen, Wolf, Rapp, \& Broekaert, 2004). Still, most studies have shown significant effects of this intervention on clients' functioning over time (Drake et al., 1998; Lapham, Hall, \& Skipper, 1995; Stahler, Shipley, Bartelt, DuCette, \& Shandler 1995).

To address the needs of multiple and frequent service users, two interventions were developed within the network of services for substance abusers in the region of Ghent (Belgium) that aim at providing coordination and continuity of care for this specific population. These interventions include (1) structural interagency care coordination to discuss shared clients and common strategies to deal with this subgroup, and (2) intensive case management. The primary assumption was that both interventions would decrease multiple service utilization and lead to better client-treatment matching. Because case management offers a more intensive and specialized approach, additional improvement was expected concerning clients' functioning, treatment participation and retention, service utilization, and satisfaction with the intervention received.

This study investigates the effectiveness of intensive case management for achieving the postulated goals among substance abusers who use multiple services or who are in need of such services due to the complexity of their situation (e.g., pregnancy, parenthood, dual diagnosis, or illegal immigration). We wanted to explore whether the case management program initially produced the intended outcomes and which elements elicited such effects; therefore, this article presents the results of a qualitative study that focused on the case management process and the outcomes generated by this intervention during the first six months. This qualitative study is part of a randomized and controlled research project that will test the preliminary outcomes and hypotheses presented here on a large sample, including a control condition not receiving this intervention. The results of this randomized and controlled trial will be reported in subsequent publications, because the number of cases will be extended cumulatively until spring of 2006 . 
QUALITATIVE STUDY ON THE EFFECTIVENESS OF CASE MANAGEMENT

\subsection{PROGRAM DESCRIPTION}

The appointment of regional care coordinators by the Belgian federal government in 2002 has stimulated cooperation and coordination in the field of substance abuse treatment (FOD Volksgezondheid, 2002). In the region of Ghent, on the one hand, this has resulted in a tri-weekly meeting of caregivers from several specialized agencies who discuss each partners' admission policy and intake and discharge procedures, and who monitor admissions, referrals, and services delivered to shared clients (Franssen, 2003). This structural approach will be further referred to as care coordination [cliëntenoverleg]. On the other hand, an adapted model of case management was implemented that corrected most of the shortcomings of the initial conceptualization of this intervention (Vanderplasschen, Lievens, \& Broekaert, 2001b). Funded by the Province of EastFlanders and the City of Ghent, we designed a 3-year intensive case management demonstration project to provide comprehensive, individualized, and continuous care; to support clients' functioning in the community and appropriate use of helping resources; and to improve coordination and communication between services. This project is described below, based on what case managers do (activities) and how these activities are delivered (conceptualization) (Godley, Finch, Dougan, McDonnell, McDermeit, \& Carey, 2000).

\subsubsection{ACtivities}

Case managers' tasks are similar to those mentioned by Moxley (1989): assessment, planning, direct services (support, crisis intervention, advice, training), indirect services (linking, coordination, outreaching, advocacy), monitoring, and evaluation. Assessment consists of a thorough analysis of individuals' needs, the severity of their problems, treatment history, risk and protective factors, clients' expectations and objectives, and other information. Based on this assessment, case managers develop or amend an individualized treatment plan that outlines specific activities intended to move clients toward desired goals. Direct services include maintaining an ongoing helping relationship with the client, training them in aspects of daily living, assisting them at time of crises, learning them to solve problems, functioning as a role model and offering potential scenarios, and accompanying clients when appropriate. When transportation is not directly available, case managers drive clients to appointments or pick them up for treatment sessions.

Besides these direct interventions, it is the case manager's task to help clients connect with providers who could meet clients' needs (linking). The case manager acts as coordinator, organizes the services of different providers and monitors the treatment process. Case managers further advocate for their clients when services are not readily available e.g., in case of waiting lists or legal or housing problems. Assertive outreach means that case managers meet with their clients in their living environment (e.g., at home, at work, at a 
treatment agency, in prison). Case managers ensure that clients receive the services specified in the treatment plan and keep track of compliance and progress toward specified goals (monitoring). Finally, disengagement and evaluation refer to the way case management is ended and include a formal evaluation of the services offered and related outcomes.

\subsubsection{CONCEPTUALIZATION}

Several dimensions indicate how case management programs are actually organized: duration, intensity, focus of services, availability, site, consumer direction, training, authority, and team structure (Ridgely \& Willenbring, 1992). The duration of case management is limited (six months), but varies depending on clients' needs and goal achievement. Clients play a prominent role in determining the goals, which - given the chronic nature of clients' problems - relate more to functional stability than to strict sobriety. Case managers have at least weekly contacts with their clients; the ratio of case managers to clients is approximately 1:10, which suggests a high intensity of case management. Case managers provide a broad range of services, and these are primarily available during regular office hours.

The project is located at the medical-social care center for substance abusers, which is situated in the city center of Ghent and mainly provides methadone maintenance treatment. In the absence of one of the case managers, clients can address the staff at this 24-hour center. Most case management services are provided at other sites, including clients' residences, public places, substance abuse treatment agencies, prison, clients' workplace, and schools.

All three case managers have masters' degrees in educational sciences and extensive experience in working with persons with substance abuse problems. Two of them are more familiar with an abstinence-oriented approach, while the other is more accustomed to the harm reduction philosophy.

Although several training and supervision sessions were organized before and during the project, case managers were primarily trained on the job. Due to the close and intensive relationship with their clients, case managers have some authority with the clients, but this authority does not always transfer when working with other agencies, especially when none of the case managers has close contacts with staff members at other agencies. Although all case managers have their individual caseload, a team approach is used to extend the availability of services and to support and supervise case managers. 


\subsection{METHODS}

\subsubsection{SUBJECTS}

Subjects in this study were drawn from a pool of multiple and frequent service users and persons who needed comprehensive care because of the complexity of their situation $(n=65)$ and whose cases were discussed during the interagency care coordination meeting [cliëntenoverleg] of February 20 and March 13, 2003. The primary eligibility criteria were substance dependence for more than two years according to DSM IV criteria (APA, 1996), problems in at least three life domains of the Addiction Severity Index (McLellan et al., 1992), a minimum of three previous treatment episodes and recent contacts with two or more specialized centers for substance abuse treatment. In order to be eligible, clients had to give informed consent for participation and could not be followed by another case management program. Clients who followed or planned to start long-term residential treatment or who had a place of residence outside the borders of the province of EastFlanders could not be included. Both of these categories were excluded because the previous study had shown that the former situation led to less intensive contacts with and limited authority of the case manager, while the latter scenario was not practical and very time-consuming (Vanderplasschen, Lievens, et al., 2001b).

All eligible persons $(n=65)$ were randomly assigned to the case management $(n=43)$ or control condition (care coordination) $(\mathrm{n}=22)$. Because we expected that not all clients would receive the same intensity of case management services, we assigned twice as many clients to the experimental condition in order to create a third condition (less intensive or intermediate case management) afterward. During the first six months of the project, a total of 20 clients participated in the case management condition and 10 in the control condition. Analysis of the data of the control group is beyond the scope of this article because of its small size and some differential characteristics of the comparison condition at that moment.

Of all clients assigned to the case management group ( $\mathrm{n}=43$ ), five refused to participate, five agreed but never showed up for the first appointment and 13 could not be retrieved when they were asked to participate. The latter source of attrition was due to a time lag between the composition of the sample of eligible clients (February-March 2003) and the actual start of case management (April-August 2003). Case management did not start until April 1, and then with only half of the intended caseload $(n=10)$, because the case managers were not appointed until March 1, 2003, and still had to be trained for this intervention. By the end of August 2003, the caseload was extended to 20 clients for two FTE case managers. 


\subsubsection{PROCEDURE}

Several data sources (e.g., standardized instruments, interviews with clients and case managers, case managers' logbooks) were used to monitor clients' functioning and the evolution of that functioning, and to compare drug-related outcome measures at baseline and 6-month follow-up. Qualitative data were collected concerning the case management process in order to assess relations between process and outcome variables.

During the care coordination meetings of February and March 2003, responsible caregivers from all eight participating agencies (4 detoxification centers, 3 outpatient centers and 1 shelter for homeless persons) presented a list of all clients who had followed or recently asked for treatment in this particular center and who met all four inclusion criteria. These eight separate lists were united, purged of duplications, and randomly divided into two groups. Shortly after the care coordination meeting of March 2003, case managers started to contact the persons assigned to the case management group in ascending numerical order, asking whether they were interested in participating in the study. If clients agreed, case managers explained the study and made an appointment for a first meeting. During this first contact, case managers further explained what kind of intervention clients could expect, obtained informed consent, and administered the baseline interview.

Client interviews were planned at start and after six and 12 months. To promote participation in baseline and follow-up assessments, clients received a shopping voucher (worth 15€) for each interview. Case managers administered baseline interviews and research assistants conducted the follow-up interviews. Baseline assessments took place between April 15 and August 31, 2003, while 6-month follow-up interviews were performed between October 16, 2003 and February 29, 2004. Usually, baseline interviews lasted about one hour and a half, while follow-up assessments took no longer than one hour. Interviews were administered at a place of participants' choice, mostly the medicalsocial care center, another treatment center, or at clients' homes or workplaces.

Baseline assessments are available for all case managed-clients $(n=20)$, but after six months it appeared to be impossible to have a follow-up interview with four persons: one could not be located because he was on the run from the police after escaping from a closed psychiatric ward, and three others repeatedly failed to keep appointments with one of the researchers. This resulted in 16 client interviews at the 6-month follow-up.

In addition to these standardized interviews, case managers kept computerized logs of their activities concerning all clients $(n=20)$ over a six-month period. Moreover, all three case managers were regularly interviewed (on monthly basis during the first three months; later every three months) about their activities, the evolution of clients' functioning, and their contacts with services. These data were tape recorded and transcribed afterward. 
QUALITATIVE STUDY ON THE EFFECTIVENESS OF CASE MANAGEMENT

\subsubsection{INSTRUMENTS}

For the evaluation of clients' functioning and service utilization at baseline and six months later, we used the Dutch version of the European Addiction Severity Index (EuropASI) (Raes, 1999). The ASI is a widely used assessment and research instrument tested in numerous treatment settings with diverse groups of clients (Broekaert et al., 2002; Hendriks, Kaplan, van Limbeek \& Geerlings, 1989; McLellan et al., 1999). It is a one-hour structured interview that measures lifetime and recent (past 30 days) severity of problems on a 10-point scale (0-9) in seven areas of bio-psychosocial functioning: medical status, employment and self-support, alcohol use, drug use, legal status, family and social relationships, and psychiatric symptoms (McLellan et al., 1992). The Dutch translation of the short version of the TCU Motivation for Treatment (MfT) scales was used for measuring motivation among case management participants (de Weert-van Oene, Schippers, De Jong, \& Schrijvers, 2002). This 24-item self-report questionnaire is scored on a 7-point Likert scale and consists of three subscales: problem recognition, desire for help, and treatment readiness. Since psychological problems were omnipresent and remained at a relatively high level 12 months later in our previous case management study (Vanderplasschen, Lievens, Broekaert, \& Rapp, 2004), we chose to use the Symptom Check List 90-Revised (SCL-90-R) to assess recent (last seven days) psychological distress (Derogatis \& Cleary, 1977). This self-report questionnaire includes 90 items and consists of nine subscales: somatization, obsessive-compulsive, interpersonal sensitivity, depression, hostility, anxiety, phobic anxiety, paranoid ideation, and psychoticism.

Besides this information from standardized instruments, data were collected during open interviews with clients and case managers. Baseline interviews with clients focused on previous service utilization and clients' subjective perspectives of their level of functioning in the seven ASI life domains. The 6-month follow-up interview assessed service utilization and treatment retention in the previous months and clients' subjective perception of their level of functioning compared with six months ago, using a 5-point Likert scale ranging from "much worse" to "much better". In addition, clients' satisfaction with services received was measured using a 5-point Likert scale ranging from "very unsatisfied" to "very satisfied" (Oliva, Görgen, Schlanstedt, Schu, \& Sommer, 2001).

Regular interviews with case managers focused on how basic functions of case management were performed and which life domains needed the most attention. After six months, case managers evaluated clients' functioning in the ASI life domains compared with the situation at start, based on a 5-point Likert scale ranging from "much worse" to "much better". 


\subsubsection{DATA ANALYSIS}

Given the qualitative approach of this study and the small sample size, data analyses are mainly limited to frequencies and case-by-case comparisons. We used the statistical software program SPSS to analyze data from the EuropASI, Mft, and SCL-90-R. Qualitative data collected during the interviews and from case managers' logs were coded based on a hierarchical coding structure, including case managers' basic functions and the ASI life domains, using the software package WinMAX 98 Pro for text analysis (Kuckartz, 1998). From the comparison of coded text segments, several important themes appeared concerning both grouping variables.

As the case management intervention appeared to be less intensive among some persons, we distinguished an "intensive" ( $\mathrm{n}=12)$ and "intermediate" $(\mathrm{n}=8)$ case management group. The former clients received at least weekly case management services, while the latter group had less than weekly contacts with their case manager. Six-month outcomes were compared between both groups, since the intensity of case management may affect its results (Braucht et al., 1995; Oliva et al., 2001; Stahler et al., 1995; Wolf, Mensink, \& Van der Lubbe, 2002).

\subsection{RESULTS}

\subsubsection{BASELINE CHARACTERISTICS}

A case-by-case overview of the baseline characteristics of clients assigned to the case management condition (cf. table 7.1., p. 199) reveals that all $(n=20)$ had chronic and multiple problems and had frequently utilized substance abuse treatment services before. Demographic variables show that one-third of these clients were women $(n=7)$, that the average age was 30.7 years, and that most clients were born in Belgium ( $\mathrm{n}=17)$.

All participants had been using drugs regularly for at least five years and had such severe drug problems that some form of treatment was indicated (ASI severity score $\geq 4$ ). Most of them $(n=12)$ abused several substances, while 4 persons used heroin as primary drug. The majority $(\mathrm{n}=15)$ had injected drugs at some time, and 13 of them were still injecting drugs the last six months before the baseline interview. Half of them $(n=10)$ had overdosed on drugs at some time, and for almost all clients $(n=19)$ their drug problems had resulted in at least five previous treatment episodes $($ mean $=18.2$; median $=13)$. Only 5 persons had severe alcohol problems at the start of the project, and 6 persons had been treated for such problems before. 
QUALITATIVE STUDY ON THE EFFECTIVENESS OF CASE MANAGEMENT

Table 7.1.: Case-by-case overview of baseline characteristics, treatment bistory and problem severity of case management participants $(n=20)$

\begin{tabular}{|c|c|c|c|c|c|c|c|c|c|c|}
\hline Case & Gender & Age & $\begin{array}{l}\text { Number } \\
\text { of } \\
\text { previous } \\
\text { treatment } \\
\text { episodes }\end{array}$ & & & Europ & sever & scores & & \\
\hline & & & & $\begin{array}{l}\text { physical } \\
\text { health }\end{array}$ & $\begin{array}{l}\text { employment, } \\
\text { education }\end{array}$ & alcohol & drugs & $\begin{array}{l}\text { police, } \\
\text { justice }\end{array}$ & $\begin{array}{l}\text { family, } \\
\text { social } \\
\text { relations }\end{array}$ & $\begin{array}{l}\text { psychological } \\
\text { health }\end{array}$ \\
\hline 1 & M & 21 & 10 & 3 & 4 & 1 & 6 & 4 & 4 & 5 \\
\hline 2 & F & 26 & 13 & 3 & 3 & 0 & 5 & 7 & 2 & 5 \\
\hline 3 & M & 21 & 15 & 1 & 7 & 0 & 7 & 2 & 7 & 7 \\
\hline 4 & M & 34 & 67 & 5 & 7 & 6 & 7 & 3 & 7 & 7 \\
\hline 5 & M & 40 & 10 & 4 & 4 & 0 & 4 & 4 & 4 & 5 \\
\hline 6 & M & 39 & 63 & 3 & 4 & 0 & 7 & 5 & 3 & 7 \\
\hline 7 & F & 24 & 9 & 5 & 5 & 1 & 6 & 1 & 3 & 3 \\
\hline 8 & F & 35 & 24 & 7 & 4 & 4 & 6 & 7 & 4 & 7 \\
\hline 9 & M & 30 & 19 & 7 & 5 & 0 & 5 & 0 & 5 & 7 \\
\hline 10 & F & 38 & 17 & 2 & 2 & 1 & 5 & 3 & 4 & 5 \\
\hline 11 & F & 31 & 7 & 4 & 4 & 7 & 5 & 1 & 4 & 7 \\
\hline 12 & M & 24 & 4 & 1 & 4 & 2 & 5 & 2 & 5 & 2 \\
\hline 13 & M & 39 & 11 & 1 & 2 & 1 & 6 & 5 & 4 & 4 \\
\hline 14 & F & 38 & 32 & 4 & 4 & 0 & 7 & 5 & 5 & 5 \\
\hline 15 & $\mathrm{M}$ & 20 & 16 & 1 & 4 & 1 & 7 & 1 & 8 & 1 \\
\hline 16 & $\mathrm{M}$ & 30 & 8 & 1 & 2 & 1 & 6 & 6 & 4 & 3 \\
\hline 17 & $\mathrm{~F}$ & 40 & 13 & 6 & 4 & 7 & 4 & 3 & 4 & 6 \\
\hline 18 & $\mathrm{M}$ & 23 & 11 & 4 & 3 & 0 & 7 & 5 & 2 & 1 \\
\hline 19 & $\mathrm{M}$ & 35 & 15 & 6 & 4 & 6 & 7 & 5 & 2 & 1 \\
\hline 20 & F & 26 & 5 & 1 & 5 & 0 & 5 & 0 & 2 & 5 \\
\hline Notes: & \multicolumn{10}{|c|}{$\begin{array}{l}\text { Severity scores } \geq 4 \text { indicates a rather serious problem for which some form of treatment is indicated } \\
\text { 0-1: no real problem, treatment not indicated } \\
\text { 2-3: slight problem, treatment probably not necessary } \\
\text { 4-5: moderate problem, some treatment indicated } \\
\text { 6-7: considerable problem, treatment necessary } \\
\text { 8-9: extreme problem, treatment absolutely necessary } \\
\text { Cases } 1 \text { to } 12 \text { received intensive case management; cases } 13 \text { to } 20 \text { intermediate case management }\end{array}$} \\
\hline
\end{tabular}

Three-quarter of the clients $(\mathrm{n}=15)$ had rather severe employment, family and/or psychological problems (ASI severity score $\geq 4$ ). Most participants were unemployed $(n=9)$ or received a disability income $(n=5)$ the three years previous to the baseline assessment, and only one person worked during the last 30 days before the first interview. Family and relational problems included conflicts with parents or partner $(\mathrm{n}=12)$ and experiences of emotional $(n=12)$ and sexual abuse $(n=6)$. Fifteen persons experienced depressive symptoms and feelings of tension or anxiety during the 30 days preceding the baseline interview, while 8 of them had been treated for psychological problems. Twothirds $(n=13)$ of the clients had attempted suicide. The average global severity index for 
psychological distress on the SCL-90-R (GSI = 202.3) appeared to be "above average" when compared with the norms for persons in treatment for substance abuse problems, but none of the global subscale scores was extremely high.

Finally, half of all clients $(\mathrm{n}=10)$ had rather serious physical health problems, and an equal number had problems with the courts (ASI severity score $\geq 4$ ). Fourteen participants suffered from chronic physical complaints and 11 were infected with Hepatitis C. Eight persons had been referred to treatment by the criminal justice system and 13 persons were currently involved with the courts; most of these were on parole $(n=9)$.

\subsubsection{THE CASE MANAGEMENT INTERVENTION}

Analysis of the interviews with and logs kept by case managers shows that most of their activities concerned coordination (37.9\%), direct services $(21.5 \%)$, and linking $(16.2 \%)$. The number of activities differed from client to client, and two groups could be distinguished: one group $(n=12)$ received weekly case management services (intensive group) and another group received less frequent services (intermediate group). While the former group accounted for $85.4 \%$ of all case management activities, the latter group was involved in $14.8 \%$ of these activities. The main difference between both groups was that the intermediate case management group was less involved in coordination $(9.1 \%)$ and linking $(15.5 \%)$ activities, while the number of direct services provided $(28.1 \%)$ was relatively high.

In general, coordination activities were mostly related to employment or financial issues $(29.6 \%)$, drug $(24.7 \%)$ and relational problems $(20.9 \%)$, and - to a lesser extent problems with the courts $(16.0 \%)$. Coordination usually consisted of face-to-face meetings with at least one other partner involved in the treatment process. In some cases $(n=9)$, the case manager brought together all partners to discuss which strategy should be followed with a particular client, especially when it concerned childcare and custody or during times the treatment process bogged down. Occasionally $(n=3)$, coordination activities were exclusively targeted at clients' social networks (e.g., sister, mother, and grandmother) rather than at professionals.

Most direct services provided by case managers (29.4\%) focused on clients' overall situations and were intended to monitor their status. These direct services could also include case managers motivating clients, supporting them to achieve their goals, providing transportation, or accompanying them when they were in need of specific services (e.g., judicial advice, employment training, or entitlement to welfare benefits). Such services were mostly related with family (19.6\%), employment (16.6\%), and drug issues $(13.5 \%)$.

Linking usually concerned substance abuse problems (30.9\%), but also employment $(25.3 \%)$ and housing problems (16.3\%). Most clients were referred to short-term residential treatment, while some clients were referred to a long-term program for dually 
diagnosed persons. According to case managers and clients, housing services such as supported or sheltered living were not sufficiently available.

Advocacy and outreaching accounted for $8.8 \%$ and $8.4 \%$ of case managers' activities, respectively. Advocating on the behalf of clients was usually directed at their employment or financial status $(43.3 \%)$ and - to a lesser extent - at housing and family problems $(17.9 \%)$, problems with the courts $(14.5 \%)$, and accessibility of substance abuse treatment agencies $(14.5 \%)$. Advocacy included discussing clients' judicial conditions with the criminal justice system, solving problems with the landlord, or adapting the regimen for individuals' methadone treatment. Outreaching activities consisted of proactive contacts with clients and were generally intended to follow-up the clients' overall situations.

Finally, assessment and planning activities were reported only once for most clients. After initial assessment and goal planning, little information was retrieved about subsequent assessments or goal setting. If case management was stopped after six months, evaluation activities were only registered in a few cases $(n=3)$.

\subsubsection{SIX-MONTH OUTCOMES}

\section{a Clients’ Functioning}

\section{ASI SEVERITY SCORES}

A case-by-case comparison of all clients who could be reinterviewed after six months $(n=16)$ showed that problem severity scores had decreased or remained stable for 10 persons, while 6 clients' situation had deteriorated concerning at least one life domain (cf. table 7.2., p. 202). Most positive effects concerned employment $(\mathrm{n}=8)$ and psychological functioning $(n=8)$, followed by drug use $(n=7)$ and family relations $(n=7)$. Positive outcomes are illustrated by the fact that - compared with the first interview more persons had worked during the last 30 days (5 vs. 4) and fewer clients were dependent on a disability income (6 vs. 8). Moreover, fewer persons had had physical health complaints for more than five days during the last 30 days (5 vs. 8 ) or had injected drugs the past six months (6 vs. 11). In addition, more persons had a stable housing situation (14 vs. 12) and fewer participants had conflicts with their partner and/or parents during the last 30 days (2 vs. 3). Finally, fewer clients experienced psychological problems such as depressive symptoms (12 vs. 14) or feelings of tension or anxiety (10 vs. 13).

On the other hand, many persons' situations did not change; for some problems, the severity even worsened, especially concerning judicial $(n=3)$, psychological $(n=3)$, and family problems $(n=2)$. The reasons for this deterioration were non-compliance with judicial conditions and increased feelings of tension or anxiety.

Motivation does not seem to affect clients' functioning at the 6-month follow-up, since both clients with high and low motivation showed improved outcomes. Clients with more psychological distress at start improved equally to clients with less severe total SCL scores, 
but in the former group more persons' psychological health had improved (5 vs. 2). More persons receiving intensive case management had improved outcomes in at least three life domains ( 7 vs. 3), while among the intermediate case management group more clients' situations deteriorated concerning at least one life domain (4 vs. 2). An equal number of clients in both groups improved concerning employment (4 vs. 4 ) and drug problems (3 vs. 4), but more persons receiving intensive case management had reduced family problems (5 vs. 2 ) and improved physical (5 vs. 1) and psychological health (7 vs. 1$)$ outcomes. Slightly more persons from the intensive case management group had reduced judicial problems (3 vs. 1).

Table 7.2.: Case-by-case overview ( $n=16)$ of the evolution of clients' functioning based on a comparison of $A S I$ severity scores at start and six months later, including clients' motivation and psychological functioning at start and the number of services contacted during the project

\begin{tabular}{|c|c|c|c|c|c|c|c|c|c|c|}
\hline \multirow[t]{2}{*}{ Case } & $\begin{array}{c}\text { Mft } \\
\text { Score }\end{array}$ & $\begin{array}{c}\text { SCL } \\
\text { Global } \\
\text { Severity } \\
\text { Index }\end{array}$ & $\begin{array}{c}\text { Number } \\
\text { of } \\
\text { services } \\
\text { contacted }\end{array}$ & \multicolumn{7}{|c|}{ Evolution of EuropASI severity scores } \\
\hline & & & & $\begin{array}{l}\text { physical } \\
\text { health }\end{array}$ & $\begin{array}{c}\text { employment, } \\
\text { education }\end{array}$ & alcohol & drugs & $\begin{array}{l}\text { police, } \\
\text { justice }\end{array}$ & $\begin{array}{c}\text { family, } \\
\text { social } \\
\text { relations }\end{array}$ & $\begin{array}{l}\text { psychological } \\
\text { health }\end{array}$ \\
\hline 1 & 155 & 184 & 8 & + & $=$ & $=$ & - & ++ & - & - \\
\hline 2 & 114 & 176 & 6 & + & - & $=$ & $=$ & - & $=$ & $=$ \\
\hline 4 & 142 & 287 & 8 & $=$ & + & ++ & $=$ & $=$ & ++ & + \\
\hline 5 & 108 & 124 & 3 & ++ & + & $=$ & + & $=$ & + & + \\
\hline 6 & 160 & 331 & 3 & $=$ & $=$ & $=$ & ++ & + & $=$ & + \\
\hline 8 & 116 & 216 & 7 & ++ & $=$ & $=$ & $=$ & $=$ & $=$ & + \\
\hline 9 & 124 & 202 & 6 & + & ++ & $=$ & ++ & $=$ & ++ & + \\
\hline 10 & 100 & 185 & 6 & $=$ & $=$ & $=$ & + & + & + & + \\
\hline 11 & 141 & 218 & 7 & $=$ & + & + & $=$ & $=$ & + & ++ \\
\hline 13 & 55 & 146 & 2 & $=$ & $=$ & $=$ & $=$ & $=$ & $=$ & - \\
\hline 14 & 157 & 354 & 5 & - & $=$ & $=$ & $=$ & $=$ & $=$ & - \\
\hline 15 & 148 & 150 & 2 & $=$ & ++ & $=$ & + & $=$ & ++ & $=$ \\
\hline 17 & 115 & 207 & 1 & $=$ & + & + & + & $=$ & + & $=$ \\
\hline 18 & 140 & 147 & 2 & $=$ & + & $=$ & + & ++ & $=$ & $=$ \\
\hline 19 & 145 & 131 & 2 & + & $=$ & $=$ & $=$ & - & $=$ & $=$ \\
\hline 20 & 59 & 304 & 2 & $=$ & + & $=$ & $=$ & - & - & + \\
\hline Notes: & $\begin{array}{l}--: \\
-: \\
=: \\
+: \\
++ \\
\text { Cas }\end{array}$ & $\begin{array}{l}\text { crease of } \\
\text { rease of } \\
\text { blem sev } \\
\text { uction of } \\
\text { eduction } \\
1 \text { to } 12 n\end{array}$ & $\begin{array}{l}\text { blem severit } \\
\text { blem severit } \\
y \text { did not in } \\
\text { oblem severi } \\
\text { problem seve } \\
\text { ived intensiv }\end{array}$ & $\begin{array}{l}\text { at leas } \\
\text { at least } \\
\text { ase / redu } \\
\text { by at lea. } \\
\text { by at le } \\
\text { sse manc }\end{array}$ & $\begin{array}{l}\text { points } \\
\text { points } \\
\text { by more than } \\
2 \text { points } \\
\text { t } 4 \text { points } \\
\text { ment; cases } 1\end{array}$ & point & & & men & \\
\hline
\end{tabular}


QUALITATIVE STUDY ON THE EFFECTIVENESS OF CASE MANAGEMENT

\section{CLIENTS' PERSPECTIVES}

An analysis of clients' subjective perspectives on their level of functioning shows that most clients' subjective perception of their problems $(n=11)$ did not differ in more than two life domains from the evolutions in the ASI severity scores (cf. table 7.2.). Three clients overestimated the progress they made compared with these more objective outcomes, while two persons underestimated these changes. Clients generally overestimated positive evolutions concerning drug problems, while psychological problems tended to be underrated.

Clients from the intensive case management group $(n=9)$ especially thought their drug $(n=8)$ and physical health problems $(n=5)$ had improved. Others said their family $(n=4)$, employment $(n=4)$, and alcohol $(n=4)$ status was better now, while 5 persons thought their psychological functioning had not changed and two persons found their judicial situation was worse compared with six months ago.

Most clients from the intermediate case management group found they had improved with drug $(n=5)$ and employment problems $(n=5)$. These clients thought their situation was more or less the same for all other problems. Two persons found their judicial situation and their psychological status had deteriorated, while two others scored their family situation as worse compared with the start of the project.

\section{CASE MANAGERS’ PERSPECTIVES}

Case managers' perspective on the evolution of clients' global levels of functioning showed that most clients did better compared with six months ago $(n=11)$, while 8 persons' global situations remained unchanged or were stabilized (cf. table 7.3., p. 204). One person's situation deteriorated completely after he dropped out from compulsory treatment. More persons from the intensive case management group (8/12 vs. 3/8) had an improved level of global functioning, while the situation of 5 persons from the intermediate case management group remained unchanged.

Case managers related most positive effects to drug use $(n=13)$, physical health $(n=12)$, and employment functioning $(n=11)$, while several adverse outcomes were observed in clients' judicial status $(n=7)$. According to the case managers, less than half of all clients improved concerning their psychological problems $(n=8)$ or their family $(n=8)$ and living situations $(n=7)$. Clients from both groups were evaluated equally in drug and employment problems and physical health, but the intensive case management group had superior outcomes for family problems (6 vs. 2), living situation (6 vs. 1), psychological health (6 vs. 2$)$, and judicial problems (5 vs. 2$)$. 
Table 7.3.: Case-by-case overview $(n=20)$ of the evolution of clients' global levels of functioning and their functioning concerning the ASI life domains, according to the case managers

\begin{tabular}{|c|c|c|c|c|c|c|c|c|c|}
\hline \multirow[t]{2}{*}{ Case } & \multicolumn{9}{|c|}{ Evaluation of clients' functioning after six months of case management } \\
\hline & $\begin{array}{c}\text { global } \\
\text { functioning }\end{array}$ & $\begin{array}{l}\text { physical } \\
\text { health }\end{array}$ & $\begin{array}{l}\text { employment, } \\
\text { education }\end{array}$ & alcohol & drugs & $\begin{array}{l}\text { police, } \\
\text { justice }\end{array}$ & $\begin{array}{l}\text { family, social } \\
\text { relations }\end{array}$ & $\begin{array}{l}\text { living } \\
\text { situation }\end{array}$ & $\begin{array}{l}\text { psychological } \\
\text { health }\end{array}$ \\
\hline 1 & $=$ & ++ & $=$ & $=$ & $=$ & + & - & - & $=$ \\
\hline 2 & $=$ & + & $=$ & $=$ & $=$ & - & + & $=$ & $=$ \\
\hline 3 & - & - & $=$ & $=$ & -- & -- & $=$ & -- & $=$ \\
\hline 4 & + & ++ & + & + & + & $=$ & $=$ & ++ & + \\
\hline 5 & + & ++ & + & $=$ & ++ & $=$ & + & ++ & + \\
\hline 6 & + & ++ & $=$ & $=$ & + & ++ & + & $=$ & $=$ \\
\hline 7 & + & + & $=$ & $=$ & + & + & $=$ & + & $=$ \\
\hline 8 & $=$ & $=$ & $=$ & $=$ & $=$ & - & $=$ & $=$ & - \\
\hline 9 & ++ & ++ & + & $=$ & ++ & $=$ & ++ & ++ & + \\
\hline 10 & ++ & $=$ & ++ & ++ & ++ & + & + & ++ & + \\
\hline 11 & + & $=$ & + & + & + & + & ++ & $=$ & + \\
\hline 12 & + & $=$ & + & $=$ & + & - & $=$ & + & + \\
\hline 13 & $=$ & + & $=$ & + & + & - & $=$ & $=$ & - \\
\hline 14 & $=$ & + & + & $=$ & $=$ & - & $=$ & - & $=$ \\
\hline 15 & ++ & ++ & $=$ & $=$ & ++ & + & ++ & ++ & ++ \\
\hline 16 & $=$ & $=$ & + & $=$ & + & + & $=$ & - & $=$ \\
\hline 17 & + & $=$ & + & + & + & $=$ & + & $=$ & $=$ \\
\hline 18 & + & + & + & $=$ & $=$ & $=$ & $=$ & $=$ & $=$ \\
\hline 19 & $=$ & + & $=$ & + & + & - & $=$ & $=$ & + \\
\hline 20 & $=$ & $=$ & + & $=$ & $=$ & $=$ & - & - & $=$ \\
\hline Notes: & $\begin{array}{l}\text { According } \\
--: \text { much } w \\
-: \text { worse } \\
=: \text { unchan } \\
+: \text { better } \\
++: \text { much } \\
\text { Cases } 1 \text { to }\end{array}$ & $\begin{array}{l}\text { o case ma } \\
\text { rse } \\
\text { ged/stabil } \\
\text { etter } \\
2 \text { received }\end{array}$ & etensive case $m$ & Iation wo & es & 0 & iate case & gement & \\
\hline
\end{tabular}

\section{- SERVICE UTILIZATION}

Both groups of case managed-clients utilized several services during the 6-month intervention period, but the intensive case management group had more than twice as many contacts with substance abuse treatment and other agencies (5.9 contacts on average) as the intermediate case management group (2.4 contacts on average). While the latter clients had more contacts with outpatient services, intensively case managed-clients were more involved with residential agencies. Better outcomes were not related to the number of services received, but rather to the length of stay in these services (cf. case $4,10,15)$. While service utilization was very high among the intensive case management 
group, case managers reported improved deliberation, coordination, and communication preceding and following clients' admissions.

\section{a SATISFACTION WITH SERVICES RECEIVED}

All but one of the case managed-clients who were interviewed at follow-up evaluated this intervention "positively" $(n=9)$ or "very positively" $(n=6)$. No differences were observed between the intensive and intermediate case management group, except that some clients $(n=3)$ from the latter group said that case management should be more intensive.

Nearly all clients $(n=14)$ stressed that they appreciated the close and confidential relationship with their case manager and the fact that he or she was able to arrange a lot for them (e.g., admission for crisis intervention). Especially clients from the intensive case management group stressed that the case manager had helped them to link with appropriate services and to stabilize their situation $(n=8)$. Overall, case managed-clients $(n=9)$ were happy with the comprehensive and client-centered approach, with the fact that they were involved themselves in the treatment process, and that they could decide where to focus. Clients $(n=7)$ further liked that the case manager supported them in achieving their goals and that they could always rely on the case manager when they needed it.

\subsection{DISCUSSION}

This qualitative study explored whether intensive case management was initially effective for improving clients' functioning concerning several drug-related problems and for ameliorating service utilization and prolonging retention among substance abusers who were recognized as frequent and multiple service users. The main incentives for addressing this specific population were that these persons represent a relatively small group that makes disproportionate use of available services and resources, and that treatment agencies experience standard treatment for these clients as ineffective (Thornquist et al., 2002; Vanderplasschen, Colpaert, et al., 2003). Results were based on a case-by-case review of 20 clients who were recruited during the first six months of the case management project. Overall, the study demonstrated positive six-month outcomes concerning several drug-related problems, but few effects concerning treatment retention and service utilization. Persons who received more intensive case management services had less severe problems at the 6-month follow-up. Finally, the intervention was qualitatively viewed as effective and valuable by the participants. 


\subsubsection{THE CASE MANAGEMENT INTERVENTION}

Several authors have identified intensive case management as an adequate strategy for reducing the number of hospitalizations and increasing the use of outpatient services, for enhancing treatment participation and retention, and - to a certain extent - for improving clients' functioning (Braucht et al., 1995; Cox et al., 1998; Drake et al., 1998; Okin et al., 2000; Stahler et al., 1995). This intervention is characterized by a comprehensive approach, assertive outreach, and the provision of direct services (SAMHSA, 1998; Vanderplasschen, Rapp, et al., in press). It appeared that case managers in this study were mainly involved in coordination and linking activities and in the delivery of direct services, which are considered core elements of this intervention (Moxley, 1989; Ridgely \& Willenbring, 1992; van Riet \& Wouters, 1996). The marginal role of planning in case managers' activities may have been caused by the short intervention period and the substantial number of crisis interventions (Wolf, 1995). Therefore, it was recommended that case managers should focus more on planning but also on clients' strengths during the rest of the study.

Two groups of clients were distinguished: an intensive $(n=12)$ and intermediate case management group $(n=8)$. Both groups received similar services, except that these were less regular among the intermediate group and they were provided with less linking and coordination activities. Differences in the number of activities were not related with motivation for treatment, but rather with less need for such services or a situation that did not allow intensive contacts (e.g., imprisonment, long-term residential treatment). Comparison of the intensive and intermediate case management group should be regarded with caution since the latter condition was not randomized, but designed afterward based on the number of services received.

\subsubsection{EFFECTIVENESS OF THE INTERVENTION}

Considerable validation for the case management intervention was found in the fact that several clients improved in the same life domains, that the outcomes from different data sources (ASI severity scores and clients' and case managers' ratings) were largely similar, and that the results confirmed the findings of our previous study (Vanderplasschen, Lievens, et al., 2001b). Case managers rated that more than half of all clients $(n=11)$ did globally better as compared with the start of the project, and that most others' situations were stabilized. Most positive changes were observed concerning physical health, drug and employment problems, and case managers evaluated that substantially more clients from the intensive case management group had better outcomes. Clients' subjective ratings of their evolution during the first six months of the project showed similar patterns, and the intensive case management group demonstrated more improvement in drug problems and physical health. Finally, the most objective measure (ASI severity scores) we used confirmed the above-mentioned results: half of all 
clients who participated in the project had improved outcomes in their employment and psychological status and their drug and family problems.

According to the ASI scores, the intensive case management group showed more improvement in physical and psychological health status and family problems. Reduced severity of family and psychological problems was less obvious from the case managers' and clients' subjective ratings, which may be due to the fact that the objective ASI indicators do not totally represent persons' subjective perceptions of these life domains. Moreover, we found that clients tend to overestimate their progress concerning drug problems and rather underestimate the evolution of their psychological problems. On the other hand, the judicial situations of several clients deteriorated, because some did not fulfill their probation conditions. An extensive assessment of clients' judicial situations may help to anticipate deterioration, besides involving judicial partners in the case management process (Godley et al., 2000).

We conclude that the case management intervention was associated for half of all clients with improved outcomes concerning drug use, employment situation, family relations, and psychological health, and that these effects were larger among the intensive case management group, especially for physical health.

Given the uncontrolled and non-randomized design, several hypotheses remain that can explain these small but positive effects. First, a "regression to the mean" may have accounted for these improvements, since most clients entered the project at a moment they weren't doing well and some positive change could be expected over time (Braucht et al., 1995; Lapham et al., 1995). Such a regression to the mean may indeed have played a role because clients with the worst SCL scores for recent psychological distress did relatively better after six months. On the other hand, this hypothesis is in contrast to the fact that most positive evolutions were observed in the life domains that case managers focused on more frequently, and that more intensive case management services generated better outcomes. Improved psychological and physical health (especially among the intensive case management group) cannot be explained by the number of case management interventions received, but is probably a consequence of reduced drug use and more frequent use of services that focused on health aspects. Second, length of stay in (residential) treatment affected outcomes positively among some clients $(n=3)$. These clients stated that case managers had an important role in supporting and stimulating them to stay in treatment. Several authors have shown a relation between case management and enhanced treatment participation and retention, and consequently improved outcomes (Evenson, Binner, Cho, Schicht, \& Topolski, 1998; Shwartz, Baker, Mulvey, \& Plough, 1997; Siegal, Li, \& Rapp, 2002). As opposed to other authors (Rapp, Siegal, Li, \& Saha, 1998), we found no association between motivation for treatment and prolonged retention or improved outcomes. Finally, several clients $(n=9)$ associated the case managers' intervention with progress they made in several life domains, an indication for the effectiveness of this intervention. 
Though decreased hospitalization and inpatient service utilization have been reported as beneficial outcomes in several studies that have utilized intensive case management (Okin et al., 2000; Witbeck et al., 2000), such effects were not observed in this study. On the contrary, we found that intensively case managed-clients used six services on average and contacted more than twice as many agencies as the intermediate case management group. Researchers have reported such outcomes in the field of mental health care as well, especially among high-risk populations for relapse and dropout (de Froidmont et al., 2001; Marshall, Gray, Lockwood, \& Green, 2000). We hypothesize that the proximity of the case manager and the fact that they provided transportation contributed to the accessibility and availability of treatment services, and that the case manager's motivating and supporting role facilitated service utilization. Other studies have also shown the importance of transportation for reducing barriers to treatment and increasing service utilization (Laken \& Ager, 1996; McLellan et al., 1999). In addition, greater service utilization among the intensive case management group may have been associated with more severe psychological problems (according to ASI severity scores), although SCL-90 scores did not show any difference between both groups. Finally, the intensity of the intervention and, consequently, the delivery of more linking and coordination services led to increased service utilization among the intensive case management group. Besides frequent utilization of short-term residential substance abuse treatment agencies, all case managed-clients were linked to various outpatient services (e.g., employment, housing, and child care services), which was one of the intended goals of the project.

While the frequent inpatient service utilization among the intensive case management group may not seem very efficient, clients strongly appreciated case managers' efforts and stated that without their help they wouldn't have been entitled to certain services. Actually, several clients $(n=4)$ from the intensive case management group were refused admission in particular treatment centers due to the troubles they had caused during previous admissions. Case managers' roles in advocating for these clients were crucial but time-consuming. According to the case managers, the severity of clients' situations did necessitate hospitalization, but compared with previous treatment episodes, substantially more coordination and deliberation were reported.

Overall, clients were very satisfied with the services provided by the case managers, both in the intensive and intermediate case management group. They especially appreciated the confidential relation with the case manager, the comprehensive and client-centered approach, and the longitudinal scope. These positive evaluations are similar to these in other studies that applied clients' perspectives (Brun \& Rapp, 2001; Godley et al., 2000; Stahler et al., 1995) and indicate that such an intensive intervention is valuable for this target population.

After all, some relatively small effects have been observed among a limited sample of frequent and multiple service users six months after the start of the project. Since the problems of the case managed-clients were severe and multiple, it could be expected that 
change would be slow and steady (Godley et al., 2000). Since it was demonstrated that initial implementation of case management does not always immediately elicit the intended outcomes (McLellan et al., 1999), additional improvement may be expected once case managers get more used to their jobs and once the program comes to full expansion. Finally, we should not be too optimistic about the effects of this intervention as it is just a supportive function and adjunct to existing services (Rapp et al., 1998).

\subsubsection{LIMITATIONS OF THE STUDY}

While the results of this study can be regarded as encouraging given the chronic and multiple problems of these substance abusers and their frequent previous unsuccessful contacts with treatment services, several limitations are important to note. First, all participants were voluntarily engaged in the project, which might mean that these clients demonstrated some level of motivation (Zanis \& Coviello, 2001). Second, the extent to which the rates of improvement should be accepted as favorable is subjective, since we did not compare with a control group. Further, the small sample size and the short-term focus were a handicap; however, the primary goal of this article was to explore whether the postulated goals could initially be realized. As this qualitative study is part of an ongoing randomized and controlled trial, the number of subjects will be extended cumulatively during this three-year demonstration project and the ultimate goal is to recruit at least 50 cases in each of the three conditions: intensive case management, intermediate case management and care coordination. Optimally, a multi-site clinical trial with a large enough sample $(n>100)$ would allow the most rigorous evaluation design and enough statistical power to detect the specific effects of this program.

Although a 6-month evaluation may provide some insight into the short-term effects of this intervention, a longitudinal approach is necessary to look for medium and long-term effects. Twelve- and 18-month follow-up interviews are planned, but no outcomes are yet available. From interviews with case managers, it appears that the situations of two persons who did well after six months deteriorated after nine months. Such fading effects have been shown in other studies (Conrad et al., 1998; Sorensen et al., 2003), but most studies' follow-up periods were not longer than 12 or 18 months.

In addition, the question remains of how long this intervention should be continued to have optimal effects. Most interventions described in the literature ended after 12 months, but various positive effects, including cost-effectiveness, have been reported with longer intervention periods (Clark et al., 1998; Drake et al., 1998; Jerrell \& Ridgely, 1999). In most cases in this study, case management was continued after six months; case managers remarked that some clients might need lifelong case management, while for others a 6-month intervention period may be sufficient. Further research is needed to determine the optimal intervention period among this target group, and assessing cost-effectiveness may provide additional insights concerning this issue. 
Case management was only recently implemented, so additional agreements are necessary to determine the exact role of this intervention in the system of available services. When case management is stopped, clients should be linked to less intensive modalities. On the other hand, it should be clarified at what moment case management is best started. Constant referral of clients to the project is necessary for its stability and continuity, and referral should be closely followed by the start of case management, for it appeared that a time lag between referral and actual start of this intervention caused considerable dropout.

Finally, despite the limited number of cases we did not succeed in retrieving all clients for a follow-up interview. While follow-up rates of over $70 \%$ are generally accepted as good (Vaughn, Sarrazin, Saleh, Huber, \& Hall, 2002), we lost 20\% of the baseline group for the follow-up interview. The use of shopping vouchers certainly stimulated clients' research participation, but it did not allow for covering the whole group at follow-up. Consequently, uncertainty remains about the outcomes of the group that dropped out. However, the interviews with case managers and analyses of the logs provided us with some information about their status. Except one, there is no reason to assume that the clients that were not interviewed at follow-up $(n=4)$ did much worse than the others. For the further course of the research project, stimulating research participation and collecting accurate data will be crucial for an adequate comparison of the three conditions.

\subsubsection{CONCLUSION}

In conclusion, this case-by-case comparison of a small sample of substance abusers suggests that intensive case management can help frequent and multiple service users to stabilize or even reduce their drug, relational, housing, and employment problems. Greater intensity of case management services led to more improvement in different aspects of functioning but also to more frequent inpatient service utilization. Deterioration of clients' situation was usually associated with increased judicial problems. The provision of direct services and linking and coordinating activities for employment, family and drug issues seemed to be related to improved outcomes on these life domains.

Overall, six-month outcomes show that intensive case management is a promising approach for dealing with these clients' problems and that this intervention was strongly appreciated by both case managers and clients. Even if little improvement could be found among some clients, this intervention contributed substantially to the coordination and communication about the treatment process and to the provision of the right services at the right time. While intensive case management may be costly relative to other less intensive approaches, the latter programs do not seem to accrue the same sorts of benefits. Analysis of the cost-effectiveness of this intervention will be necessary to assess whether case management provides substantial cost savings, in addition to enhanced levels of psychosocial functioning among a target population that makes disproportionate use of available services and resources. 
ACKNOWLEDGEMENTS. We would like to thank all clients, case managers, and services participating in this project. We are especially grateful to the Province of East-Flanders [Provincie Oost-Vlaanderen], the Regional Board on Mental Health Care [PopovGGZ], the City of Ghent [Stad Gent, and the Medical-social care center (Ghent) [Medisch-sociaal Opvangcentrum voor druggebruikers van de Stad Gent] for their financial and logistic support. 


\section{REFERENCES}

American Psychiatric Association (APA) (1996). DSM-IV: Diagnostic and statistical manual of mental disorders (fourth edition). Washington: American Psychiatric Association.

Braucht, G.N., Reichardt, C.S., Geissler, L.J., Bormann, C.A., Kwaitkowski, C.F., \& Kirby, M.W. (1995). Effective services for homeless substance abusers. Journal of Addictive Diseases, 14(4), 87-109.

Broekaert, E., Haack, M.J., Kaplan, C., Oberg, D., Sallmén, B., Segraeus, V. et al. (2002). The Biomed II IPTRP Project: Implementation of Diagnostic Instruments. European Addiction Research, 8(4), 201-203.

Brun, C., \& Rapp, R. (2001). Strengths-based case management: individuals' perspectives on strengths and the case manager relations. Social Work, 46(3), 278-288.

Clark, R.E., Teague, G.B., Ricketts, S.K., Bush, P.W., Xie, H., McGuire, T.G. et al. (1998). Costeffectiveness of assertive community treatment versus standard case management for persons with co-occurring severe mental illness and substance use disorders. Health Services Research, 33(5), 1285-1308.

Conrad, K.J., Hultman, C.I., Pope, A.R., Lyons, J.S., Baxter, W.C., Daghestani, A.N. et al. (1998). Case managed residential care for homeless addicted veterans: results of a true experiment. Medical Care, 36, 40-53.

Cox, G.B., Walker, R.D., Freng, S.A., Short, B.A., Meijer, L., \& Gilchrist, L. (1998). Outcome of a controlled trial of the effectiveness of intensive case management for chronic public inebriates. Journal of Studies on Alcohol, 59(5), 523-532.

de Froidmont, C., Gosset, C., Reginster, J., Tellier, V., De Geest, S., Denhaerynck, K. et al. (2001). Ontslagmanagement in Belgische psychiatrische ziekenhuizen: pilootproject, tweede fase. Luik - Leuven: Université de Liège, Service de santé publique et d'épidémiologie - Katholieke Universiteit Leuven, Centrum voor ziekenhuis- en verplegingswetenschap.

Derogatis, L.R., \& Cleary, P.A. (1977). Confirmation of dimensional structure of SCL-90 - study in construct-validation. Journal of clinical psychology, 33(4), 981-989.

de Weert-van Oene, G., Schippers, G., De Jong, C., \& Schrijvers, G. (2002). Motivation for treatment in substance-dependent patients. European Addiction Research, 8(1), 2-9.

Drake, R.E., McHugo, G., Clark, R., Teague, G.B., Xie, H., Miles, K. et al. (1998). Assertive community treatment for patients with co-occurring severe mental illness and substance use disorder: a clinical trial. American Journal of Orthopsychiatry, 68(2), 201-215.

Evenson, R.C., Binner, P.R., Cho, D.W., Schicht, W.W., \& Topolski, J.M. (1998). An outcome study of Missouri's CSTAR alcohol and drug abuse programs. Journal of Substance Abuse Treatment, 15, 143-150.

FOD Volksgezondheid, Veiligheid van de Voedselketen en Leefmilieu (2002). Implementatie van de functie zorgcoördinator binnen de overlegplatforms geestelijke gezondheidszorg met betrekking tot de behandeling van personen met een middelengerelateerde stoornis, unpublished contract. Brussel: Directoraat-generaal Organisatie Gezondheidsvoorzieningen, Dienst Geestelijke Gezondheidszorg, Cel Gezondheidszorg Drugs. 
Franssen, A. (2003). Where the rubber meets the road (Presentation at the annual meeting of PopovGGZ, 9-5-2003). Drongen: PopovGGZ.

Godley, S.H., Finch, M., Dougan, L., McDonnell, M., McDermeit, M., \& Carey, A. (2000). Case management for dually diagnosed individuals involved in the criminal justice system. Journal of Substance Abuse Treatment, 18(2), 137-148.

Hendriks, V., Kaplan, C.D., van Limbeek, J., \& Geerlings, P. (1989). The Addiction Severity Index: Reliability and validity in a Dutch addict population. Journal of Substance Abuse Treatment, 6(2), 133-141.

Jerrell, J.M., \& Ridgely, M.S. (1999). Impact of robustness of program implementation on outcomes of clients in dual diagnosis programs. Psychiatric Services, 50(1), 109-112.

Keene, J., Bailey, S., Swift, L. \& Janacek, G. (2000). The tracking project: a collaborative multiagency database for shared clients/patients to inform policy development. Journal of Interprofessional Care, 14(4), 325-336.

Keene, J., Swift, L., Bailey, S. \& Janacek, G. (2001). Shared patients: multiple health and social care contact. Health and Social Care in the Community, 9(4), 205-214.

Kertesz, S., Horton, N., Friedmann, P., Saitz, R. \& Samet, J. (2003). Slowing the revolving door: stabilization programs reduce homeless persons' substance use after detoxification. Journal of Substance Abuse Treatment, 24(3), 197-207.

Kinnunen, A. \& Nilsson, M. (1999). Recent trends in drug treatment in Europe. European Addiction Research, 5(3), 145-152.

Kuckartz, U. (1998). WinMAX. Scientific text analysis for the social sciences. User's guide. Berlin: Udo Kuckartz, BSS.

Laken, M.P., \& Ager, J.W. (1996). Effects of case management on retention in prenatal substance abuse treatment. American Journal of Drug and Alcohol Abuse, 22(3), 439-448.

Langdon, P.E., Yagüez, L., Brown, J. \& Hope, A. (2001). Who walks through the 'revolving-door' of a British psychiatric hospital? Journal of Mental Health, 10(5), 525-533.

Lapham, S.C., Hall, M., \& Skipper, B.J. (1995). Homelessness and substance use among alcohol abusers following participation in project H\&ART. Journal of Addictive Diseases, 14(4), 41-55.

Marshall, M., Gray, A., Lockwood, A., \& Green, R. (2000). Case management for people with severe mental disorders. The Cochrane Library, Systematic Review (2). Oxford: Cochrane Library, Update software.

McCarty, D., Caspi, Y., Panas, L., Krakow, M. \& Mulligan, D. (2000). Detoxification centers: who's in the revolving door. The Journal of Behavioral Health Services \& Research, 27(3), 245-256.

McLellan, A.T., Hagan, T.A., Levine, M., Meyers, K., Gould, F., Bencivengo, M. et al. (1999). Does clinical case management improve outpatient addiction treatment? Drug and Alcohol Dependence, 55, 91-103.

McLellan, A.T., Kushner, H., Metzger, D., Peters, F., Smith, I., Grissom, G. et al. (1992). The fifth edition of the Addiction Severity Index. Journal of Substance Abuse Treatment, 9, 199-213.

Moxley, D. (1989). The practice of case management, Sage Human Services Guides Vol. 58. Newbury Park: Sage publications.

Nassen, E. (2001). Tien stappen in de concretisering van een nieuw begrippenkader voor de geestelijke gezondheidszorg. Tijdschrift voor Klinische Psychologie, 31(1), 37-48. 
Okin, R.L., Boccellari, A., Azocar, F., Shumway, M., O'Brien, K., Gelb, A. et al. (2000). The effects of clinical case management on hospital service use among ED frequent users. American Journal of Emergency Medicine, 18(5), 603-608.

Oliva, H., Görgen, W., Schlanstedt, G., Schu, M., \& Sommer, L. (2001). Case management in der Suchtkranken- und Drogenhilfe: Ergebnisse des Kooperationsmodells nachgehende Sozialarbeit Modellbestandteil Case management, Berichtszeitraum 1995-2000. Köln: Fogs, Gesellschaft für Forschung und Beratung in Gesundheits- und Sozialbereich mbH.

Raes, V. (1999). European Addiction Severity Index (EuropASI). Handleiding De Sleutel. Merelbeke: De Sleutel.

Rapp, R.C., Siegal, H.A., Li, L., \& Saha, P. (1998). Predicting post-primary treatment services and drug use outcome: A multivariate analysis. American Journal of Drug and Alcohol Abuse, 24(4), 603-615.

Ridgely, M.S., \& Willenbring, M. (1992). Application of case management to drug abuse treatment: overview of models and research issues. In R.S. Ashery (Ed.), Progress and Issues in case management (NIDA Research Monograph 127) (pp. 12-33). Rockville: National Institute on Drug Abuse.

Shwartz, M., Baker, G., Mulvey, K.P., \& Plough, A. (1997). Improving publicly funded substance abuse treatment: the value of case management. American Journal of Public Health, 87, 16591664.

Siegal, H.A., Li, L., \& Rapp, R.C. (2002). Case management as a therapeutic enhancement: Impact on post-treatment criminality. Journal of Addictive Diseases, 21(4), 37-46.

Sorensen, J.L., Dilley, J., London, J, Okin, R.L., Delucchi, K.L., \& Phibbs, C.S. (2003). Case management for substance abusers with HIV/AIDS: a randomized clinical trial. American Journal of Drug and Alcohol Abuse, 29(1), 133-150.

Stahler, G.J., Shipley, T.F., Bartelt, D., DuCette, J.P., \& Shandler, I.W. (1995). Evaluating alternative treatments for homeless substance-abusing men: outcomes and predictors of success. Journal of Addictive Diseases, 14(4), 151-167.

Substance Abuse and Mental Health Administration (SAMHSA). (1998). Comprehensive case management for substance abuse treatment (TIP Series 27). Rockville: U.S. Department of health and human services, Public Health Service, Substance abuse and mental health services administration, Center for substance abuse treatment.

Thornquist, L., Biros, M., Olander, R., \& Sterner, S. (2002). Health care utilization of chronic inebriates. Academic Emergency Medicine, 9(4), 300-308.

Vanderplasschen, W., De Bourdeaudhuij, I., \& Van Oost, P. (2002). Co-ordination and continuity of care in substance abuse treatment: an evaluation-study in Belgium. European Addiction Research, 8, 10-21.

Vanderplasschen, W., Lievens, K. \& Broekaert, E. (2001a). De instroom in de Oost-Vlaamse drughulpverlening: registratie van aanmeldingen en intakes tussen februari 1999 en mei 2000 (Orthopedagogische Reeks Gent Nummer 13). Gent: Universiteit Gent, Vakgroep Orthopedagogiek.

Vanderplasschen, W., Lievens, K., \& Broekaert, E. (2001b). Implementatie van een methodiek van case management in de drughulpverlening: een proefproject in de provincie Oost-Vlaanderen 
(Orthopedagogische Reeks Gent Nummer 14). Gent: Universiteit Gent, Vakgroep Orthopedagogiek.

Vanderplasschen, W., Colpaert, K., Lievens, K. \& Broekaert, E. (2003). De Oost-Vlaamse drughulpverlening in cijfers: kenmerken, zorggebruike en uitstroom van personen in behandeling. (Orthopedagogische Reeks Gent Nummer 15). Gent: Universiteit Gent, Vakgroep Orthopedagogiek.

Vanderplasschen, W., Lievens, K., Broekaert, E., \& Rapp, R.C. (2004). Implementation of case management for substance abusers: an exploratory study in Belgium. Manuscript submitted for publication.

Vanderplasschen, W., Rapp, R.C., Wolf, J., \& Broekaert, E. (in press). Comparative review of the development and implementation of case management for substance use disorders in North America and Europe. Psychiatric Services (accepted for publication, May 13, 2004).

Vanderplasschen, W., Wolf, J., Rapp, R.C., \& Broekaert, E. (2004). Review of the effectiveness of different models of case management for substance abusers. Manuscript submitted for publication.

van Riet, N. \& Wouters, H. (1996). Casemanagement: een leer-en werkboek over de organisatie en coördinatie van zorg-, bulp-en dienstverlening. Assen: Van Gorcum.

Vaughn, T., Sarrazin, M.V., Saleh, S.S., Huber, D.L., \& Hall, J.A. (2002). Participation and retention in drug abuse treatment services research. Journal of Substance Abuse Treatment, 23(4), 387-397.

Willenbring, M. (1996). Case management applications in substance use disorders. In H. Siegal, \& R. Rapp (Eds.), Case management and substance abuse treatment: practice and experience (pp. 51-76). New York: Springer Publishing Company.

Witbeck, G., Hornfeld, S., \& Dalack, G.W. (2000). Emergency room outreach to chronically addicted individuals: A pilot study. Journal of Substance Abuse Treatment, 19(1), 39-43.

Wolf, J. (1995). Zorgvernieuwing in de GGZ: evaluatie van achttien zorgvernieuwingsprojecten. Utrecht: Nederlands Centrum Geestelijke Volksgezondheid.

Wolf, J., Mensink, C., \& van der Lubbe, P. (2002). Case management voor langdurig verslaafden met meervoudige problemen: een systematisch overzicht van interventie en effect. Utrecht: Trimbos-instituut, Ontwikkelcentrum Sociaal Verslavingsbeleid.

Zanis, D.A., \& Coviello, D. (2001). A case study of employment case management with chronically unemployed methadone maintained clients. Journal of Psychoactive Drugs, 33(1), 67-73. 



\section{Chapter 8}

\section{General discussion}

ABSTRACT. In this last chapter we resume the main findings from this dissertation and discuss these, based on available literature. We further look at the implications of our findings for the practice of substance abuse treatment. Finally, we recite some limitations of the presented studies and provide some guidelines for further research. 



\subsection{INTRODUCTION}

This dissertation focused on the organization of substance abuse treatment in a specific region (Ghent, East-Flanders) and on an alternative approach to optimize the quality of treatment and service delivery for substance abusers. In particular, the study aimed at (1) evaluating aspects of coordination and continuity of care in agencies that addressed this target population in this region, (2) at implementing and evaluating a model of case management for assisting substance abusers with multiple and complex problems, and (3) at integrating this intervention in the network of available services. To achieve these different objectives we conducted seven separate studies.

First, we examined to what extent coordination and continuity of care was provided in available services, as could be derived from interviews with caregivers and a study of client files (chapter 2). Based on the results of this study, it was recommended to improve coordination and continuity of care both at individual and structural level.

Second, we studied the implementation and evaluation of case management for substance abusers (chapters 4, 5, 6 \& 7).

Available evidence about the implementation of this intervention was reviewed, based on the literature and experiences from three countries (the United States, the Netherlands, and Belgium) (chapter 4). We presented answers to six key questions that should be dealt with when implementing case management.

In addition, we evaluated the initial implementation of a model of case management in the region of Ghent for substance abusers with multiple and complex problems (chapter 5). We focused on client outcomes, mediating variables and aspects of implementation that needed to be adapted in view of further application of this intervention.

The effectiveness of different models of case management was examined based on the results of empirical studies that have been published in peer-reviewed journals (chapter $\sigma$ ). We looked at the differential effectiveness of models of case management for various substance abusing populations, including dually diagnosed persons, chronic public inebriates, substance abusing women, and drug-involved offenders.

The effectiveness of intensive case management was evaluated among a small sample of substance abusers that utilized multiple services (chapter 7 ). This qualitative study was part of an ongoing controlled trial and reported on the preliminary 6-month outcomes concerning clients' functioning, service utilization, and clients' satisfaction with the services received.

Finally, we provided a framework for integrating case management into the existing system of services (chapter 3). We described the incentives and preconditions for the evolution towards the integration of different treatment systems (first part of chapter 3). Next, we distinguished various steps for the establishment of an integrated system for 
substance abusers, and focused on the role of case management in such a system (second part of chapter 3).

This final chapter (chapter 8) presents an integrated overview and discussion of the main findings from these distinct studies, including implications and limitations of this dissertation and recommendations for further research.

\subsection{MAIN FINDINGS}

\section{- PREVALENCE OF MULTIPLE AND COMPLEX PROBLEMS AND SERVICE UTILIZATION AMONG SUBSTANCE ABUSERS}

According to caregivers, the vast majority of substance abusers that follow treatment in the region around Ghent (88\%) have significant other problems in addition to their substance abuse problems, particularly relational and physical health problems (chapter 1). Most of these persons experienced drug problems for more than two years, and half of all registered clients had been treated in at least three different agencies. Based on the eligibility criteria of the first case management study (chapter 5), we concluded that more than one quarter of all clients $(27 \%)$ that followed treatment in this region could be characterized as substance abusers with multiple and complex problems.

These results were further elaborated during two utilization studies that involved most substance abuse treatment agencies in the region around Ghent (chapter 1). Analysis of the service utilization of all registered substance abusers showed that about $20 \%$ had had at least twice an initial intake assessment during this 6- and 8-month registration period, and that about $15 \%$ was registered in at least two different centers. The number of "revolving door clients" or "drug treatment tourists", i.e. persons who had had an intake assessment in at least three different agencies, was relatively small $(2.9 \%$ and $4 \%$, respectively), but this numerically small subgroup accounted for 10 to $14 \%$ of all treatment demands.

The complexity of these persons' substance abuse problems was illustrated by the strong correlations between case managed-clients' problems: the severity of drug problems was clearly associated with psychological and relational problems, while clients' health problems related to their psychological, employment and alcohol problems (chapter 5). In addition, the 12-month follow-up showed that severity of drug problems was related to clients' medical, psychological, and family problems.

\section{a INDICATORS OF COORDINATION AND CONTINUITY OF CARE}

Despite these clients' multiple and complex problems and various treatment episodes and some clients' contacts with multiple services, no systematic and/or 
formalized coordination and continuity of care was observed in any of the treatment agencies studied (chapter 2). Some key informants indicated a trend toward more cooperation, coordination and communication between services, but these were scarce and merely "ad hoc"-initiatives. Overall, a lack of objective, systematic, and joint thought and action characterized this field. This could be derived from cooperation and communication that was based on personal choice and benevolence, divergent intake procedures, the lack of a common and standardized registration system, and referrals that were determined almost exclusively by subjective factors. Moreover, indicators of continuity of care were nearly totally absent. This appeared from the lack of treatment planning, monitoring of the treatment process and follow-up of clients, caregivers' reluctance to interfere in clients' situations after treatment as other services may be involved, and few strategies to deal with so-called "treatment tourists". Finally, several key informants stressed the necessity of enhancing coordination of care at client and structural level, and - to a lesser extent - of providing more continuous services.

\section{a EVOLUTION TOWARDS THE INTEGRATION OF DIFFERENT TREATMENT MODALITIES}

In several countries, an evolution towards networking and integration of different treatment modalities was observed (chapter 3). The nature of clients' problems and organizational problems in the field of substance abuse treatment necessitate such an

approach, as well as the observation that no single intervention is effective for all kinds of substance abuse problems and that clients' treatment careers consist of various interventions rather than one single treatment episode. Also, economic concerns have inspired the reorganization of health care services (first part of chapter 3).

A similar reorganization of mental health care and substance abuse treatment is under way in Belgium. Discussion groups, including practitioners, directors, policymakers, and researchers revealed that a common language and concerted approach and an inventory of available services, duplicated work and missing links are regarded as important prerequisites for integrating different interventions that stem from an abstinence-oriented or harm reduction approach (first and second part of chapter 3).

The proposed reorganization of treatment services should be based on clients' treatment needs and should respect the uniqueness of each approach (second part of chapter 3). The theoretical conceptualization of such an integrated treatment system should be followed by its actual implementation. Monitoring and evaluating will be necessary to assess if this alternative organization of treatment services allows the realization of the postulated goals. Case management is regarded as an appropriate method to coordinate and monitor the trajectory clients follow in such an integrated treatment system. 


\section{- ELEMENTS ASSOCIATED WITH SUCCESSFUL IMPLEMENTATION} OF CASE MANAGEMENT

A comparative review of case management practices in the United States, the Netherlands, and Belgium showed that this intervention is especially indicated to address shortcomings in the organization, delivery and efficiency of available services (chapters 4 \& 5). Case management is usually addressed at substance abusers with multiple and complex problems who are at risk of falling through the cracks of the system. This intervention intends to improve the effectiveness of substance abuse treatment by enhancing treatment access, participation and retention, coordinating service delivery and utilization, and promoting clients' functioning and quality of life.

Several authors have identified crucial elements of the implementation of case management, including program fidelity, robustness of implementation, the use of manuals and protocols, training and supervision, a team approach, focus on clients' strengths, client-case manager relationship, delivery of direct services, administrative support, outreaching, treatment planning, providing money to purchase services or to pay for occasional expenses, an adapted subsidizing system, integration in the network of available services, accessibility and availability of services, and pre-contracting of services (chapter 4). Specialized models of case management have been applied for specific goals, but overall little evidence is available that particular elements of this intervention elicit favorable outcomes. Success of the implementation of case management can only be evaluated if the continuity of the project is guaranteed during a minimal period and if an accurate representation is available of what the intervention entails.

Finally, the two case management studies we conducted (chapters $5 \& 7$ ) revealed that clients especially appreciated the close and ongoing relationship with the case manager, their direct involvement and participation in the treatment process, and case managers' monitoring and outreaching function. In addition, case managers stressed the continuous and comprehensive approach and the community-based services as important features of this intervention.

\section{- DELIVERY OF INDIVIDUALIZED, COMPREHENSIVE, COORDINATED, AND CONTINUOUS SERVICES}

Both studies further showed that case management clearly contributed to more individualized care, since treatment planning started from a comprehensive assessment of clients' strengths and weaknesses and clients themselves directed the treatment process (chapters $5 \& 7$ ). Case managers did not only focus on clients' drug problems, but also addressed employment, housing, financial, relational, judicial and health problems, and linked clients to agencies that offered such services, if necessary (chapter 7). Case management's contribution to the coordination of care appeared from the fact that case 
managers brought together all partners involved in the treatment process during case conferences and that linking and coordination activities accounted for half of all case management activities. Finally, both case management studies have shown that it is possible to provide continuing care to clients that have repeatedly dropped out from treatment before. Case managers monitored clients' situations during a 6- and 12-month period, respectively, irrespective of where clients stayed or how they did (chapters $5 \& 7$ ). Attrition rates were relatively low and clients were generally satisfied to very satisfied with the services provided.

\section{- IMPACT ON TREATMENT PARTICIPATION AND RETENTION AND SERVICE UTILIZATION}

Results from both studies about the impact of case management on treatment retention and service utilization were somewhat conflicting (chapters $5 \& 7$ ). The first study in which case management was added as an additional treatment modality to several agencies showed increased treatment retention among several clients and, in addition, a significant impact on client outcomes (chapter 5). Frequent service utilization, especially various short treatment episodes, was associated with adverse outcomes. On the other hand, the second study in which case management was conceptualized as a specific module offered by the network of services that was usually started shortly after clients had had contacts with a least two different treatment agencies, showed particularly high service utilization among the intensive case management group (chapter 7). Long length of stay in treatment was only observed among a few clients. Both groups of case managed-clients consisted of substance abusers with multiple and complex problems and a considerable treatment career, but the sample in the second study had also recently used several services. We concluded that intensive case management was initially not successful to reduce service utilization among this group of multiple and frequent service users, but could help to retain clients with similar problems in treatment if they were already engaged in a certain treatment program.

\section{IMPACT ON CLIENTS' FUNCTIONING}

Both case management studies showed similar outcomes concerning clients' functioning: stabilized and even reduced severity of drug, family, and employment problems among most clients (chapters 5 \& 7 ). However, these reductions were relatively small and for most clients further follow-up of their situations was still indicated. The first study showed additional improvement in legal problems and few change in psychological problems, while the second study demonstrated deteriorated legal problems but relatively improved psychological functioning among several clients. The focus of case managers' 
activities and the life domains positively affected at follow-up were clearly related in both studies.

Clients and case managers involved in the first study attributed improved outcomes to the treatment followed rather than to case management, but a supportive role of this intervention to other substance abuse treatment services was assumed (chapter 5). No association was found between other mediating variables (e.g., motivation, coercion) and case management outcomes. In the second study, most clients associated improved outcomes with the case management services received (chapter 7). Further evidence for the effectiveness of this intervention was derived from the observation that more intensive case management services were related to better outcomes. Finally, even if intensive case management could not reduce problem severity among some clients, clients and case managers found that it helped at least to stabilize clients' situations.

\section{EVIDENCE FOR THE EFFECTIVENESS OF CASE MANAGEMENT}

Our review of published evaluation studies showed no compelling evidence of the effectiveness of case management (chapter ๑). Still, several studies have demonstrated positive effects of this intervention concerning client outcomes (e.g., drug use, employment, housing), service utilization, treatment access and retention, quality of life, clients' satisfaction and cost savings. Only some randomized and controlled trials have shown the effectiveness of case management compared with standard treatment or other interventions. Still, most studies have shown significant effects of this intervention over time, though not differential from those of other interventions. In addition, several studies have shown a positive association between length of participation and retention in case management services and outcomes.

Some evidence is available for the effectiveness of intensive case management for affecting psychosocial functioning and service utilization among substance abusing populations with multiple and complex problems (e.g. homeless persons, drug-involved offenders, dually diagnosed persons). Also, some evidence was found for the effectiveness of generalist and strengths-based case management for enhancing treatment participation and retention. Moreover, the latter intervention has been proven to be effective for improving employment functioning among substance abusers entering residential treatment. On the other hand, insufficient evidence is available about the effectiveness of brokerage and clinical models due to a lack of randomized and controlled trials. Finally, no evidence was found for the effectiveness of case management over longer periods of time, although positive effects and efficiency have been demonstrated if this intervention was continued during 24 to 36 months. 


\section{- DisCUSSION OF MAIN FINDINGS}

In general, data presented in this dissertation confirmed that many substance abusers have multiple and complex problems (McLellan, Arndt, Metzger, Woody, \& O'Brien, 1993; McLellan et al., 1999) and the more recent insight that substance abuse should be regarded as a chronic and relapsing disorder, including the possibility of recovery (Brindis \& Theidon, 1997; McLellan, 2002). However, few services (are equipped to) provide the coordination and continuity of care necessary to deal with these problems and collaborative efforts for so-called "shared clients" are generally lacking. Case management was identified as a promising approach for delivering coordinated and continuous care and an integrated treatment system for substance abusers was presented as an adequate framework for implementing this intervention in Belgium.

As in several other countries (de Weert-van Oene \& Schrijvers, 1992; Koller, 1999; Nizzoli, 1999), various shortcomings were observed concerning the quality of substance abuse treatment in the region around Ghent, especially concerning coordination and continuity of care. A stepwise plan to systematize and optimize communication between treatment agencies, the use of new technologies, a common registration and file keeping system, and centralized intake facilities were all suggested as alternatives to address some of the shortcomings in the present-day organization of treatment services. Ultimately, we opted for the implementation of a model of case management and the establishment of an integrated treatment system. The first because various studies had reported positive outcomes related to this intervention (Shwartz, Baker, Mulvey, \& Plough, 1997; Siegal, Rapp, Li, Saha, \& Kirk, 1997; Mejta, Bokos, Mickenberg, Maslar, \& Senay, 1997; Willenbring, Ridgely, Stinchfield, \& Rose, 1991), the second because this concept was proposed by the influential National Council for Hospital Facilities [Nationale Raad voor Ziekenbuisvoorzieningen (NRZV)] as the future organization of mental health care in Belgium (Knapen \& Van Holsbeke, 1997).

The feasibility of the integration of different treatment modalities in a comprehensive system of services was discussed during an international symposium, and its conceptualization was further elaborated by a group of experts in the province of EastFlanders. Similar efforts to bridge the gap between abstinence-oriented and harm reduction approaches have been observed in the United States (Marlatt, Blume, \& Parks, 2001). The discussions during the international symposium led to the formulation of several prerequisites for the integration of different treatment modalities that reflected similar ideas as those postulated by American experts. The American system of "managed care" was identified as a far-reaching example of the reorganization of health care services that was mainly inspired by economic concerns and produced several adverse outcomes for clients (Galanter, Keller, Dermatis, \& Egelko, 2000; Gould, Levine, \& McLellan, 2000; Zarkin \& Dunlap, 1999). Similarly, the fusion of treatment agencies in the Netherlands, 
resulting in large-scale organizations, primarily started from profit-making concerns. However, results of our discussion groups showed that the treatment needs of clients and their social networks should be the starting point for the reorganization of treatment services. A functional and client-centered - rather than institution-based - organization of substance abuse treatment includes more guarantees for offering clients the type of treatment they need at a certain moment. Case management was described as an efficient tool to monitor and coordinate the trajectory clients follow in such an integrated treatment system (Drake, Yovetich, Bebout, Harris, \& McHugo, 1998). Implementation of an integrated treatment system was recognized as a long-term process that is preceded by at least three other steps and that should be followed by an evaluation of its effectiveness. Given this dissertation's scope on case management, we focused exclusively on the steps preceding the implementation, including the development of a common language and approach, a theoretical conceptualization of what this integrated system should entail, and an inventory of available and needed services. Step-by-step implementation of this theoretical model, and evaluation of the implemented system will be necessary to test if this alternative organization of treatment services contributes to comprehensive and continuous care, efficiency of service delivery, increased transparency and flexibility, and client satisfaction (de Weert-van Oene \& Schrijvers, 1992; Wolf, 1995).

Deliberate implementation of case management has been associated with successful outcomes (Burns, Fioritti, Holloway, Malm, \& Rossler, 2001; Inciardi, Martin, Butzin, Hooper, \& Harrison, 1996; Jerrell \& Ridgely, 1999; Wolf, Mensink, \& van der Lubbe, 2002) and, therefore, we looked at available evidence about crucial aspects of implementation. Although we identified various important factors, we found little evidence from randomized and controlled trials about the role of specific features in case management. As opposed to the field of mental health care, few measures are available for the implementation of (different models of) case management (Teague, Bond, \& Drake, 1998), leaving many alternatives to those implementing this intervention. Based on a literature study and several discussions with researchers from the United States and the Netherlands, we addressed six key questions that should be dealt with when implementing case management for substance abusers.

Results of the initial implementation of case management were in line with these from similar studies that followed clients after residential treatment (Conrad et al., 1998; Saleh et al., 2002; Shwartz et al., 1997; Siegal et al., 1997). Reported effects after 12 months were small to modest, and concerned improved drug use, employment and family functioning, reduced attrition, and increased participation and retention in treatment. Clients and case managers attributed these effects to treatment retention rather than to case management, what made us conclude that these effects were mainly mediated by enhanced participation and retention in treatment (Rapp, Siegal, Li, \& Saha, 1998; Siegal, Li, \& Rapp, 2002). Also other authors have shown a positive relation between length of stay in treatment among case managed-clients and improved outcomes (Cox et al., 1998; Evenson, Binner, Cho, 
Schicht, \& Topolski, 1998; Mejta et al., 1997). It thus appears that case management has primarily a supportive role towards participation and retention (Rapp et al., 1998). The relatively positive outcomes we found were especially encouraging given the participating clients' histories of various treatment episodes, dropout and relapse. Several others have shown that case management can be successful among substance abusers with severe and complex problems (Lightfoot et al., 1982; McLellan et al., 1999).

Following initial implementation of case management, we evaluated the effectiveness of this intervention based on a review of available literature and the evaluation of an adapted model of case management. It may not surprise that we did not find sufficient evidence for the (differential) effectiveness of case management, as most social interventions have modest effects at best (Lipsey, 1990). Still, a meta-analysis of the effectiveness of different interventions for alcohol use disorders has shown that case management was identified among the ten most effective interventions for this target population (Miller \& Wilbourne, 2002). We concluded that some evidence is available for the (differential) effectiveness of intensive, generalist, and strengths-based case management. This lack of evidence is merely due to a lack of randomized and controlled trials and the comparison with other viable interventions or standard treatment (Orwin, Sonnefeld, Garrison-Mogren, \& Smith, 1994). If case management was not compared with another intervention, several significant effects have been found over time concerning service utilization, treatment participation and retention, client satisfaction, and different aspects of clients' situations and quality of life (Evenson et al., 1998; Godley et al., 2000; Lanehart, Clark, Rollings, Haradon, \& Scrivner, 1996; Okin et al., 2000; Oliva, Görgen, Schlanstedt, Schu, \& Sommer, 2001). However, uncontrolled studies leave uncertainty about the factors that have caused certain effects.

The identification of a numerically small group of frequent and multiple service users that makes disproportionate use of available resources was the starting point for the evaluation of the effectiveness of intensive case management for assisting this group of substance abusers with multiple and complex problems. Initial outcomes showed that this intervention could indeed help to promote psychosocial functioning among this population (Okin et al., 2000; Thornquist, Biros, Olander, \& Sterner, 2002; Witbeck, Hornfeld, \& Dalack, 2000), but it did not reduce service utilization, on the contrary. Clients attributed their improved situations to the case managers' interventions and experienced these as valuable and effective. One of the most important findings was that clients receiving more intensive case management services contacted more services, and also had better outcomes. Some authors have found similar outcomes (McLellan et al., 1999), while others found no association between increased service utilization and improved outcomes and related higher dosages of case management to more severe problems at follow-up (Vaughan-Sarrazin, Hall, \& Rick, 2000; Huber, Sarrazin, Vaughn, \& Hall, 2003). 


\subsection{IMPLICATIONS FOR THE PRACTICE OF SUBSTANCE ABUSE TREATMENT}

The specific aim of this study was to improve coordination and continuity of care in the field of substance abuse treatment in the province of East-Flanders (Belgium). Based on the various studies we conducted, several recommendations are provided to practitioners, treatment providers, and policymakers facing similar challenges in other regions.

One of the most important implications of this study is that treatment for substance abusers should consist of a continuum of services that are organized from a comprehensive and continuing care perspective. At present, few programs are equipped to provide such services and collaborative efforts will be needed to provide such wraparound and comprehensive services over longer periods of time. The aspects of coordination and continuity of care we evaluated may provide some insight into some important indicators of quality of care, but this norm also refers to the effectiveness and efficiency of treatment programs (de Weert-van Oene-Schrijvers, 1992). We should evaluate if programs achieve the postulated goals and at what price. If we agree that substance abuse is a chronic and relapsing disorder and that treatment will consequently consist of a sequence of interventions, we will need to adapt research methodologies and evaluate individuals' treatment goals rather than program's objectives (McLellan, 2002).

While several authors have described the practice of case management (Siegal \& Rapp, 1996), relatively few have focused on its implementation or have evaluated it. Thorough analysis of available literature and experiences from the United States, the Netherlands, and Belgium led to the conclusion that at least six key questions should be addressed when implementing case management for substance abusers. Program developers should make clear what are the motives, objectives and target group of this intervention, and how it should be integrated in the existing system of services. They should further choose an adequate model of case management and describe its core features. Next, the skills, qualifications and other requirements of case managers should be defined, followed by the question how the continuity of the project will be guaranteed and how this intervention will be evaluated. Taking these questions into account should lead to more deliberate implementation and, eventually, to more consistency and evidence-based practice. Further discussion of these questions might result in the development of protocols and manuals that describe what the intervention entails and how it should be practiced.

Diverging results have been reported about the effectiveness of case management. Our review showed that this intervention can (help to) promote various positive results, but only some evidence is available that case management is more effective than other interventions. Its effects are mainly related to enhancing treatment participation and 
retention, and only if direct services are provided additional effects on clients psychosocial functioning can be expected. Intensive models of case management will be best suited for clients with multiple and severe problems, while clients who are not motivated may be better off with strengths-based case management. Finally, results of this review should provide program developers with realistic expectations about potential outcomes of this intervention. After all, we should not forget that this intervention was originally designed to provide ongoing and supportive care to clients and to link them with community resources (Rapp et al., 1998).

Although case management has some tradition for assisting substance abusers in the United States (Ashery, 1992; Siegal \& Rapp, 1996), its implementation in Europe is still in its infancy. While several European countries face similar substance abusing populations and the same organizational problems, only some countries have implemented case management to guide substance abusers through the complex network of services (EMCDDA, 2001). From this study but also from evaluation studies in Germany and the Netherlands, it appears that this - originally American - intervention has great potential for assisting substance abusers with multiple and complex problems in need of several services over a longer period of time (Oliva et al., 2001; Wolf \& Planije, 2002). It has been shown that this intervention can easily be implemented in the European health care and social welfare system to enhance participation and retention among clients following in- or outpatient treatment or to promote service utilization among those (at risk of) dropping out of treatment. One of the most important observations was that case management could contribute to the stabilization and reduction of clients' problems, even if these were severe and chronic.

While the implementation of case management has not always led to the intended results (Martin \& Scarpitti, 1993; Sorensen et al., 2003), agreement exists about its appreciation by clients, which is consistently high. Although case management may seem a radical intervention relative to clients' situations, clients are willing to be followed by a case manager when those services are concrete and grounded in their own interests. This observation and the relative effectiveness of this intervention for persons for whom treatment has repeatedly failed, supports our idea that case management should - ideally be an integral component of every substance abuse treatment program in order to connect clients to a variety of services and tailor these to their unique needs.

Finally, we demonstrated that case management should be well integrated in the system of available services. The framework we provided for this integration is strictly related to the Belgian context, but it may also have some potential for improving the organization of substance abuse treatment in other regions or countries.

Perhaps the best way to describe the practical implications of this dissertation is by giving an overview of the evolutions in the field of substance abuse treatment in East-Flanders 
within the last seven years. The evaluation of coordination and continuity of care in treatment agencies that address substance abusers (1998-1999) led to the implementation of case management as an additional treatment service in several agencies (1999-2000). In addition, the expressed need for more transparency resulted in an utilization study that did not only aim at providing information about the basic characteristics of substance abusers who ask for treatment, but also at describing the main features of the participating services (1999-2001). Meanwhile, the search for more structural cooperation in the field of substance abuse treatment led to the exploration and discussion of the concept of "integrated treatment systems" (2000-2001). Moreover, tri-weekly care coordination meetings were organized to discuss each partner's admission policy, intake and discharge procedure and to address the phenomenon of so-called "shared clients" (2001). The appointment of a regional care coordinator (2002) further stimulated the integration of treatment services and led to a formal agreement between all organizations in this region concerning the establishment of a comprehensive treatment program for substance abusers (2003). The first realization of this formal network of service providers was the establishment of a module "case management" (2003) to address frequent and multiple service users in substance abuse treatment agencies.

\subsection{LIMITATIONS OF THE STUDY}

Although the limitations of each separate study were already mentioned, we focus in this section on some overall limitations of this dissertation. Its main aim was the implementation of an intervention that could improve coordination and continuity of care. Consequently, this dissertation did not embrace a large-scale effectiveness study of case management but consisted of several small studies, including literature reviews, a prepost test, analyses of interviews and focus groups, and other qualitative research methods.

A first limitation was that the study was limited to the clear-cut geographical region around Ghent, which includes a large number of (residential) treatment agencies. The type and availability of services and other contextual differences may hamper the general nature of the presented results. Moreover, similar constraints may have hindered the comparability of the data in the review studies.

Second, no longitudinal approach could be applied. We rather studied several projects that preceded or were related to the implementation of case management. Due to financial and practical constraints, case management interventions were limited to 12 and 6 months, respectively. As these may be long enough periods to bring about change, no information was collected whether these effects were sustained over time.

Third, both case management studies consisted of relatively small samples. The lack of a sufficiently large sample was compensated by the use of multiple data sources to analyze 
outcomes and a qualitative study of various process variables. Presented data from both studies lack statistical power, but provide insight into several aspects of the implementation process and related outcomes. The pilot study explored potential effects of this intervention, while the second study used a small sample since the initial effectiveness of intensive case management was studied among a specific subgroup that is numerically small. This qualitative study is part of an ongoing randomized and controlled trial that can test the insights, outcomes and hypotheses from previous phases of the study among a much larger sample.

Fourth, despite extensive efforts it appeared to be very difficult to compose a similar and sufficiently large control group. Some caregivers were rather reluctant to engage clients for a control condition due to ethical and practical reasons. They argued that it is unwarranted to deny clients a potentially helpful intervention, and further stressed that the principle of randomization is opposed to the eligibility procedure that is part of intake assessments in most substance abuse treatment agencies (Inciardi, Martin, \& Scarpitti, 1994). Clients are usually not inclined to participate in research if they don't see any advantage of such participation (Vaughn, Sarrazin, Saleh, Huber, \& Hall, 2002). Therefore, we used shopping vouchers to promote participation in the second study, what certainly contributed to less attrition among the control group. Overall, it remains very difficult to engage substance abusers - especially those with multiple and complex problems - for research purposes. The best way to enhance research participation among this group is to plan initial research assessments shortly after randomization and to contact them immediately while in (residential) treatment.

Fifth, the standardized instruments that were used in this study were mainly self-report instruments. Given the socially deviant behavior of the population studied, an increased chance of socially desirable answers may have occurred. However, validity and reliability of the applied instruments was high and in the second study data from case managers' logs were used to control for clients' situations (ASI scores). These appeared to be highly consistent with clients' self-reports. Still, it was recommended to use additional outcome measures in order to collect more objective data (e.g. official statistics, medical databases, urine analysis) besides self-reported data. Moreover, as clients' improvements were mostly slow and steady, instruments are needed that allow to detect such small differences and that can be administered regularly (e.g., every month instead of every six months). In addition, it may be more important to look at persons' quality of life rather than at general outcome indicators.

Finally, a selection bias may have played a role. We should be aware of such bias since clients were randomly selected but could still chose whether or not to participate. This may have caused participants who showed some level of motivation. It can be questioned if the same results would have been observed among persons who were coerced to participate in case management (Godley et al., 2000). The first study showed that the level 
of motivation was related to early dropout from case management, but not to better outcomes. Therefore, it will be important to regularly assess motivation, since this is a changing process that affects treatment outcomes (Prochaska, DiClemente, \& Norcross, 1992).

\subsection{FUTURE RESEARCH}

This dissertation provided us with several insights about the organization of substance abuse treatment in the region of Ghent and ways to improve the coordination and continuity of present-day treatment services, particularly by implementing case management for substance abusers with multiple and complex problems. However, several research questions remain which should be addressed in future research.

First, little is known about the effectiveness and efficiency of available services. Treatment outcomes should be studied among a cohort of substance abusers over a longer period of time in order to study the cumulative or separate effects of various treatment episodes. Such information may provide us with adequate information to optimize treatment programs and client-treatment matching. Moreover, we should not solely focus on drug abuse problems. The percentage of alcohol abusers outnumbers that of drug abusers many times, but little information is available about the organization and effectiveness of treatment services for alcoholics in the region of Ghent and in other Belgian regions. The distinction of treatment services for both populations is strictly artificial. Since alcohol use disorders are as well characterized by multiple, chronic and relapsing problems, case management may also be an important addition to the treatment services for this target group, as has been demonstrated in several studies (Braucht et al., 1995; Cox et al., 1998).

Second, the implementation and evaluation of an integrated treatment system for substance abusers was beyond the scope of this dissertation. Additional research will be needed to test if the theoretical conceptualization and step-by-step approach that we described really helps to improve the delivery of services for substance abusers.

Third, this dissertation provided information about how case management should be implemented and what outcomes can be expected, but the relation between both aspects remains unclear. Our review of the implementation of this intervention provided little evidence about such crucial elements. In the field of mental health care, the main research focus has recently shifted to the identification of these key features of case management (Burns et al., 2001). Case management practices for substance abusers may also benefit from such findings among mentally ill persons, but it will also be necessary to assess the factors that make this intervention work among persons who abuse substances.

Fourth, evaluation studies are needed that apply a longitudinal approach in order to examine whether case management effects can be sustained over time. Such long-term 
effects have been demonstrated after 24 and 36 months (Drake et al., 1998; Jerrell \& Ridgely, 1999), but other studies have shown fading effects after 9 to 12 months (Conrad et al., 1998; Saleh et al., 1998). Further research is needed to determine the optimal intervention period, and also to explore if case management should be combined with other interventions or more specialized models of case management over time (Clark et al., 1998). In addition, the effectiveness and efficiency of case management without time limit needs to be evaluated, as this might be an alternative to some persons' chronic and pervasive problems.

Finally, more randomized and controlled trials among sufficiently large samples especially in Europe - are necessary to further evaluate the effectiveness of case management. Further experimental research is particularly needed concerning strengthsbased and clinical models of case management, since these have rarely been studied, but seem to generate positive results. In addition, the cost-effectiveness of this intervention should be evaluated relative to other interventions for the population studied. While case management may be an effective intervention, we don't know yet much about its efficiency among substance abusers. 


\section{REFERENCES}

Ashery, R.S. (Ed.) (1992). Progress and Issues in case management (NIDA Research Monograph 127). Rockville: National Institute on Drug Abuse.

Birchmore-Timney, C., \& Graham, K. (1989). A survey of case management practices in addictions programs. Alcoholism Treatment Quarterly, 6(3/4), 103-127.

Braucht, G.N., Reichardt, C.S., Geissler, L.J., Bormann, C.A., Kwaitkowski, C.F., \& Kirby, M.W. (1995). Effective services for homeless substance abusers. Journal of Addictive Diseases, 14(4), 87-109.

Brindis, C.D., \& Theidon, K.S. (1997). The role of case management in substance abuse treatment services for women and their children. Journal of Psychoactive Drugs, 29(1), 79-88.

Burns, T., Fioritti, A., Holloway, F., Malm, U., \& Rossler, W. (2001). Case management and assertive community treatment in Europe. Psychiatric Services, 52(5), 631-636.

Clark, R.E., Teague, G.B., Ricketts, S.K., Bush, P.W., Xie, H., McGuire, T.G. et al. (1998). Costeffectiveness of assertive community treatment versus standard case management for persons with co-occurring severe mental illness and substance use disorders. Health Services Research, 33(5), 1285-1308.

Conrad, K.J., Hultman, C.I., Pope, A.R., Lyons, J.S., Baxter, W.C., Daghestani, A.N. et al. (1998). Case managed residential care for homeless addicted veterans: results of a true experiment. Medical Care, 36, 40-53.

Cox, G.B., Walker, R.D., Freng, S.A., Short, B.A., Meijer, L., \& Gilchrist, L. (1998). Outcome of a controlled trial of the effectiveness of intensive case management for chronic public inebriates. Journal of Studies on Alcohol, 59(5), 523-532.

Drake, R.E., McHugo, G., Clark, R., Teague, G.B., Xie, H., Miles, K. et al. (1998). Assertive community treatment for patients with co-occurring severe mental illness and substance use disorder: a clinical trial. American Journal of Orthopsychiatry, 68(2), 201-215.

Drake, R.E., Yovetich, N.A., Bebout, R.R., Harris, M., \& McHugo, G.J. (1997). Integrated treatment for dually diagnosed homeless adults. Journal of Nervous and Mental Disease, 185(5), 298-305.

European Monitoring Centre for Drugs and Drug Addiction (EMCDDA). (2001). Annual report on the state of the drugs problem in the European Union 2001. Luxembourg: Office for Official Publications of the European Communities.

Evenson, R.C., Binner, P.R., Cho, D.W., Schicht, W.W., \& Topolski, J.M. (1998). An outcome study of Missouri's CSTAR alcohol and drug abuse programs. Journal of Substance Abuse Treatment, 15, 143-150.

Galanter, M., Keller, D., Dermatis, H., \& Egelko, S. (2000) The impact of managed care on substance abuse treatment: A report of the American Society of Addiction Medicine. Journal of Addictive Diseases, 19(3), 13-34.

Godley, S.H., Finch, M., Dougan, L., McDonnell, M., McDermeit, M., \& Carey, A. (2000). Case management for dually diagnosed individuals involved in the criminal justice system. Journal of Substance Abuse Treatment, 18(2), 137-148. 
Gould, F., Levine, M., \& McLellan, A.T. (2000). Treating the substance- abusing patient in the public sector : "Medical necessity" versus "social necessity and social responsibility" in the Philadelphia target cities demonstration project. Journal of Substance Abuse Treatment, 18(1), 75-77.

Huber, D.L., Sarrazin, M.V., Vaughn, T., \& Hall, J.A. (2003). Evaluating the impact of case management dosage. Nursing Research 52(5), 276-288.

Inciardi, J. A., Martin, S. S., Butzin, C. A., Hooper, R. M., \& Harrison, L.D. (1996). An effective model of prison-based treatment for drug-involved offenders. Journal of Drug Issues, 27(2), 261-278.

Inciardi, J.A., Martin, S.S., \& Scarpitti, F.R. (1994). Appropriateness of assertive case management for drug-involved prison releasees. Journal of Case Management, 3(4), 145-149.

Jerrell, J.M., \& Ridgely, M.S. (1999). Impact of robustness of program implementation on outcomes of clients in dual diagnosis programs. Psychiatric Services, 50(1), 109-112.

Koller, E. (1999). The policy-maker's perspective. In European Monitoring Centre for Drugs and Drug Addiction (EMCDDA) (Ed.), Evaluating the Treatment of Drug Abuse in the European Union, EMCDDA Scientific Monograph Series $N^{\circ} 3$ (pp. 79-84). Luxembourg: Office for Official Publications of the European Communities.

Knapen, J., \& Van Holsbeke, J. (1997). Een masterplan voor de organisatie en inhoudelijke vernieuwing van de geestelijke gezondheidszorg. Situering van en toelichting bij twee adviezen van de nationale raad voor ziekenhuisvoorzieningen. Hospitalia, 41(4),148-154.

Lanehart, R.E., Clark, H.B., Rollings, J.P., Haradon, D.K., \& Scrivner, L. (1996). The impact of intensive case-managed intervention on substance-using pregnant and postpartum women. Journal of Substance Abuse, 8(4), 487-495.

Lightfoot, L., Rosenbaum, P., Ogurzsoff, S., Laverty, G., Kusiar, S., Barry, K. et al. (1982). Final Report of the Kingston Treatment Programmed Development Research Project. Ottawa, Canada: Department of Health and Welfare, Health Promotion Directorate.

Lipsey, M. (1990). Design sensitivity: statistical power for experimental research. Newbury Park: Sage.

Marlatt, G.A., Blume, A., \& Parks, G. (2001). Integrating harm reduction therapy and traditional substance abuse treatment. Journal of Psychoactive Drugs, 33(1), 13-22.

Martin, S.S., \& Scarpitti, F.R. (1993). An intensive case management approach for paroled iv drug users. Journal of Drug Issues, 23(1), 43-59.

McLellan, A.T. (2002). Have we evaluated addiction treatment corretcly? Implications from a chronic care perspective. Addiction, 97(3), 249-252.

McLellan, A.T., Arndt, I., Metzger, D., Woody, G., \& O'Brien, C. (1993). The effects of psychosocial services in substance abuse treatment. Journal of the American Medical Association, 269, 1953-1959.

McLellan, A.T., Hagan, T.A., Levine, M., Meyers, K., Gould, F., Bencivengo, M. et al. (1999). Does clinical case management improve outpatient addiction treatment. Drug and Alcohol Dependence, 55, 91-103.

Mejta, C., Bokos, P., Mickenberg, J., Maslar, M., \& Senay, E. (1997). Improving substance abuse treatment access and retention using a case management approach. Journal of Drug Issues, 27(2), 329-340. 
Miller, W.R., \& Wilbourne, P.L. (2002). Mesa Grande: a methodological analysis of clinical trials of treatments for alcohol use disorders. Addiction, 97(3), 265-277.

Nizzoli, U. (1999). Treatment information systems: the Emilia-Romagna experience. In European Monitoring Centre for Drugs and Drug Addiction (EMCDDA) (Ed.), Evaluating the Treatment of Drug Abuse in the European Union, EMCDDA Scientific Monograph Series No3 (pp. 63-66). Luxembourg: Office for Official Publications of the European Communities.

Okin, R.L., Boccellari, A., Azocar, F., Shumway, M., O'Brien, K., Gelb, A. et al. (2000). The effects of clinical case management on hospital service use among ED frequent users. American Journal of Emergency Medicine, 18(5), 603-608.

Oliva, H., Görgen, W., Schlanstedt, G., Schu, M., \& Sommer, L. (2001). Case management in der Suchtkranken- und Drogenhilfe: Ergebnisse des Kooperationsmodells nachgehende Sozialarbeit Modellbestandteil Case management, Berichtszeitraum 1995-2000. Köln: Fogs, Gesellschaft für Forschung und Beratung in Gesundheits- und Sozialbereich $\mathrm{mbH}$.

Orwin, R.G., Sonnefeld, L.J., Garrison-Mogren, R., \& Smith, N.G. (1994). Pitfalls in evaluating the effectiveness of case management programs for homeless persons: lessons from the NIAAA Community Demonstration Program. Evaluation Review, 18(2), 153-207.

Prochaska, J., DiClemente, C., \& Norcross, J. (1992). In search of how people change: applications to addictive behaviors. American Psychologist, 47(9),1102-1114.

Rapp, R.C., Siegal, H.A., Li, L., \& Saha, P. (1998). Predicting post-primary treatment services and drug use outcome: A multivariate analysis. American Journal of Drug and Alcohol Abuse, 24(4), 603-615.

Saleh, S.S., Vaughn, T., Hall, J.A., Levey, S., Fuortes, L., \& Uden-Holmen, T. (2002). Effectiveness of case management in substance abuse treatment. Care Management Journal, 3(4), 172-177.

Shwartz, M., Baker, G., Mulvey, K.P., \& Plough, A. (1997). Improving publicly funded substance abuse treatment: the value of case management. American Journal of Public Health, 87, 16591664.

Siegal, H.A., Li, L., \& Rapp, R.C. (2002). Case management as a therapeutic enhancement: Impact on post-treatment criminality. Journal of Addictive Diseases, 21(4), 37-46.

Siegal, H.A., \& Rapp, R.C. (Eds.) (1996). Case management and substance abuse treatment: practice and experience. New York: Springer Publishing Company

Siegal, H.A., Rapp, R.C., Li, L., Saha, P., \& Kirk, K. (1997). The role of case management in retaining clients in substance abuse treatment: an exploratory analysis. Journal of Drug Issues, 27(4), 821-831.

Sorensen, J.L., Dilley, J., London, J, Okin, R.L., Delucchi, K.L., \& Phibbs, C.S. (2003). Case management for substance abusers with HIV/AIDS: a randomized clinical trial. American Journal of Drug and Alcohol Abuse, 29(1), 133-150.

Teague, G.B., Bond, G.R., \& Drake, R.E. (1998). Program fidelity in assertive community treatment: development and use of a measure. American Journal of Orthopsychiatry, 68(2), 216231.

Thornquist, L., Biros, M., Olander, R., \& Sterner, S. (2002). Health care utilization of chronic inebriates. Academic Emergency Medicine, 9(4), 300-308. 
Vaughan-Sarrazin, M.S., Hall, J.A., \& Rick, G.S. (2000). Impact of Iowa case management on use of health services by rural clients in substance abuse treatment. Journal of Drug Issues, 30(2), 435-463.

Vaughn, T., Sarrazin, M.V., Saleh, S.S., Huber, D.L., \& Hall, J.A. (2002). Participation and retention in drug abuse treatment services research. Journal of Substance Abuse Treatment, 23(4), 387397.

Willenbring, M.L., Ridgely, M.S., Stinchfield, R., \& Rose, R. (1991). Application of case management in alcohol and drug dependence: matching techniques and populations. Rockville: National Institute on Alcohol Abuse and Alcoholism.

Witbeck, G., Hornfeld, S., \& Dalack, G.W. (2000). Emergency room outreach to chronically addicted individuals: A pilot study. Journal of Substance Abuse Treatment, 19(1), 39-43.

Wolf, J. (1995). Zorgvernieuwing in de GGZ: Evaluatie van achttien zorgvernieuningsprojecten. Utrecht: Nederlands Centrum Geestelijke Volksgezondheid.

Wolf, J., Mensink, C., \& van der Lubbe, P. (2002). Case management voor langdurig verslaafden met meervoudige problemen: een systematisch overzicht van interventie en effect. Utrecht: Trimbos-instituut, Ontwikkelcentrum Sociaal Verslavingsbeleid.

Wolf, J., \& Planije, M. (2002). Case management voor langdurig verslaafden met meervoudige problemen. Utrecht: Trimbos-instituut, Ontwikkelcentrum Sociaal Verslavingsbeleid.

Zarkin, G.A., \& Dunlap, L.J. (1999). Implications of managed care for methadone treatment. Findings from five case studies in New York State. Journal of Substance Abuse Treatment, 17(12), 25-35. 


